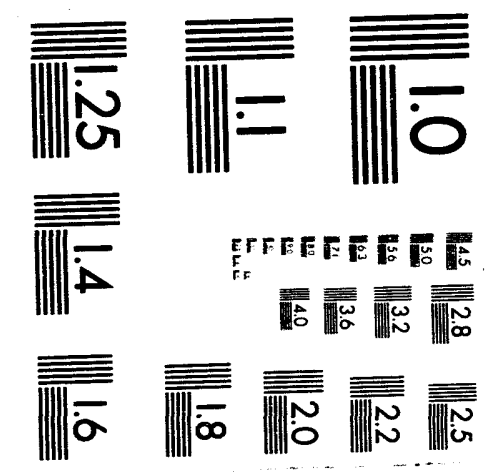



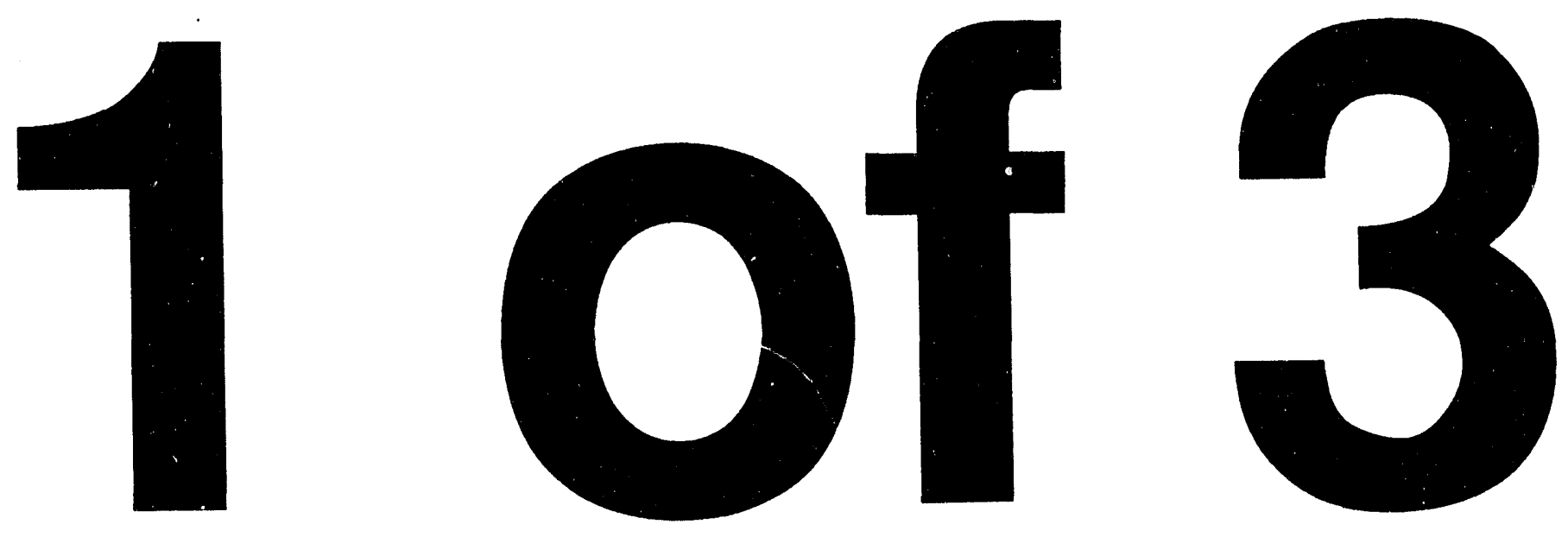
NUREG/CR-6156

\section{Summary of Comments Received from Workshops on Radiological Criteria for Decommissioning}

Manuscript Completed: January 1994

Date Published: Januar 1994

Prepared by

J. Caplin, G. Page, D. Smith, C. Wiblin

Advanced Systems Technology, Inc. 3490 Piedmont Road, NE

Atlanta, Ga 30305

\section{Prepared for}

Division of Regulatory Anplications

Office of Nuclear Regulatory Research

U.S. Nuclear Regulatory Commission

Washington, DC 20555-0001

NRC FIN L1618 


\begin{abstract}
The Nuclear Regulatory Commission (NRC) is conducting an enhanced participatory rulemaking to establish radiological criteria for site cleanup and decommissioning of NRC-licensed facilities. Open public meetings were held during 1993 in Chicago, IL, San Francisco, CA, Boston, MA, Dallas, TX, Philadelphia, PA, Atlanta, GA, and Washington, D.C. Interested parties were invited to provide input on the rulemaking issues before the NRC staff develops a draft proposed rule. This report summarizes 3,635 comments categorized from transcripts of the seven workshops and 1,677 comments from 100 NRC docketed letters from individuals and organizations. No analysis or response to the comments is included. The comments reflect a broad spectrum of viewpoints on the issues related to radiological criteria for site cleanup and decommissioning. The NRC also held public meetings on the scope of the Generic Environmental Impact Statement (GEIS) during July 1993. The GEIS meetings were held in Washington, D.C., San Francisco, CA, Oklahoma City, OK, and Cleveland, $\mathrm{OH}$. Related comments from these meetings were reviewed and comments which differed substantially from those from the workshops are also summarized in the body of the report. A summary of the comments from the GEIS scoping meetings is included as an Appendix.
\end{abstract}




\section{CONTENTS}

Section

Page

ABSTRACT

iii

FOREWORD

vii

$\begin{array}{lll}1.0 & \text { INTRODUCTION } & 1\end{array}$

1.1 Background 1

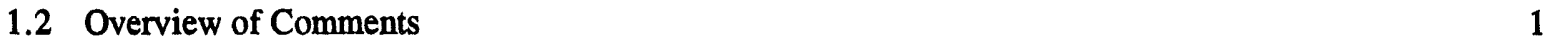

2.0 SUMMARIES OF COMMENTS BY ISSUE

2.1 Need for and General Content of Rulemaking 3

2.1.1 Need and Scope $\quad 3$

2.1.2 Responsibilities and Requested Community Involvement 4

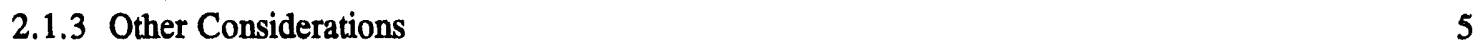

2.2 Compatibility $\quad 7$

2.2.1 NRC/EPA Criteria $\quad 7$

2.2.2 Roles of Federal Agencies and State, Local, and Tribal Governments 9

2.3 Process to Be Used in Developing Rule 10

$\begin{array}{ll}\text { 2.3.1 Importance of Public Participation } & 10\end{array}$

$\begin{array}{ll}\text { 2.3.2 Feedback on Workshops } & 11\end{array}$

2.3.3 Guidance on Standards Development 12

2.4 Approaches for Establishing Radiological Criteria for Decommissioning 13

2.4.1 Risks Limits and Risks Goals $\quad 13$

2.4.2 Best Available Technology 16

$\begin{array}{ll}\text { 2.4.3 Return-to-Background } & 17\end{array}$

$\begin{array}{ll}\text { 2.4.4 Other Approaches for Establishing Criteria } & 20\end{array}$

2.5 Establishing a Basis for Risk Goals or Limits $\quad 21$

2.5.1 National and International Consensus $\quad 21$

2.5.2 Risk/Dose Relationship $\quad 22$

$\begin{array}{ll}2.5 .3 \text { Background Radiation } & 23\end{array}$

$\begin{array}{ll}2.5 .4 & \text { Individual and Collective Doses } \\ 2.5\end{array}$

$\begin{array}{ll}\text { 2.5.5 Modeling/Pathways } & 24\end{array}$

2.6 Balancing Risks and Benefits 25

2.6.1 Performing Assessments $\quad 25$

2.6.2 What Risks Should Be Considered $\quad 26$

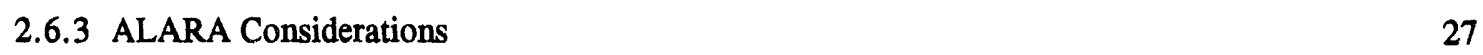

2.6.4 Effective Use of Resources 28 


\section{CONTENTS (Continued)}

Section

Page

2.7 Intangible Characteristics of Criteria $\quad 30$

2.7.1 Acceptability/Fairness $\quad 30$

2.7.2 Stability and Consistency

$\begin{array}{ll}2.7 .3 \text { Clarity } & 32\end{array}$

$\begin{array}{ll}2.7 .4 \text { Flexibility } & 32\end{array}$

2.8 Implementation $\quad 33$

2.8.1 Site Cleanup $\quad 33$

2.8.2 Demonstrating Compliance with the Criteria 34

$\begin{array}{lll}2.9 & \text { Finality/Grandfathering } & 35\end{array}$

2.10 Generic Versus Site Specific Considerations 36

$\begin{array}{ll}2.11 \text { Sites Which Cannot Be Released for Unrestricted Use } & 37\end{array}$

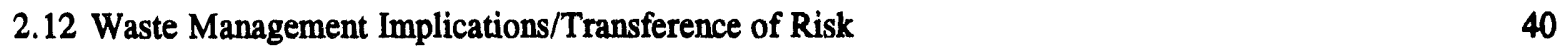

2.13 Special Considerations $\quad 44$

2.13.1 Mixed Waste 44

2.13.2 Doses from Radon and Radon Daughters $\quad 45$

2.13.3 Handling Previously Buried Waste $\quad 47$

2.13.4 Minimizing the Generation of Contamination and Radioactive Wastes 47

$\begin{array}{ll}2.14 \text { Environmental and Social Considerations } & 48\end{array}$

2.15 Recycle of Contaminated Materials $\quad 49$

Appendices

$\begin{array}{lll}\text { Appendix A Issues for Discussion at Workshops } & \text { A-1 }\end{array}$

$\begin{array}{lll}\text { Appendix B Decommissioning Case Studies } & \text { B-1 }\end{array}$

$\begin{array}{lll}\text { Appendix C Commenter Listing } & \text { C-1 }\end{array}$

$\begin{array}{ll}\text { Appendix D Comment References } & \text { D-1 }\end{array}$

$\begin{array}{lll}\text { Appendix E } & \begin{array}{l}\text { Summaries of Comments from GEIS Scoping Meetings on } \\ \text { Radiological Criteria for Decommissioning }\end{array}\end{array}$ 


\section{FOREWORD}

The Nuclear Regulatory Commission (NRC) is conducting an enhanced participatory rulemaking to establish radiological criteria for site cleanup and decommissioning of NRC-licensed facilities. As part of this rulemaking, worksiops were held as open public meetings during 1993 in Chicago, IL; San Francisco, CA; Boston, MA; Dallas, TX; Philadelphia, PA; Atlanta, GA; and Washington, D.C. The purpose of the workshops was to solicit commentary on the fundamental approaches and issues that must be addressed in establishing radiological criteria for decommissioning. Written comments on approaches and issues also were solicited. Iaterested parties were invited to provide early and comprehensive input on the rulemaking issues before the NRC staff develops a draft proposed rule.

The purpose of this report is to summarize comments categorized from transcripts of the seven workshops and from NRC docketed letters from individuals and organizations. This report also includes a review of comments received regarding radiological criteria for site cleanup and decommissioning as a result of the public meetings held on the scope of the Generic Environmental Impact Statement (GEIS) during July 1993. These meetings were held in Washington, D.C., San Francisco, CA, Oklahoma City, OK, and Cleveland, OH.

This report contains information that is being considered by the NRC in developing the radiological criteria. The results, approaches and/or methods described in this NUREG are provided for information only. Publication of this report does not necessarily constitute NRC approval or agreement with the information contained herein.

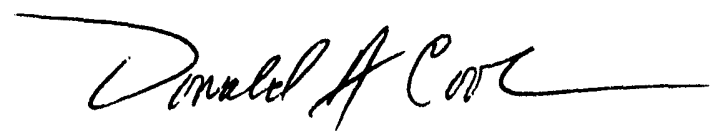

Donald A. Cool, Chief

Radiation Protection and

Health Effects Branch

Division of Regulatory Applications

Office of Nuclear Regulatory Research 


\section{INTRODUCTION}

\subsection{Background}

On June 27, 1988, the Commission published in the Federal Register (53 FR 24018) a final rule on general requirements for decommissioning nuclear facilities. The amended regulations addressed decommissioning planning needs, timing, assurance of the availability of funds for decommissioning, and environmental review requirements. That rule did not cover acceptable levels of residual radioactivity for decommissioned facilities. The rule indicated that specific requirements on how clean a nuclear facility must be to qualify for decommissioning would be dealt with later in a separate action.

On December 11, 1992, the Commission published in the Federal Register (57 FR 58727) a notice that it was preparing to initiate rulemaking on establishing radiological criteria for the decommissioning of NRC-licensed facilities. The notice listed a schedule for seven workshops throughout the United States beginning in January 1993, in Chicago, San Francisco, Boston, Dallas, Philadelphia, Atlanta, and Washington, D.C. ${ }^{1}$

The purpose of the workshops was to solicit commentary from affected interests on the fundamental approaches and issues that must be addressed in establishing radiological criteria for decommissioning. Written comments on approaches and issues also were solicited. Material presented and used for discussion at the workshops included "Issues for Discussion at Workshops", undated, and "Decommissioning Case Studies" dated January 1993, and are found as Appendix A and B. Transcript 3 of the Workshops and copies of related letters are available for inspection or copying for a fee in the NRC Public Document Room, 2120 L Street, NW, (Lower Level), Washington, DC.

As part of the effort to codify radiological criteria for decommissioning to determine the extent to which radioactive contamination must be removed or reduced in lands and structures before a nuclear facility can be released and its license terminated, the NRC held public meetings on the scope of the GEIS during July 1993 in Washington, D.C., San Francisco, CA, Oklahoma City, OK, and Cleveland, $\mathrm{OH}$. Interested parties were invited to provide early and comprehensivs input before the NRC staff develops the GEIS. A notice in the Federal Register, June 18, 1993, also invited comments.

\subsection{Overview of Comments}

This report summarizes those comments made during the proceedings and comments received by letter. There were 3,635 comments categorized from records of the seven workshops and an additional 1,677 comments from 100 NRC docketed letters from individuals and organizations. A listing of commenters is found in Appendix C.

The comments were organized to the issues and sub-issues identified in Section 2. The summaries are found in Section 2 with a unique comment number, listed in parenthesis, assigned to each comment within an issue, and therefore the source of each comment can be identified as to origin, commenter, beginning page number, and beginning paragraph or line number. This information is found in Appendix D. Comments received during the workshops are numbered under 7,000 while docketed letter comments are numbered greater than 7,000.

The authors reviewed 1,596 comments related to radiological criteria for site cleanup and decommissioning which

1 The workshops were held as follows: Jan. 27\&28-Chicago, IL; Feb. 23\&24-San Francisco, CA; Mar. 12-Boston, MA; Mar. 23\&24-

Dallas, TX; Apr. 13\&14-Philadelphia, PA; Apr. 29\&30-Atlanta, GA; May 6\&7-Washington, D.C. 
were received as a result of the GEIS scoping meetings held during July 1993. Comments that were different from those received as a result of the workshops were summarized in the body of the report. These comments were designated with a $G$ prefix . Information concerning the origin of these comments can be found in Appendix E. Appendix E also contains a complete summary of the comments from the GEIS scoping meetings.

The comments reflect a broad spectrum of viewpoints on many of the issues related to radiological criteria for site cleanup and decommissioning. 


\section{SUMMARIES OF COMMENTS PER ISSUE}

\subsection{Need for and General Content of Rulemaking}

\subsubsection{Need and Scope}

Almost all commenters supported the NRC's plans to develop radiological decommissioning standards and recommended that the rulemaking proceeding go forward expeditiously $(1,2,3,4,38,351,412,528,561,644$, $672,732,736,887,893,980,1416,1748,2077,2086,2371,2376,2506,2531,2892,3357,3662,3664,3848$, $4443,4521,4529,4537,7119,7358,7365,7486,7765,7933,8122,8269,8454,8493,8525,8629,8785,8832$, 8833). Other commenters stated that the rulemaking should not be hurried $(1299,2451,4148,4180,4517,4533)$, and one opposed the rulemaking (8834). Reasons given for supporting the rulemaking included:

Responsibility and accountability will be defined (980); criteria must be practical (1377).

A case-by-case approach is inconsistent, inefficient and impractical $(1,2,561,7358,7486,7765,8525$, 8785).

A single national standard helps to avoid interstate commerce complications entailed in having a number of different standards (4278).

This will give us the ability to get on with decommissioning $(38,2077,7358,7765,8785)$.

Licensees are concerned that decommissioning requirements individually negotiated with the NRC might be changed (8629).

Both the operators and the public will know what is expected at the onset of licensing $(1994,3662,3702$, 7119, 7358, 7486).

Costs of decommissioning can be better estimated, planned for, and reduced (732, 893, 1748, 1994, 2077 , $4443,7765,8833)$. Also, funds available for decommissioning can be applied to actual cleanup instead of for preparation of descriptive reports (7119).

Three commenters requested that the NRC make the standards as simple as possible and give reasoning for what is proposed $(1753,2457,7870)$. If something is believed not to be dangerous, the NRC should convince us of this (1753). Another commenter stated that radiological risks should be put in perspective with other risks the public faces (3664).

Some commenters recommended that the NRC should consider and possibly establish both radiological and chemical decommissioning standards $(759,771,7764,8835)$. Other commenters recommended that the NRC should not regulate non-radiological risks that are regulated by other agencies $(766,1159,7470,7517)$. Three commenters recommended that NRC sites undergoing decommissioning should be cleaned up for non-radiological contaminants simultaneously under other applicable agencies' regulations $(1159,1708,7470)$.

Two commenters recommended that the NRC consider in the rule-making all pertinent issues raised in the uranium mill tailings regulations $(6,1730)$. Another commenter requested that the rulemaking clarify the extent to which the new radiological criteria apply to uranium mill tailings sites (8463). 
One commenter while favoring the NRC's efforts to develop decommissioning standards cautioned that this will be an effective undertaking only if the EPA concurrence is obtained (8454).

One commenter advised that the procedural requirements and basic structure of the standard be codified. This includes the process for determination of ALARA and how to address sites that may not meet a risk limit (8895).

One commenter stated the risk goal concept should be part of the regulation. How to comply with the regulations should be given in regulatory guides and be subject to peer and public review (8899).

One commenter proposed that the criteria address the need for complete emergency response to potential incidents and the necessary training of medical and emergency response personnel (G825).

\subsubsection{Responsibilities and Requested Community Involvement}

Several commenters recommended that the rulemaking should clearly specify that licensees are responsible for taking remedial actions to clean up the sites which they contaminate $(1678,1717,2564,2997,3635,3903,3936$, $4266,7519,7587,7655)$. One commenter stated that if the NRC imposes lingering liabilities for firms this could be an incentive for them to go out of business (4218). Two commenters recommended that the rulemaking should specifically address who is responsible for cleaning up a site if a licensee ceases to exist $(1717,2972)$. Two commenters suggested that perhaps the law should be changed to have the Department of Energy take title to a site and the NRC license the site in perpetuity $(1606,1610)$.

Several commenters questioned whether the NRC could be trusted to oversee decommissioning and some recommended the establishment of an independent agency to do this $(1276,1770,1792,1793,4040,7596,7607$, $7756,7761,8218)$. Other commenters questioned the legitimacy of the NRC $(1180,2976)$.

Many commenters recommended that the rulemaking should provide for and ensure local citizen group participation in overseeing the decommissioning of contaminated sites and the enforcement of requirements $(247,569,571,905$, $1259,1262,1297,1363,1438,1449,1562,1643,1696,1713,1736,1782,1785,1800,2045,2055,2485,2638$, $2727,2732,2742,2825,2871,3316,3321,3324,3327,3415,3551,3584,3668,3725,3900,4042,4043,4045$, $4113,4159,4183,4185,4199,4215,4220,4234,4245,4264,4401,4411,4415,4420,4429,4430,4435,4436$, $4437,4449,4652,4655,7081,7327,7334,7348,7460,7472,7532,7556,7594,7673,7905,7960,7972,7977$, $8153,8182,8200,8283,8288,8509,8518,8704,8806,8807,8808,8810,8836)$. One commenter wanted all intervenors to prove that they are directly impacted by the decommissioning and formed from the physical area of the affected communities (G911). One commenter noted that citizen group participation is not needed for all licensed operations (2560). Several recommended that funding should be provided for this purpose by the organizations which are responsible for site cleanup or by the federal government $(569,571,1438,1562,1696$, 1713, 2558, 2727, 2742, 3551, 3795, 3900, 4042, 4045, 4303, 4323, 4395, 4401, 4428, 4434, 4460, 7327, 7334, $7556,7972,7983,8509)$. One commenter requested that the decommissioning process allow for full public hearings to receive appropriate citizen input at each site (7960). Another commenter cautioned that a tremendous burden would be placed on licensees, regulators, and the public if every site had to go through a decommissioning hearing process (2916). Another commenter stated that there should not be a long drawn out decommissioning process with hearing after hearing (3321). One commenter cautioned that special interests groups could prevent cleanup (8786). Other commenters suggested that the citizen participation should be modeled similar to the Federal Clean Up Boards and be provided with technical assistance grants $(1782,3300,3525,4655)$.

One commenter recommended that the role of tribal authorities should be addressed in the rulemaking (1722). 


\subsubsection{Other Considerations}

Many comments were offered concerning possible provisions that might be placed in the decommissioning rulemaking. These included:

The rules should be written to assure implementation of enforceable standards without loopholes (1702, $2847,7007,7635,7637,7639,7784,8252,8769,8837)$, and should not be interpretable in a way other than originally intended $(1622,3435,4009,7784)$.

The starting point for setting decommissioning standards is to specify acceptable dose levels (8467). Limits must be related to total effective dose equivalent (8195).

The standards for workers and the public should not be different (834).

The standards should be consistent with past NRC cleanup criteria $(8,443,446)$ and include quantitative limits for loose and fixed contamination, activation products, and concentrations of radioactivity in soil, ground water, and surface water $(942,965,1353,2755,7159,7621,7885,7990,8104,8385,8429$, $8435,8572,8778,8838)$.

Various options should be considered along with their costs before deciding on the requirements of the imposed rule $(1205,2753,2755,7560,4842)$.

Hopes that the rules will require thorough cleanup to unrestricted use even if it takes a long time before the license can be terminated (4284).

Cost should not be a limiting factor in deciding what standards should be applied $(7672,7820,8242,8793)$.

Reconsider changing the definition of decommissioning to permit restricted use of sites $(1682,2335,2703$, $3186,3266,3299,3309,3513,3563,3568,4651,7412,7416,7797,7827,7864,7926,7928,8046$, $8460,8602,8839)$, entombment $(2335,2786,7416,7827)$, and delayed decommissioning $(640,7412$, 7827,7880 ). Also, assure that the definition is not biased towards the concerns of industry (8766).

Distinguish between types of facilities and establish different requirements for these; also consider short-lived radioisotopes differently from long-lived ones (101, 445, 888, 972, 1054, 1706, 1762, 2034, $2069,2370,2403,2523,2779,3186,3266,3504,3645,4001,4293,4654,4829,7572,7921,8019$, $8255,8444,8543,8777,8840,8841)$.

Radon requires special consideration because of its high natural background (8899).

Define "return-to-background" in terms of radionuclides that were not present prior to the operation of the facility (7806).

Place a 50-year limit on moth-balling reactors (8771).

Require an Environmental Impact Statement for decommissioning each reactor $(7593,8771,8842)$. 
Avoid the unnecessary generation of radioactive wastes and assure that sufficient funds are set aside for their control and disposal $(2490,3442,3563,7607$, 7868, 8843).

There may be a legal constraint on the degree to which the NRC may consider costs to licensees in setting standards, except to the extent that the NRC is going beyond adequate protection (73).

Licensees should submit a decommissioning plan for review and approval $(973,2504,2637,4785,7432$, 7593, 7930, 7969, 8005, 8587).

Licensees should reassess and the NRC should review whether enough money has been or is being set aside for decommissioning to meet the new radiological cleanup standards $(175,2929,7078,7612,7727$, $7868,8776,8765)$ and in the event a plant might close prematurely $(319,903,7727)$.

The rules should include a requirement for certification of compliance with applicable limits $(1929,4485$, 7635).

The NRC should permit the approval of exceptions or exemptions to the standards where the cost of cleanup is disproportionately high for the achieved reduction of risk $(969,7864,7925)$.

The NRC should not allow broad exceptions or exemptions and incomplete cleanup of sites $(7007,7587)$.

Care should be taken not to prescribe technology requirements too specifically for this could hinder development of better technologies $(1761,3248)$.

Provide a well-defined way of knowing when the decommissioning objective has been reached (2551, $2603,2622,4294,4404,7885$ ); avoid requirements that are extremely difficult or impossible to enforce $(7635,7637,7990,8429)$.

The ALARA principle should be defined and applied in the decommissioning rule, and a level should be specified below which further site cleanup is not required $(1958,2071,2497,2652,4409,4650,7432$, 8087). Also, the rulemaking should require the submission of a decontamination and decommissioning ALARA plan (8587).

All information pertaining to decommissioning should be open to disclosure and made available to the public $(3684,3719,3720,3748,3758,3771,3832,4651,7336,8764)$.

Require licensees to pay into a fund for distribution to people who are subjected to risks from contaminated sites (3906).

Being clear at the front-end about decommissioning expectations is important to getting things properly done $(2756,2931)$ and decommissioning proposals should be submitted at the design stage $(3403,3909)$.

Use conventional units for radiological criteria (such as rem, roentgen, and curie) followed by International Systems of Units in parenthesis (7639), define all units used, and explain all acronyms (7867, 7954). Two commenters recommended that dose limits should be expressed in both rad and rem units $(7114,7954)$.

Specify in the rulemaking that licensees who decommission the operations under an NRC-approved 
decommissioning plan will not be subject to future standards unless these address a significant threat to the public health and safety $(4162,7115,7925,7928,8111,8145)$.

Provide 18 to 24 months after publication of the rulemaking before it becomes effective (7930).

Specify the use of no particular model in assessing whether the prescribed decommissioning limits have been met; perhaps require that the model must be validated and verified $(1353,4376,8106,8572,7990$, 8087, 8763).

Consider including in the cleanup criteria the presumption that any health effects that could have been attributable to radiological effects came from the site unless proved otherwise $(4438,7801)$.

Clarify the relation of NRC decommissicning requirements to the EPA's Superfund program (8844).

Assure NRC's decommissioning requirements are not compromised by free trade agreements such as a North American Free Trade Agreement (7739).

The NRC should specify performance requirements rather than prescriptive requirements $(7835,7864$, $8106,8133,8230,8572,8659,8845)$.

The NRC should specify both performance and prescriptive requirements (8484).

Consider exposure of people off-site as well as onsite $(7839,7890)$.

The NRC should specify a range of degrees in prescriptive requirements rather then performance requirements $(8252,8483,8746)$; specify concentration and activity levels limits rather than risk limits or goals (4843).

Address the cleanup of sites with special significance to groups, including homelands and historical sites (7314).

Some commenters requested that the NRC provide specific guidance on the decommissioning standards so that licensees and the public will know what applies and what contamination levels must be met; details should be placed in Regulatory Guides $(1690,1702,2652$, 2779, 2811, 3235, 3519, 7423, 7426, 7827, 7885, 8104, 8106, $8133,8385,8429,8484,8572,8659,8845)$ including reference to acceptable standards prepared by standards writing organizations $(7423,7426)$.

\subsection{Compatibility}

\subsubsection{NRC/EPA Criteria}

Some commenters recommended that NRC and EPA radiological decommissioning standards should be identical $(232,245,912,2105,2858,3224,3234,3244,3245,3497,7284,7633,8783)$. In particular, it was recommended that the NRC's standards conform to the EPA's RCRA and Superfund drinking-water standard $(2678,8517,8723)$. Three commenters recommended that drinking water standards should remain under EPA's authority $(234,235,4461)$. Many commenters recommended that NRC and EPA standards should be at least compatible $(231,239,338,427,527,744,1328,1364,1374,1930,1948,2277,2882,3234,3241,3247,3252$, $3254,3325,3518,3526,3898,4186,4647,4828,7152,8015,8093,8114,8116,8168,8205,8455,8517,8528$, 
$8601,8653,8702,8740,8784,8846,8847,8893)$. Not only should the standards be consistent, but also the methods of pathway analyses should be consistent $(4510,8330)$ and guidance should be extended to the regional levels (7264). If requirements are not compatible, there is the possibility that a site decommissioned under NRC standards might later require additional cleanup under EPA's Superfund standards $(231,1340,4168,8205)$. Some commenters cautioned against the NRC's patterning its standards after the EPA's Superfund regulations (244, 1744, $3277,3295,3303,4270,7255,8239$ ). Others stated that Superfund has some good provisions and needs to be made to work $(2458,3306,4845)$. Two commenters stated that the NRC's rulemaking should include Superfundlike provisions for interim cleanup actions $(4297,8306)$. Some commenters suggested that it might not be in the public interest for the NRC and the EPA to harmonize risk goals unless the most stringent standards are adopted $(1012,1712)$. One commenter stated that nuclear regulation laws should be revised in light of concepts that have come out of environmental laws over the past ten to twenty years (3821). Another commenter stated that NRC's compatibility policy should be delineated in the rulemaking (7016).

Several commenters stated that it is important that whatever standards the NRC adopts should not have to be improved upon by other federal agencies or by state or local governments $(242,3241,3245,3325)$. One commenter encouraged the EPA to develop separate standards from the NRC $(8114,8322,8455,8779)$. Another commenter suggested that EPA use ICRP methods to compute dose to risk factors (8788). Even when a state takes the same standard and puts it in a different form, the change could have a significant impact on those subject to the standard (3325). NRC standards should be specific with respect to what kinds of concentrations result in what level of risk (2373) and should be verifiable and measurable $(4830,8848)$. Some commenters stated that decommissioning standards need to be considered not only for radioactive materials under the NRC's jurisdiction, but also for other sources of radiation $(241,940,2665,2667,2670,2698,2852,2858,3036,3044,3063,3224$, $3553,4290,4828,4830,7488,7867)$.

Other commenters stated that there is a need for consistency in the regulation of radioactive materials and hazardous chemicals $(744,951,1269,2422,3227,3252,3835,7488,8432,8723)$. Still other commenters questioned whether radioactive materials and hazardous chemicals are comparable and whether that adoption of a single standard for these materials is appropriate $(2572,3845,3861,3868,3947,7255,8742)$. One commenter stated that it is not possible to comply with existing waste disposal standards when mixed radioactive and chemical wastes are involved (3966). Other commenters stated that if the NRC and the EPA use different approaches for regulating risk, they will not have comparable regulations that are practical to apply $(3237,3252,8114)$. Still other commenters objected to dual regulation by the NRC and the EPA $(7846,8015,8653)$.

Differences in the radiological standards being presently applied by the NRC (in accordance with recommendations of national and international standards groups) site-by-site and those applied by the EPA under the Clean Air Act and Superfund were discussed. The EPA uses a risk goal of ten to the minus four to ten to the minus six (240, $1458,1646,2127,3621,3768,3823,3913)$. A risk of ten to the minus four corresponds to a dose of three millirems per year $(238,239,240)$. One commenter states that a dose constraint of $30 \mathrm{mrem} / \mathrm{year}$ is consistent with ten to the minus four lifetime risk if conservative but realistic assumptions are used (8881). The NRC has been using a dose limit of 100 millirems per year $(238,239,240,3621,3768)$. Two commenters stated that EPA risk numbers should provide the underpinning of NRC decommissioning standards $(7030,7456)$.

Some commenters stated that the different risk (dose) levels of the two agencies should be resolved $(239,1025$, $7284,8653)$. Others argued that the difference between the two levels is relatively small $(238,8325,8559,8569$, 8653 ) because the EPA applies its three millirems restriction as a risk goal and permits higher levels (exemptions) whereas the NRC applies its 100 millirems restriction as a risk limit and then requires further reduction under the ALARA (as low as reasonably achievable) principle (238). The EPA is not always achieving the three millirems risk goal $(240,8325)$, but the NRC is always meeting the 100 millirems risk limit. Accordingly, one commenter 
stated that the two risk levels as used by the NRC and the EPA are consistent $(8054,8569)$. One commenter cautioned that NRC should not apply its decommissioning standards more restrictively than the EPA $(8325,8330)$.

One commenter observed that under the NRC's present dose limit of 100 millirems an individual's cancer risk is increased from 20 percent to 20.3 percent and under the EPA's risk goal of three millirems is increased from 20 percent to 20.03; and such differences are not observable (237).

\subsubsection{Roles of Federal Agencies and State, Local, and Tribal Governments}

Several commenters recommended that there should be closer coordination among the various federal, state, and local government agencies in the development of standards $(249,722,790,925,1373,1650,1709,1952,1955$, $2470,2571,2861,3228,3256,3259,3689,4055,4182,4189,4197,4214,4219,4225,4288,4681,7075,7421$, $7473,7595,7750,7759,7762,7798,8113,8439,8682,8703,8780,8803,8804)$. One commenter stated that duplication of effort is frustrating to the public, expensive, and of dubious value (7595). Another commenter stated that without agreement and approval by all jurisdictions, those regulated are stymied (8113). Still another commenter stated that because of world-wide United States responsibilities the NRC and the EPA should assure that federal and state regulations are not in serious conflict with recommendations of international organizations (3256). Other commenters stated that the EPA and the NRC should develop decommissioning standards together (2383, $7759,8459,8682,8703,8780,8781,8782,8803,8804)$.

One commenter stated that there are some really diverse standards and criteria out there and these add to confusion of the public (374). Another commenter recommended that licensees should be regulated by a single regulatory authority instead of being subject to multiple regulatory jurisdiction, e.g., by the NRC, the EPA, and the states (3557).

One commenter stated that the EPA needs to conduct some type of annual audit of the NRC to see if it is carrying out its responsibilities properly (1650). Other commenters stated that the EPA and the NRC should maintain their independence because this helps to preserve the public health and welfare $(3222,7356,7939,8239)$. Still another stated that the EPA does not need to regulate NRC-licensed facilities when it determines that the NRC's program provides an ample margin of safety (1663).

Some commenters recommended that Agreement States should be equal partners with federal agencies $(939,1879$, 3228). In particular, the NRC should involve Agreement States at the front end of rulemaking $(3228,4055,7625$, 7629,8280 ). Several commenters stated that it must be decided whether Agreement States must adopt all of the federal standards verbatim or whether they might adopt more striugent standards $(2009,3278,3628,4165,4841$, 7477). Some commenters stated that Agreement States should conform to NRC standards $(7582,8280)$. Others stated that Agreement States should have flexibility in implementing the standard $(3499,4846)$, but one commenter indicated that states already have flexibility to adopt standards either more stringent or more lax than those of the NRC (4177).

One commenter stated that the whole scheme of interlocking regulatory procedures could stand to be looked at as a whole and possibly very seriously revised to make more common sense (778). Another commenter stated that the NRC and the EPA should assure that final actions are taken with respect to site cleanup so that state and local governments do not have to deal with it further $(331,1446)$. Still another commenter indicated that states should have complete say over questions of finality or continued imposition of standards (2484).

Many commenters requested that the roles of all federal, state, tribal, and local governments should be addressed $(246,706,907,1178,1335,1378,1973,1984,1986,1988,1997,2004,2010,2016,2042,2046,2048,2056$, $2152,2333,2476,2479,2486,2509,2515,2517,2673,2896,2933,3546,3661,3689,4163,4197,4219,4223$, 
$4250,4262,4272,7759,8203,8287,8511)$. Some commenters stated that special attention should be given to state, tribal and local government concerns $(117,137,531,706,1973,1984,1986,1988,2004,2010,2016,2046$, 2048, 2056, 2333, 2484, 2486, 2509, 2515, 2517, 3546, 3789, 3873, 3882, 3956, 4163, 4197, 4210, 4225, 4250, $4262,4272,4300,7458,7468,7473,7475,7762,8184,8199,8203,8511,8744,8748,8751,8754)$. One commenter stated that state and local governments should be able to enforce NRC standards when the NRC fails to do so $(3579,7337)$. Some commenters stated that tribes should be treated the same as states $(907,1650,1651)$.

Other commenters recommended that states, tribes and local governments should be allowed to impose more stringent cleanup criteria than those specified in federal rules $(312,581,1969,3267,4230,7337,7922,7959$, $8229,8511,8849$ ), because they have concurrent, continuing, and overlapping responsibilities with the NRC (1045). In particular, states should have some latitude to develop different standards owing to different situations in different states (1878). Other commenters stated that state and local governments should not be able to set more stringent standards $(7883,8148,8158)$. Some commenters recommended that the NRC should not preempt state regulation of sites after these are released by the NRC and are no longer subject to NRC regulation $(3607,4173$, 4304, 7463). Also, NRC should not preempt State determinations for regulating solid waste which contains radioactive materials $(7716,7458,7461,7468,7475,8173,8177,8184,8229)$. Some commenters stated that generic criteria should be developed sufficiently stringent so that state and local governments will not need to impose more stringent criteria $(347,2048,4172)$. Other commenters stated that there must be compatibility between federal agencies' and states' standards to assure against inconsistency between states in interstate transactions $(3259,4246,4269,4487)$. Another commenter stated that if states and localities want to impose more stringent standards, they should pay their share of the costs for meeting the additionai requirements (4478).

Three commenters expressed concern about the roles of the EPA and the DOE in decommissioning $(2854,2905$, 8787). One commenter stated that the DOE should be regulated by a federal agency (3416). Others requested that the impact of NRC decommissioning standards on the DOE be considered $(2933,2934,8803)$. One commenter noted that DOE uses a dose constraint of $30 \mathrm{mrem} /$ year (8879). Still another requested that the NRC rulemaking not cause confusion with the DOE's West Valley Demonstration Project (2582).

One commenter raised questions about the respective roles of federal and state agencies in light of the State Compact Agreements expressed concern about the costs to the states to ensure protection of the public (7076).

\subsection{Process to Be Used in Developing Rule}

\subsubsection{Importance of Public Participation}

Several commenters noted that interactive public participation is important to the process of NRC rulemaking (303, $307,311,346,552,627,674,761,762,901,1219,1244,1368,1383,1389,1437,1737,1904,2374,2898$, $3081,3087,3524,3570,3588,4075,4847,7003,7476,7741,7790,7793,7893,7895,8181,8202,8422)$, and that this would be facilitated through better education of the public $(5,7,343,674,693,712,713,715,762,822$, $837,847,849,886,1247,1249,1323,1579,1769,1873,1882,1887,1891,1907,3570,3612,4075,4831$, $7087,7091,7095,7744,8545,8548)$. Participation in rulemaking should include knowledgeable public health officials, physicians, and health scientists $(4287,4848)$. One commenter recommended the formation of citizen groups paralleling those of the EPA $n$ the Federal Restoration Program (G270). Some commenters recommended that the public comment period for the notice of enhanced rulemaking be extended $(4451,4849)$. Some commenters requested that the NRC hold an additional public meeting around the country after the decommissioning rules are published for public comment $(711,7893)$. One commenter believed that no citizen group has been omitted (664). 


\subsubsection{Feedback on Workshops}

Most commenters expressing views on this subject approved of the NRC holding the workshop meetings to receive advice and recommendation on site cleanup issues $(653,695,705,710,798,800,801,803,809,1042,1254$, $1255,1313,1820,1885,2759,2762,2763,3438,3439,3441,3443,3445,3467,3471,3479,3480,4074,4452$, $4453,4455,4458,4459,4462,4463,4464,4465,4466,4467,4832,4850,7093,7161,7330,7559,7729,7730$, $7790,7892,7894,7975,8186,8261,8423,8523,8524,8628,8789,8856)$. Some recommended that more meetings of this type should be held on a regular basis $(568,695,801,809,1042,1749,1820,1885,4457,4461$, 4466) and recommended that the NRC should provide financial assistance to support such public participation (695, $1876,4073,7748,7794)$. Some commenters voiced skepticism that public participation of this kind would make a difference in what the NRC decides to do $(567,636,647,665,666,667,710,741,800,1011,1282,1385,3102$, $4072,4076,7109,7330,7794,7973,8794)$. Some stated that holding and attending the meetings was not money well spent $(7363,7375)$.

Several commenters stated that a better representation of citizen and public interest groups at the workshops was needed $(313,660,665,676,677,861,962,1274,1282,1315,1863,1864,1865,1867,2195,2413,4773,4803$, $7745,8523)$. One commenter openly disagreed (636).

Other commenters stated that the U.S. Geological Survey and professional ecologists should have been invited $(1507,1529)$. Some other commenters stated that the NRC did not give adequate notice on the workshops (607, $647,653,660,665,676,710,717,1866,1867,1869,1870,1905,1911,4815,7976)$. Other commenters stated that participants in the workshops should have been given opportunity to recommend agenda items (1251, 1546, $1551,1553,1917,1918,1920,1921,2764,2765)$. Additional comments on the workshops and possible future meetings included:

Future announcements of meetings should be sent to people who have attended previous meetings rather than rely on Federal Register notices $(297,714,7794)$; send out press releases announcing future meetings (7976).

Fortunately, this was not billed as a consensus conference, because it is unlikely any of us would leave with a consensus (439). One commenter wanted to develop consensus (1472).

Consider holding a public forum the evening before or after the workshops (716).

GEIS scoping meetings should be held in the same areas as the workshops and additional sites should be considered $(708,717,718)$.

After the NRC develops the decommissioning standards, hearings should be held at these same locations (711).

The NRC should give greater weight to comments by citizen representatives than to industry comments (7974).

It is important to pick good meeting locations (881).

There was not enough media coverage of the workshops $(1311,1817,1819)$.

Informal discussions outside the formal workshop sessions were very beneficial (1872). 
You will not get the right people to attend meetings unless you specifically invite them (1675).

Allow additional time for the meetings (7748).

Evening and weekend meetings should be considered (1877).

Smaller group meetings within the workshop would have been better $(1918,2761)$.

Provision of more technical information to participants would have been helpful $(1253,1254,1341,1919$, $4815,7679,8790,8792)$.

Breaking the workshop into small groups is not a good idea $(1922,2762)$.

At least one afternoon should be reserved for discussion of agenda items identified by participants (1920, 1921).

The facilitators should make people stick to the subject of decommissioning at the workshops and to specified topics $(3476,7271,7363)$. One commenter desired direct repartee (2766).

Audience participation would be more effective if comments were not excessively delayed (7106).

No individual or element should be allowed to dominate discussions (7106).

\subsubsection{Guidance on Standards Development}

Several commenters recommended that NRC decommissioning standards should be based on and be consistent with the scientific information and advice of such organizations as the National Council on Radiation Protection and the International Commission on Radiological Protection $(444,650,934,971)$. See discussion also under Section 2.5.1 of this document. The standards should be driven by the need to protect people and not by such things as aesthetics, land use, and environmental protection (8425). Other commenters recommended that consideration should be given to suppressed scientific information $(302,367,422,538,1087,1324,1916,4851)$. See discussion also under Section 2.4.4 of this document. One commenter noted that the debate on health effects, called for by workshop participants, is already being waged in the peer-review scientific arena and recommended that the health-risk debate be based on the best available knowledge (1102). Other commenters stated that the NRC's decommissioning standard should be based on what we want for the future and not be based on past problems $(2629,2855)$. One commenter stated that utilities have a conflict of interest in the rulemaking proceedings so their comments should be limited to what is technically feasible (7728).

One commenter stated that the question of what risk level is acceptable is not really that much of a scientific decision; rather it is a question of what the public finds acceptable (10). One commenter was frightened by the way government panders radical environmental organizations (G297). Another commenter suggested that the NRC should determine whether standards are to be technologically-based or politically-based; if the latter don't waste time on technological input (328). Still another stated that the definition of "political" could apply to interests of the general public or to interests of industry (2936). Several commenters stated that the standards have to be based on technology and not on politics $(376,646,4282,7823,8775,8850)$. Some commenters stated that standards should be developed taking political realities into account $(1375,3398,3580,3940)$. Another commenter stated that the NRC's decommissioning standard should not be influenced by difficulties of measurement or costs of implementation (2563). 
One commenter stated that the NRC's backfit rule in 10 CFR 50.109 would be a good model for establishing when to apply decommissioning standards, including a test of whether a new requirement results in a substantial increase in overall public health and safety and whether its benefits outweigh its costs (8598). Another commenter recommended that the Generic Environmental Impact Statement should offer detailed descriptions of what the NRC believes would be the consequences of various alternatives as well as information on how the NRC's estimates were developed (7354). Still another commenter stated that the NRC should reconsider whether SDMP sites should be required to comply with the new decommissioning standards (7923). One commenter recommended selecting a few sites of varying contamination to apply the GEIS through decommissioning prior to final adoption of standards for everyone (G190).

Several commenters stated that the NRC must build trust before some members of the public will be willing to accept standards proposed by the NRC $(1462,193 j, 2444,2733,2740,2749,2751,2767,3189,3218,8851)$. Presently these people do not trust anything to do with nuclear energy $(1339,1462,1484,1933,2444)$.

One commenter stated that a national debate should be held, or a commission should be appointed, to idertify the public risks that exist throughout society and to recommend how to spend limited resources in dealing with them (2329). Another commenter suggested that a participatory process take place to discuss the differences in background (2253).

One commenter stated that while radiation protection standard may relate to risk, it is too fundamental a quantity to state in the decommissioning standards. They should be stated in terms of radiation exposure, radiation dose or radioactivity concentration. Either lifetime dose is the most appropriate radiological criterion for decommissioning, or estimation and expression in average annual effective dose to members of the critical group would be practical (8067).

One commenter suggested that the regulations not be overly prescriptive and that guidance for achieving compliance be included in regulatory guides which consider public comment (8900).

The issue of expanding the definition of "decommissioning" to cover more than license termination and unrestricted use raises questions about waste policy and future liability $(7332,7927,8006)$.

\subsection{Approaches for Establishing Radiological Criteria for Decommissioning}

\subsubsection{Risks Limits and Risks Goals}

Most commenters from state governments, the nuclear utilities, the fuel cycle industry, the medical community and non-fuel cycle industry, cleanup contractors, and professional society/standard-setting organizations favored a risk-based or dose-based standard over a standard based on best available technology or return to background (12, $17,18,24,26,27,28,29,30,31,32,35,37,41,42,45,364,392,411,487,502,520,751,981,989,1063$, $1090,1100,1146,1179,1304,1355,1404,1536,1671,1677,1681,1705,1724,1775,1928,1954,1959,1964$, $2025,2063,2110,2157,2175,2292,2344,2395,2407,2412,2437,2455,2462,2496,2502,2538,2541,2569$, $2608,2636,2710,2777,2783,2851,2999,3023,3023,3028,3033,3085,3261,3358,3374,3387,3478,3527$, $3532,3541,3560,3575,3592,3599,3615,3636,3657,3680,3738,3743,3751,3755,3766,3769,3773,3778$, $3805,3826,3871,3877,3899,3911,3953,3972,4102,4106,4157,4198,4206,4488,4852,7000,7020,7027$, $7031,7131,7283,7285,7296,7428,7489,7497,7523,7566,7574,7623,7628,7642,7690,7770,7825,7848$, $8117,8339,8349,8352,8359,8433,8531,8537,8607,8618,8676,8801,8802,8814,8815,8821,8852)$.

Several commenters opposed using a risk-based standard $(22,418,946,987,1000,1113,1655,1990,2179,2184$, $2185,2418,2546,2979,3484,3733,3760,4112,4193,4398,4419,4472,7101,7126,7155,7341,7381,7399$, 
$7645,7803,7898,7986,7987,8711)$. Some commenters cautioned that risk goals and limits should be used with care $(7275,7302,7752,8027,8051,8082,8560,8611,8638,8663,8869)$. Another commenter rejected dosebased standards for several stated reasons (7986). One cummenter suggested that the decommissioning standard include concentration and activity level limits derived from risk goal and risk limits rather than specifying a risk goal or risk limit by itself (7001). Another commenter suggested the use of concentration screening levels based on small doses to avoid costly evaluations (8886).

Reasons given for supporting and opposing a risk-based standard included the following:

In support:

Historically NRC regulations have been risk-based and these have provided a very good safety record (29, $3592,7848,8531,8636,8823)$.

A risk-based standard provides site-to-site flexibility and assures that longer-lived and toxic radionuclides are cleaned up more restrictively than other less hazardous radionuclides and that specified risk/dose levels are not likely exceeded $(27,30,31,32,2496,3012,3261,8302,8494)$.

A risk-based standard will assure uniform treatment of different hazards $(1954,2395,3527,3575,3766$, $8339,8494,8618,8823)$.

EPA cleanup standards in the Clean Air Act and Superfund are risk-based (520, 3085, 3911, 7031, 7848, 8557).

Risk-based limits will assure protection of the public $(28,8302,8676)$.

There must be some notion of acceptable risk whether we like it or not $(487,1775)$.

This will achieve consistency with the levels of health protection recommended by the intermational scientific community (8823).

There is a higher level of stability associated with setting a risk level than in using a background standard $(2538,3028,8631)$.

A risk-based approach provides a means to get on with decommissioning more quickly $(364,1589,8349)$.

A risk-based standard would minimize decommissioning costs and afford a better allocation of finite resources $(1681,1964,2407,2462,2608,2641,2710,7285,7848,8117,8823)$.

In opposition:

There is no safe level of radiation risk exposure $(1113,1990,1995,2596,2979,3484,4112,4472,7126$, $7381,7399,7645,8208,8711)$.

Setting acceptable risk levels is like playing God $(7341,7987)$.

The only acceptable goal is probably background $(2035,2060,2546,2617,2625,4193,4398,4419,7090$; 7381). 
A risk-based standard mimics the Below Regulatory Concern (BR $)$ ) concept which the NRC rejected (22, $946,2179,2198,8711)$.

A risk-based standard could be unstable, because the public's perception of acceptable risk might change $(418,1655)$.

Use of a risk based standard would not allow a balancing of societal benefits and societal costs (7645).

Verification of risk-based standards is theoretical. Modeling depends on the good faith of licensees and places the burden on intervenors or the NRC (987).

Biological effects of radiation are not prcdictable (1000) and risk data are not sufficiently reliable $(1000$, 2184, 2979, 3094, 3733).

Standards based on acceptable risk could lead to litigation (2185).

A limit may be used to justify not cleaning up further (3392).

Most commenters who supported risk-based or dose-based standards favored limits over goals $(24,27,28,35,41$, $42,45,364,411,413,502$, 981, 989, 1063, 1100, 1146, 1179, 1304, 1320, 1536, 1589, 1671, 1705, 1724, 1928, $1959,2025,2063,2157,2175,2462,2502,2524,2538,2569,2608,2650,3028,3085,3261,3358,3541,3636$, $3751,3755,3805,3871,3911,3972,4102,4106,4852,7020,7027,7131,7296,7428,7489,7497,7523,7533$, $7566,7623,7628,7770,7825,7848,7854,787,4,8117,8124,8154,8191,8257,8302,8326,8349,8352,8406$, $8636,8660,8663,8666,8801,8802,8813,8814,8815,8852)$. A risk limit is the highest risk believed acceptable and efforts are made to get below this level as much as reasonably achievable. A risk goal is a level that is desirable to achieve, but exceptions are allowed when this level cannot be met. A risk limit is enforced; a risk goal is not (20). Some commenters suggested that perhaps both a risk goal and a risk limit should be specified $(26,392$, $1775,3023,7000,7302,7359,8064)$.

Most of the commenters who supported a risk limit recommended that it be coupled with an ALARA (as low as reasonably achievable) requirement $(14,27,37,109,392,487,502,981,1063,1090,1100,1320,1928,1959$, $2157,2289,2431,2441,2442,2455,2502,2524,2538,2591,2593,2600,2608,2650,2777,3023,3028,3033$, $3358,3387,3478,3592,3599,3751,3805,3877,3972,4102,4106,4206,4488,7428,7523,7566,7628,7770$, $7775,7848,7851,7854,7874,8124,8154,8191,8257,8302,8326,8406,8443,8468,8471,8478,8494,8531$, $8549,8607,8631,8660,8720,8801,8813,8821,8822,8863)$. Two commenters recommended that ALARA efforts to reduce dose not be applied below a screening level of a few millirems per year $(7775,8443)$. Another commenter suggested that most licensees could be accommodated by establishing very low radioactivity levels which if met would not require an ALARA analysis (8051). Several commenters opposed ALARA on the grounds that it gives licensees more flexibility than is desirable $(2305,2435,2459,2546,2625,3871,4419,4853)$. Other commenters opposed ALARA on the grounds that cleanup should not be required below the specified risk limit (14, $37)$ and that ALARA is not enforceable $(2439,2645,2653)$. Two commenters stated that if the ALARA principle is used it must be defined and set out as a requirement $(2602,8896)$. Two commenters questioned the quantification of ALARA (7117, 7131, 7302).

One commenter noted that once the risk limit is achieved, the multi-attribute analysis (e.g., ALARA) allows consideration of practicality; however, if risk goals are applied, the multi-attribute analysis is not necessary (8902, 8908).

Another commenter stated that the EPA and the FDA have established arbitrary minimal risk goals as regulatory 
standards; most other agencies take risk/benefit into consideration and this is recommended (3812). One commenter stated the EPA's selection of values for radionuclides in water could be construed as subjective (8722).

Some commenters distinguished between establishing a risk limit and adoption of a dose limit $(18,37,487,1404$, $2197,2777,3387,3592,3599,3615,3680,7489,7533,7566,7574,7698,7825,7874,8066,8319,8474,8607$, 8815). One commenter stated that the health physics profession has recognized for over 40 years that people cannot agree on the risk concept (3599). However, another commenter believes a risk level can be accepted by the public (889).

Two commenters noted that constraints may be needed to assure exposure limits are met in the event more than one site might contribute personal exposure $(8100,8799)$. One commenter suggested a limit of $100 \mathrm{mrem} / \mathrm{year}$ and a dose constraint of $30 \mathrm{mrem} /$ year (8875). Aside from multi-unit nuclear power stations, licensed sites tend to be separated enough in distance that a potentially exposed group is unlikely to be exposed to radioactive material from more than one site $(8100)$.

Another commenter recommended that the NRC use 10,000 person-rem as the threshold below which, for low doses and low dose rates, there is no cancer risk and that ALARA should be applied at a value of not more than $\$ 10,000$ per person-rem for collective doses above 10,000 person rem. An alternative recommendation was that if a 100-year /risk model would not predict one cancer fatality, no further decontamination was required. The ALARA principle should be used in cases where the 100 -year dose is greater than that which will result in one cancer fatality (G791).

\subsubsection{Best Available Technology}

Almost all commenters on this option voiced objections to a possible best effort/best available technology standard $(47,49,52,53,54,55,316,393,496,819,825,1085,1183,1194,1200,1347,1812,1818,2029,2061,2074$, $2136,2145,2170,2177,2180,2183,2258,2346,2592,3031,3032,3310,3384,3974,4207,4854,7025,7335$, $7401,7491,7576,7691,7811,7856,8056,8356,8448,8613,8644,8713,8725)$.

Reasons given included:

Such a standard would be extremely subjective ( $819,2029,2177,2258,7491,7691,8356)$; it would mean different things to individuals $(53,2346,7856,8448,8565,8644)$; and its connotation is to do what is practical, not what is needed $(49,1085)$.

Best effort would be a subsidy to the nuclear industry (316).

Best effort is a cop out (1818).

Costs should nnt outweigh health and environmental costs $(433,2029)$.

A best technology standard is similar to the rejected below regulatory concern (BRC) notion (2180).

There would be no end point to decommissioning costs $(54,393,2136,3384,4207,8056,8356,8357$, $8448,8565,8613,8874)$.

Costs could be more significant than the risk approach $(3310,3974)$; such a standard would be unstable $(2145,2183)$. 
Lax standards could be set on the basis of today's inadequate technology $(496,7335)$.

Such a standard could thwart innovative technology developments $(1812,7401)$.

For most reasonable risk-limit standards, there is not much limitation on technology $(2177,8356)$.

Best effort is inconsistent with recommendations of the ICRP and NCRP (7576).

Some commenters stated that best-effort could be an appropriate adjunctive approach $(2039,7277,7382,7647$, $7899,7902,7993,8480$ ). Other commenters said best available technology should perhaps be applied in conjunction with a risk-based standard $(3029,7127)$.

One commenter stated that there might be some financial incentive used by the NRC to induce industry to use the best available technology for achieving the lowest levels of cleanup (4855). Other commenters said compliance with NRC decommissioning standards should be demonstrated by the best available technology $(899,7297)$. Still other commenters stated that the NRC should explore the use of the best available technology world-wide (587, 7320, 8732). Two commenters suggested that best effort determinations must consider both available technology and associated costs $(51,1332)$.

One commenter suggested that if a best available technology standard is adopted, the NRC should provide flexibility to permit the use of new technologies without having to wait for a regulation change (1812). Another commenter suggested that if the NRC takes the best available technology approach, it should place details in guides and not in NRC regulations (48).

\subsubsection{Return-to-Background}

Most commenters from Citizen/Environmental Organizations and some from other organizations favored a return-to-background standard $(62,63,65,70,71,350,386,398,399,410,421,424,448,458,474,476,556$, $783,810,874,929,1021,1023,1028,1037,1086,1319,1330,1423,1469,1471,1475,1482,1486,1569$, $1658,1668,1674,1741,1751,1786,1908,1916,1989,2018,2022,2038,2047,2057,2072,2079,2083,2092$, $2113,2168,2237,2307,2309,2323,2377,2492,2510,2519,2555,2567,2771,2846,2877,2930,3003,3016$, $3042,3074,3105,3282,3381,3549,3587,3593,3602,3666,3709,3714,3734,3824,3828,4192,4209,4310$, $4399,4418,4423,4426,4475,7006,7008,7009,7013,7065,7092,7102,7103,7146,7164,7171,7324,7328$, $7338,7343,7352,7383,7392,7554,7557,7601,7611,7669,7742,7782,7805,7813,7900,7963,7967,7979$, $7981,8212,8219,8223,8231,8234,8245,8259,8514,8695,8696,8699,8707,8714,8718,8727,8729,8737$, 8745).

Reasons given for supporting and opposing a return-to-background standard included the following:

In support:

This standard would provide more stability in the long-term $(71,448,1658,7979,8234)$ even if it presents difficulty in definition and demonstration of compliance $(350,424,458,1023,2113,7408)$.

Any lesser standard would be a subsidy to industry $(783,810,8245)$.

Growing studies show that low-levels of radiation increase health risks $(1471,1668,1739,2113,2771$, $7092,7102,7328,7383)$. The NRC has no moral right to permit a risk higher than that from background $(1668,1989)$. 
This is the only standard without a notion of below regulatory concern (BRC) $(421,2567,3587)$.

Sites should be returned to the condition they were in before nuclear operations commenced $(410,1021$, $1028,1482,1486,1908,1989,2057,3074,3105,3828,4310,7352,7557,7611,7669,7782,7805$, $7813,7900,7967,8212$ ).

All risk estimates must be suspected as erroneous; it is better to err on the side of safety and go towards zero (2377).

Finality in decommissioning is not politically realistic unless the end point is background $(2361,2519$, $3824,7102,7979)$.

This is the only standard suitable for unrestricted site use $(1078,1916,3549,3593)$.

It is wise and prudent to decontaminate down to background (1569), and this will provide the needed level of surety (70).

This is most acceptable and possibly the only standard that the public is willing to accept $(62,63,398$, $1741,2072,3074,3602,7102,7324,7554)$.

If other than a return-to-background standard is adopted, industry will remain liable for contamination at a site $(1660,1751,4209)$.

Stardards based on acceptable risk will lead to a litigator $(1674,7963)$.

In opposition:

This option does not consider risk or cost $(7577.7649,7692,7853,8059,8360,8364,8451,8566)$.

Cleauup to background is more than what is needed for safety $(395,408,685,1047,1543,1670,2150$, $2251,2553,2577,2700,2709,2818,7125,7492,7692,7859,8364,8646,8870$ ) and is economically unfeasible (2355).

A return-to-background standard would be more costly than a risk standard $(2031,2223,3368)$ and would result in a significant waste of limited resources $(395,442,463,490,1768,2577,3721,8566)$.

Such a standard would result in the accumulation of the most volume of low-level wastes $(1636,2295$, $4104,4235,7404)$ and would result in ineffective use of low-level waste disposal space (68).

A risk-based standard is a more equitable approach than a return-to-background standard $(3770,3779$, 3924).

A return-to-background standard would trigger alarms that are meaningless $(66,3721)$.

This standard may not be achievable $(60,1068,1814,2351,2525,2550,2606,2815,3336,3754,7125$, $7692,8615)$ and could push technology beyond its present capability $(64,3312,8370)$.

This option is incompatible with ICRP and NCRP recommendations $(7404,7577)$.

Determination of levels of radiation at or near background is elusive and multifaceted. Background varies 
spatially, temporally, and seasonally with climate and over long time frames in ways that are not well understood $(435,457,463,484,500,534,1068,1186,1190,1192,1198,2090,2100,2364,2433,2525$, $2540,2543,2545,2550,2570,2574,2585,2706,2770,2981,3026,4349,4445,4856,7125,7150$, $7273,7308,73677615,7618,7692,7859,8062,8188,8256,8451,8646)$.

It is technically impractical to set the limit at background or undetectable above background $(1439,1694$, $2351,7125,7692,8190,8370$ ). The standard would shift with improving measurement technology and would provide no point of finality to the cleanup process $(69,450,1694,2826,8190,8370)$.

The use of a return-to-background standard does not ensure regulatory stability $(1188,1195,8256,8566)$.

Such a standard could result in more money being spent for monitoring and proving you are at background than is spent on decontamination efforts (453).

A return-to-background standard could create greater health risks than those being remediated $(482,1272$, $2031,4104,4235,8059,8870)$.

Movement of contaminated soil to reach background will bring about unnecessary exposure $(68,7404$, $8059,8360,8646$ ). Also, there is not much you can do about contaminated groundwater (589).

A return-to-background standard for unrestricted use could cause more harm through removal of top soil than if left in place $(2274,8360)$.

High technology measurements will not clarify what background is. They will just show that it fluctuates and is not a clear, achievable number (2243).

If a return-to-background standard is used, farmers would have to be told to clean up their fields, and people who buy Brazil nuts would have to ship the shells to a low-level radiation waste site (547).

Going to background is unacceptable and it will be litigated $(533,4388)$.

Opposed for other reasons or without stating a reason $(1195,1305,1429,1439,1672,1704,2885,3343$, $7184,7404,8149,8188)$.

Several comments were offered concerning how a return-to-background standard might be implemented by the NRC.

Some commenters stated that nuclear facilities should be designed to be returned to background $(929,7967)$. Another commenter stated that perhaps a return-to-background standard could be applied at some sites, but not broadly applied at all sites (588).

Another commenter stated that the attraction of a return-to-background standard, as opposed to a numerical limit, is that this standard empowers the community to reach consensus on how clean is clean. What is important is how the limit is determined and who determines it (1786).

Still another commenter indicated that if the NRC adopts a return-to-background standard, it must specify what kinds of measurements must be made, including sensitivity and reliability of instruments and how to demonstrate that the standard has been achieved (67). The variability of background and the difficulty of precise analytical measurements at low levels require a logical approach to defining background (7294). "Background " does not 
mean zero, but rather a level of radioactivity based on an average of the test results of a number of samples taken in known noncontaminated areas adjacent to the site being decommissioned (7619).

\subsubsection{Other Approaches for Establishing Criteria}

Some commenters stated there is a large body of scientific literature not embraced by the NCRP and ICRP that indicates there is no safe level of radiation exposure $(326,372,623,1019,1049,1914,2111,2181,3731,4857$, $7384,7723,7788)$, or radiation is more harmful than recognized by them $(1213,4758,2385,2717,3160,3283$, $7012,7664,7732,8217,8253)$. Several references were mentioned in this connection $(1228,1583,2111,3006$, $3135,3150,3283,3302,3611,3731,3793,3951,4857,7664,7689,7723,7788,8217,8253,8375$ ). Some commenters suggested that national and international scientific advisory bodies might not be totally objective (1292, 3402,7788 ). Other commenters stated that the public will never trust health effect studies unless conducted by independent individuals or organizations $(372,2227,2917,2938,4175)$. One commenter questioned the value of having the public rather than scientists evaluate technical data (1240).

Two commenters stated that the Department of Energy, the nuclear industry, and the NRC have covered up the true health effects of radiation that bear on the issue $(1789,2447)$. Other commenters said that the government generally covers up knowledge of health effects from nuclear facilities because it doesn't want to know about them $(692,1248,2230)$. Still other commenters stated that more study is needed before the NRC decides on decommissioning standards $(1019,1169,1403,2267,3093,3125,3177,3741,3775,4056,4058,4374,7107$, $7118,7483,7654,7689,7732,7763,8519,8708)$. One commenter recommended that the NRC invite those people who are outside the "internal scientific" community for an open discussion of what levels they believe should be set $(1222,2181)$. Another commenter stated that the debate on health effects called for by some workshop participants is already being waged in the peer-review scientific arena (1103). Studies not deemed acceptable by peer review should be given special scrutiny before their recommendations become the basis for regulatory policy (7287). Other commenters stated that the health-risk debate should not be conducted based upon information from isolated incidents, but should be based upon the best available knowledge $(324,1103)$. Others stated that consensus can be reached without one hundred percent agreement and in fact international consensus on reasonable levels of risk have been established by national and international scientific groups $(1545,4858)$.

One commenter suggested that the EPA should be requested to explain or justify its claim that its risk limits for toxic chemicals can be used for the control of radioactive material contamination (7256). Other commenters stated that the EPA's chemical risk standards may not be directly applicable to radiological protection risks $(7838,7940$, 8240,8318 ). Additionally, it was suggested that the NRC consider requiring cleanup of man-made residual contamination only to a level below that of the preexisting background radiation levels; if naturally occurring background radiation exposures are reduced, require less cleanup of the man-made radioactive materials ( 7265 , 7380).

Some commenters stated that the National Cancer Institute (NCI) had studied the radiation dose versus cancer incidence rates around nuclear power plants and had concluded that there are no significant health effects at those sites $(1080,1742,1821)$. Other commenters stated that the NCI study was poorly designed and purely a political cover $(1225,1248)$.

One commenter suggested that perhaps a national debate should be held or some sort of study commission should be established to determine what real risks exist in society and how the limited resources available to deal with them should be spent (2334). One commenter indicated that all four approaches be incorporated into the criteria (7272).

Two commenters referred to studies which indicate that low doses of radiation may be beneficial $(3269,7287)$. 
One commenter urged NRC to regard "hormesis" with great skepticism (7947).

One commenter believes that the final decisions are political (2306).

\subsection{Establishing a Basis for Risk Goals or Limits}

\subsubsection{National and International Cersensus}

Many commenters suggested that a proper basis for establishing risk goals or risk limits would be the recommendations of the U.S. National Council on Radiation Protection and Measurements (NCRP) and the International Commission on Radiological Protection (ICRP) (112, 309, 650, 958, 985, 1208, 1218, 1314, 1363, $1522,1537,1584,1962,1977,2013,2028,2121,2158,2193,2200,2204,2248,2290,2586,2683,2867,2873$, $3257,3263,3270,3347,3360,3389,3514,3555,3561,3595,3600,3616,3736,3744,3781,3878,3935$, 3946, 4188, 4194, 4252, 4808, 7032, 7269, 7288, 7388, 7405, 7418, 7429, 7487, 7490, 7494, 7522, 7534, 7545, 7562, $7568,7578,7634,7643,7695,7769,7824,7872,7878,8011,8022,8030,8043,8049,8070,8094,8125,8169$, $8279,8289,8301,8307,8320,8324,8335,8340,8371,8411,8415,8434,8456,8485,8496,8500,8538,8608$, $8655,8853,8911)$. Some commenters noted that national and international consensus standards take into consideration the effects of low-level radiation $(1050,1568,3171)$ and are based on the assumption that low-levels of radiation cause health effects $(89,92,1572,3163,3171,4149,4155,7104,7157,8520)$. Some questioned that assumption and believed that health risks are not substantially increased by exposure to low-levels of radiation (87, $88,90,401,1051,1266,1574,1598,1941,2193,3839,4152,4385,4483,7128)$.

One commenter stated that a combination of risk limits and risk goals or "screening levels" is used by NRC and DOE, by the international community, and in some cases by EPA. DOE is considering use of a site specific dose constraint of $30 \mathrm{mrem} /$ year to ensure individuals do not exceed $100 \mathrm{mrem} / \mathrm{vear}$ from all sources (8878).

One commenter stated that where possible the NRC rule should be consistent with the guidance and standards of other radiation protection guidance and regulatory groups. The rule must be consistent with EPA's "generally applicable " radiation standards for decommissioning and should be consistent with other related initiatives (8894).

Some commenters stated that establishment of decommissioning standards based on current recommendations of the NCRP and the ICRP would be like building on shifting sands because present understanding of the health effects of low-level radiation is not 'very good, and applicable standards are going lower and lower as we get additional information $(74,75,76,81,84,519,1000,1035,1212,1233,1436,1524,1540,1568,2415,3400)$. Others stated that there is no safe level of radiation risk exposure $(1114,1710,2138,2210,4479)$. Still others stated that ICRP standards need to be revised to account for recent studies which show low-levels of radiation are more harmful than previously thought $(3010,3284)$. See discussion also in Section 2.4.4. Other commenters disagreed that radiation standards are decreasing over time $(85,680)$ and stated that some radiation standards have in fact been liberalized over time (86).

Those favoring acceptance of NCRP and ICRP recommendations stated:

More is known about radiation hazards than about those of any other toxic substance $(82,2013)$.

The ICRP and the NCRP recommend that protective actions should be both justified and optimized (8022) and do more good than harm (8029). In the case of individual sources, there should be dose constraints set below the dose limit (1314). 
Enough is known about the health effects of radiation to establish a reasonable estimate of risk from a particular radiation dose $(391,415,2849)$.

There has not been any great new knowledge about the effects of radiation at low doses for a long time $(77,78,79)$.

You should be cautious about information that has not been through a scientific peer review (2290).

Those opposed stated that any radiation exposure above background poses an unacceptable risk $(91,397,404,438$, $634,638,1143,1540,1669,1710,1766,1739)$ and they distrust the body of expert consensus reported to be out there $(1582,1740,1940,2415,3103,3833)$.

The IAEA recommended limits for decommissioning are greater than the IAEA limit of 1 millirem/rear for recycling to uncontrolled use (3337).

Standards by professional organizations such as the American Nuclear Society and the American Society for Testing and Materials will help the industry and the public know what and how decommissioning will be done (4260).

One commenter suggested that DOE requirements for radon are similar to 40 CFR 192 and allow for no action if the concentrations are predominately from background (8934). Also, NCRP Report No. 116 and international and Canadian recommendations of $20 \mathrm{pCi} / 1$ for radon were noted (8942).

\subsubsection{Risk/Dose Relationship}

Several commenters recommended that the NRC consider adopting a risk limit standard equating to a radiation dose of 25 to 100 millirems per year $(113,525,526,1155,1208,1523,1532,1533,1536,1570,1572,1647,1688$, $1703,1773,1930,2129,2217,2277,2554,4809,4859,7112,7321,7394,7493,7501,7533,7536,7569,7642$, $7696,7842,7899,8012,8024,8026,8032,8036,8044,8290,8339,8342,8388,8416,8479,8549,8553,8575$, $8649,8657,8690,8811,8816,8817,8818,8819)$. According to two commenters a 100 millirems per year limit would increase the cancer risk in the population only slightly above its normal incidence rate $(4657,1728)$. One commenter believes that damage may be increased at smaller doses (2983). One commenter stated that one cancer death per 285 person-rem as conservative (3156) while another endorsed the number (1470). Other commenters stated that the 100 mrem per year limit under the NRC's present rules and the 3 mrem per year limit under the EPA's rules should be reconciled $(522,4660,4860,4861)$. See discussion also in Section 2.2.1. Some commenters recommended adoption of a radiation dose limit of 10 to 30 millirems per year $(7496,7498,7501$, $7503,7508,7608,7747)$. Other commenters recommended adoption of a risk goal of 3 to 10 mrem per year $(7696,7842)$.

One commenter stated that a dose constraint in the range of $30 \mathrm{mrem} / \mathrm{year}$ is generally consistent with the EPA risk standard of ten to the minus four lifetime risk (8880).

Still other commenters recommended that the NRC should consider adopting a risk limit standard equating to a dose of one (1) millirem per year to an individual and 1 to 100 person-rem per year to the population around a site (3054, 3153, 7807, 7908). Other commenters stated that such dose limits are much too low to adopt $(2241,3232$, $3352,8155,8377)$. Another commenter stated that the NRC's generic standard should be established at a level that is reasonably safe; however, "safe" has been defined at such a low level, trivial in comparison to natural background, that people have been unnecessarily frightened (3732). 
Two commenters stated that the non-threshold theory may not be true and the imagined low-level effects do not occur $(4143,4151)$. One commenter believes there is an increased low dose effect at $0-5$ rem (4797). Another commenter wants "chronic low dose exposure" considered (2454). Another believes that radiation risks are low and hard to quantify (3151). One commenter stated that small doses may adversely affect fetal development (half a rad) (3138).

The uncertainty of radiation effects is unimportant to decommissioning because the doses from decommissioning are relatively small (83).

One commenter suggested that NRC should consider hiring a medical doctor to lend credibility to its staff with respect to qualifications in the field of epidemiology and radiation biology (7260).

\subsubsection{Background Radiation}

Many commenters recommended that the NRC establish as its decommissioning standard a risk/dose limit on the order of the variability of natural background radiation occurring across the United States $(93,97,98,416,1009$, $1453,2201,2494,2648,2819,2874,2930,3170,3459,3707,3735,3745,4811,7339,7362,7651,8820,8825)$. The reasons given were that no health risks are attributable to background variations $(931,2440,2648,2819,3076$, $3089,3364,8854$ ) and studies show that there is no increase in cancer incidence over the wide range of background radiation in the U.S. $(93,98,2494,2718,2874,7323)$. One commenter recommended that the NRC establish its decommissioning standard at a small fraction of natural background radiation levels (few millirem per year) (7776). Some commenters disagreed that background radiation variations are safe $(740,1463,3068,3069,3320,3739$, 3746).

One commenter suggested that experts will have to determine local benchmarks if a background limit is used (479). One commenter stated that all background measurements carry errors which must be dealt with (1307). One commenter stated that background is not a well defined concept (1452).

Natural background, excluding exposure to radon, in Colorado is on the order of 200 millirems a year and in the coastal states of Florida and Louisiana is on the order of 100 millirems $(95,96,447,1535,4862,7111,7362$, 8363). One commenter suggests that a reference to use for background radiation exposures to people in the United States is 360 millirem per year per person, and suggests expression of other exposures as multiples or fraction of that number (2400). Also, the variability of background at locations in the same state can be as much as 100 millirems a year (94). The difference of $10 \mathrm{C}$ millirems was recommended by many as the dose limit of choice. See discussion in Section 2.5.2. For discussion of those favoring a return-to-background standard see discussion in Section 2.4.3.

One commenter said that DOE makes allowances for radon concentrations that are predominately due to background (8934).

One commenter recommends creation of an advisory board, composed of federal and state environmental officials, environmental scientists, public health experts, representatives of environmental and citizen organizations, labor unions, and others from society affected by the issue, to make impartial, location specific assessments of background radiation (7347). 


\subsubsection{Individual and Collective Doses}

Several comments were made concerning how risk standards should be applied to the population who may be exposed to residual radioactivity at a released site. Most commenters favored applying a risk limit to individuals $(107,114,115,1006,1338,1808,2131,2601,3716,4413,4468,4863,7495,7535,7548,7644,7771,7877$. $8069,8292,8395,8436,8442,8539,8677)$ and believed it unnecessary to specify a collective dose limit $(104$, $106,1499,2134,4413,4468,7037,7042,7443,7547,8069,8088,8139,8295,8395,8442,8472,8581,8586$, $8590)$. Others stated that collective dose limits should be applied $(103,108,2634,3148,3154,3533,7909,7949$, $8247,8521,8884)$. If collective dose limits are applied, they should be consistent with ICRP and NCRP recommendations (8041). One commenter remarked that if collective dose is used, it should be applied in a comprehensive manner; for exa uple, in evaluating an appropriate cleanup standard the doses to the public from transporting material off site for disposal should be evaluated against the doses receiveci by the public around the site if the material is left in place (8396).

With respect to the calculation of individual doses, some commenters favored applying a risk limit to a maximally exposed individual $(106,1006,1108,3143,3716,3784,7037,7041,7567,7826,7909,8329,8670,8752)$ while others favored applying it to some sample of a critical population group $(114,991,2131,2411,2684,2799,3168$, $3921,4468,4504,7130,7397,7438,7443,7538,7548,7826,7877,8075,8139,8292,8295,8343,8395,8436$, $8472,8586,8912$ ). One commenter favored use of a credible population group, not a hypothetical individual (7281). Four comments argued that risk limits should be applied to the most susceptible people in the population $(1367,3124,3133,7156)$. Another commenter indicated that both individual and collective doses or population risk must be considered and based on realistic scenarios and average values if comparisons of alternatives are to be equitable $(8866,8915,8916)$.

\subsubsection{Modeling/Pathways}

Several commenters pointed out that, whatever risk standard the NRC may adopt, compliance will likely need to be determined by a computer model $(532,812,835,988,1693,1755,2132,2285,2620,2803,2806,2808,2810$. $2821,2921,3114,3144,3169,3419,3453,3509,3650,3656,3673,3717,3799,3893,3922,7445,7542,7552$, $7913,7964,8073,8086,8140,8466,8491)$ except for small operations when contamination levels are within specified generic criteria (2809). Some commenters expressed reservations about the use of models stating that models can be slanted to the desired results $(598,684,2805,2807,2924,3591,4063,7048,7694,7916,7989)$, different modeling assumptions will give you different answers $(598,720,996,2925,4397)$, and modeling has large uncertainties $(7004,7393,7442,7910,8076,8089,8674)$. One commenter stated that meaningful dose estimates must be calculated or measured using actual data and proven models and cautioned that risk models commonly overestimate doses and risks by factors of 10 to a thousand (G75). Some situations may not fit a model $(997,2216,2615,3060,3790)$, and modeling is costly and slows down cleanup $(1308,2844,7004)$. Other commenters stated that decontamination limits should be established and dose modeling should not be relied on to demonstrate compliance $(2808,7002,7293,7505,7524,7989,8576)$. Other commenters defended the use of models and the integrity of individuals who use them $(111,525,700,835,884,2823,4362)$. Two commenters stated that models will be needed even if a return-to-background standard were adopted $(812,2686)$. Other commenters cautioned that reasonable assumptions must be made $(105,7913,8315)$ and the NRC/EPA should develop a standardized methodology $(1363,1895,1898,2660,2912,2913,3238,3246,4160,4375,4406,4508$, $7419,7448,7514,8086,8109,8476,8576)$.

One commenter recommended that funds should be allocated for research and development on modeling and technology for evaluating and dealing with environmental effects (2618). A commenter suggested that NRC provide detailed guidance documents on acceptable methodology for performing assessments, including scenarios 
for use of land, buildings, and equipment (7513). Another commenter stated that methods for accounting for exposure pathways are available in regulatory guides (2676).

Several commenters stated that all exposure pathways to man should be considered to assess possible future doses from a contaninated site $(173,1848,2262,2340,2409,2420,2597,2687,2994,3022,3096,3464,4503,4514$, $4518,7069,7141,7445,7446,7570,7841,7916,7962,8097,8131,8146,8408,8410,8476,8678,8679,8755$, 8926).

Comments were split on whether risk limits might be needed for different exposure pathways. Some stated that standards for different pathways are essential to ensure environmental protection, particularly for groundwater and air pathways $(867,869,1071,1844,1846,1848,1852,1854,2216,2245,2268,2275,2677,2681,2689,2692$, $2712,2713,2715,2720,2837,2839,2840,2925,3136,3411,4030,4523,7481,8201,8250$ ). Others opposed establishment of separate limits for each exposure pathway $(7050,7054,7446,8146,8408,8487,8540,8678$, $8925,8928)$ and believed that risk standards set to protect humans would properly ensure environmental protection $(730,997,1227,1517,2782,3423,3430,3782,4865,8410)$. See discussion also in Section 2.14.

One commenter stated specific site inventories may be used for screening sites but such criteria must include consideration of all pathways (8931).

One commenter believes pathways are "totally trivial and ridiculous" (1230).

\subsection{Balancing Risks and Benefits}

\subsubsection{Performing Assessments}

Several commenters stated that the NRC should establish its decommissioning standards based on a complete assessment of the total costs and benefits associated with different options $(216,217,224,226,323,342,1946$, $2012,2427,2552,2632,2887,3066,3070,3077,3092,3098,3188,3213,3410,3492,3506,3511,3530,3927$, $4257,4307,4317,4330,4367,4440,4469,4484,4866,4867,7005,7024,7039,7258,7350,7400,7417,7526$, $7646,7650,7833,7837,8275,8394,8529,8619,8809,8864)$. Other commenters added that the NRC must compare the risks that exist without remediating to the standard with the risks that exist with implementation of the standard $(220,230,957,1165,1807,2552,2579,2986,4344,4868,4869,7043,8308,8397)$. Still other commenters stated that resources should be expended only to reduce observable health effects and not remediation of calculated or hypothetical health effects $(224,227,305,772,1110,1927,2640,7280,7295,7439,8313)$. One commenter expressed concern over the influence of groups with little or no scientific background which is causing expensive and misguided solutions for environmental problems (G915). Some commenters stated that whether risks are acceptable should depend on what the risk to benefit ratio is $(230,2632,2887)$. One commenter placed public health before costs (317).

One commenter stated that a dose or risk constraint to ensure protection of individuals must be based on a realistic risk or impact analysis (8877).

One commenter stated that in assessing risks one should integrate over a time of at least 1000 years (3131). Other commenters stated that the time frame should be related to the radionuclides involved $(7038,7049,8446)$. One commenter suggested that potential future risks might be discounted as is done in economic discounting (8920). Other commenters stated that there should be a screening level below which no further assessment is required $(1405,4870,7539,7646)$. Concentration screening levels (activity per unit mass or unit area) that could be measured and that are based on small doses could be used (8887), or specific site inventories may be a reasonable 
approach (8929). Another commenter stated that computer models or tools should be made available for public use (3429).

Some commenters objected to cost-benefit balancing $(794,797,1020,3469,3523,3572,4329,8246)$. Other commenters offered admonitions concerning risk-benefit assessments $(1270,1910,2889,3071,3326,3405,3542$, $3651,3761,3788,3883,4370,4473,7942,7946,7951,7994,8072,8077,8078,8194,8310,8331,8347,8404$, $8591,8858,8862,8890,8913,8914,8917,8918,8919,8923,8927,8947)$. One commenter stated that a multiattribute analysis (e.g., ALARA analysis) allows consideration of practicality (8904) on the site- specific level (8906). Some commenters disagreed altogether with the use of economics in deciding decommissioning standards $(781,1893)$.

One commenter noted that there are many cost-benefit studies from other sources that might be used for comparison in evaluating cost-benefit for decommissioning and suggested that the NRC might compile some of this information to educate the public on the issues (1828). One commenter stated the NRC's previous estimates of decommissioning costs were inaccurate and too low (2980). Another commenter stated that the cost of decommissioning has not been adequately addressed (4311).

A commenter noted a problem when balancing risks, costs, and benefits is the assignment of a dollar value to such things as a life, discomfort, ecological impacts, and public concern. The commenter suggests that it may be desirable to implement some other unit of equivalency (8909).

\subsubsection{What Risks Should Be Considered}

Many commenters stated that for the most effective use of resources and fairness, the NRC must consider in the risk-benefit balance not only radiological risks to workers and the public, but also non-radiological risks and indirect risks associated with the regulation of decommissioning activities $(211,212,214,215,219,223,419,470$, $578,749,750,753,756,807,970,1029,1163,1236,1277,1359,1399,1443,1485,1505,1544,1804,2178$, $2260,2343,2535,2883,2953,2954,3091,3110,3132,3159,3304,3329,3363,3404,3406,3407,3428,3455$, $3641,3763,3808,3811,3816,3925,3932,3944,4093,4115,4202,4319,4338,4371,4383,4441,7074,7099$, $7259,7440,7528,7612,7700,7941,7945,7988,8014,8204,8241,8267,8285,8297,8304,8314,8345,8365$, $8380,8383,8391,8430,8499,8530,8535,8584,8620,8648,8691,8949)$. Some commenters stated that non-radiological risks should not be considered $(7137,8243)$. Other commenters stated that the NRC should not base its decommissioning standards on cost/benefit arguments $(7995,8243)$. One commenter stated that the Health Physics Society concludes that, "there is no ecological or conservation basis for establishing radiation protection standards different from those...involved in any other health issue for which benefits are weighed against costs" (466).

Some commenters stated that risks only to man should be considered while others stated that risks to the environment should also be considered. If specific site inventories are used for screening sites, the criteria must be based on all possible detriments (8930). See discussion in Section 2.14.

Some commenters stated that the NRC should consider risks at a decommissioned site from both radiological and non-radiological substances $(746,1163,1207,1275,1982,2088,2107,2313,2859,3110,3123,3141,3458$, $3463,3619,3663,3804,3811,4535,7259,7528,7875,7919,8204,8380,8499)$. One commenter stated that the cost/benefit analysis for chemicals should be different than for radiological materials (7836). See discussion also in Section 2.2.1. The NRC should consider risks both to workers who perform decommissioning activities and to the general public who are exposed during and after the decommissioning $(796,1029,2859,2968,2974,3393,3406$, $3604,4108,4315,4320,4328,7289,7530,8535)$. One commenter stated that occupational radiation exposures 
received during decommissioning activities should not be a part of the decommissioning analysis (7058). Some commenters stated that all harmful effects of exposure to radiation in addition to fatal cancers should be considered $(2630,3742,3777,4373,4871,7040,8209,8241)$.

One individual commented that if the NRC is going to consider societal risks in the rulemaking, it would need to revisit things like the one-step licensing where it refused to consider this (16). A commenter stated that collective dose or population risk should be, considered when conducting a multi-attribute analysis (8883).

Several commenters stated that the NRC should consider possible risks to humans that might result if the decommissioning standard causes a curtailment of medical uses of radioactive materials $(336,441,1397,1451$, $1661,1906,2721,2879,3203,3641,4154,4872$ ).

Other commenters favored $(1939,3019,3141,3545,3747,4400)$ and disfavored $(2430,3158,3351,3382,3397$, 3421 ) distinguishing between voluntary and involuntary risks when making cost/benefit analyses.

One commenter wants all future potential land use evaluated and not just the next one (3765). A commenter noted that it is important to consider both current and future populations $(8922,8924)$.

\subsubsection{ALARA Considerations}

Under the ALARA concept, decommissioning activities are continued beyond meeting applicable risk/dose limits in efforts to reduce radiation exposures As Low As Reasonably Achievable (ALARA). Most commenters recommended that the NRC's radiological criteria should incorporate this principle $(204,310,936,959,994,1017$, $1024,1091,1098,1099,1107,1322,1348,1824,1957,2064,2070,2287,2503,2526,2539,2590,2594,2595$, $2599,2631,2649,2704,2778,2894,2989,3014,3025,3030,3361,3369,3372,3383,3385,3388,3408,3466$, $3490,3522,3564,3597,3601,3681,3699,3752,3807,3815,3879,3973,4103,4107,4208,4253,4279,4314$, $4333,4353,4386,4389,4391,4408,4450,4477,4489,4813,7022,7132,7133,7268,7279,7303,7390,7396$, $7431,7434,7435,7502,7516,7525,7531,7571,7624,7630,7697,7772,7773,7843,7849,7852,7855,7858$, $7876,7912,8023,8037,8126,8136,8138,8156,8192,8258,8303,8311,8321,8327,8350,8389,8407,8441$, $8470,8173,8488,8495,8498,8532,8533,8550,8554,8556,8558,8570,8574,8585,8589,8609,8632,8637$, $8662,8664,8668,8669,8685,8721,8749,8861,8865,8903,8937)$. See discussion also in Section 2.4.1. Some commenters said that ALARA efforts to reduce dose should not be applied below a screening level $(994,1957$. $2894,3025,4799,7773,8037,8052,8129,8441,8481,8944)$. Several commenters disagreed with the use of an ALARA provision $(524,961,1007,1015,1157,1316,2073,2304,2547,2616,2624,2643,2644,2647,2654$, $3412,3772,3872,4190,4216,4231,4396,4417,4422,4471,4873,7812,7992,8251$ ). Some commenters stated that the meaning of ALARA should be specified in the rulemaking or in guidance documents $(1024,1157,2604$, $2647,3322,4226,4393,4402,4412,7023,7036,7097,8085,8882,8897)$. Others stated that ALARA is already incorporated in NRC regulations and works effectively $(1017,2646,2651,2778,3800,4477,7279,8669)$.

Several commenters stated that state and local governments should be involved in ALARA determinations (3872, $4190,4216,4394,4414,7920,8749)$. Commenters both favored and cautioned against turning ALARA into site specific criteria $(7133,7303,8907)$.

Several commenters stated that the upper risk/dose limit should be set at a sufficiently low level to assure adequate public protection and that ALARA costs should be considered only in connection with how far below the limit further decontamination will be carried out $(195,791,936,959,1824,4814,7430)$. Organizations have used and proposed a wide-range of dollars spent per man-rem averted under ALARA operations ( 197, 198, 202, 1081, $2627,7023,7279,8079,8083,8090,8138,8251,8403)$. For applying ALARA, valuation of a health effect averted should be derived from data on health decisions that society, not government agencies, has made (8091). 
One commenter cautioned that standards of ALARA must never be allowed to be determined by those with vested interests (G237).

Some commenters stated it is unrealistic to set a fixed value for this, because of the many variables at nuclear facilities $(199,200,7036)$. Others stated that it is possible to develop such a number $(1206,1214,4353)$. One commenter stated that in some cases, due to a reluctance or difficulty associated with assigning a dollar value to such things as a life, discomfort, ecological impacts, and public concern, it may be desirable to implement some other unit of equivalency (8910).

One commenter stated it is important to consider current and future populations and that under the ALARA process future doses could be discounted along with other future costs (8921).

Other commenters indicated that a complete ALARA cost-benefit assessment cannot be calculated without a population dose and that this may not be meaningful for decommissioned sites $(201,204,1331,8403,8441)$. Notwithstanding, commenters stated that although a complete ALARA cost-benefit may not be possible, ALARA will help to establish bounds for protecting the public $(204,8403)$.

One commenter said that ALARA should be achieved by derating or shutting down nuclear reactors (1074).

One commenter said that ALARA in decommissioning should be distinguished from day-to-day operations (3359).

One commenter advised that the ALARA process address both radiological and non-radiological risks to the workers performing clean-up (8948).

\subsubsection{Effective Use of Resources}

Several commenters stated that cleaning up to any specified level is technically achievable; it is simply a matter of how much it will cost $(228,449,565,1123,1201,1798,1815,3345,8735)$. Some said that they believed decommissioning costs to return sites to unrestricted use could be so high that the sites should be kept under continued control and maintained as a restricted area $(558,560,8580)$. One commenter would like to see a large amount of money spent on resolving waste problems (3208).

Many commenters objected to a return-to-background standard and stated it would be a waste of money to try to do this $(99,400,452,489,491,688,752,780.821,1541,1635,1673,1699,1768,1772,1815,1823,1827,2030$, $2373,2388,2392,3711,3865,3963,4390,4874,7407,7579,7580,7616,7860,8060,8366,8871)$. Those objecting indicated that under a return-to-background standard risks would be reduced below what is acceptable and decommissioning costs would be prohibitively high. Some favoring a return-to-background standard recognized that this could be expensive $(2115,3004)$. See the discussion also in Section 2.4.3. Other commenters objected to a best available technology standard, because it is believed to require unreasonable expense without regard to benefit $(2642,8057,8450,8606)$. See discussion also in Section 2.4.2.

Some commenters suggested that money saved on unnecessary decommissioning activities might be used in other activities more beneficial to the public $(209,218,222,464,727,1534,1943,2393,2860,3146,3157,3290$, $3711,3840,3852,3858,3937,4384,4812,4839,7760,7944,8013,8031,8080,8081)$. Other commenters stated that money saved on decommissior ing costs would not necessarily be available for societal betterment $(468,3855$, 4379).

Some commenters stated that a $\mathrm{g}$, neric decommissioning standard would assure a better allocation of resources for 
cleanup $(1966,2051,2078)$. One commenter stated that efficient and effective allocation of resources is influenced by public perception which sometimes motivates public agencies (7755).

A number of other comments were made on the importance of costs in the setting of decommissioning standards as follows:

Some commenters stated that adoption of risk limits would assure appropriate expenditure of resources $(2027,2501)$, but these should be translated to measurable criteria for application by small users of radioactive materials $(2067,8888)$.

Superfund decommissioning costs have been high $(1745,8355)$.

Costs are likely to be the determining factor in all decommissioning standard choices and options (221, $1204,1805,2578,2588,3446,8278,8384)$.

Resources should be spent wisely $(229,662,1201,1267,1281,1662,1729,2328,2360,2392,2410$, $2428,2438,2610,2860,3001,3244,3345,3346,3353,3375,3426,3531,3535,3620,3631,3711$, $3818,3840,3852,3915,3918,3934,3943,3963,4005,4092,4144,4238,4241,4347,4366,4482$, $4875,4876,7116,7120,7282,7305,7311,7561,7565,7640,7760,8057,8080,8157,8333,8337$, $8355,8384,8392,8767)$.

Costs of decommissioning should be considered before the plant is built (1329).

The amount of money spent on decommissioning to achieve health benefits should be in the same range as those spent for remediating other hazards in society (7529).

Decommissioning costs are not fungible, nor within the NRC's authority to disburse (210).

People will pay anything to clean up the environment $(808,2082,2562)$.

Industry should not be producing radioactive contamination in the first place because the cost of cleaning up is so tremendously high $(369,802,1993,3417)$. One commenter said the cost is borne by the public (793).

Cleanup costs are minuscule compared to total costs of operations, but are substantial (4308).

Many commenters stated that the NRC should base its decommissioning standards upon risk/benefit analyses $(7760,7774,8013,8060,8074,8080,8081,8119,8278,8431,8564)$. See discussion in Section 2.6.1.

One commenter stated that standards which minimize waste and permit recycle are in the national interest because they permit more eifective use of waste disposal capacity and conserve resources (8952). 


\subsection{Intangible Characteristics of Criteria}

\subsubsection{Acceptability/Fairness}

Several commenters recommended that NRC decommissioning standards be based on consensus judgments of acknowledged national and international radiation experts $(330,402,649,958,1823,3344,3493,3737,4196$, $8336,8457,8497)$. See the discussion also in Section 2.5.1 for additional information. One commenter stated the NRC should provide a thorough and reasoned explanation for whatever decommissioning standards are adopted and why it did not choose other suggested approaches (7871). Educating the public about background radiation may assist in the public's acceptance of cleanup criteria greater than background (7151). The standards adopted should provide needed protection of the public but should not go beyond this $(2768,2769,2888,3161,3338,3349,3379$, $3444,3477,3728,3753,3850,3945,4382,7869,8160,8166,8171,8264,8336,8348,8546,8625,8641,8647)$. Some commenters observed that a generic decommissioning standard is important for public acceptability and fairness both to those regulated and those exposed to decommissioned sites $(3659,3671,3686,3697,8354)$. Several commenters stated that regardless of the basis for assessing risk levels, the choice of what levels of risk are acceptable should be made by the public $(11,122,124,125,633,3569,7658,7706,7810,8701,8712)$. The question of distinguishing between voluntary and involuntary risks bears on this issue $(2286,2432,2864,3061$, $3142,3197,3350,3543,3905,7753,7791,8272,8274,8286)$. Some commenters stated that safe risk levels should be established across the board for all substances $(2316,3941)$. See discussion also under Section 2.6.2.

Some commenters voiced a general distrust of corporations, the scientific community, federal agencies, and state governments $(368,396,403,654,947,948,1004,1014,1401,1420,1435,1489,1492,1563,1581,1707,1734$, 1738, 1925, 1932, 1938, 2036, 2104, 2207, 2319, 2405, 2626, 2729, 2736, 2737, 2738, 2739, 2741, 2743, 2744, 2745, 2748, 2750, 2753, 2848, 2977, 3108, 3172, 3174, 3176, 3315, 3433, 3516, 3581, 3757, 3774, 4348, 4356, $4381,4425,4492,4816,7100,7266,7675,7706,7724,7731,7791,7869)$. One commenter advised not repeating past actions such as undue exposures for"expedient" reasons (2985).

Various comments were given concerning how to make decommissioning standards acceptable to populations near decommissioned sites. One commenter suggested that people living nearby would normally embrace decommissioning standards because decommissioning will reduce any existing radiation risks from ongoing operations (119). Another commenter stated that the public will not accept the concept of acceptable risk when there is scientific uncertainty about risks (7100). Others stated that the acceptability to nearby populations will depend on what voice a local community will have in deciding whether a decommissioning plan is satisfactory for a given site $(248,785,1261,2508,2557,2559,2655,2731,2734,3414,3690,4410,7978,8286,8701)$. Site employees living nearby may regard the small exposures incurred as acceptable $(1010,1016)$. Whether or not it is sat. .ctory depends on what decontamination levels will be achieved $(335,409,1008,7575,7598)$, what the ensuing risks will be $(639,661,920,1109,1280,1288,4132,7575,7753,7791,8428)$, and how the decommissioned site may be used in the future (541). Other commenters stated that the NRC's new decommissioning standards should apply to all present, past, and future sites $(8004,8503)$. Some commenters recommended that licensees be required to set aside funds to facilitate local public information and participation and, perhaps, funds for financial compensation to people nearby who might be adversely affected $(1044,1571$, 2731).

Commenters urged that decommissioning standards be established so that full costs of operating a nuclear facility throughout its decommissioning can be evaluated up front $(120,733,737,1342,1497,2052,2757,3493,3659$, 8266). This will enable utilities to plan for recovery of all decommissioning costs and permit regulatory agencies to hold nuclear organizations fully accountable for this activity $(1497,1531,1554,1777,1992,2095,2469,2869$, 
$3051,3129,3902,4541,7706,7731)$. Several commenters indicated that the NRC should make its decommissioning standards explicitly clear and explain how these will provide adequate protection of the public health, safety, and welfare $(121,333,779,3065,8710)$. In particular, one commenter stated that it will be difficult to pick a risk standard and justify it with computer modeling unless the standard and modeling is understandable to the public (123). Another commenter stated that public confidence will be assured by setting a screening level that is measurable and verifiable (8128).

Two commenters stated that it would be unfair to permit states to set limits more or less restrictive than the national standard since that would result in unequal and involuntary transfer of risk to people in other states $(4490,8281)$. Another commenter rejected the idea that state regulations should not be more stringent than federal rules (7478). One commenter stated that it is imperative that the NRC and the EPA agree on underlying bases and assumptions prior to beginning a dialogue in a public forum on the appropriate value to be used in assessing site cleanup (8323).

\subsubsection{Stability and Consistency}

Several commenters stated that decommissioning standards are needed by the NRC to facilitate long-term planning by the nuclear industry $(306,353,3496,3660,3676,3706,4201,7083,7564,7766,7799,8527,8599)$ and to provide stability against constantly changing standards over the years $(127,129,130,306,938,1177,1203,3639$, $3724,4195,8527,8542)$ These should be consistent with clean-up criteria applied in the past $(2908,3556,4251$, 4512,8475 ). Without generic standards, the standards applied on a case-by-case basis will be wasteful of regulatory resources, non-uniform, and applied differently from place to place $(353,1279,4277,7083,7599,8159)$. Some commenters stated that even generic standards may not be completely stable $(15,128,1181,1196,3181,3272$, $3297)$, because they will need to be changed as a result of newly perceived health effects $(339,1036)$ and improvements in technology (546). Other commenters stated that a risk-based standard with the ALARA principle will be the most stable standard $(548,1123,1402,2026,3262,4251)$. One commenter believes some sites should be treated differently and site cleanup not sacrificed for regulatory stability (3265).

Commenters stated that there is a need for compatibility and consistency between the regulations and standards of the EPA, the NRC, and the states $(523,529,2106,2880,3243,3260,3328,3496,3498,3517,4184,4201,4213$, $4221,4247,4267,4277,4291,4507,7799,8021,8438,8654,8830$ ). It is difficult for state regulators to explain to the public why federal agencies do not always use the same numerical limits (1558). Other commenters said that the NRC's adoption of a risk/dose limit of 100 millirems per year, with a proper application of ALARA, would result in a risk of ten to the minus six per year and a ten to the minus four lifetime risk which would be consistent with the EPA's Superfund goal/limit $(1153,3767)$.

A state official recommended that a consistent approach should be established for radioactive materials used and produced in the nuclear industry and for naturally occurring radioactive materials $(548,3122,3230,3554,3639$, 8021). According to several commenters, a return-to-background standard would not ensure regulatory stability $(1177,1185,1187,1189,1193,1197,2910,4392,8567)$. One commenter stated that only a return-to-background will achieve regulatory stability (8233). If a return-to-background standard is used and if consistency is to be achieved, farmers would have to clean up their fields, and people who buy Brazil nuts would have to ship their shells to a low-level radioactive waste site (548). Also, consistency is needed in the risks considered acceptable in the development of standards for chemical toxicants and those for radioactive materials and radiation $(3576,3625$, $3834,3844,3862,3867,3949,4507)$.

For stability and consistency the NRC should be careful about granting exceptions (3047). One commenter stated there was inconsistency in the NRC's positions on effects of low level radiation (3162). 


\subsubsection{Clarity}

Several commenters stated that the rulemaking should give clearly defined direction on how to go about getting sites cleaned up and decommissioned $(131,742,914,1366,1393,1595,2257,3253,3434,4659,7021,7085,7881$, $8562,8610,8612,8642)$ and emphasized the need for simple and unambiguous requirements $(134,288,964,1366$, $1412,1580,1888,3434,3447,7029,7292,7881,8642,8661)$. Quantitative definitions of decommissioning criteria for unrestricted release are needed $(964,1386,1412,1580,2257,7719)$. In this regard, the standards should not be subject to different interpretations by lawyers $(132,1580,8665)$. Three commenters noted a lack of knowledge about concepts and terms regarding dose $(7089,7248,8791)$.

Several commenters recommended that the standards should be set out as numerical and measurable quantities (132, $288,742,2257,2813,7021,7719,7881,7953,8118,8772)$. Other commenters suggested that clear guidelines for demonstrating compliance should be provided $(914,7292,7351,7719,7881,8103,8118,8458,8610,8612,8661$, 8665).

One commenter said that we are not communicating effectively because "risk" means different things to different people (2398).

\subsubsection{Flexibility}

Many commenters requested that flexibility be provided in the NRC's decommissioning standards and criteria (33, $116,135,136,298,379,382,428,743,915,1343,1346,1410,1417,1813,1838,1855,1980,2505,3038$, $3040,3055,3319,3436,3495,3500,3609,3644,3647,3655,3672,3687,3691,3695,4609,7061,7427,7828$, $7850,8016,8028,8048,8299,8300,8312,8382,8437,8868)$. Flexibility was discussed with respect to the following considerations:

State and local concerns need to be addressed $(116,136,3319,3500,4178)$.

The rule must be flexible enough to accommodate site differences, e.g., types of radionuclides present, the geology and environmental surroundings, individuals who may be exposed, and possible exposure patterns $(33,135,743,1310,1855,1961,1971,2001,2023,2381,2903,3038,3040,3055,3288,3495,3618$, $3647,3655,3672,3687,3698,7061,7427,7779,7831,8028,8344,8489)$.

Exposure of future generations must be considered $(382,428)$.

Setting a return-to-background standard would reduce flexibility $(1455,7617)$.

Standards may need to be stricter as new scientific information comes to light $(379,380,2498,2542$, 3609).

New technologies should be allowed without awaiting rulemaking changes $(1199,1813,3249)$.

Provide flexibility where meeting restrictive requirements could result in exorbitant costs $(4877,8299$, 8344).

Radon from naturally occurring radioactive materials will be encountered at sites (1838).

One commenter stated that care must be exercised to ensure that "flexibility" in generic rules does not translate to 
"loopholes" that would impair the NRC's ability to protect public health (1421). Another commenter stated that too much flexibility can undermine standards (4158). Still another commenter suggested that the rulemaking address requests for exemption from codified dose limits (7512).

\subsection{Implementation}

\subsubsection{Site Cleanup}

Several commenters stated that they were concerned about licensee responsibility for cleanup of contaminated sites and whether sufficient funds are available to decommission each contaminated site $(1972,2797,2865,2870,3217$, $3367,3380,4357,4359,4542,7707,7726$ ). Some of them stated that the NRC should assure that licensees are held strictly liable for any site not meeting the cleanup criteria $(2820,7817,8237,8244)$. Other commenters stated that sites should be decommissioned quickly while others disagreed $(1161,3370,3954,4516,4528,4531,4542$, 7590).

Commenters stated that the NRC should ensure citizen participation in decommissioning from the earliest stage of cleanup $(1260,1327,1395,1448,1972,1985,1987,2639,4878,7904,8284,8805,8824)$, should provide for aid to local communities similar to the technical assistance grants under EPA Superfund rules (1160,3296), and should be modeled on those of the Federal Facility Clean Up Board (SSAB) $(2828,2829)$. Another commenter suggested that public citizen groups should be involved in environmental monitoring and have an option to split samples with the NRC on a voluntary basis (2824).

According to several commenters the cost of decommissioning could be high $(564,789,1998,2548,2561,2587$, $2611,2797,3515,3866,4088,4170,4240,7809,8244,8736$ ), but cleanup technologies are believed by most commenters to be available for achieving whatever level is set by the NRC $(263,264,265,277,564,824,826$, $828,1022,1096,1640,1998,2102,2301,2349,2352,2587,2746,2793,2794,2795,2796,2941,2966,3250$, $3895,4150,4242,4361,4368,4427,7319,7603,7809,7907)$. The NRC should describe acceptable methodologies for cleanup and measurement to reduce subjective judgments $(2790,2792,3251,3520,4341,4407$, $4416,4433,7291,7422)$. Commenters suggested that decommissioning proposals should be submitted and approved at the design stage, and, consequently, newer facilities should be easier to decommission $(3399,3486$, 4364).

A number of approaches to decommissioning were discussed, including levels to be adopted and possible restrictions on releases $(429,455,501,604,789,828,831,1005,1022,1067,1111,1210,1360,1376,1395$, $1459,1692,1767,1774,1923,2096,2099,2213,2299,2365,2521,2527,2797,2798,2876,3056,3072,3073$, $4433,4531,4817,4879,7044,7053,7121,7123,7135,7312,7319,7385,7425,7544,7667,7680,7687,7777$, $7809,7817,7830,7999,8001,8038,8198,8237,8244,8294,8544,8568,8757)$. Some commenters gave views on whether criteria should be developed for selecting a cleanup contractor $(1345,1456,1457,1467)$. Other commenters stated that workers who perform cleanups should be appropriately trained and protected $(2899,3437$, $3608,4321,4327,7108,7291,7613)$. Some sites have been released to unrestricted use (3683).

Some commenters requested that sites undergoing decommissioning under NRC regulations be simultaneously held to standards for chemical non-radiological contamination under other agencies' applicable regulations $(758,1160$, $2827,4324,7982)$. The EPA's RCRA and CERCLA regulations were specifically mentioned $(1683,8180,8639)$. Some commenters spoke favorably about Superfund while others spoke against it $(2795,3294,3296,3301,3305)$.

Several commenters stated that the costs of decommissioning are a primary consideration and that risk/benefit balances should be performed to ensure that the amount of health benefit gain justifies the effort and costs necessary 
to achieve it $(564,789,2794,2795,2890,3348,3448,4316,4318,4331,4343,4351,4365,4442,4470,8757$, 8885). One commenter was concerned that "small messes" might be cleaned up while ignoring larger ones (3062).

\subsubsection{Demonstrating Compliance with the Criteria}

Several commenters recommended that the NRC should establish numerical limits that are measurable in its decommissioning standards and cautioned against reliance on models for demonstrating compliance $(133,267,283$, $898,776,913,1202,1354,2000,2003,2324,2780,2881,3356,3521,3590,3603,3627,4016,4387,4480$, $4818,4821,4880,4881,7504,7573,7622,7699,7758,7873,7991,8101,8293,8332,8367,8414,8427,8604$, 8855). One commenter recommended full-scale characterizations of representative sites, using the same methodology to be implemented to demonstrate compliance with the final standard (G1121). See discussion on modeling also under Section 2.5.5. If we have a regulation that says risk levels shall be such and so, we still need to know how many picocuries per gram can be left in the soil, because that is what we will analyze for $(276,1093$, $2701,2868,2893,3058,3059,3095,3356,3510,4360,7718,8105,8197)$. Other commenters stated that NRC should provide flexibility in implementation of the standard to avoid high cost of compliance actions that produce little or no reductions in risk $(7778,8889)$. Commenters cautioned that the NRC cannot leave it to the licensee and whatever he says goes $(275,1174,1296,1794,2041,2982,3152)$. There must be no misunderstanding about the objective in a decommissioning project $(287,4826,8039,8604)$. The NRC should avoid regulatory requirements that are extremely difficult or impossible to enforce and should avoid giving optional methods of compliance (7636, $7882,7897,7991)$. Other commenters suggested that historically there has been insufficient monitoring at sites which have undergone decommissioning $(542,963,1070,3058,4820)$. Licensees must carry out appropriate monitoring to demonstrate that the standards have been met, and the NRC must make sufficient confirmatory measurements to check this and appropriately enforce them $(286,898,932,1041,1263,1720,1779,1912,2987$, $2988,4486,4818,4824,4826,7015,7071,7124,7129,7267,7301,7353,7597,7668,7718,7787,7906,8709$ ).

Several commenters stated that demonstration of compliance with NRC decommissioning rules and applicable radiological limits is a major issue $(266,269,270,337,913,1641,7636,8293)$. The NRC must provide clear guidelines with respect to the kinds of measurements that are necessary and the models that are acceptable to demonstrate compliance. With respect to measurements, guidance should cover:

Acceptable measurement methods $(279,763,927,7148,8577,8901)$.

Extent of measurements needed (266).

Use of field instruments versus laboratory instruments $(266,8332,8334)$.

Statistical sampling $(266,279,8577)$.

Calibration standards and measurement certification $(279,7148)$.

With respect to models and methodologies, guidance should be provided on their use, uncertainties, and how to apply site specific characteristics $(285,327,344,1220,1265,1354,1434,1849,2685,2688,3067,3095,3152$, $3356,3510,3521,3590,4825,4882,7550,7886,7965,8039,8105,8108,8387,8577,8680,8876)$. A generic screening should be devised that can decide a generally applicable level below which cleanup is not required (7051, $8039,8101,8102,8127,8334,8341,8353,8552)$. One commenter indicated that logically, there is little to be said for the concept of a generic site inventory level (7144). Commenters recommended that guidance for determining dose from different pathways be consolidated $(1226,1237,1894,7447)$. Other commenters remarked 
that whatever standards and criteria the NRC adopts must be practical and able to be implemented in the field (268, $308,322,8197)$.

One commenter stated that a big problem in decommissioning a site is disappearing records and fading collective memory; NRC decommissioning standards should address this (7368).

Several commenters stated thai it would be technically difficult to meet anu enforce a return-to-background standard because of continuing measurement fluctuations in background radiation and inherent measurement uncertainties (statistics) of instruments $(273,274,451,1441,1676,2091,2348,2434,2576,2584,2701,2705,4086,4273$, $4350,4358,4387,4563,4821,4822,4883,8063,8367,8452,8616)$.

Some commenters stated that historically the NRC has failed to enforce its rules diligently and better performance is needed $(2987,2988,2998,3582,4265,4296)$. One commenter stated that the NRC should require licensees to certify compliance, and this will put the burden of documentation and proof of compliance on the licensee (7636).

One commenter recommended that the NRC should not grant exemptions from its decommissioning standards (1968). Another commenter recommended that the NRC consider granting exceptions if alternative means of protecting public health and safety can be demonstrated (1172).

\subsection{Finality/Grandfathering}

Commenters stated that the NRC's decommissioning standard should be long-lasting and provide a final solution for decommissioning sites that are contaminated with radioactive material $(143,332,387,543,937,1400,1747,2068$, 2087, 2389, 2507, 2512, 2549, 2699, 2886, 3704, 4161, 4169, 4176, 4179, 4204, 4222, 4239, 4256, 4446, 7011, $7583,7757,7857,7911,7924,7980,8018,8058,8110,8112,8144,8167,8193,8338,8358,8449,8595,8614$, $8630,8633,8643)$. The NRC's standard should be consistent with EPA rules to assure that a site remediated under NRC rules will not require further remediation under EPA rules $(521,3242,4166,4191,8206)$.

One commenter suggested that states should be required to adopt federal decommissioning standards (3330). Other commenters disagreed $(1967,4171,4305)$. Several indicated that state and loc.l governments should have a say in what is acceptable at a site $(2482,2507,4205,4232)$.

Some commenters questioned whether it is possible to have finality in decommissioning standards, because of likely new information and improved technology in the future $(1325,2084,2093,2300,2308,2530,4232,7153,7604)$. They stated that sites should continue to be remediated as necessary to meet new standards $(138,139,140,515$, $516,573,575,617,1151,1156,1967,4166,7017,7604,8003,8236)$. Those opposed stated that rules should be changed only if a substantial increase in public safety can be demonstrated $(141,142,3242,3391,4161,4169$, $4204,4239,4256,7278,7300,7402,7583,7924,7929,8018,8112,8144,8163,8338,8595,8597,8633)$.

Some commenters argued against the NRC's licensing a site forever to cover possible residual contamination, but some commenters favored a continuing NRC license and regulatory control $(1414,1718,2084,2518,2566,2935$, 4217).

Some commenters stated that a return-to-background approach would provide regulatory stability $(1659,2146$, $2308,2518,4171,4205,8236)$ and that finality would be best served because anything less stringent will make industry legally liable for inadequate cleanup $(1659,1750)$. Others thought a return-to-background standard would cause more instability $(1695,2500,2529,2537,2549,2699,8150,8193,8369)$. 


\subsection{Generic Versus Site Specific Considerations}

Most commenters favored the NRC's establishing a generic standard over site specific standards (157, 345, 352, $354,357,361,363,414,417,659,954,979,982,983,1002,1033,1089,1097,1321,1326,1406,1407,1408$, $1409,1411,1413,1415,1418,1419,1424,1425,1426,1442,1445,1447,1450,1822,1953,1965,1981,1999$, 2021, 2024, 2040, 2043, 2044, 2049, 2050, 2054, 2058, 2062, 2065, 2075, 2076, 2089, 2166, 2203, 2378, 2495, $2656,2850,2857,3002,3013,3020,3021,3027,3035,3037,3039,3041,3048,3053,3084,3632,3633,3637$, $3642,3643,3646,3653,3654,3658,3670,3674,3678,3685,3688,3692,3694,3696,3700,3705,3710,3712$, $3715,3727,4022,4200,4254,4280,4444,4447,4526,4536,7098,7276,7304,7507,7563,7592,7600,7767$, $8020,8211,8346,8351,8526,8541,8624,8634)$. While supporting the establishment of a generic standard, some urged the NRC to:

Permit site-specific considerations $(160,349,357,360$, , 585, 651, 1627, 1953, 2040, 2043, 2049, 2054, 2062, 2076, 2872, 3021, 3037, 3039, 3053, 4022, 4884, 7592, 7781, 7816, 7832, 7891, 8346, 8372, $8504,8706,8738,8750,8756,8770$ ) and site-specific modeling for licensees to demonstrate compliance $(156,681,982,1002,2621,3508,3649,3654,3670,4022,7507)$.

Recognize differences in the kinds of nuclear operations carried out at a site $(159,1407,1409,1415$, $2065,2203,2522,3008,3021,3503,3674,7304,7781,7816,8756$ ).

Define the terms used in the standard and include quantitative limits so that there is an understanding of the requirements, equal application of them, and avoidance of wastage of time and resources $(348,966,1411$, $1413,2065,2166,3677)$.

Establish one acceptable limit rather than upper and lower limits $(363,1426,8640)$.

Base the generic standard on technology and not on politics (375).

Establish return-to-background as the acceptable standard $(1422,1468,2021,2058,2522,3002,3015$, $3041,3665,3713)$. What flexibility would be allowed if no pre-operational readings were taken (2901)?

Avoid establishing return-to-background as the acceptable standard (1450, 3027, 3708).

Assure new risks are not created somewhere else (1442).

Assure participation by local communities in establishing site-specific limits (144\%, 2040, 2044, 2054 $2872,3084,3665,3692,3700,3723,4200,7903,8706,8738,8750$ ).

Provide flexibility to accommodate stricter standards dictated by newly acquired scientific information $(378,2495)$.

Provide flexibility for parties to come to agreement $(659,1002,1120,1409,1415,2058,2495,2904$, $3037,3039,3053,3646,3670,3685,3694)$, but ensure there are no "loopholes" $(1419,1425,3632$, 3653).

Adopt a risk-based standard and provide for practical implementation (1097, 1822, 1953, 2024, 2203, $2850,3027,3084,3536,3633,3643,3649,3678,3715,4022,4254,8351,8469,8634)$. 
Some commenters expressed reservations or voiced objections to the establishment of a generic standard $(348,366$, $371,488,656,897,986,1117,1306,1318,1428,1525,2033,2534,3202,3286,3401,3669,4064,4532,7062$, $7142,7360,7937,8053,8121,8232)$. Reasdns given were:

A generic standard should be developed only after public airing of the many issues and scientific information not supported by the nuclear industry $(366,371,4064,4532)$.

Site specific parameters and past experience should be considered $(488,897,986,1117,1306,1318$, $1481,2033,2534,3202,3286,7062,7142,7863,8053,8121,8232,8372,8504)$.

Political considerations should influence radiation exposure guidelines, and political compromise may cause a generic standard to provide less protection than would a collection of standards $(7937,8232)$.

A generic standard may not be compatible with certain Indian treaty rights and may not address important environmental and cultural conditions (656).

A federal generic regulation must not preempt more restrictive state or municipal regulations and requirements (8232).

Verification of compliance with a generic standard is purely theoretical. Modeling depends on the good faith of licensees, and assuring compliance places a burden on intervenors or the NRC staff (986).

There is a lack of technical information and a problem with modeling (1117).

The scientific and medical communities do not agree on the effects of low-level radiation $(1525,4064)$.

One commenter stated it would be a grave mistake to use a generic ALARA for all sites (7134). Several commenters recommended site-specific ALARA assessments (7134, 7433, 8137, 8390, 8905, 8946).

\subsection{Sites Which Cannot Be Released for Unrestricted Use}

Most commenters stated that the NRC should establish standards for both unrestricted and restricted release of sites $(166,167,169,170,172,555,559,562,764,830,906,919,1027,1030,1077,1083,1121,1126,1128,1394$, $1427,1432,1653,1654,1691,1698,1701,1956,1974,2032,2037,2220,2315,2318,2320,2368,2445,2480$, $2489,2516,2520,2532,2556,2623,2702,2862,2937,3009,3046,3049,3050,3057,3113,3164,3180,3185$, $3264,3273,3275,3287,3289,3291,3293,3308,3331,3332,3362,3394,3512,3537,3548,3559,3562,3567$, $3586,3623,3648,3675,3679,3718,3726,4237,4261,4271,4276,4289,4295,4298,4322,4524,4534,4827$, $7096,7122,7138,7387,7409,7411,7527,7584,7588,7605,7722,7780,7796,7829,7862,7879,7896,7901$, $7918,8002,8017,8045,8047,8096,8120,8161,8175,8187,8270,8305,8309,8317,8373,8381,8399,8418$, $8445,8461,8501,8578,8594,8600,8622,8658,8673,8728,8898)$. Some commenters disagreed and recommended that the NRC decommission sites only if these are maintained under continued regulatory controls $(355,388,436,536,550,1039,1134,1137,1140,1490,1603,1665,1684,1802,1926,1991,2017,2477,2480$, $2939,3080,3106,3116,3128,3175,3183,3281,3307,3482,3634,4026,4378,4494,7389,7702,7712,8235$, 8238) while still others recommended that the NRC require sites in all instances to be cleaned up suitably for unrestricted release $(359,362,478,675,765,1124,1556,2775,2842,2853,3011,3057,3318,3323,3583$, $3594,3613,3667,3968,3979,4174,4275,4283,4285,4543,4885,7045,7325,7345,7355,7370,7551,7555$, $7558,7631,7785,7955,8008,8235,8238,8522)$. Some commenters cautioned that unrestricted release may not be possible if groundwater is contaminated $(590,1121)$ or if previously buried wastes are on site $(8760,8945)$. 
Some commenters stated that sites should continue to be licensed by the NRC if they cannot be reasonably decontaminated $(2536,2928,7033,7409,7424,7588,7683,7702,7785,7808,7819,7879,7896,7901,8002$, $8309,8505,8578,8600,8658)$. Some commenters suggested that the NRC consider different levels of decommissioning or decontamination for different categories of licensees $(562,572,2520,3185,3221,3264,3332$, $3675)$. Others recommended that decommissioning of nuclear sites should be delayed (moth-balling) $(355,642$, $1560,1924,7373,7411,7956,8505,8626$ ) or that radioactive materials should be stored or entombed on site $(163,299,355,510,1432,1083,1119,1603,2189,2318,2320,2368,2380,2471,2489,2939,3080,3106$, $3128,3183,3307,3482,7722,7829,8164,8510)$ under continuing licensing responsibility. Also, commenters stated that the NRC should consider the option of restricted future use of decommissioned facilities only after a rigorous public participation process $(7471,8510,8753)$. Several commenters stated that the NRC should provide public access to decommissioning records and maintain oversight of decommissioned sites $(171,1394,1490,1603$, $1991,2017,3057,3106,3183,3307,3482,3634,4378,4494)$. Other commenters stated that citizen groups should participate in determining what constitutes unrestricted use $(8705,8747,8753)$ and in the oversight of contaminated sites $(1336,1394,1714,2556,3298,3318,3667,3726,4322)$. Another commenter cautioned that regulating the restricted release cases could involve some expensive and difficult zoning problems for local authorities $(832,7471)$. One commenter stated that if a site cannot be decontaminated to acceptable levels, it should become the property of a state or the federal government (7033). Another commenter stated that every piece of property should have, as part of its deed record, information about its former contamination with radioactive materials (7066). Still another commenter suggested that if contamination is covered up by paint, concrete, or plaster so as to be undetectable, it is questionable whether that area of the facility is truly contaminated (7122).

Those favoring both restricted and unrestricted release standards, those favoring restricted release standards, and those favoring unrestricted release standards gave the following reasons for their positions:

\section{- FOR BOTH RESTRICTED AND UNRESTRICTED RELEASE STANDARDS}

Unrestricted release should be the goal, but realistically some sites cannot be cleaned up suitably for such release $(169,906,1121,1394,1427,1432,1654,2516,2623,2862,2937,3049,3164,3275,3293$, $4237,4271,4289,4298,4322,4524,7588,7722,7683,7796,7862,7896,7901,8705,8717,8719$, $8728,8891)$.

Whether to require clean-up to unrestricted release standards or require continued restrictions should depend on the total risk and cost-benefit of the decommissioning operations $(172,2037,3009,3024,3113$, $3180,3273,3287,3362,3623,3648,3718,4276,7138,7387,7722,7780,7901,8017,8047,8096$, $8305,8317,8373,8381,8399,8501,8578,8622,8717)$.

Standards for both restricted and unrestricted release would minimize costs $(555,559,2702,3113,3308$, $3331,3537,3679,4276,7780,7862,8017,8045,8047,8381,8399,8501,8717,8733,8743)$.

Such standards would build public confidence that the NRC is protecting public health and not just industry's interests $(919,1030,2445)$.

Only a return-to-background standard is acceptable for unrestricted release and restricted use standards are needed for other decommissioned sites $(1077,1138,1394,2037,2320,2489,2520,2556,3101,3548$, 3586).

Limiting of decommissioning standards to unrestricted release misleads the public because it excludes real 
circumstances where risk ...sessment might show that some restriction on use is necessary (1128).

The EPA's Superfund implementation covers both unrestricted and restricted releases $(1701,3332)$.

\section{- FOR RESTRICTED RELEASE STANDARDS}

If a problem develops down the road, restricted release gives you an opportunity to address it $(164,1603$, $1665,2017,3106,4026,4378,4886$ ).

Perpetual care will be required for sites $(165,405,1991,2939,3106,3116,3128,3175,3183,3482)$.

Nuclear power plants could be converted to other alternative power production (4545).

Sites are economically and technologically not feasible to remediate to unrestricted release standards in the foreseeable future $(341,436,536,1802,1991,3116)$.

Licensees should have continuing responsibility, expense, and liability for wastes they have generated (388, $550,944,1131,1134,1137,1490,1991,2477,2480,2939,3106,3128,3130,3183,3482,3634)$.

Although unrestricted release might be an appropriate goal, all decommissioned sites should be posted so the public is aware and can decide whether they want to come on site (1140).

Sites should be restricted until the public's uncertainty about the credibility of the industry, the EPA, and the NRC is resolved $(1926,2017)$.

\section{- FOR UNRESTRICTED RELEASE STANDARDS}

Companies may not be around any longer when additional remedial actions may be required $(168,2775)$.

Sites should be made available for subsequent use (359).

Maintaining continuing controls over a site under restricted release standards would be costly and possibly ineffective $(432,478,7955,8008)$.

In no case should a site be permitted to have residual radioactive materials under continued controls beyond 100 years $(765)$.

If a site is not suitable for unrestricted release, it should be considered case-by-case $(1119,7325,7342$, $7355,7370,7373,7411,8831)$. There should not be any health risks to people off-site after decommissioning (2250).

Restricting use of sites creates problems of jurisdictional authority and control for state and local governments $(1124,2775,4174)$.

If sites cannot be returned to background, they should not be decommissioned $(1556,2842,3623,7325$, $7342,7345,7355,7370,7551,7555,7558,7785,8238$ ).

Restrictions on land use could deprive access to sacred American Indian sites, homelands and historical sites $(1783,3583,7315)$. 
Several commenters made suggestions with respect to the kinds of restrictions that might be placed on decommissioned sites which are not released for unrestricted use. These included:

Perpetual care requirements $(164,165,169,388,480,510,572,2532,2814,3106,3425,4547,4887)$; including devolving trusteeship upon each successive owner the liability for intended future use (G319).

Indefinite extension of liabilities through possession-only type licenses; require present and past landowners, operators and waste generators to be responsible for cleanup (G799).

Deed restrictions or easements, including restriction against use for any single-family, multiple-family, schools, motel, or recreational facilities $(167,170,405,1135,1653,7409,7424,7584,7631,7918,8047$, $8501,8578,8594,8600,8658)$.

Zoning restrictions permitting certain uses but not others $(170,1027,1040,1083,4544,8161,8418,8501$, 8578).

Government take-over and continued oversight $(1609,7033,7819)$.

Use of covenants based on half lives of radioactive materials onsite with a finite period for specified restrictions (1691).

Some sites can not be released under any condition (900).

One commenter suggested that land use not be restricted on the basis of a small amount of man-made radioactivity that presents no perceivable or calculated health risk (1166).

One commenter suggested that the restricted use decommissioning should be viewed as a factor influencing any of the alternative approaches for codifying residual radioactivity criteria rather than as a separate alternative approach (G1285). Another believed that assessments of future land use should be integrated as four sub-alternatives (residual, agricultural, recreational, and commercial/industrial) within each alternative considered, instead of being treated as an independent sixth alternative (G1134).

\subsection{Waste Management Implications/Transference of Risk}

Several commenters questioned whether there is enough space at a regional disposal facility for the voluminous soils and other materials that are expected from decommissioned sites $(148,154,668,1038,1613,1700,1983$, 2006, 2015, 2298, 2336, 2724, 3195, 3729, 3961, 4085, 7331, 7374, 7465, 7609, 7792, 7984, 8123, 8189). Other commenters stated that irrespective of where or how wastes are disposed the costs of nuclear wastes management will be high $(1752,7374,7705,7709,7714,7725,7746,7792,7802,7821,8009,8216,8221,8222$, $8224,8228,8254,8603)$. Some suggested that until existing waste disposal problems are solved the rulemaking should be delayed $(151,356,643,668,679,1547,1561,2773,3730,7371,7413)$. See also discussion in Section 2.11. One commenter hoped the NRC has learned from past experience and will require new licensees to provide a waste management plan before, not after, they contaminate a site or generate wastes (7331).

The extent to which low-level waste disposal space will be a problem depends on how low the NRC sets its radiological decommissioning standards $(146,1139,2613,3566,3596,3729,3975,4089,4097,4515,7307,8196$, $8379,8400,8536,8603)$. The lower they are set the more the volume of contaminated wastes will exponentially increase $(146,1139,1594,1619,1633,4091,4236,8379,8603)$. The extent to which the ALARA principle is applied will also affect the amount of waste to be produced $(1082,4134,8536,8582)$. Several commenters 
suggested that the volume of waste required to be placed in a regional waste disposal site should be kept to a minimum $(13,148,154,7309,8536)$. Other commenters stated that if a permissive standard is set this could result in the spread of contamination into the environment $(3970,7329,7371,7659,7671,7674,7677)$.

Several commenters stated that if a return-to-background standard for decommissioning is established, this would create the most waste $(570,1060,1633,2114,2291,2347,4101,4236,7406,8368)$ and result in unnecessary and costly effort that would merely transfer the small risks involved $(394,503,514,686,1444,1542,1628,1746$, $2271,2337,2354,2363,2387,2408,2528,3187,3216,3729,3916,3919,3926,3961,3964,4080,4087,4095$, $4096,4099,7386,7406,8061,8400$ ). Other commenters suggested that the NRC consider the impact that its standard would have on naturally occurring radioactive materials $(1599,2397,2401,7866,8061,8196)$ and phosphogypsum if it were applied to that material (1649). Many commenters stated that a return-to-background standard is needed while many others disagreed. See discussion also in Section 2.4.3.

Several commenters stated that waste volumes should be reduced $(583,612,614,1144,2291,2332,2468,2817$, $2911,4094,4098,4101,4134,7309,7313,8165,8196,8513)$. Other commenters stated that there should be lower cost alternatives for the disposal of very low level wastes $(2358,2359,2375,2387,3187,7307)$. One commenter stated that consideration should be given to permitting disposal of low-level wastes in a solid waste landfill (2390). Other commenters disagreed $(1474,1476,3075,7329,7371,7659,7671,7674,7677,7743$, $8222,8513)$. Two commenters stated that shipment of wastes to foreign countries or dumping into international waters should be prohibited $(7088,8254)$.

Many commenters recommended that consideration be given to keeping radioactive wastes on-site and not moving these to off-site disposal facilities $(149,150,152,153,213,304,318,373,477,483,492,551,577,583,586$, $628,1046,1055,1058,1059,1065,1084,1370,1380,1431,1561,1577,1586,1591,1602,1605,1616,1628$, $1686,1801,2298,2317,2325,4369,7046,7059,7068,7073,7139,7374,7386,7406,7415,7465,7586,7666$, $7676,7682,7713,7735,7786,7984,8176,8189,8228,8268,8316,8379,8398,8400,8420,8502,8621)$. Reasons given included minimizing the total risk $(213,7068,7139,7406,7415,8061,8316,8379,8398,8400$, 8621 ), avoidance of transference of risk $(304,373,1046,1058,1084,1527,1631,7386,8268,8398,8621)$, avoidance of contaminating new pristine sites $(150,594,799,3204,7386,7786)$, making use of security systems already in place (7068), lack of waste disposal facilities (2325), avoidance of net land loss $(583,2233,7682)$, selection of the most cost effective disposal alternative $(7139,7406,7415,8379,8400,8502,8621)$, and questions about the safety of transporting wastes off-site $(304,577,628,1616,7068,7139,7306,7406,7415,7586,7666$, $7735,8061,8268,8316,8379,8398)$. One commenter requested the rule require that all communities along transportation routes for radioactive materials be informed of the potential hazards and emergency procedures (G197).

Some commenters recommended that on-site retrievable-storage facilities be established and that wastes be required to be stored on-site $(213,304,318,373,483,583,1058,1084,2379,2449,3079,3184,7068,7374,7676,7735$, $7984,8165,8228,8507)$. Commenters suggested that appropriate actions should be taken to assure that the stored wastes do not threaten public health and safety $(1591,2085,3190,3340,7676,7735)$, including such requirements as continued licensing by the NRC $(1561,1602,2478,2481,2565,3127,3184,3395,3960,8507)$, continued licensee responsibility and financial liability $(485,511,551,923,1488,1561,1566,1628,2565,3184,7656$, $7682,8507)$, public oversight $(1561,1637)$, encapsulation or other containment of wastes to minimize leakage to the environment $(475,492,628,1065,1560,1586,1602,1637,2280,7735,7984,8214)$, storage of wastes above ground $(1065,7676,7735)$, continual health and safety monitoring $(628,2565,7374,7676,7682,7735,7984$, 8228 ), and denial of public access (security) $(477,1561,1586,1602,7676,8228)$. Some commenters suggested that the option of leaving radioactive wastes on-site should be considered as a temporary or intermediate option to permit decay of radioactive wastes and allow time for resolving long-term waste disposal problems $(483,492$, 
$2326,3967,4527,4530,7609,7957,8165,8507)$.

Some commenters recommended that radioactive wastes should be stabilized in place on-site and that appropriate steps should be taken to minimize and monitor for releases to the environment $(149,150,152,153,477,492,551$, $577,583,586,628,1031,1046,1055,1059,1065,1577,1801,2367,3340,7139,7415)$. One commenter stated that there should be no finality for wastes; those generating the wastes should have continuing liability (4233). Some commenters recommended that an inventory of contaminated sites be compiled $(149,150,152,153)$ and that these sites be considered for designation as low-level waste disposal sites $(149,150,152,153,1055,1801,2915)$. Other commenters suggested that decommissioning wastes should be disposed of at existing mill-tailings sites (155, 2338,2350 ). One commenter said it might be more cost-effective to buy out nearby residents and move them elsewhere than to move the waste (1577).

Several commenters stated that many of the existing contaminated sites may not be acceptable for waste storage or disposal and perhaps could not meet NRC waste storage and waste disposal licensing requirements $(586,1057$, $1059,1076,1079,1136,1605,1611,1721,2190,2369,2382,3193,3207,3207,3210,3975,7072,8254,8512)$. Others stated that hearings should precede the licensing of any designated site $(1623,8183)$. Also, citizen input should be sought before a decision is made permitting on-site storage or movement to another site $(8183,8508$, 8512).

Some commenters expressed reservations about decommissioning nuclear utilities to the status of low-level waste sites $(1144,1176,1349,3220,3487,8151)$. Others favored movement of long-lived radioactive waste to a central or regional waste management facility to reduce the number of sites and to improve safety $(1607,2696,2711$, $2714,2716,2719,3440,3978,4448,7543,7549,7606,7632,8143,8151)$. Commenters observed that if all decommissioned sites were designated as low-level waste repositories there would be over 200 such sites, and this many is not needed $(1072,7682)$. Others indicated that the use of decommissioned sites as radioactive material waste repositories could affect states which are planning to establish low-level waste facilities, because income from wastes at decommissioned sites is anticipated and expected $(1055,8185)$.

One commenter stated you cannot satisfy everyone about disposal of radioactive wastes whether on-site or off-site (1587). Another stated that there is not overwhelming opposition to low-level waste facilities (4140). Another commenter wants the results of analysis publicly available to make informed decisions (4128).

Some commenters suggested that the government should take over and assure perpetual care of restricted release sites $(1605,1607,1764,2417,3395,3424,3470,4539,7034)$. Two commenters stated that perhaps the law should be changed to have the DOE take title to waste disposal sites and have them licensed in perpetuity by the NRC $(1605,1607)$. A similar proposal for NRC licensing of the DOE was made by another commenter with respect to high-level waste storage facilities at Hanford (579). Other commenters cautioned that in the long-term even governments are likely to change $(1604,2513)$.

Several commenters stated that new definitions of high-level wastes and low-level wastes are needea $(596,878$, $1372,1591,1881,1886,1892,1947,2372,2483,2784,3465,3539,3540,3589,3891,4066,4090,7084,7866$, $8513)$. Other commenters said that the term low-level waste is confusing $(1947,3891,7866)$; when you get into the nuts and bolts of waste classification under current regulations in 10 CFR 61, it is not all low-level (1947). It was suggested that waste categories should be classified by risk $(2372,2784,4090,7866,8513)$, longevity and half-life $(597,878)$, dispersibility and biological pathway $(878,7309,7866,7971,8513)$, longevity and toxicity $(877,1372,7084,7866)$ and intensity and longevity $(1552,7866)$. Several commenters recommended that toxic waste should not be reclassified to a category such as below regulatory concern $(1491,7364,7371,7659,7661$, $7671,7674,7677,7743,7792,8222,8513)$. Other commenters warned against classifying radioactive materials 
too low, because it could adversely affect non-nuclear commercial operations $(2342,2397,2401,8196)$. One commenter expressed concern that states might set different definitions for what to consider as non-radioactive material, inasmuch as this could result in difficulty moving materials from place to place (4248).

One commenter stated that the NRC was in the process of changing its definitions and standards for high-level and low-level radioactive wastes and this is causing delays in resolving waste management problems (574). Other commenters stated that the States of Washington and Oregon had petitioned the NRC to give a decision on the appropriate fractionation of high-level to low-level waste to use in a high-level waste treatment process such as vitrification $(591,596)$. Still another suggested that the NRC look at a law passed by the State of Vermont for their low-level waste act in which a study is required of the separation of long-lived and short-lived radionuclides (880).

Other commenters stated that properly designated high-level and low-level wastes should be separated; less hazardous wastes should not be intermixed with more hazardous wastes $(1586,1591,7309,7971)$. Some wastes are more difficult to deal with than other wastes $(2020,2421,2468,4082,4325,7971)$. Another commenter stated that ninety-nine percent of decommissioning wastes are low-level wastes (978). Other commenters stated that the problems of handling radioactive wastes are more socio-political than technical $(3200,3976,4100,4520)$. One commenter implied that the form of the waste might change during cleanup (1052).

Some commenters stated that they did not believe recommendations for reclassifying wastes were relevant to decommissioning because the material of interest is only residual waste at the site $(690,895)$. Another commenter agreed that decommissioning is not affected, but the problems of low-level waste disposal are generally affected (690).

One commenter stated that continued delays in establishing high-level and low-level nuclear waste repositories detracts from the value of setting decommissioning standards (902). Another commenter stated that technology is not available for establishing a high-level waste repository (1809). Still another commenter stated that when there is someplace available to send high-level wastes, suitable technology will be developed (699). In this connection, one commenter stated that NRC should monitor an investigation of health and safety standards by a National Academy of Sciences Committee on Technical Bases for Yucca Mountain (8739). Other commenters stated that these wastes could presently be placed in independent fuel storage facilities (377) or that dry cask storage could be used $(694,696,697,698,839)$.

Some commenters suggested that certain waste disposal methods may not be safe $(618,1302,1460,1479,1548$, $1549,1632,1884,2467,7077,7704,7998,8254)$. Disposal of low-level liquid wastes into municipal sewer systems $(1382,1548,1632)$, solid wastes into a primitive trench in the sand $(618)$, incineration $(1465,2680,2690$, $2693,7998,8254)$, and dilution (4119) were identified as unacceptable practices. Several commenters stated that groundwater must be properly protected under all disposal methods $(1302,2280,4211)$. The NRC should make known to research institutions and to Congress the continuing need for waste disposal research $(7077,7371,7786)$. One commenter advocated a complete reevaluation of waste policies (1301). One commenter suggested that a solid waste landfill would be cost effective (2391). One commenter suggested that waste be placed "deep in the earth" (3097).

Some commenters noted that once nonhazardous wastes pass out of the NRC's regulation, the NRC must not attempt to further regulate these wastes or to preempt state regulation; from the point these materials enter the solid waste stream they will be managed under the Resource Conservation and Recovery Act (RCRA) and applicable state solid waste laws and regulations $(7457,7459,7464,7465,7467,7474,7485,8174,8178)$. 
One commenter indicated that nuclear utilities represent less than two percent of all licensees but their decommissioning waste is about 80 percent of the volume and caution is needed because the utilities want to minimize expense (7010) . One commenter noted that power plants produced 98 percent of the total activity shipped in Pennsylvania (2019). Another commenter noted that government and industry conceal the fact that nuclear power generates nearly all the radioactive contamination (7333).

Some commenters suggested that medical radioisotope wastes should be distinguished from nuclear power-plant and industrial-research generated wastes, because they differ in volumes, masses, and half-lives $(605,1596,1763$, $1883,2369,2394,2463,2483,4456,7082,7622,7652$ ). According to other commenters, medical wastes can be dealt with by simple on-site storage until these decay to safe levels since the half-lives of medical radioisotopes are short $(1596,7082)$. If requirements on low-level waste disposal are made too stringent and costly, these will adversely affect the use of radioisotopes for medical research and for medical diagnosis and treatment $(2353,3201)$. Other commenters stated that there are important legitimate uses of radioactive materials in medicine that should be protected $(2945,7082,7298)$. Other commenters questioned why medical wastes should not be required to meet the same decommissioning standard as other radioactive wastes $(508,4454)$, and another questioned why the medical community cannot find alternatives to the use of radioactive materials $(2958,7935)$.

Commenters stated that the rulemaking must include full consideration of the transference of risk issue $(304,1278$, 1287, 1444, 1585, 2098, 2108, 2233, 2291, 2605, 3111, 3199, 3578, 3809, 3874, 3926, 4007, 4101, 4105, 4156, $4491,4888,7386,8268,8398)$. Some commenters stated that wastes should be transferred to other locations only if this will result in a reduction of risk $(614,3578)$ and should not be sent off-site if equivalent risks are transferred from one place to another $(632,1058,2271,7387)$. Another commenter disagreed stating that transferred material will be in a better place than when it was at the original site of use (144) and will entail no significant transference of risk (2291). Several commenters stated that people generally do not want wastes moved nearby where they live $(1294,1298,2310,2722,3209)$. One commenter stated that transfers of radioactive wastes are presently governed in practice by considerations of the transference of risk issue (1804).

Another commenter stated that the federal government had already decided that risk will be transferred under provisions of the 1980 Low-Level Radioactive Waste Policy Act (145).

\subsection{Special Considerations}

\subsubsection{Mixed Waste}

Several commenters recommended that the NRC's decommissioning rulemaking should address the issue of mixed radioactive wastes which consist of radioactive materials from NRC licensed operations intermixed with other hazardous materials $(176,599,943,1601,1951,1975,3043,3045,3191,3236,3528,3965,4326,7257,7466$, $7469,7484,8421,8761$ ). Some commenters expressed a concern that under NRC regulations radioactive materials licensed by the NRC might be cleaned up, but other hazardous materials could be left there $(1715,7257)$.

Some commenters recommended that there should be consistency between the regulation of radioactive materials and chemically hazardous materials $(775,955,1387,2396,3226,3528,3577,3614,3626,7257,8724)$. The regulations should be developed as generic standards equally applicable to all hazardous materials $(955,1387,1951$, $1975,2223,3236,3837$ ). Other commenters cautioned that development of generic standards equally applicable to chemical wastes as well as radioactive materials would be difficult $(2424,3239,3622,3803,3813,3846,3863$, $3869,3888,3896,3950)$. 
Some commenters stated that they disapproved of the jurisdictional arrangements between the NRC and the BPA for dealing with mixed chemical and radioactive wastes $(909,3236,3965)$. One commenter recommended that instead of having more than one regulator the NRC should be the one to regulate mixed waste (770). Another commenter stated that in applying for a Part B permit under mixed waste regulations, they got hit by dual regulations such that they could not be in compliance with either one of them or meet both (775). Other commenters recommended that the rulemaking make clear that mixed wastes continue to be regulated under the hazardous waste regulatory system and that issues related to these should be resolved under the Resource Conservation and Recovery Act, Subtitle C $(4081,7455,7469,8179)$.

Several commenters raised the question of needed standards also for the regulation of naturally-occurring and accelerator-produced radioactive materials $(599,600,1356,2008,3043,3064,3226,8019)$.

\subsubsection{Doses from Radon and Radon Daughters}

Many commenters recommended that the NRC should impose limits to control exposure from radon emissions at decommissioned sites because radon exposures could be a significant health problem $(182,1231,1289,1832,1834$, $1835,1839,1896,2659,2666,2668,3451,4496,4498,4501,4506,7145,7451,7452,7540,7844,7887,7917$, $8042,8092,8249,8412,8465,8490,8635,8651,8758$ ). Another commenter stated that radon standards should be approached the way the ICRP approaches general standards setting --- justification, optimization, and limitation $(702,7451,7844)$. Other commenters stated that the Health Physics Society recommends that a specific concentration limit for the precursors of radon be applied to contaminated soil $(4501,4502,4505,4511,4513$, $7452,7540,8412$ ) and that a radon screening level of one picocurie per gram above the normal concentration for the region be established for soils containing radium 226, radium 228 or thorium 232 (2658).

Other commenters disagreed and recommended that the NRC not regulate radon for many reasons, including technical difficulties in distinguishing between man-induced and naturally-occurring radon $(182,184,185,188$, $724,725,1285,2544,4509,8617$ ). One commenter stated that it was unfathomable how one could remediate a site to levels on the order of those being considered in the rulemaking when the outdoor air concentration of radon corresponds to about 0.002 working levels and the EPA has recommended that the public's exposure to radon be limited to 0.02 working levels, which corresponds to about one (1) rem per year depending on occupancy (864).

Commenters in favor of the NRC setting a radon standard stated the following:

Control radon exposures by limiting the quantities of precursors permitted in soil $(7540,7844,7887,8042$, $8092,8412,8490$ ).

Radon should not be regulated locally; it should be done at the federal and Agreement State level (183). Many Agreement states regulate NORM (2671).

Although in favor, it would not seive the public's best interest to revisit thousands of residential structures or reinvade people's property (702).

Radon standards should be consistent with EPA requirements $(8651,8675,8681)$.

It should be possible to make a good estimate of how much radon comes from licensed materials (1829).

It is not understandable why one would not want to look at the radon issue just because it is technically difficult $(1834,4496,7145)$. 
If radon exposure in excess of EPA guidelines can be shown to be background, requirements for cleamup should not be specified by the NRC $(7451,7452,7515,7880,7917,8688)$.

Commenters not supporting the NRC's setting a radon standard stated the following:

Health effects from radon exposure can be mitigated through padding your basement, venting it, and not letting your kids sleep in it $(177,179,8617)$.

The need to deal with radon at licensed sites should be considered site-to-site $(182,1837,3722)$.

The biggest problem with radon is demonstrating compliance $(184,7056,7515)$.

Radon control should be left to local zoning boards and housing authorities $(185,8617)$.

If you take care of thorium and uranium in the soil, you have probably taken care of the radon problem (186).

The costs make cleanup unfeasible; it becomes a matter of isolating the site (2674).

Standards should not be clouded by background radiation issues or radon complexities $(188,724,725)$.

The NRC should embrace existing regulations for controlling exposures from radon and other naturallyoccurring radionuclides (321).

Other commenters not necessarily favoring or disfavoring the NRC's setting a radon standard stated the following:

Radon should be treated separately from and differently from other radioactive materials $(1831,7515$, $7844,7938,8092,8207,8635,8686,8933)$.

We can distinguish, through sampling, contributions from natural background sources and those from introduced sources $(2661,4499)$. The results of a national survey by the EPA will be available soon (866).

DOE requirements for radon are patterned after EPA's 40 CFR Part 192; however, other alternatives such as the higher limit recommended in NCRP Report No. 116 should be considered $(8935,8936,8938$, 8941).

Attempts to determine the source of radon or thoron are difficult $(7056,8683)$.

For a background based standard, we would have to be able to model a temporal variation of background $(815,3451,3457)$.

The radon problems point out the need for a convergence of regulations for controlling radiation from all sources in a less confusing way $(2663,3376,3449)$.

Radon calculations for background have too large a dose factor of 200 where it should be twelve (1215, 1234). 
Radon should not become a scapegoat for decommissioning issues (1466).

Standards should not be set which are not practicable to achieve $(3450,3452)$.

The average exposure of every person in this country is on the order of 200 millirems per year from radon in their houses (3456).

Radon exposures can be changed by altering the physical conditions at the site $(4500,8617)$.

Reducing natural background levels would represent a new public policy direction and demonstration of excessive health effects in a particular location (7056).

\subsubsection{Handling Previously Buried Waste}

Almost all commenters stated that previously buried radioactive wastes on-site at the time of decommissioning should be considered for remediation against the NRC's decommissioning standards even if the wastes in question were permitted under past NRC waste disposal provisions $(193,194,576,615,1150,1154,1171,1350,1620$, $2311,2533,3206,4077,4131,4136,4137,4141,4167,7057,7454,7520,7737,7915,7931,7958,8000,8095$, $8147,8226,8393,8401,8593,8689,8692,8759,8943)$. One commenter stated that formerly buried waste should be left alone unless it presents a real problem (2296). Some commenters stated that a pathway analysis and independent epidemiological studies should be carried out whenever buried wastes are on-site (1897). One commenter cited examples of cases of previously buried wastes on-site when NRC records indicated no wastes were buried there $(1666,7369,7737)$. One commenter stated that efforts must be made to induce the licensee to provide full disclosure about previous radioactive releases, accidents, and burials of materials on site. The commenter recommended the NRC draw from NRC files, citien's records and citizen testimony (G839). A commenter from an Agreement State noted that several Agreement States prohibited on-site burials before the NRC did this in 1981 (582).

One commenter suggested that perhaps jurisdiction over health and safety could pass after decommissioning from the NRC to the EPA under the EPA's RCRA and Superfund programs (4167).

\subsubsection{Minimizing the Generation of Contamination and Radioactive Wastes}

Many commenters recommended that the NRC should discourage or stop licensing those nuclear operations which generate nuclear wastes $(493,637,648,673,949,1066,1092,1115,1256,1291,1300,1480,1495,1816,1945$, $2357,2760,2897,2932,2955,2970,2990,3078,3100,3107,3173,3182,3194,3205,3365,3422,3481,3598$, $3958,7238,7357,7398,7610,7653,7665,7703,7711,7734,7934,7936,7996,8210,8225,8694)$. Some commenters requested specifically that the operation of nuclear power plants be stopped $(629,673,805,891,916$, $949,1075,1141,1232,1235,1291,1334,1518,1642,1903,1913,2103,2162,2399,2657,2723,2735,2949$, $2951,3078,3083,3107,3109,3215,3219,3314,3378,3468,3491,4111,4123,4124,4474,4889,7657,7970$, $8265,8694,8698$ ). Several commenters stated that environmental organizations would be willing to talk about ways to decommission nuclear operations and to dispose of radioactive materials only if nuclear power plants were no longer permitted to operate $(916,2723,2735,3219,4111,4123,4127,7657,7703,7795,8623)$. Other commenters, while stopping short of recommending a cessation of nuclear power, stated that they believed nuclear power was not a useful activity $(1286,1494,2261,2446,2473,3418)$. One commenter suggested that other energy options, which produce less pollution than nuclear and coal, should be explored (554).

Other commenters supported the continuation of nuclear power $(620,671,2963,2964,3473,3475,4133,8277)$. 
Some cautioned that stopping the generation of nuclear wastes would prohibit important medical procedures (2944, $2947,2950,3214)$. Some commenters excluded the diminishment of medical radioisotope usage from their recommendation to stop the generation of nuclear wastes $(1066,2949,7653)$. One commenter recommended that the medical community find alternatives to the use of nuclear-generated materials (2959).

Some commenters recommended that the ruiemaking should deal with source reduction of nuclear wastes $(181,486$, $949,2487,2491,2947,3052,3165,3215,3565,4084,4122)$ and NRC evaluation of ways of minimizing waste production before a license is issued $(191,192,2511,2878,3908)$. One commenter stated that reduction of waste generation does not belong in the NRC's decommissioning regulation (180).

One commenter believes it is in the national interest to minimize waste volumes. Standards which permit recycle of valuable materials conserve our national resources and allow effective use of our radioactive waste disposal capacity. (8950).

Some commenters observed that high costs of decommissioning and waste disposal could help to minimize waste generation $(190,370,2080)$. Another commenter stated that high costs while reducing the amount of wastes generated could work against good cleanup at the time of decommissioning (189). Other commenters suggested that the future costs of waste handling might be taken care of by requiring operators of nuclear power plants to pay into a fund established to maintain long-term institutional controls over nuclear wastes $(804,2491,4354)$.

One commenter urged the NRC not to take sides for or against nuclear power and stated that the policy debate on the relative merits of various power-generating options should be held in another forum (4130).

\subsection{Environmental and Social Considerations}

Many commenters recommended that the NRC develop standards for protecting natural ecosystems in addition to standards for protecting humans $(258,261,425,544,622,625,735,795,1118,1122,1132,1239,1511,1520$, $1860,1937,2255,2679,3086,3166,4525,7585,7591,8215,8220)$. Others expressed a concern for environmental protection without recommending for or against separate environmental standards $(635,792,795$, 1303, 1333, 1390, 1398, 1473, 1483, 1493, 1850, 1976, 1996, 2094, 2192, 2264, 2619, 2752, 2754, 2758, 2971, $3333,3341,3472,3534,3538,3624,3822,3887,4028,4212,4274,4299,4337,4493,7290,7414,7663,7678$, $7708,7715,7740,7751,7800,7948,8010,8426,8700,8730)$. Some commenters recommended that the NRC should develop a biocentric standard rather than an anthropocentric standard whether or not separate environmental and health standards are developed $(255,257,262,407,8220)$. A large number of commenters recommended that protection of human health is sufficient to protect any known ecological system, so only a standard for protecting humans is needed, and this is the view of the International Commission on Radiological Protection (256, 462, 465, $730,1048,1498,1513,1516,2269,2425,3750,3780,3783,3930,7391,7441,8058,8409)$. One commenter stated that natural systems standards would be extremely difficult or impossible to enforce (259).

Some commenters indicated that it is important for the NRC to consult with professional ecologists and geologists in connection with the rulemaking $(1508,1520,1530)$.

Other commenters recommended that the decommissioning standards should be sufficiently flexible to afford protection into future generations $(383,430,2419,7591,7948,8010,8215)$ and information concerning radioactive materials left at a site should be passed on (833). If this is not done, individuals may be unknowingly exposed $(260,294)$.

Several commenters recommended that special attention should be given to the protection of groundwater (425, 
$1122,1239,1624,1841,1858,1862,1901,1915,2679,3413,4212,4525,7948)$. Other commenters recommended against establishing a separate risk-level for protection of groundwater as long as a limit-based standard is applied overall to external and internal exposure pathways $(43,2122,3427,3432)$.

Many commenters recommended that case-by-case consideration should be given for special environmental and social/cultural issues associated with homeland, historical sites, and Native American lands, because they contain religious sites and sacred areas $(250,253,300,358,540,658,1358,1784,3585,3787,4302,7063,7316)$; in particular, Indian people depend on their lands for water, natural food, medicine, and traditional use $(250,580$, 995, 1733, 1787, 3787). One commenter stated that the American Indian Religious Freedom Act requires federal agencies to consider the impact of proposed actions on sacred site areas and the Native American Grave Protection and Repatriation Act governs the uncovering of burial sites (250). Other commenters stated that it is beyond Native American language or thought processes to accept the loss of sacred lands indefinitely $(1358,3585)$ and contaminated lands should within 100 years be returned for any unrestricted use (540). Still other commenters recommended that valuable land or water should eventually be returned for society's unrestricted use $(584,1032$, 3585,7318 ).

Several commenters cautioned against establishment of unnecessarily restrictive decommissioning standards that could cause severe environmental damage trying to clean up soil and vegetation to background levels $(385,471$, $1634,2266,2992,3762,3819,4243,8362,8860,8872,8892)$, because such actions could totally change a site's ecology (254).

Many commenters stated that the rulemaking process should take into consideration societal needs and costs in relationship to decommissioning requirements $(1478,2007,2014,2609,2725,2844,2856,2866,2969,3082$, $3099,3149,3485,3573,3640,3856,3859,3933,3938,4109,4129,4145,4203,4299,4312,4313,4339,4342$, ij45, 4346, 4355, 4372, 4495, 7086, 7391, 7436, 7581, 7641, 7943, 7950, 8084, 8271, 8273, 8276, 8362, 8534, $8: 19,8583)$.

\subsection{Recycle of Contaminated Materials}

Comments were offered for and against the question of whether the NRC should permit recycling of contaminated materials. Those favoring $(292,611,613,616,823,1148,1615,3552,4117,4121,7310,7372,7479,7489$, $8142,8405,8592,8672,8951)$ recommended recycling to save resources. Those opposing $(592,609,1158,1283$, $1477,1593,1639,1652,1667,1687,2297,2303,2466,3198,3342,3971,4029,4125,4135,7014,7670,7736$, $7966,7997,8227,8260$ ) recommended against recycling to limit public risk. Some commenters recommended that the NRC consider this matter carefully, perhaps separately from the decommissioning rulemaking $(290,293,2402$, $3211,4083,4249,4538$ ). Other commenters stated that the IAEA has recommended that the maximum dose to any individual from recycled materials not exceed one (1) millirem per year $(3335,8374,8378)$. Other commenters stated that if a radiation level limit is specified for decommissioning, this in effect will establish a level that is exempt from further control and result in recycling of materials contaminated to the extent permitted by the decommissioning rulemaking $(291,535,1630)$. One commenter, who favored recycling contaminated materials, suggested that the NRC require full public knowledge and informed consent in each case involving the reuse and recycling of such materials (7479). One commenter stated the NRC has a site release criterion as zero detectable above background (2708). One commenter recommended that the NRC include a regulatory requirement for the regulated entity to state how it proposes to recycle and meet the standards demanded by the receiving recycling facilities and the appropriate State and local regulatory agencies (G862).

One commenter stated that NORM issues are important in recycling of radioactive wastes, e.g., coal ash and fly ash recycled into building materials are more radioactive than permitted under standards for mill tailings cleanup (4142). 


\section{APPENDIX A}

\section{ISSUES FOR DISCUSSION AT WORKSHOPS}




\section{PROPOSED RULEMAKING TO ESTABLISH RADIOLOGICAL CRITERIA FOR DECOMMISSIONING}

ISSUES FOR DISCUSSION AT WORKSHOPS 
SUMMARY

The Commission proposes to revise 10 CFR Part 20 to include radiological criteria for termination of licenses and release of 1 and and structures for unrestricted use. It is the Commission's intent that the criteria developed in this rulemaking would apply to almost all licensed facilities and sites.' However, it would not apply to sites already covered by a Commission approved decommissioning plan. An estimate of the numbers and types of facilities expected to be covered by this rulemaking is provided in the BACKGROUND section of this paper. A discussion of how the Commission proposes to implement the criteria can be found in the section entitled PROPOSED COMMISSION ACTIONS. There may be a small number of sites where cleanup to criteria for unrestricted release developed in this rulemaking may not be practical. The approach to handling such cases is an issue for discussion.

The purpose of this issues paper is to describe the background and issues that would be associated with a rulemaking to establish radiological criteria for decommissioning, and to focus discussions in a series of public workshops on rulemaking issues. The format for each issue is arranged by first describing the general issue to be considered, then providing a background discussion of the issue with potentially useful information for the workshop discussions. A list of sub-issues is also provided.

The description of issues is divided into two parts. First are two primary issues dealing with: 1) the objectives for developing radiological criteria; and 2) the application of practicality considerations. The objectives constitute the fundamental approach to the establishment of the radiological criteria, and the NRC staff has identified four distinct alternatives including: 1) Risk Limits, where a limiting value is selected and criteria are

2 The criteria would not apply to the disposition of uranium mill tallings, low-level waste disposal facilities, or high level waste repositories since these have al ready been addressed in separate regulatory actions. They would apply, however, to uranium mills and ancillary facilities that support radioactive waste disposal (e.g., surface facilities for the high level waste repository). 
established below the limit using practicality considerations; 2) Risk Goals, where a goal is selected and practicality considerations are used to establish criteria as close to the goal as possible; 3 ) Best Effort, where the technology for decontamination considered to be the best available is applied; and 4) Return to Preexisting Background, where the decontamination would continue until the radiological conditions were the same as existed prior to the licensed activities.

Following the primary issues are several secondary issues that are related to the primary discussions, but which were believed to warrant separate presentations and discussions. These include additional considerations such as the time frame for dose calculation, the individuals or groups to be protected, the use of separate criteria for specific exposure pathways such as groundwater, the treatment of radon, and the treatment of previously buried materials.

\section{BACKGROUND}

The Nuclear Regulatory Commission (NRC) has the statutory responsibility for protection of health and safety related to the use of source, byproduct, and special nuclear material under the Atomic Energy Act. The NRC believes that one portion of this responsibility is to assure safe and timely decommissioning of nuclear facilities which it licenses, and to provide guidance to licensees on how to $p l a n$ for and prepare their sites for decommissioning. Decommissioning, as defined by the NRC, means to remove nuclear facilities safely from service and to reduce residual radioactivity to a level that permits release of the property for unrestricted use and termination of the license. ${ }^{2}$

Once licensed activities have ceased, licensees are required to decommission their facilities so that their licenses can be terminated. This requires that radioactivity in land, groundwater, surface water, buildings, and equipment

\footnotetext{
Appendix $A$.

2 A glossary of other terms generally used by the NRC can be found in
} 
resulting from the licensed operation be reduced to levels that allow the property to be released for unrestricted use. Licensees must then demonstrate that all facilities have been properly decontaminated and that, except for any residual radiological contamination found to be acceptable to remain at the site, radioactive material has been transferred to authorized recipients. Confirmatory surveys are conducted by NRC, where appropriate, to verify that sites meet NRC radiological criteria for decommissioning.

There are currently about 24,000 licensees in the United States. About one third of these are NRC 1icensees, while the remainder are licensed by Agreement States through an agreement entered into under the Atomic Energy Act, Section 274. These licensees include universities, medical institutions, radioactive source manufacturers, and companies that use radioisotopes for industrial purposes. About 50\% of NRC's 7,500 materials licensees use either sealed radioactive sources or small amounts of short-lived radioactive materials. Decommissioning of these racilities should be relatively simple since there is usually little or no residual radioactive contamination to be cleaned up and disposed of. Of the remaining 50\%, a small number (e.g. radioactive source manufacturers, radiopharmaceutical producers, and radioactive ore processors) conduct operations which could produce substantial radioactive contamination in portions of the facility. The population of nuclear fuel cycle facilities which will require decommissioning includes 112 nuclear power plants (at 75 sites); 74 non-power (research and test) reactors; 14 fuel fabrication plants, 2 uranium hexafluoride production plants, 49 uranium mill facilities, and 9 independent spent fuel storage installations. These facilities will have to be decontaminated to acceptable levels before they can be safely released for unrestricted use.

The facilities listed in the NRC's Site Decommissioning Management Plan (SDMP), discussed later in this issues paper, provide an fllustration of how a facility or equipment might become contaminated through the use of radioactive material in forms which are not encapsulated to prevent the spread or dispersal of material. Sealed sources, including items such as check sources, do not pose a contamination problem unless the encapsulation is broken. When radioactive material in unsealed forms is used, such as in the nuclear fuel

$$
A-4
$$


fabrication industry, in production of radiopharmaceutical medicines, or in research the equipment used to process and handle the material becomes contaminated by the small quantities of material that adhere to surfaces of valves, piping, etc. If material is spilled, then the area of the spill becomes contaminated.

Essentially everything which comes in contact with the radioactive material must be considered as contaminated and checked for the presence of residual radioactive material. Thus areas surrounding facilities could become contaminated by the movement of materials, equipment, and people into and out of the areas containing the radioactive material. NRC requires that contamination control:procedures be used to minimize or prevent the movement of radioactive materials into other areas. Nevertheless, some areas may become contaminated over the course of time due to breakdowns in the control procedures. Contamination may also be spread by the movement of water or other'fluids containing the radioactive materials through or along piping, equipment, walls, floors, sumps, drains, etc. In some cases, this has resulted in significant quantities of radioactive material in the ground under or around buildings and facilities.

In addition to contamination, some licensed operations can produce radioactive materials through the process of activation. Examples of such operations are nuclear reactors. These activated materials can also lead to the need to decontaminate or dispose of the radioactivity during decommissioning.

Several hundred NRC and Agreement State licenses are terminated each year. The majority of these licenses involve limited operations, produce little or no radioactive contamination, and do not present complex decommissioning problems or potential risks to public health or the environment from residual contamination. However, as the nuclear industry matures, it is expected that more and more of the larger nuclear facilities which have been operating for a number of years will reach the end of their useful lives and have to be decommissioned. Thus both the number and complexity of facilities that will require decommissioning is expected to increase. 
The NRC has a program underway to effect timely decommissioning of about 40 problem sites which either have not been decommissioned properly or have been engaged in the decommissioning process for an extended time. The Commission has established a Site Decommissioning Management Plan (SDMP) for effecting timely decommissioning of these problem factlities. Sites being handled under the SDMP vary in degree of radiologic hazard, cleanup complexity, and cost. Some sites comprise tens of acres that require assessment for radiological contamination, whereas other sites have contamination known to be limited to individual bulldings or discrete piles of tailings or contaminated soil. Many sites involve active licenses, but some sites involve formerly licensed sites, or sites where the responsible party is unable or unwilling to perform cleanup. These sites also vary in degree of completion of decommissioning. At some sites, little or no decontamination work has been done, whereas at other sites, decommissioning plans have been submitted or license termination is in the offing.

The effort to have these SOMP sites cleaned up and decommissioned has been hampered in part because licensees view the absence of definitive decontamination criteria as an incentive to defer decommissioning pending issuance of formal NRC requirements. The General Accounting office (GAO), which has been critical of the Commission's inability to effect timely decommissioning of these sites, has recommended that NRC enhance its decommissioning efforts by reconsidering its radiological criteria for decommissioning?.

Until new criteria are in place, the Commission intends to proceed with decommissioning nuclear facilities on a site-specific basis as the need arises considering existing criteria coupled with the concept that residual radioactivity be as low as is reasonably achievable (ALARA). Case and activity-specific decisions concerning decommissioning of sites will continue to be made as necessary during the pendency of this process. Since the SDMP sites could pose unnecessary environmental and public risk or financial burden

- GAO Report to Congress, "NRC's Decommissioning Procedures and Criteria Need to Be Strengthened", GAO/RCED-89-119, May 1989 
If they are not cleaned up and decommissioned in a timely manner, the Commission's effort to effect timely decommissioning of these sites is proceeding in parallel with this proposed rulemaking action. The NRC published an Action Plan to ensure timely remediation of sites listed in the SOMP in the Eederal Register." It should be noted that as a matter of current policy the NRC does not plan to require additional cleanup of sites in response to criteria established in this rulemaking, provided that the ifcensee or responsible party cleaned up the site, or was in the process of cleaning up the site in full accordance with an NRC-approved decommissioning plan at the time of promulgation.

Internationally, most efforts have been focussed upon derivation of criteria for waste and recycle, using guidance published by the International Atomic Energy Agency. Decommissioning criteria have generally been established on a case specific basis, and the NRC staff is not aware of other international efforts similar to this rulemaking to define radiological criteria for decommissioning.

\section{NEED FOR RULEMAKING}

The Commission believes that there is a need to incorporate into its regulations radiological criteria for termination of licenses and release of 1 and and structures for unrestricted use. The intent of such an action would be to provide a clear and consistent regulatory basis for determining the extent to which lands and structures must be decontaminated before a site can be decommissioned. The Commission believes that inclusion of criteria in the regulations would result in more efficient and consistent licensing actions related to the numerous and frequentiy complex site decontamination and decommissioning activities anticipated in the future. In addition, a rulemaking effort would also provide an opportunity to reassess the basis for the residual contamination levels contained in existing guidance in light of

‘57 FR 13389, April 16, 1992. 
changes in basic radiation protection standards $s^{s}$ and decommissioning experience obtained during the past 15 years.

Current regulations do not explicitly address radiological criteria for decommissioning. Pending NRC rulemaking on generic radiological criteria for decomissioning, the NRC continues to use its current criteria and practices.' The NRC could continue to decommission on a site-specific basis using existing guidance. However, the Commission believes that codifying radiological criteria for decommissioning in the regulations would: result in more efficient use of NRC and licensee resources; (2) lead to more consistent and uniform application across all types of licenses; (3) provide a more stable basis for decommissioning planning; and (4) eliminate protracted delays in decommissioning which results as licensees wait for generic regulatory criteria before proceeding with decommissioning of their facilities.

The criteria would apply to the decommissioning of all types of NRC licensed facilities, including materials licensees, power reactors, non-power reactors, fuel reprocessing plants, fuel fabrication plants, uranium hexafluoride 23360]

- As codified in the May 21, 1991 revision of 10 CFR Part 20 [56 FR

- In June 1988 the Commission published a final rule on General Requirements for Decommissioning Nuclear Facilities (53 FR 24018, 27 June 1988). However, this rule did not specifically address radiological criteria for decommissioned sites.

1 Regulatory guidance, criteria, and practices include the following with emphasis on contamination levels that are ALARA: "Disposal or On-site Storage of Thorium or Uranium from Past Operations" Branch Technical Position, October 23,1981, 46 FR 52061; "Termination of Byproduct, Source, and Special Nuclear Materiais Licenses", Policy and Guidance Directive FC 83-23, November 4, 1983; Termination of Operating Licenses for Nuclear Reactors" Regulatory Guide 1.86, June 1974 ; letter to Stanford University from James R. Miller, Chief, Standardization and Special Projects Branch, Division of Licensing, Office of Nuclear Reactor Regulation, NRC, Docket No. 50-141, April 21, 1982; "National Primary Drinking Water Standards," 40 CFR 141; "Radiation Dose Guidel ines for Protection Against Transuranium Elements Present in the Environment as a Result of Unplanned Contamination, " 42 FR 60956, November 30, 1977. Guidance is specified in terms of acceptable levels of residual contamination at decommissioned sites. 
production plants, and independent spent fuel storage installations." They would apply to nuclear facilities that operate through their normal lifetime, as well as to those that may be shut down prematurely. There may be a small number of sites where cleanup to criterla for unrestricted release developed in this rulemaking may not be practical. The approach to handling such cases is an tssue for discussion.

On July 3, 1990, the Commission published a Below Regulatory Concern (BRC) Policy Statement in the Eederal Reaister. The BRC Policy was intended to guide a broad range of commission actions, including exemptions from Commission regulations, as well as the development of generic health and safety standards such as those involved in this rulemaking. Subsequent to the publication of the BRC Policy, the Cormission placed an indefinite moratorium on the implementation of the BRC Policy because of the broad public concern expressed over the new Policy.' After the Commission placed the indefinite moratorium on the implementation of the BRC Policy, it decided to initiate this rulemaking to address the critical need for generic site cleanup and decomissioning standards for NRC-licensed facilities. The Commission determined that it should proceed with a fresh approach to the development of these standards that is independent of the now defunct BRC Policy.

- The criteria would not apply to the disposition of uranium mill tallings, low-level waste disposal factlities, or high level waste repositories since these have already been addressed in separate regulatory actions. They would apply, however, to uranium mills and ancillary facilities that support radioactive waste disposal (e.g., surface facilities for the high level waste repository).

- Section 2901 of the recently enacted National Energy Policy Act of 1992 (H.R. 176) revoked the Commission's July, 1990, BRC Policy Statement. Section 2901 also reyoked the Commission's poitcy statement of August 29, 1986 that established criteria to guide Commission exemption decisions on specific low-level radioactive waste streams. This latter policy was developed in order to comply with Section 10 of the Low-level Radioactive Waste Policy Amendments Act of 1985 . The Commission will be issuing a formal withdrawal of these two policy statements in the Eederal Register in January, 1993. 
Concurrent with the NRC rulemaking on site cleanup standards, the Environmental Protection Agency (EPA) is proceeding to develop standards and guldance for Federal agencies in the area of radiation protection, including standards for the cleanup of contaminated sites. The NRC and EPA plan to coordinate their efforts in this area in order to ensure that effective and consistent site cleanup standards are established, while minimizing duplication of effort. Accordingly, the EPA will not only be an important participant in the NRC rulemaking workshops but the NRC also plans to consult extensively with EPA throughout the rulemaking process. It is anticipated that the information gathered during the workshops on the NRC standards will al so be relevant and useful to the EPA efforts in the area of site cleanup standards. The NRC will also participate in EPA efforts in this area, such as the activities of the EPA Interagency Working Group on Radiation protection. The objective of the NRC and EPA cooperative efforts is to attempt to reach an agreement that the NRC standards established in the enhanced participatory rulemaking are sufficient to provide adequate protection to the public health and safety for NRC-licensed sites. The EPA efforts could then focus on the site clean-up standards for non-NRC licensed sites, such as DOE and DOD facilities. This is consistent with the principles and procedures set forth in a recent Memorandum of Understanding between the NRC and EPA to guide each agency's actions in areas of mutual regulatory concern. ${ }^{30}$

\section{PROPOSED COMMISSION ACTIONS}

The normal pattern for NRC rulemaking is the development, of a proposed rule by the NRC staff for Commission consideration, publication of the proposed rule for public comment, consideration of the comments by the NRC staff, and preparation of a final rule, as appropriate, for Commission approval. As directed and approved by the Commission, the NRC staff plans to enhance

10 Eederal Register, Vo1. 57, 54127, November 16, 1992, "Memorandum of Understanding Between the Nuclear Regulatory Commission and the Environmental Protection Agency" 
participation in this process through a series of workshops for interested parties. The workshops are planned to elfcit informed discussions of options and approaches, and the rationale for options and approaches. While these workshops are not designed to seek "consensus" in the sense that there is agreement (or at least a lack of disagreement) on the issues, the workshops are to be conducted at a very early stage of rulemaking to enhance participation of interested parties and the public with the following objectives: a) to ensure that the relevant issues have been identified; b) to exchange information on these issues; and c) to identify underlying concerns and areas of disagreement, and, where possible, approaches for resolution. It is the Commission's hope that the interactions that will take place among the participants in the workshop environment will foster a clearer understanding of the positions and concerns of the participants.

The proposed rulemaking activities, if pursued, are expected to result in publication of a proposed rule and a draft Generic Environmental Impact Statement (GEIS). It is the Commission's intent that the criteria developed in this rulemaking would apply to almost all licensed facilities and sites." However, it would not apply to sites already covered by a Commission approved decommissioning plan. An estimate of the numbers and types of facilities expected to be covered by this rulemaking can be found in the BACKGROUND section of this paper.

The Commission intends to publish a Notice of Intent to prepare a aEIS for this rulemaking effort. Separate meetings will be held with interested Federal, state, and local agencies and organizations to discuss the scope of the GEIS. However, information, comments, and suggestions from the discussion of the issues in this paper would be taken into account by the NRC in preparing the GEIS. In addition, one or more Regulatory Guides would be

"The criterla would not apply to the disposition of uranium mill tailings, low-level waste disposal factlities, or high level waste repositories since these have already been addressed in separate regulatory actions. They would apply, however, to uranium mills and ancillary facilities that support radioactive waste disposal (e.g., surface facilities for the high level waste repository). 
published to provide licensees with guidance on how licensees could demonstrate compliance with the regulation.

The Commission's plan for implementing the rule is described below. The Commission would issue supporting documents concurrent with the rule which provide guidance on implementation of the residual contamination criteria in the rule. These documents would include a "Guidance Manual for Conducting Radiological Surveys in Support of License Termination" (NUREG/CR-5849) and a Technical Basis Document, "Residual Radioactive Contamination from Decommissioning: Technical Basis for Translating Contamination Levels to Annual TEDE" (NUREG/CR-5512). The Guidance Manual for Conducting Radiological Surveys is intended to provide licensees with specific guidance on planning, conducting, and documenting site surveys which could be used to demonstrate that the site has been decontaminated to a level consistent with the Commission's criteria. The Technical Basis Document would provide an acceptable method for translating residual radioactivity levels (measurable quantities) to doses to individuals. Generic dose rate conversion factors are being developed for screening. In addition, the technical basis is expected to include a computer model which can be used for conducting a screening scenario/pathway analyses with site-specific parameters so that site-specific dose rate conversion factors can be calculated. The NRC anticipates that in most cases these dose rate conversion factors could be used to determine compliance with criteria resulting from the rulemaking action.

Work on the supporting documents is already underway, and drafts are available for information. However, these documents are not intended to constrain the approach taken by the commission in developing radiological criteria. Instead, they are intended to provide a technical underpinning which would be useful irrespective of the approach or the criteria finally adopted by the commission. These documents will be revised as necessary to conform to the final criteria.

In addition to the activities directly supporting a rulemaking action on decommissioning criteria, the NRC has a number of other related activities in progress in the general area of decommissioning. These activities include: 
(1) rulemaking to define the timeliness of decommissioning, and (2) rulemaking to require licensees to list in one location all land, buildings, and equipment involved in licensed operations. These activities will not be specifically considered as part of the discussions on radiological criteria for decommissioning.

\section{ISSUES FOR DISCUSSION}

Before the Commission formally proposes to proceed with rulemaking as described above, it is prepared to consider a wide range of alternative approaches, including maintaining the status auo. The basic question before the Commission is, "What level or levels of risk, dose, residual radioactivity, or other decommissioning criteria, would provide acceptable protection of health and safety and the environment?" The answer to this question must be reasonable and practical to implement and to enforce for the broad range of facilities which require decommissioning.

The Commission believes that the key issues and sub-issues discussed below are at the foundation of the basic question posed above. Therefore, the Commission solicits comments and information on these issues before proceeding with a proposed rulemaking. These issues, and other relevant and substantial issues identified by interested parties, will serve as the basis of discussion at a series of workshops. Workshop participants will be expected to present the rationale for their preferences and positions in the workshop setting. The workshop discussions will be used by the NRC staff in developing a proposed rule or, if considered appropriate, pursuing an alternative strategy for decommissioning.

The discussion of issues is divided into two parts. First are two primary issues dealing with the objectives for developing radiological criteria, and the application of practicality considerations. Following these issues are several secondary issues that are related to the primary discussions, but which were believed to warrant separate presentations and discussions. The format of discussion for each issue is arranged by first describing the general issue to be considered, then providing a background discussion of the 
issue with potentially useful information for the workshop discussions. A list of sub-issues is also provided to focus the discussions. It is important to recognize that the Commission does not regulate natural background or fallout from weapons or other sources beyond its authorit.y. Therefore, the following decommissioning issues are to be considered as they apply to radioactivity that is both attributable to licensed operations and is above background levels.

The Commission does not intend to include the issue of Agreement State compatibility with NRC requirements as a topic for discussion in the workshops. The Commission has a concurrent process to establish a general policy on compatibility and does not believe it would be efficient to have two separate forums focussing on the same subject. The Commission believes that the ongoing process to establish the general policy on compatibility would be the more appropriate forum to discuss all compatibility issues. In addition, parties will be afforded the opportunity to comment on compatibility issues at the time of the publication of a proposed decommissioning rulemaking. This approach will allow the workshops to focus upon the central technical issues and approaches to the radiological criteria for decommissioning.

\section{PRIMARY ISSUES FOR DISCUSSION}

Issue I: What objective(s) should serve as the basis for establishing radiological criteria for decommissioning?

\section{Discussion:}

There are four fundamental kinds of objectives that could serve as the starting point for developing radiological criteria for decommissioning (i.e., release for unrestricted use). They are described briefly below.

1. RISK LIMITS--Establishment of limits above which the risks to the public are deemed unacceptable. The objective in this case would be to find a limit above which risks would be unacceptable, and then establish 
additional criteria to further reduce exposures to levels below the unacceptable to the extent practical. With this objective, a site could be released for unrestricted use if there were reasonable assurance or demonstration that members of the public would not be exposed to an unacceptable risk from radioactivity remaining at the site.

In practical terms this objective would mean that the radioactivity remaining at the site must be below some upper limit established by the NRC as representing the boundary of unacceptable exposure to an individual or group of individuals. Below this upper limit, exposures would be further reduced to levels which are "As Low As Reasonably Achievable" (ALARA) taking into account various factors of practical implementation (cost versus benefit), and socioeconomic considerations. (See Issue 2)

2. BISK GOAL--Establishment of risk goals below which the risks to the public are deemed trivial. This objective would be to find a level of public and environmental risk below which risks are considered trivial, and then require decontamination to levels which are either below the goal, or as close to those goals as practical. Using this objective, a site would be released for unrestricted use if the radioactivity remaining at the site were as close as practical to the goals selected. If the decontamination goals were met or exceeded, then no further consideration of decontamination would be required.

In practical terms, residual radioactivity levels greater than the corresponding risk goals would be accepted provided they are as close as reasonably achievable to the risk goals. If the levels of radioactivity were below the levels corresponding to the goals, then no decontamination would be required, regardless of feasibility.

3. BEST EFFORT - - Best effort emphasizing use of available technology. The objective in this case would be to establish criteria representing what is achievable using the "best" available technology. A site would be released for unrestricted use if the only residual radioactivity 
remaining at the site is that material which cannot be removed using the best available technology. This objective is technologically driven. Theoretically, it could lead to ramovai of all radioactivity attributable to licensed activities or to an undefined level limited by the efficiency of the technology. Cost can be a factor, but is not taken into consideration on the basis of cost versus benefit balancing.

4. RETURN TO EACKGROUND LEVELS. This objective would be to remove all radioactivity attributable to licensed activities. A site would be released for unrestricted use only if all radioactivity attributable to licensed activity were removed. This objective could be difficult to implement either because of the costs associated in reducing residual radioactivity to background levels or because of the difficulty in demonstrating that a return to background levels had been achieved. Demonstrating a return to background levels could be especially difficult at sites where the background levels were not recorded prior to beginning licensed operations, or at facilities licensed to use nuclides such as uranium or thorium which al ready exist in varying degrees in the natural background.

The following information is provided to aid discussion and is focused first on the Risk Limits and Risk Goals objectives and secondly on the Best Effort and the Return to Background objectives:

The fundamental principle underlying all NRC regulations and activities has been that radiation doses to members of the public from licensed activities must be reduced io levels estabiished as limits (Risk Limits objective). ${ }^{12}$ The limits pose the boundary of unacceptable public risk regardless of the cost required to achieve such reduction, and risks should be further reduced to levels which are ALARA. This principle is articulated in 10 CFR Part 20, and the Commission currently uses this principle as the basis for decommissioning nuclear facilities. For example, the typical practice in

\footnotetext{
${ }^{22}$ Although NRC regulations are designed to limit risk, not all limits in the regulations were established on the basis of risk.
} 
decontaminating an area is to remove contamination through sweeping, washing, chemical stripping, scabbling thin layers of concrete, etc. The area is then surveyed and the results compared to the appropriate established criteria. If the area does not meet the criteria, then further steps are taken to reduce the level of radioactivity remaining. Once the levels are met, then further steps are considered to lower the remaining levels, but the decision to use these steps take into account the costs of the step and the reduction that is anticipated. This principle is also the basis for certain actions by the Environmental Protection Agency in the area of radiation protection, and is a fundamental principle outlined in both national and international recommendations.

In its recent recommendations on radiation protection, the International Commission on Radiological Protection (ICRP) has introduced the concept of a "constraint" in establishing the appropriate level of protection for any particular source of radiation exposure such as a decommissioned facility. ${ }^{23}$ A constraint is a selected level, below the dose limit (the dose limit corresponds to an acceptable risk), to provide assurance that any given individual would not receive a dose in excess of the dose limit, even if that individual were to be exposed to several sources simultaneously. As described by the ICRP, the concept of ALARA would be applied after the constraint was met. This approach is similar to the approach already utilized by the NRC in establishing criteria for effluents from nuclear power plants in 10 CFR Part 50 Appendix I and by the Environmental Protection Agency in the generally applicable environmental standards such as 40 CFR Part 190 and in 40 CFR Part 61, the regulations implementing the Clean Air Act.

The Risk Goals objective was recently applied by the Environmental Protection Agency in the selection of values for radionuclides in drinking water. In its proposal, the EPA established maximum contaminant level goals (MCLGs) for radionuclide levels, then established maximum contaminant levels (MCLs) which were greater than the goals in recognizing factors such as availability of

\footnotetext{
23International Commission on Radiation Protection, ICRP Publication 60, November 1990.
} 
technology, costs to remove radionuclides, and numbers of individuals involved. This is an extreme application of the risk goal principle, because the risk goal was legislatively set equal to zero. It is recognized that these goals may not be literally achievable. Furthermore, confusion has resulted from fallure to distinguish between levels and goals.

In addition, several national and international agencies and organizations, including the NRC, have adopted or proposed numerical risk or dose levels for public exposure from activities and practices involving radioactive materials. These risk levels may provide a basis for initiating a dialogue on numerical levels of risk or dose which would provide an acceptable basis for establishing radiological criteria for decommissioning. In addition, EPA has established or proposed other risk objectives that should be considered, such as EPA standards related to the Clean Air Act, the Resource Conservation and Recovery Act (RCRA) and the Comprehensive Environmental Response, Compensation, and Liability Act (CERCLA also known as "Superfund") which may need to be considered in establishing criteria. For example, the EPA has established health based limits for numerous chemicals under RCRA. On May 20 , 1992, (57 FR 21450) the EPA publisined a proposed rulemaking on the identification of hazardous waste which included, as an option, the use of multiples of these health based limits in determining the appropriate approach to management of the waste as hazardous or other solid waste. Although The proposed approach has been withdrawn, EPA plans to continue assessing the merits of approaches used by others ( 57 FR 49280, October 30, 1992).

The Commission's current radiological criteria for decommissioning, are stated in terms of acceptable levels of residual contamination and external dose rates at one meter from contaminated surfaces. These criteria have been conservatively estimated, considering the most highly' exposed population group of individuals, to result in potential doses ranging between one and several 
tens of millitrem per year Total Effective Dose Equivalent (TEDE/y) (exclusive of doses from radon and its daughter products). ${ }^{24}$

The EPA Clean Air Act and regulations provide practical examples of the application of the Best Effort regulatory principle. Among other things, the Clean Air Act requires the EPA Administrator to set new standards for emission of air pollutants based on the best, adequately demonstrated, technological system, taking into account the cost of achieving emission reduction, energy requirements, and any non-air impacts on the quality of health and the environment. Another section of the Clean Air Act permits the EPA Administrator, based on the same considerations as listed above, to set standards based on a design, equipment, work practice, or operational standard, or combination of these." The EPA uses several implementing concepts in promulgating Clean Air Act regulations, including maximum achievable control technology (MACT), generally available control technologies (GACT), and best demonstrated technology (BDT), and each of these concepts include considerations of cost and other factors listed in the Clean Air Act. ${ }^{36}$ These terms are defined in Appendix B.

The Return to Background objective for clean-up of facilities has been applied particularly for chemical hazards which do not normally exist in nature, and the approach often taken is to establish the clean-up objective at zero contaminants. In situations where some type of background, or natural concentrations of chemicals already exist, such as contaminants in a groundwater aquifer, the objective is sometimes expressed in terms of non-

\footnotetext{
14 For some radioisotopes (e.g., ${ }^{230} U$ ), acceptable residual levels may be based on non-radiological effects (e.g., the chemical toxicity of uranium) if the non-radiological effects are potentially more hazardous than the radiological effects.

28Public Law 101-549 (104 STAT. 2399) November 15, 1990, (Clean Air Act Amendments of 1990, Sections 111 and 112).

${ }^{16}$ For examples, see 56 FR 64382, December 9, 1991, "National Emission Standards for Hazardous Air Pollutants for Source Categories:

Perchloroethylene Emissions Fro- Dry Cleaning Facilities," (Proposed Rule), and 55 FR 26953, June 29, 1990, "Standards of Performance for New Stationary Sources; Volatile Organic Compound (VOC) Emissions From the Synthetic Organic Chemical Manufacturing Industry (SOCMI) Reactor Processes" (Proposed Rule).
} 
degradation of the existing situation, meaning that no additional materials should be present beyond those already existing.

There may be some sites where the cost of meeting the selected criteria would be exorbitant. Consideration should be given to the disposition of such sites. Such sites could be handled in a manner simflar to, or reflect elements of, the way the Commission deals with uranium mill tailings sites under the provisions of the Uranium Mill Tailings Radiation Control Act of 1978, As Amended (UMTRCA). Under the provisions of UMTRCA, mill tailings sites are partially decontaminated, stabilized, and subject to requirements for restricted use and long-term care and are not released for unrestricted use. EPA's CERCLA/Superfund Program also allows cost to be a consideration in site cleanup; however, cost is typically not a primary consideration in setting environmental levels under RCRA or the Clean water Act (CWA). Implementation under these programs is primarily focussed on "Best Demonstrated Available Technology" (BDAT).

The NRC has several possible approaches to codifying radiological criteria for decommissioning. One approach is to establish limits in terms of dose in the regulation and then provide listings of specific residual radioactivity levels for different radionuclides either as an appendix to the regulation or as a Regulatory Guide. This is the approach of 10 CFR Part 20 for the dose limits, where the values in Appendix $B$ of Part 20 serve as a method for demonstrating compliance with the dose limit, rather than being a limit themselves. Alternatively, the Commission could codify specific values for residual radioactivity for each radionuclide of concern as part of the regulation. similarly, a Risk Goal could be codified in terms of a dose or a risk, or alternatively, as specified levels of radioactivity. If the chosen decommissioning objective were Best Effort, then the method of determining the appropriate technology could be codified or the technology itself could be codified. For the Return to Natural Background objective, the method for determining background and accuracy of determinations could be the substance of the regulation or quantitative levels of radioactivity could be codified. 
The terms of the regulation could be important to the extent that they could affect the Commission's flexibility in applying the regulation and also the flexibllity the licensees would have in demonstrating compliance. If objectives were codified in terms of specific measurable quantities such as concentrations of radioactive materials, neither the Commission nor the licensees would have flexibility to take site specific factors into account when trying to demonstrate compliance. However, if the objective were codified, individual licensees could conduct a site specific analysis to demonstrate to the Commission that their site would meet the objective with different residual radioactivity levels than those determined by the Commission based on a generic, conservative analysis.

Past experience has shown that changes to the regulations containing specific criteria are much more difficult to complete and require more resources than if the criteria are contained in a Regulatory Guide. However, past experience has also shown that enforcement of specific, measured values is unambiguous, direct, and unencumbered by lengthy litigation.

\section{Sub-issues:}

1. At what numerical level would the regulatory objective for decommissioning provide an acceptable basis for protection of the public health and safety and the environment?

a. If the Commission chooses a Risk Limit objective, should the Commission use the public dose limits in 10 CFR $20(100 \mathrm{mrem} / \mathrm{y})$ as the 1 imit on doses from residual radioactivity at decommissioned sites or establish separate constraints for decommissioning? If separate constraints are set, what should be the basis for these constraints?

b. If the Commission chooses a Risk Goal objective as its basis for establishing criteria, on what basis should the goal be established?

c. If the Commission chooses a Best Effort objective as its basis for establishing criteria, what level of technological availability should 
be used? How often should the applicable areas of technology be updated for this criteria? What criteria should govern the number of applications of the technology to achieve lower levels of residual radioactivity, i.e., how would the point of diminishing returns be established? Recognizing that application of technology could result in widely varying levels of residual radioactivity, should an additional limit be placed on the level of residual radioactivity? If new technologies become avallable that are significantly more efficient in decontaminating a site, should these new technologies be applied to previousiy decommissioned sites? If so, what criteria should require the reopening of a site for decontamination?

d. If the Commission chooses the Return to Background objective as a basis for establishing criteria, how should background levels of radiation and radioactive material be established? For example, should a single level be chosen for each naturally occurring radionuclide, or should the local level of background be used, or some other criterion? How should the chosen approach, single or local level, be measured and to what accuracy?

2. What other alternatives should be considered as a general framework for establishing objectives? Should the commission consider combinations of the fundamental objectives and if so, which combinations and on what basis?

3. What role should EPA initiatives play in setting objectives? For example, the EPA used about a 10-4 lifetime risk of fatal cancer for members of the most highly exposed population group and a general lifetime risk level on the order of $10^{-6}$ as a basis for National Emission Standards for Hazardous Air Pollutants." Are there other established or proposed risk objectives that should be considered?

1740 CFR Part 61, "National Emission Standards for Hazardous Air Pollutants; Radionuclides. "Final Rule and Notice of Consideration, 54 FR 51654, December 15, 1989 
4. What consideration should be given to standards or objectives proposed or adopted by other groups (e.g. International Atomic Energy Agency, (IAEA))?

5. What should be done in those cases where sites cannot reasonably be decontaminated to the point where they are appropriate for unrestricted use?

6. How prescriptive should the regulation on radiological criteria for decommisstoning be? For example, should the Commission codify the decomissioning objective(s) and provide detalls (e.g., residual radioactivity concentration, etc.) of a method of compliance elsewhere, such as in a Regulatory Guide, or should the regulation be more prescriptive?

Issue II. How should practicality considerations be applied,particularly if the Commission were to adopt either the Risk Limit objective or the Risk Goal objective in its radiological criteria for decommissioning rule?

\section{Discussion:}

ALARA is an acronym for as low as is reasonably achievable and means making every reasonable effort to reduce or maintain exposures to radiation as far below established dose limits as is practical taking into account the state of technology, the economics of improvements in relation to the state of techrology, the economics of improvement in relationship to the benefits to the public health and safety, and other societal and socioeconomic considerations, and in relation to the utilization of nuclear energy and licensed material in the public interest. This covers a broad spectrum of actions and activities including cost-benefit analysis of procedures and proposals, avallability and application of measurement technologies, and avallability of disposal facilities. The same factors that have been traditionally used in radiation protection (Risk Limit objective based) are also the factors that would be used in determining how close practical criteria can be made to a Risk Goal objective. Thus, in the present context, the term ALARA can be used to represent the practical process (that is, cost versus benefit evaluation process) of reaching either the lowest acceptable 
risk below an Risk Limit or the lowest risk above a Risk Goal as discussed in Issue 1.

The employment of practicality considerations, including costs, availability of technology, etc., has been recognized as valid in a number of contexts, both in the area of radiation protection and in the regulation of hazardous chemicals and wastes. For example, in recommendations approved by the President on Radiation Protection Guidance to Federal Agencies for occupational Exposure, the concept of ALARA was specifically included." Likewise, the EPA has acknowledged the validity of considering costs and benefits in determining levels for regulation of chemicals in various arenas, as 11 lustrated by the EPA response to a petition requesting revocation of food additive regulations." The NRC rulemaking is being conducted under the Atomic Energy Act, which allows consideration of ALARA, provided the public health and safety are protected.

There are a variety of ways the principle of ALARA can be applied. In both the Risk Limit and Risk Goal objectives, ALARA can be applied on a case-bycase basis with a site-specific analysis required for each site.

Alternatively, generic ALARA criteria could be established which would be applicable to all sites or to categories of sites. This latter alternative is equivalent to combining both the Risk Limit and the Risk Goal objectives.

A credible ALARA analysis must consider all of the costs and benefits associated with decontaminating a site to different residual radioactivity levels and must be carefully documented to demonstrate that all reasonable alternatives and technologies have been considered. It should take into account: (1) radiation doses (public and occupational) and environmental impacts both from the process of decommissioning the site and from the residual radioactivity which will remain at the site after it has been decommissioned, and (2) all of the costs and other risks (e.g. occupational,

\footnotetext{
${ }^{20} 52$ FR 2822, January 27, 1987.

${ }^{10} 56$ FR 7750, February 25, 1991.
} 
transportation) associated with the decontamination and decommissioning the site. It should also include an analysis which clearly demonstrates how overall costs and benefits change with changing residual radioactivity levels. The analysis must be properly documented. This should include documentation of the methodology and the sources of data used in the analysis, and include an assessment of the uncertainties associated with the results of the analysis. ALARA analyses can be carried out on either a generic or site specific basis. Generic analyses by their very nature will produce results with higher uncertainty than those that can be obtained from a site specific analysis. Therefore, a more conservative approach would have to be adopted when conducting a generic analysis to assure that the results of the analysis are appropriate to all of the sites and activities to which the analysis is expected to apply.

\section{Sub-issues:}

1. Should the Commission require that ALARA be determined on a sitespecific basis for each site to be decommissioned? If not, how should ALARA be applied? Should the Commission establish generic ALARA criteria (i.e., Meeting the generic criteria would be considered ALARA for any site without need for further site specific cost versus benefit analysis.)? If generic ALARA criteria are used, should a single ALARA criterion be established for all sites, or should different ALARA criteria be established for different categories of sites or facilities. If ALARA criteria are established for different categories of sites, on what basis should the different categories be established?

2. Irrespective of whether ALARA is applied on a site-specific basis or generically, on what basis should the ALARA analysis rest? What level of review by the NRC staff should be required to evaluate this basis? For example, if a cost versus benefit analysis were to be used, what monetary value per averted collective dose (i.e. dollars/person-rem) should the Commission use as a basis for making the determination? How should the level of difficulty in measuring certain radionuclides in some circumstances be 
handled? How should the staff address soctetal and socloeconomic aspects of the ALARA andiysis?

\section{SECONDARY ISSUES FOR DISCUSSION}

Secondary Issue A.: What additional considerations should be taken into account when establishing radiological criteria for deconmissioning?

\section{Discussion:}

In developing criteria, there is often a question of exactly who the standard is designed to protect. For example, the criteria may be established to protect a theoretical, maximally exposed individual, regardless of whether such an individual could actually exist. Alternatively, the criteria could be established on the basis of providing protection for more realistically exposed individuals, and could include consideration of a so called "critical group" which would be a small number of individuals that are representative of that population likely to receive the greatest dose. A "critical group" approach would often mean that it would be possible for the exposure of some single individual to be greater than the average of the group, and therefore experience a dose or risk in excess of the criteria.

Related to the question of the characteristics of the individual to be protected is the question of whether protecting individuals assures that the population, as a whole, that might be exposed is adequately protected. Various positions have been advanced on this subject, with some indicating that protection of each individual automatically assures protection of the population as a whole, and others indicating that additional criteria might be needed to protect the population. The hypothesis usually used for the requlation of radiation dose is a linear relationship between dose and risk, implying that an increment of dose, no matter how small, and no matter when delivered, will have an equal impact. This reasoning has been used to support 
the position, in some cases, that an additional criterion should be applied to the collective dose from a particular facility or source. On the other hand, each decommissioned facility can only expose a limited number of people.

In developing criteria for decommissioning, the codified definition of decommissioning, f.e. to reduce radioactive materials levels to a point where the site is suitable for unrestricted use, becomes important. Once a site has been released, an individual or group could use the property and any structures on the property in any legally acceptable way they wished, including renovating the structures for other purposes, excavation or other property modifications, and removal of materials from the site for use in other locations or for other purposes. Thus, when considering the appropriate criteria for unrestricted use, consideration may also need to be given to the potential for reuse, recycling, or disposal of structures or materials remaining on the site.

An additional consideration in the selection of radiological criteria is the time frame over which the criteria should be applied. There have been a number of different, values suggested and used in vari..... standards of the NRC and EPA, ranging from 100 years to over 10,000 year radionuclides with relatively short half-lives, decay negates the need, valuations in the distant future. However, for long-lived radionuclides, and particularly for chains of radionuclides where daughter products will gradually increase until equilibrium is reached (e.g., uranium and thorium), the time frame for considerations is potentially important. Time periods are also important when certain pathways, such as a groundwater pathway, are considered, since the movement of radionuclides through the pathway may be very slow under certain circumstances.

\section{Sub-issues:}

1. Should the Commission base its considerations on a theoretical, maximally exposed individual, or upon some type of "critical group" approach? What endpoint(s), such as cancer fatalities or cancer incidence, genetic effects, etr., should be used in establishing the radiological criteria? 
2. Should the Commission include consideration of an exposed population in addition to providing criteria for individuals? If so, how should this influence the criteria?

3. Should the Commission consider the potential, after release for unrestricted use, for reuse of building structures and the removal of soil from a site in determining the appropriate criteria? If so, how should these factors be included? Should the removal of materials lead to a different standard than if materials were to remain on the site? If so, what is the rationale or basis? Should consideration be given to consistency or linkage with waste disposal regulations, particularly in situations where large quantities of material may require remove: during the decommissioning process?

4. How far into the future should calculations be carried out when making estimates and determining the applicability of criteria? Should the Commission place a maximum value on the time frame to be considered, or should the criteria be applicable irrespective of time as which a maximum exposure could occur? For low levels of radioactivity should other changes in the environment, such as global warming and ice age cycles, geologic changes, etc., be factored into considerations of the applicability of the criteria?

Secondary Issue B.: If the objective the Commission adopts is either the Risk Limit or the Risk Goal, how should the regulation be structured with respect to exposure pathways? Should the rule apply comprehensively to all major pathways (routes) of exposure to the public or should the rule have criteria to limit specific exposure pathways, such as radionuclides in groundwater?

\section{Discussion:}

This issue arises because, over long periods of time residual radioactivity from decommissioned sites could contaminate groundwater that would later be used for drinking or irrigation. Furthermore, groundwater could be contaminated from more than one decommissioned site if another site were 
nearby. The Environmental Protection Agency has established limits for radioactivity in drinking water ${ }^{20}$ and, under the authority of RCRA and CERCLA, applies these limits to most potable ground water, but there are no Federal standards for groundwater contamination at decommissioned facilities.

In 10 CFR Part 20, the Commission has adopted the International Commission on Radiation Protection (ICRP) recommendations to account for doses from all pathways in one term. The Commission combines the doses from external exposures, ingestion and inhalation into the term, "Total Effective Dose Equivalent" (TEDE). That is, there is an internationally recognized methodology for weighing the doses and combining them into a single number, TEDE, that enables comparison of doses regardless of the pathway of exposure-external, ingestion or inhalation. ${ }^{21}$

Conceptually, the NRC could establish an verall limit or goal for a site, and allow the contribution (dose or risk) from each pathway of exposure (e.g. air, water, direct radiation, food) to vary so long as the total remained consistent with the overall limit or goal. Alternatively, a secondary limit or goal in addition to the overall criterion could be established to limit the extent to which a particular pathway could contribute to the total. A third possibility is that separate criteria could be established for each particular exposure pathway, independent from each of the other pathways.

2040 CFR Part 141. EPA regulations are applied to public water systems and not individual users. For beta and/or gamma emitters the dose to the whole body or an organ is 1 imited to $4 \mathrm{mrem} / \mathrm{y}$, while for alpha emitters Maximum Contaminant Levels are set in terms of $\mathrm{pCi} / 1$ and exclude radon and urantum. The EPA has published a proposed revision of these regulations, expressed in terms of a $4 \mathrm{rem} / y$ effective dose equivalent (see 56 FR 33050). The proposed revision also includes specific limits on radon and uranium.

22 For example, the technical basis document translating radioactivity in the environment to dose (PROPOSED COMMISSION ACTIONS section above, $p$. ?) accounts for radiation doses from major sources originating in soij, air, and water and combines the respective pathway doses into a conversion factor for TEDE. 
If a separate limit or goal were chosen for groundwater, then details of the method for estimating doses or risk due to water use at future times after decommissioning would be required. One method could be to establish Generic Site Inventory levels $s^{22}$, as a screening criterion based upon an analysis for a generic site. The basis for this approach could be that residual radioactivity from sites meeting these generic screening levels would not be expected to contaminate drinking water supplies in excess of EPA standards under any reasonably foreseeable circumstances regardless of the type of facility, or size, location, or hydrogeologic features of the site. Such an approach would also need to consider the possibility that building structures remaining onsite at the time of unrestricted release could be demolished and become part of the overall site inventory avallable to the groundwater. It is noted that Generic Site Inventory Levels that provide a reasonable margin of safety for all sites are likely be extremely restrictive and thus impractical for some sites. Potential impracticality could be addressed by providing licensees who demonstrate that Generic Site Inventory Levels are unnecessarily restrictive for their particular site with the option of conducting a site specific analysis to project compliance with EPA drinking water standards or other criteria specified in the rule.

\section{Sub-issues:}

1. What consideration should be given to the potential for cumulative drinking water contamination from two or more decommissioned sites in the same general area?

2. If specific exposure pathway criteria were chosen, which pathways should have specific criteria and on what basis should these criteria be established?

${ }^{22}$ A Generic Site Inventory Level would be total amount of radioactive material from the licensed operation which could be left at a decommissioned site without having to conduct a site specific analysis to determine whether allowing this radioactive material to remain at the site might result in unacceptable contamination of drinking water supplies. 
3. If the Commission chooses specific criteria for groundwater or water use, should it establish Generic Site Inventory Levels for screening residual radioactivity at decormissioned sites? Should the basis for such levels be to provide reasonable assurance that EPA drinking water standards will not be exceeded? Should a single Generic Site Inventory Level be established for all sites, or should levels be tallored to specific class of decommissioned sites (e.g., all nuclear power plant sites)? If so, on what basis should sites be categorized? Alternatively, should the Commission require that a site specific assessment of drinking water contamination potential be carried out for each site or a combination of the above?

Secondary Issue C.: For sites where uranium, radium or thorium contamination may have resulted from licensed activities, how should exposures from radon ( ${ }^{232} R_{n}$ and $\left.{ }^{232} R n\right)$ and its decay products be considered when the facility is decomnissioned?

\section{Discusston:}

Small quantities of uranium, radium and thorium are present in all soil types throughout the United States. These naturally occurring materials are responsible for part of the natural background radiation exposure to members of the public, and are precursors for radon gas--the single greatest contributor to natural background exposures. Because radium occurs naturally in the environment, accurate determinations of doses from radon resulting from licensed operations can be very difficult. First, radium from licensed operations contaminating building structures will produce radon within the structure. This radon will be in addition to radon present due to naturally occurring radium within or under the building. Radon concentrations from natural sources in buildings are known to be variable, and may be subject to variations due to factors such as building ventilation, weather, etc. Secondly, a fraction of the radium in the soil of the site could be from licensed operations and could contribute to indoor radon levels of any building later constructed on the site. The correlation between soil concentrations of uranium, radium or thorium have been shown to be not well 
correlated with the eventual levels of radon within a building. Given the above factors, approximate estimates of the amounts of uranium and thorium and their decay products (including radium) on site as a result of licensed operations might be made by taking direct measurements at a site in conjunction with offsite measurements to establish background levels. However, the estimation of indoor radon concentrations attributable to licensed operations for the present and future structures appears elusive. ${ }^{23}$

Based on information available to the NRC, there appears to be no practical way, using current technology, to distinguish between small amounts of radon from licensed operations and that radon resulting from natural background. This inability appears to be due to (1) the natural background levels of radium in rocks and solls and the resulting concentrations of radon ${ }^{24}$, the variability of doses at a given site from naturally occurring radon ${ }^{2}$, and $(3)$ the difficulty in correlating indoor radon levels with the concentrations of radon in the soll outside the structures. ${ }^{26}$ There are some who believe it may be virtually impossible to demonstrate that doses from

\footnotetext{
${ }^{23}$ Radon may also be a problem for a licensee that has never possessed materials containing uranium or thorium if they are located in an area of elevated natural radon levels. In these cases an individual in the structure could receive doses in excess of the criteria for decommissioning from sources outside the original responsibility of the licensee.

24 Soil radium concentrations in the U.S. average about $1.5 \mathrm{pCi} / \mathrm{g}$. The average indoor radon concentration is about $1.5 \mathrm{pCi} / 1$ which produces an estimated dose to a resident (assuming 75\% occupancy) of about $150 \mathrm{mrem} / \mathrm{y}$. EPA Radon Reference Manual, EPA 520/1-87-20, September, 1987, Pp.3-5 and 7-2.

2s The transport of radon through the environment is subject to considerable uncertainty and variability. In the case of indoor radon, variables such as highly localized geology, structural features, and changing weather, among others, combine to make accurate prediction of doses very difficuit.

26 As is the case for transport of radon through the environment, there are considerable uncertainties in the modeling of the movement of radon into a structure and the concentrations of radon that will exist at any given time. Numerous studies have shown that seemingly identical structures in similar environments can nevertheless have considerably different radon concentrations.
} 
radon which result from 1 icensed operations have been reduced to levels much below the EPA suggested action level of $4 \mathrm{pCi} / 1$ for indoor radon."

\section{Sub-issues:}

1. For sites where licensed activities have involved uranium, thorium, or other materials which decay to radon, are there practical and reliable ways to distinguish between radon and its daughter products attributable to residual radioactivity from licensed operations at a site and that radon attributable to natural background? Are there methods for estimating such doses with reasonable assurance using modelling techniques, direct measurements, or some combination of the two? At what dose levels can these distinctions be made?

2. If there is no way of distinguishing doses from radon resulting from licensed operations at levels well below the 100 mrem annual limit for public doses (10 CFR Part 20.1301), what alternatives would be considered acceptable? For example, would it be acceptable to require the licensee to demonstrate the site had been cleaned up to levels approaching ambient background levels measured at nearby representative sites or buildings? Would this alternative be acceptable even when these background levels would result in doses which are a large fraction of, or even exceed 10 CFR Part 201 imits for the public (100 mrem/y)?

3. Should the Commission consider criteria similar to existing EPA guidelines and standards even though these doses may be higher than the public dose limits in the revised 10 CFR Part $20(100 \mathrm{mrem} / \mathrm{y})$ ? Alternatively, should the Commission require licensees to reduce doses from radon and its daughter products as far below the EPA standard as reasonably achievable? How would compliance with such a requirement be judged (see Issue II)?

27 The level at which EPA suggests action be taken to reduce radon concentrations in homes. See "A Citizen's Guide to Radon, 2nd Edition - "The Guide to Protecting Yourself and Your Family from Radon", 402-K92-0001, Office of Air and Radiation; U.S. Environmental Protection Agency, June,1992. 
4. How should the Commission handle radon exposures in excess of EPA guidelines in factlities of licensees that have never possessed uranium, radium, or thorium materials?

Secondary Issue D.: How should the Comnission regard materials previously buried on-site under disposal provisions in 10 CFR Part 20 in the context of decomnissioning?

\section{Discussion:}

Under certain conditions, 1 icensees may dispose of radioactive wastes by burial on their own property. Before 1981, NRC regulations (10 CFR 20.304) allowed disposal, without prior approval, of limited quantities of specified nuclides under prescribed conditions. On July 28, 1981, 10 CFR 20.304 was revoked. However, onsite disposal can still be undertaken by individual licensees under 10 CFR 20.302, provided the disposal is specifically approved by the NRC or an Agreement State.

NRC requirements in 10 CFR 20.302 and 20.2002 allow licensees to request specific approval to dispose of licensed radioactive material in a manner not otherwise authorized by the regulations. In accordance with 10 CFR 20.2002, any such request must be accompanied by specific data and analyses necessary for the staff to determine whether such disposal would have an adverse effect on the health and safety of the public or the environment. The radioactive material involved in the requests is generally very low activity waste contained in large volumes of material, such as sludge from sanitary sewers and storm drains, soils contaminated by spills and leaks, and dredged material from discharge canals and settling ponds.

The requirements in 10 CFR Part 20 do not explicitly limit the quantity or concentration of the radioactive material. Past practices have limited approvals to small concentrations of radioactive material and correspondingly low to very low potential doses to members of the public and the environment. 
Maximum potential doses have generally been less than a few millirem per year.

\section{Sub-issues:}

1. When preparing their sites for decommissioning, should licensees be required to consider radioactive materials disposed of on-site in accordance with provisions of NRC or Agreement State regulations as part of the total inventory of residual radioactivity that must be considered when preparing a site for decommissioning?

2. Should a site specific analysis of the risks, costs, and benefits be performed before a decision is made to take any remedial action (e.g. exhumation and removal of buried radioisotopes, or delaying release of a site to allow decay of short lived buried radioisotopes) involving radioactive material previously disposed of at a site? 


\section{APPENDIX A}

\section{A GLOSSARY OF GENERAL TERMS USED BY THE NRC ${ }^{20}$}

Activity (Radioactivity) is the rate of disintegration (transformation) or decay of radioactive material. The units of activity are the curie (Ci) and the becquerel (Bq).

ALARA (acronym for "as low as is reasonably achievable") means making every reasonable effort to maintain exposures to radiation as far below the dose limits in this part as is practical consistent with the purpose for which the licensed activity is undertaken, taking into account the state of technology, the economics of improvements in relation to state of technology, the economics of improvements in relation to benefits to the public health and safety, and other societal and socioeconomic considerations, and in relation to utilization of nuclear energy and licensed materials in the public interest.

Background radiation means radiation from cosmic sources; naturally occurring radioactive materials, including radon (except as a decay product of source or special nuclear material) and global fallout as it exists in the environment from the testing of nuclear explosive devices. "Background radiation" does not include radiation from source, byproduct, or special nuclear materials regulatec by the commission.

Byproduct material means --

(1) Any radioactive material (except special nuclear material) yielded in, or made radioactive by, exposure to the radiation incident to the process of producing or utilizing special nuclear material; and

(2) The tailings or wastes produced by the extraction or concentration of uranium or thorium from ore processed primarily for its source material content, including discrete surface wastes resulting from uranium solution extraction processes. Undergruund ore bodies depleted by these solution

28 10 CFR Part 20.1003 [56 FR 24018, May 21, 1991] 
extraction operations do not constitute "byproduct material" within this definition.

Collective dcse is the sum of the individual doses received in a given period of time by a specified population from exposure to a specified source of radiation.

Commission means the Nuclear Regulatory C mmission or its duly authorized representatives.

Committed dose equivalent $\left(H_{r, s o}\right)$ means the dose equivalent to organs or tissues of reference $(T)$ that will be received from an intake of radioactive material by an individual during the 50-year period following the intake.

Committed effective dose equivalent $\left(H_{E, s o}\right)$ is the sum of the products of the weighting factors applicable to each of the body organs or tisslies that are irradiated and the committed dose equivalent to these organs or tesues $\left(H_{E, 80}=\Sigma W_{T} H_{T, 80}\right)$.

Dose or radiation dose is a generic term that means absorbed dose, dose equivalent, effective dose equivalent, committed dose equivalent, committed effective dose equivalent, or total effective dose equivalent, as defined in other paragraphs of this section.

Dose equivalent $\left(H_{T}\right)$ means the product of the absorbed dose in tissue, quality factor, and all other necessary modifying factors at the location of interest. The units of dose equivalent are the rem and sievert (SV).

Effective dose equivalent $\left(H_{\varepsilon}\right)$ is the sum of the products of the dose equivalent to the organ or tissue $\left(H_{T}\right)$ and the weighting factors $\left(W_{T}\right)$ applicable to each of the body organs or tissues that are irradiated $\left(H_{E}=\right.$ $\left.\sum W_{T} H_{T}\right)$.

Exposure means being exposed to ionizing radiation or to radioactive material. 
External dose means that portion of the dose equivalent received from radiation sources outside the body.

Generally apolicable environmental radiation standards means standards issued by the Environmental Protection Agency (EPA) under the authority of the Atomic Energy Act of 1954, as amended, that impose limits on radiation exposures or levels, or concentrations or quantities of radioactive material, in the general environment outside the boundaries of locations under the control of persons possessing or using radioactive material.

Government agency means any executive department, commission, independent establishment, corporation wholly or partly owned by the United States of America, which is an instrumentality of the United States, or any board, bureau, division, service, office, officer, authority, administration, or other establishment in the executive branch of the Government.

Individual means any human being.

Internal dose means that portion of the dose equivalent received from radioactive material taken into the body.

License means a license issued under the regulations in Title 10, Code of Federal Regulations, Parts 30 through $35,39,40,50,60,61,70$, or 72 .

Licensed material means source material, special nuclear material, or byproduct material received, possessed, used, transferred or disposed of under a general or specific license issued by the Commission.

Licensee means the holder of a license.

Limits (dose 1 imits) means the permissible upper bounds of radiation doses. 
Member of the oublic means an individual in a controlled or unrestricted area. However, an individual is not a member of the public during any period in which the individual receives an occupational dose.

Monitoring (radiation monitoring, radiation protection monitoring) means the measurement of radiation levels, concentrations, surface area concentrations or quantities of radioactive material and the use of the results of these measurements to evaluate potential exposures and doses.

Nonstochastic effect means health effects, the severity of which varies with the dose and for which a threshold is believed to exist. Radiationinduced cataract formation is an example of a nonstochastic effect (also called a deterministic effect).

NRC means the Nuclear Regulatory Commission or its duly authorized representatives.

Occupational dose means the dose received by an individual in a restricted area or in the course of employment in which the individual's issigned duties involve exposure to radiation and to radioactive material from licensed and unlicensed sources of radiation, whether in the possession of the licensee or other person. Occupational dose does not include dose received from background radiation, as a patient from medical practices, from voluntary participation in medical research programs, or as a member of the general public.

Public dose means the dose received by a member of the public from exposure to radiation and to radioactive material released by a licensee, or to another source of radiation efther within a licensee's controlled area or in unrestricted areas. It does not include occupational dose or doses received from background radiation, as a patient from medical practices, or from voluntary participation in medical research programs.

Radiation (ionizing radiation) means alpha particles, beta particles, gamma rays, $x$-rays, neutrons, high-speed electrons, high-speed protons, and 
other particles capable of producing lons. Radiation, as used in this part, does not include non-ionizing radiation, such as radio- or microwaves, or visible, infrared, or ultraviolet light.

Bestricted area means an area, access to which is 1 imited by the licensee for the purpose of protecting individuals against undue risks from exposure to radiation and radioactive materials. Restricted area does not include areas used as residential quarters, but separate rooms in a residential building may be set apart as a restricted area.

Site boundary means that 1 ine beyond which the land or property is not owned, leased, or otherwise controlled by the licensee.

\section{Source material means--}

(1) Uranium or thorium or any combination of uranium and thorium in any physical or chemical form; or

(2) Ores that contain, by weight, one-twentieth of 1 percent $(0.05$ percent), or more, of uranium, thorium, or any combination of uranium and thorium. Source material does not include special nuclear material.

Special nuclear material means--

(1) Plutonium, uranium-233, uranium enriched in the isotope 233 or in the isotope 235, and any other material that the Commission, pursuant to the provisions of section 51 of the Act, determines to be special nuclear material, but does not include source material; or

(2) Any material artificially enriched by any of the foregoing but does not include source material.

Stochastic effects means health effects that occur randomly and for which the probability of the effect occurring, rather than its severity, is assumed to be a linear function of dose is thout threshold. Hereditary effects and cancer incidence are examples of stochastic effects.

Survey means an evaluation of the radiological conditions and potential hazards incident to the production, use, transfer, release, disposal, or pre- 


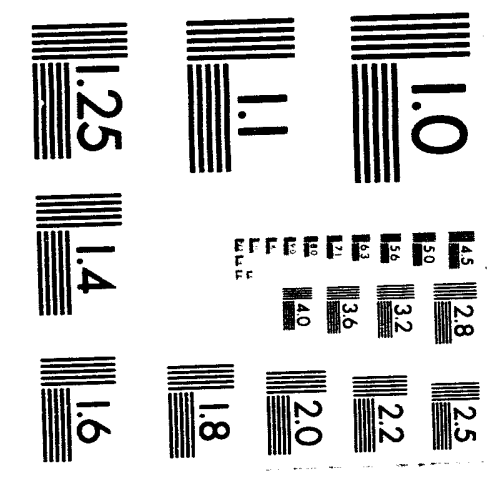



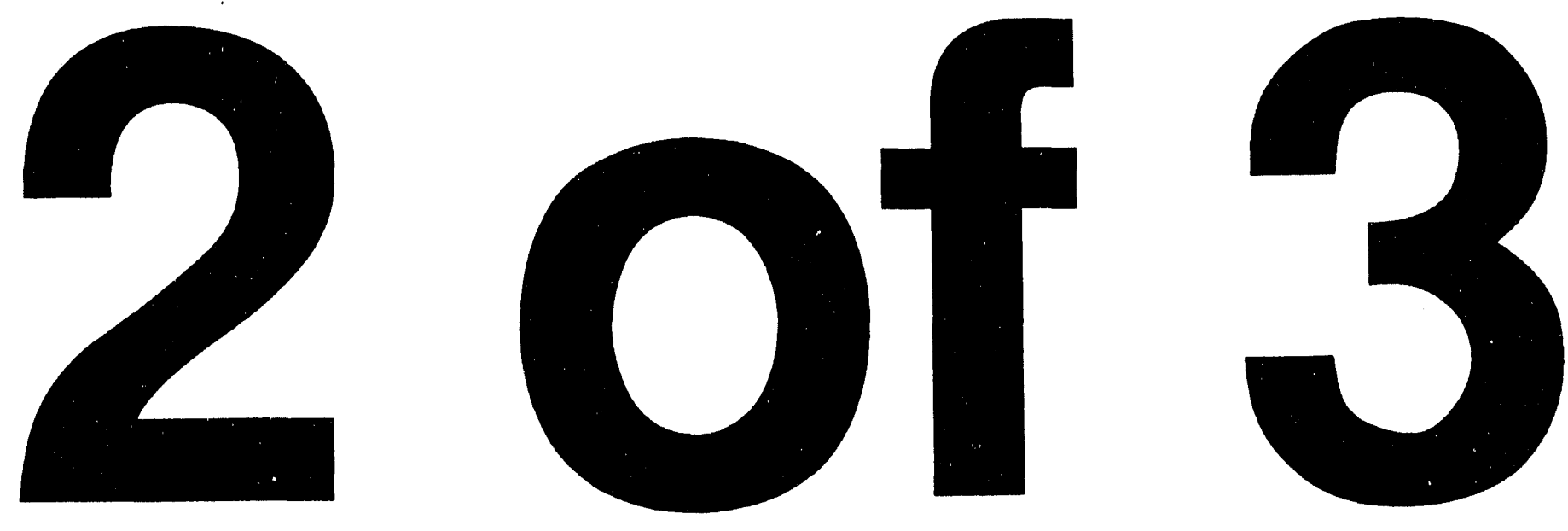
sence of radioactive material or other sources of radiation. When appropriate, such an evaluation includes a physical survey of the location of radioactive material and measurements or calculations of levels of radiation, or concentrations or quantities of radioactive material present.

Iotal Effective Dose Equivalent" (TEDE) means the sum of the deep-dose equivalent (for external exposures) and the committed effective dose equivalent (for internal exposures).

Unrestricted area means an area, access to which is neither limited nor controlled by the licensee.

Uranium fuel cycle means the operations of milling of uranium ore, chemical conversion of uranium, isotopic enrichment of uranium, fabrication of uranium fuel, generation of electricity by a light-water-cooled nuclear power plant using uranium fuel, and reprocessing of spent uranium fuel to the extent that these activities directly support the production of electrical power for public use. Uranium fuel cycle does not include mining operations, operations at waste disposal sites, transportation of radioactive material in support of these operations, and the reuse of recovered non-uranium special nuclear and byproduct materials from the cycle.

Whole body means, for purposes of external exposure, head, trunk (including male gonads), arms above the elbow, or legs above the knee. 


\section{APPENDIX B}

IERMS AND CONCEPTS ASSOCIATED WITH THE BEST EFFORT (TECHNOLOGY-BASED) 'ROACH PUT FORTH IN THE CLEAN AIR ACT ${ }^{29}$

Best Available Control Technology (BACT) - An emission limitation based on the maximum degree of emission reduction which (considering energy, environmental, and economic impacts and other costs) is achievable through application of production processes and available methods, systems, and techniques. In no event does BACT permit emissions in excess of those allowed under any applicable Clean Air Act provisions. Use of the BACT concept is allowable on a case by case basis for major new or modified emissions sources in attainment areas and applies to each regulated pollutant. ${ }^{30}$

Best Demonstrated Technology (BDT) - The technology on which the EPA will base the standards, i.e., application of the best technological system of continuous emission reduction which (taking into account the cost of achieving such emission reduction, and any nonair quality health and environmental impact and energy requirements) the Administrator determines has been adequately demonstrated. ${ }^{31}$

Generally Available Control Technologies (GACT) - The EPA Administrator may elect under certain circumstances to promulgate standards or requirements which provide for the use of generally available control technologies or management practices to reduce emissions of hazardous air pollutants. ${ }^{32}$

20 Public Law 101-549 (104 STAT. 2399) November 15, 1990, (Clean Air Act Amendments of 1990).

so "EPA Glossary of Environmental Terms and Acronym List", OPA-87-017, August 1988.

32 Clean Air Act Amendments of 1990, Section 111 (a)(1)

32 Clean Air Act Amendments of 1990, Section $112(d)(5)$ 
Maximum Achievable Control Technology (MACT) - Emissions

limitations based on the best demonstrated control technology or

practices in similar sources to be applied to major sources

emitting one or more of the listed toxic pollutants."J

Residual Risk - The quantity of health risk remaining after application of the MACT (Maximum Achievable Control Technology). ${ }^{34}$

33 Glossary of Terms - Clean Air Act Amendments of 1990

3A Glossary of Terms - Clean Air Act Amendments of 1990 
APPENDIX B

DECOMMISSIONING CASE STUDIES 


\section{Decommissioning Case Studies}

A Sampling of Actual Decommissioning Case Studies for Review by the Participants in the Workshops that Support the U.S. Nuclear Regulaiory Commission's Enhanced Participatory Rulemaking on Radiological Criteria for Decommissioning

January 1993

U.S. Nuclear Regulatory Commission 


\section{Decommissioning Case Studies}

\section{Introduction}

The Nuclear Regulatory Commission recently initiated an Enhanced Participatory Rulemaking to develop radiological criteria for decommissioning for NRC-licensed facilities. NRC is enhancing opportunities for participation of affected interests on the rulemaking issues before the NRC staff develops the proposed rule. Consistent with this objective, NRC is conducting a series of workshops to solicit commentary from affected interests on the fundamental approaches and issues that must be addressed in establishing radiological criteria for decommissioning. As announced in the Federal Register on December 11, 1992 (57 FR 58727), the workshops will be held in January through May 1993 at seven locations throughout the United States.

In approving the plan for the Enhanced Participatory Rulemaking to develop Radiological Criteria for Decommissioning, the Commission directed the NRC staff to prepare summaries of actual decommissioning cases and provide them to workshop participants as background information. The commission intended the cases to include several types of facilities and cover a range of sites. The objective of providing the cases to the workshop participants was to illustrate the practical aspects of decommissioning facilities with radiological contamination, including examples of cases where decommissioning was hampered by technical, cost, administrative, or other factors.

This paper presents a suite of six case studies to illustrate "real world" decommissioning experiences and make tangible the abstract concepts, such as radiation dose, risk, and monitoring limitations, that lie at the root of the discussions at the workshops. The case studies represent a range of facilities, including a research power reactor, two fuel cycle facilities, two nuclear materials facilities, and a nuclear missile accident site. Two of the facilities primarily involved naturally occurring radioactive materials; the other four primarily involved artificially produced radionuclides. The sites are also distributed geographically in the states of connecticut, New Hampshire, New Jersey, New York, Oklahoma, South Dakota. The sites are summarized in Table 1.

Although not all of the facilities were licensed under the Atomic Energy Act by NRC or an Agreement state, they all illustrate practical aspects of decommissioning nuclear facilities. Three of the facilities are currently licensed by NRC. One of the facilities was licensed by an Agreement state prior to decommissioning, after which the license was terminated. One site was licensed by an Agreement state, but is currently being remediated under the Environmental Protection Agency's (EPA's) 
Superfund Program under the Comprehensive Environmental Response, Compensation, and liability Act. One of the facilities was not licensed and is being remediated under the Installation Restoration Element of the Defense Environmental Restoration Program by the Air Force. Cleanup activities at this site are being monitored by EPA as if the site was in the superfund program.

For each case study, NRC staff has assembled summary information that illustrates specific decommissioning issues. The summaries include brief descriptions of the facility, nature and extent of contamination, decommissioning criteria, decommissioning approach, current status, and lessons learned. Where appropriate, maps and diagrams have been included to provide the reader with a visual image of the extent and nature of decommissioning action. Although more detailed information is available for each site, the case studies have been intentionally kept brief and focused to illustrate generic issues and avold undue attention during the workshops to individual cases.

Table 1. Summary of Decommissioning Case studies

\begin{tabular}{|c|c|c|c|c|}
\hline Name & Location & $\begin{array}{c}\text { Facility } \\
\text { Type }\end{array}$ & $\begin{array}{c}\text { Principal } \\
\text { Radionuclides }\end{array}$ & $\begin{array}{c}\text { Regulatory } \\
\text { status }\end{array}$ \\
\hline $\begin{array}{l}\text { UNC-Naval } \\
\text { Products } \\
\end{array}$ & Montril1e, Cr & $\begin{array}{l}\text { Fued } \\
\text { Paclitey }\end{array}$ & $\begin{array}{l}\text { HLgh Enrlehed } \\
\text { Uranlum }\end{array}$ & $\begin{array}{l}\text { Aetive NRC } \\
\text { LLeenge }\end{array}$ \\
\hline $\begin{array}{l}\text { Rerr-McGeo } \\
\text { Clmarron }\end{array}$ & Crescent, OK & $\begin{array}{l}\text { Fued } \\
\text { Facildey }\end{array}$ & $\begin{array}{l}\text { Low Ensiched } \\
\text { Uranium, } \\
\text { Plutonium }\end{array}$ & $\begin{array}{l}\text { Active NRC } \\
\text { Llcense }\end{array}$ \\
\hline $\begin{array}{l}\text { Pathfinder } \\
\text { Atomic Power } \\
\text { Plant }\end{array}$ & $\begin{array}{l}\text { Sioux Falds, } \\
\text { SD }\end{array}$ & $\begin{array}{l}\text { Research } \\
\text { Power } \\
\text { Reactor }\end{array}$ & $\begin{array}{l}\text { Activation } \\
\text { Producte ( }{ }^{\infty} \mathrm{Co}, \\
\text { oni, ssel }\end{array}$ & $\begin{array}{l}\text { Aet lve NRC } \\
\text { Lleense }\end{array}$ \\
\hline GTE-Sylvania & $\begin{array}{l}\text { Manchester, } \\
\text { NH }\end{array}$ & $\begin{array}{l}\text { Materials } \\
\text { Pacility }\end{array}$ & Thorium & $\begin{array}{l}\text { Terminated } \\
\text { NH II cense }\end{array}$ \\
\hline $\begin{array}{l}\text { Radlum } \\
\text { Chomical } \\
\text { Company }\end{array}$ & Hoodside, $N X$ & $\begin{array}{l}\text { Materialo } \\
\text { racility }\end{array}$ & Radium & $\begin{array}{l}\text { Terminated } \\
\text { NY Iicense: } \\
\text { superfund } \\
\text { site }\end{array}$ \\
\hline $\begin{array}{l}\text { BOMARC } \\
\text { Miseile } \\
\text { Aceident site }\end{array}$ & $\begin{array}{l}\text { Ocean County, } \\
\text { NJ }\end{array}$ & $\begin{array}{l}\text { Nucloar } \\
\text { Heapone } \\
\text { site }\end{array}$ & Plutonium & $\begin{array}{l}\text { Defense } \\
\text { Inctallation } \\
\text { Restoration } \\
\text { Program }\end{array}$ \\
\hline
\end{tabular}

The decommissioning case studies follow. Readers with questions should contact Michael Weber, NRC, Mail Stop 5E4, Washington, DC 20555 or (301) 504-1298. 
Decommissioning Issues

- Technical basis for translating residual contamination into radiological dose and/or risk

- Averaging of residual contamination concentrations over clean soil due to heterogeneous nature of contamination

\section{Facility Description}

The UNC Incorporated (UNC) Naval Products Facility fabricated nuclear fuel for naval reactors at a facility in Montville, CT. Beginning in 1974, the Montville facility made operational discharges of small concentrations of highly enriched uranium to an onsite septic field as an effluent from the liquid radioactive waste treatment facility. These effluents were discharged in accordance with the license for the UNC-Montville facility. Discharge of enriched uranium to the leach field terminated in November 1987, when NRC authorized discharge of the waste water directly to the sanitary sewer system of Montville, CT, which was acceptable because of the low concentrations of the enriched uranium in the effluent.

In March 1990, UNC announced plans to decomnission the Montville facility and terminate their license. UNC-Montville submitted a plan for decommissioning the facility on June 1, 1990. One part of this plan specifically addressed the decomissioning of the formerly used septic leach field. The final revision of the septic leach field decommissioning plan was submitted on May 22, 1992. The site also contains numerous buildings. These are being decommissioned in accordance with the June 10, 1991 decommissioning plan.

\section{Nature and Extent of Contamination}

The septic leach field consisted of two parts. Septic field 1 consisted of 43 4-inch diameter perforated pipes of varying lengths, arranged in parallel 2.5 feet wide by 2.5 feet deep stone-filled trenches, each separated by 5.5 feet of clean soil and buried 3 to 8 feet below the soil surface. Septic field 2 consisted of 2 groups of 6 six-foot diameter perforated concrete drywells spaced in a polygonal pattern approximately 40 feet apart and each surrounded by 2 feet of crushed rock. The size and orientation of septic leach field 1 is illustrated in Figure 1 and septic leach field 2 in Figure 2. Gross alpha concentrations averaged $>100 \mathrm{pCi} / \mathrm{g}$ for samples of the fine-grained material between the stones in the trenches in septic field 1. When averaged over the mass of the stones as well as the fine grained material between the stones, this activity concentration was about $38 \mathrm{pCi} / \mathrm{g}$. Ingrowth of decay products was not significant due to their virtual absence in the original enriched uranium and the limited amount of time since discharge. 
The major regulatory criteria applied to cleanup of the septic leach field included the following:

1. Option 1 Concentration Criteria from the 1981 NRC Branch Technical Position (BTP) on Disposal or Onsite Storage of Thorium or Uranium Wastes from Past Operations (46 FR 52061; October 23, 1981) $30 \mathrm{pCi} / \mathrm{g}$ for enriched uranium.

2. The dose via the groundwater-drinking water pathway was limited to a maximum of $2.3 \mathrm{millirem} / \mathrm{yr}$ Total Effective Dose Equivalent (TEDE), consistent with the dose basis for Option 1 concentrations for enriched uranium in NRC's 1981 BTP (in lieu of EPA's proposed drinking water standard of $4 \mathrm{milli}$ rem/yr EDE or limit of $20 \mu \mathrm{g} / 1$ for uranium $(30 \mathrm{pCi} / 1))$.

UNC proposed a value of $\$ 25,000$ per person-rem averted be used in calculations to show that residual contamination would be as low as reasonably achievable (ALARA), if above the Option 1 concentrations. UNC concluded, however, that the Option 1 criterion in the 1981 BTP would be applied to the site. Therefore, no additional effort was necessary to reduce contamination levels below the Option 1 criterion.

\section{Decommissioning Approach}

UNC removed, packaged, and shipped for off-site disposal all distribution and service pipes, distribution boxes, sludges, and drywell cylinders. UNC also removed the residually contaminated materials in excess of the decommissioning criteria described below. UNC verified compliance with the cleanup criteria using a biased survey of the leach field with sample's taken every $10 \mathrm{~m}$ along the centerline of the exposed trenches. Hotspots were identified and surveyed in a manner consistent with the approach described in NUREG/CR-5849. In determining compliance with the hotspot criteria, the licensee averaged samples along a single horizontal planar surface and not vertically over the trench depths.

To demonstrate compliance with the groundwater protection criteria, the licensee will use the RESRAD dose assessment computer code to estimate potential doses to hypothetical future onsite residents, who could consume potentially contaminated groundwater. The modeling done in support of the groundwater pathway assessment assumed that the total activity in the septic field was distributed over the mass of the septic field (including the clean soil between trenches and drywells).

The decommissioning project for the entire leach field cost approximately $\$ 2,000,000$ dollars and was completed in 12 months. 
The licensee has completed decontamination of the septic field to BTP option 1 levels. The licensee has also completed its termination survey for the leach field. NRC's contractor has performed a confirmatory survey, but the results of this survey have not been received.

\section{Lessons Learned}

The contamination in the leach field existed in a fine-grained matrix between or on the 1.5-inch diameter stone used in the leach field. This raised an issue about whether to allow the stone to constitute part of the mass of the soil samples taken in the field because the interior of the stone was not contaminated. Resolution of this question affected the calculations that translate residual radiological contamination into dose to an potential site resident. In response to the licensee's proposal, NRC decided that the stone should be included in the mass of the sample (thus reducing the concentration of each sample) because it was not reasonable to assume that the fine-textured material would be separated from the stone to any significant degree in reasonable exposure scenarios.

The licensee initially attempted to correlate gross alpha data from the field to uranium concentrations. This did not work because natural background gross-alpha measurements were too variable. In addition, the chemical form of the uranium in the field did not lend itself to the type of gross alpha analytical technique attempted on these samples. Further, the laboratory chosen by the licensee for analysis of soil samples generated gross-alpha values that were consistently lower than measured uranium concentrations, whereas the gross-alpha values should have been greater than uranium concentrations. The licensee expended considerable effort. trying to resolve the apparent disparities between the gross-alpha values and the uranium concentrations. Consequently, the licensee wasted time, money, and effort trying to evaluate the adequacy of the septic field decommissioning using gross-alpha analysis. The licensee ultimately selected a?ternative laboratories and analytical techniques to determine uranium concentrations directly.

Based on this experience, the licensee and NRC learned the following lessons:

- The hotspot criteria in NUREG/CR-5849 are applicable to heterogenous contamination.

- Licensees can complete ALARA analyses in planning decommissioning for various levels of clean-up.

- The adequacy of 1 icensee or contract laboratory Quality Assurance/Quality Control programs for radiological analysis should be confirmed by the licensee, in consultation with NRC, before radiological surveys to ensure that compatible and proper techniques will be used. 


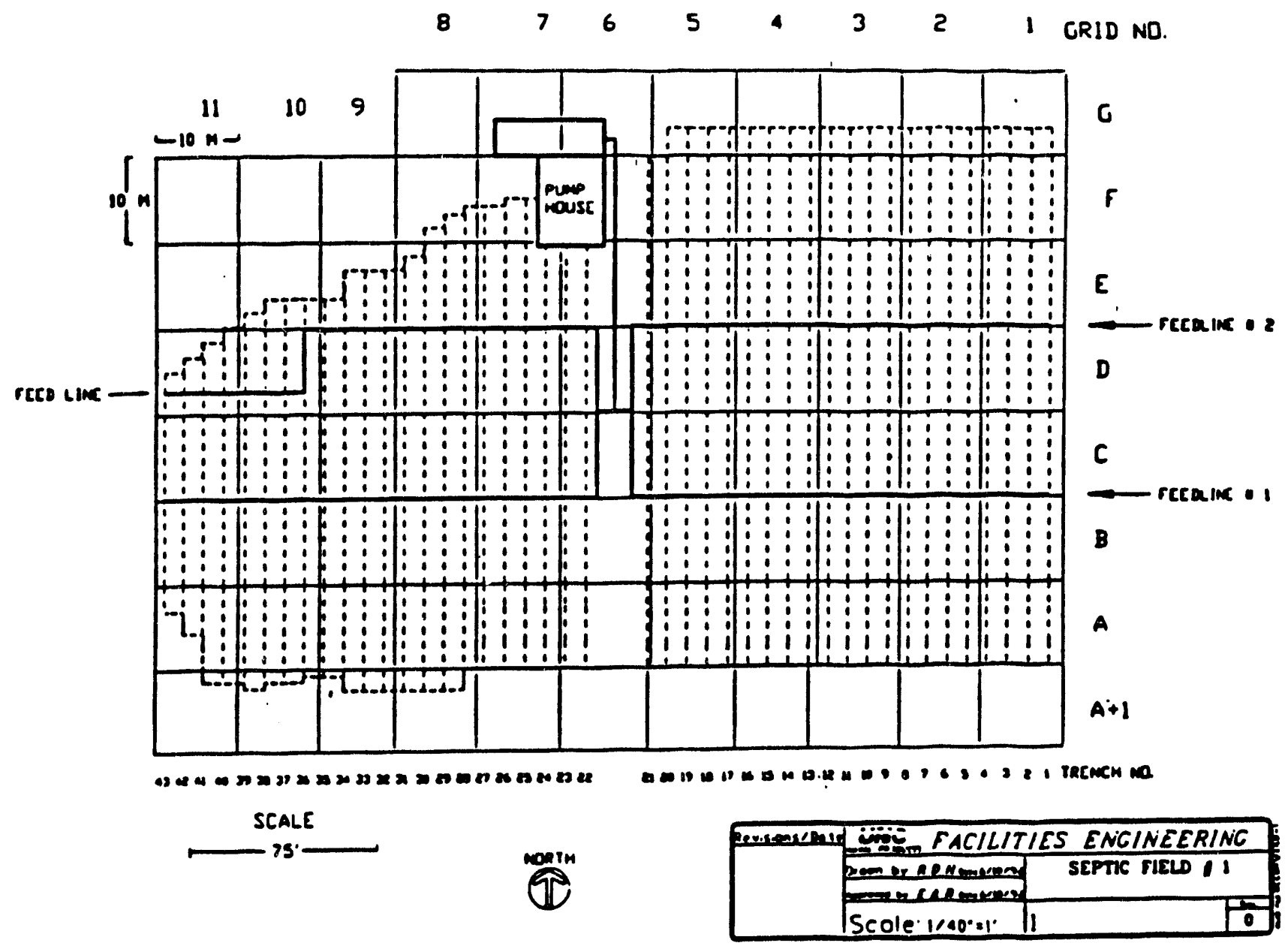

Figure 1. Size and Orientation of Septic Leach Field 1 


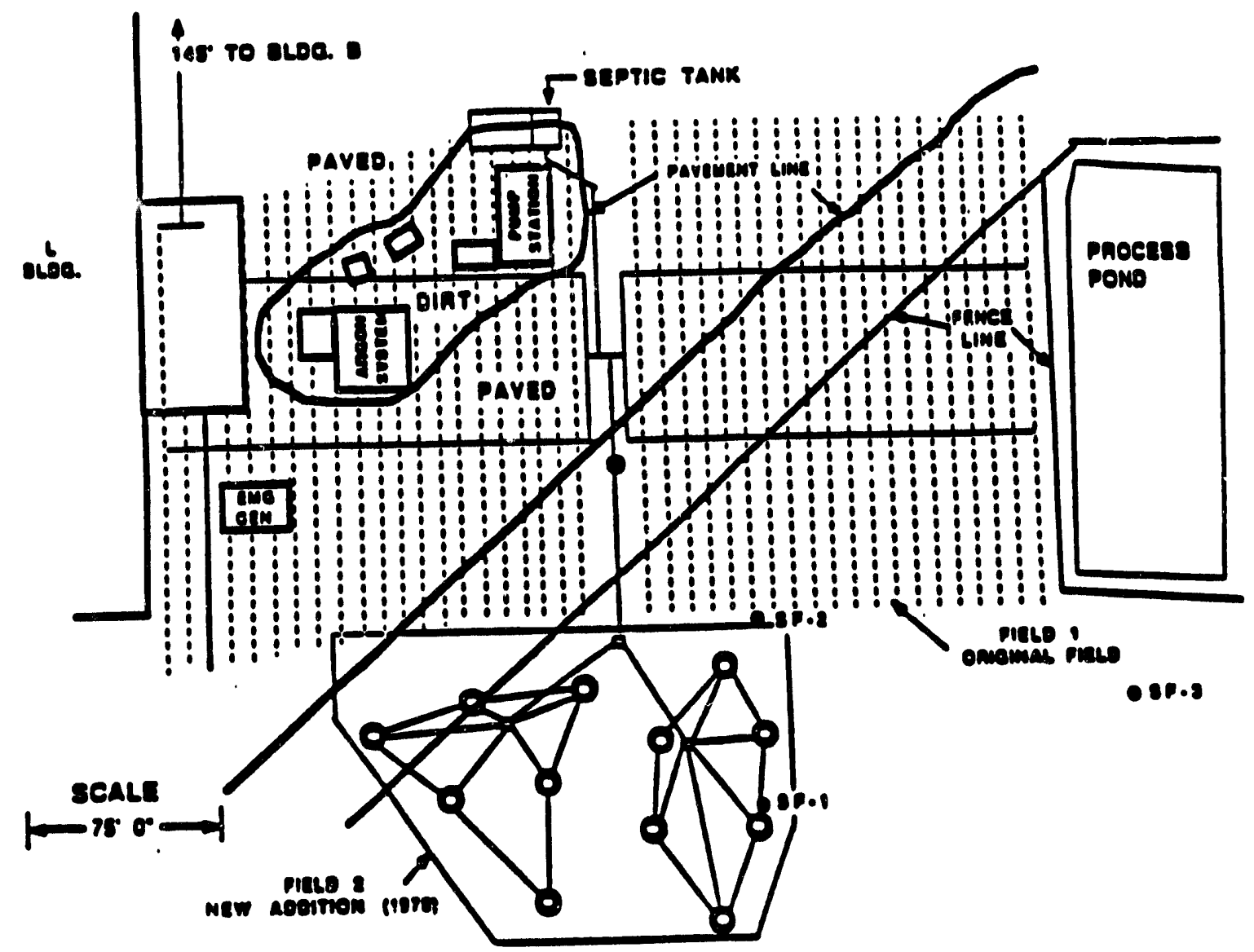

Figure 2. Size and Orientation of Septic Leach Field 2 


\section{Kerr-McGee, Cimarron Plants \\ Crescent, Oklahoma}

Decommissioning Issues

- Technical basis for allowing on-site burials of uranium contaminated soils

- Approach to termination of multiple licenses

- Appropriate time period for dose calculations

\section{Eacility Descriotion}

Kerr-McGee operated two fuel fabrication plants, one for mixed-oxide fuels and one for low-enriched uranium fuels, near Crescent, Oklahoma. The 1100-acre site is located in a rural part of central Oklahoma, 30 miles north of Oklahoma City, in a farming area. The Cimarron site is listed in the NRC's Site Decommissioning Management Plan.

In addition to the two fuel fabrication plants on the site, the licensee operated several waste-water treatment settiing ponds and a burial area (for burials previously allowed under 10 CFR 20.304), which were licensed as part of the uranium plant. Both buildings were contaminated with uranium and plutonium. The settling ponds are contaminated with uranium, while the burial areas (two additional areas recently discovered) contain uranium and trace amounts of thorium from waste disposals associated with offsite activities. Fuel fabrication operations at both plants were terminated in 1975. Major contaminated facilities include the plutonium plant $\left(\sim 26,000 \mathrm{ft}^{2}\right)$, the uranium plant $\left(-60,000 \mathrm{ft}^{2}\right), 3$ waste-water treatment settling ponds, and waste burial areas. There were also five previous waste water treatment ponds; these ponds were closed in 1977 and 1978.

\section{Nature and Extent of Contamination}

Decontamination of the mixed oxide facility began in 1979, and in 1989, an NRC contractor completed a confirmatory survey that demonstrated that this facility met decommissioning guidelines. No plutonium contamination has been identified outside of the mixed oxide building. The yard outside this facility is contaminated with small concentrations of uranium from the nearby uranium plant. Cimarron Corporation submitted a request for license termination for this facility in August 1990, followed by a request in November 1990 to allow renovations in order to facilitate non-nuclear operations, which NRC approved.

The soil around the uranium plant and the uranium plant building are contaminated with low-enriched uranium (ranging from 2 to 9.1 percent ${ }^{235} \mathrm{U}$ ). Soll in the settling ponds and the burial grounds are also contaminated with uranium with concentrations generally in the range of 30 to $100 \mathrm{pCi} / \mathrm{g}$ of about 
1.3 percent average enrichment. Although a known burial area was exhumed and resulting wastes shipped offsite for disposal, other apparent 10 CFR 20.304 burials exist at the site. In addition, elevated uranium concentrations were documented in samples taken during the closure of the five former waste water ponds at the site. The waste-water treatment lagoons also contain chemical contamination (primarily nitrate contamination $\left(\mathrm{NO}_{3}\right)$ ). Groundwater in one area of the site is also contaminated with uranium and non-radiological constituents (e.g., $\mathrm{NO}_{3}$ ).

About $400,000 \mathrm{ft}^{3}$ of soil contaminated with enriched uranium with concentrations averaging $70 \mathrm{pCi} / \mathrm{g}$ in the top 1 to 2 feet of the ground surrounding the processing buildings. Samples rom the closed ponds indicated that appreciable portions of the bottoms of two ponds consisted of contaminated soils in the range of 300 to $400 \mathrm{pCi} / \mathrm{g}$ uranium prior to tilling, which occurred at the time of closure of the ponds. Consequently, concentrations of uranium in the bottom sedimen'ts would now be expected to be lower due to mixing of the contaminated material with clean sediments during tilling.

\section{Decommissioning Criteria}

The major regulatory criteria applied during decommissioning include the following:

1. Guidelines for Decontamination of Facilities and Equipment Prior to Release for Unrestricted Use or Termination of Licenses for Byproduct, Source, or Special Nuclear Material, July 1982 (An Enclosure to Policy and Guidance Directive FC 83-23)

2. Acceptable Soil Contamination Levels, Enclosure 3 to Policy and Guidance Directive FC 83-23, November 4, 1983

3. Option 2 Concentration Criteria from the 1981 NRC Branch Technical Position (BTP) on Disposal or Onsite Storage of Thorium or Uranium Wastes from Past Operations (46 FR 52061; October 23, 1981) -- for enriched uranium, the criterion is $100 \mathrm{pCi} / \mathrm{g}$ (soluble), $250 \mathrm{pCi} / \mathrm{g}$ (insoluble)

The first group of criteria defined acceptable surface contamination levels on building surfaces; the second group of criteria were applied to the soils surrounding the buildings. The soil criteria were consistent with the criteria in the 1981 BTP and included a value of $25 \mathrm{pCi} / \mathrm{g}$ for total plutonium. The BTP was applied to a proposed onsite burial of soil contaminated with uranium in accordance with 10 CFR 20.302.

\section{Decommissioning Aporoach}

Kerr-McGee has finished decontaminating the plutonium plant under an NRCapproved decommissioning plan. At the uranium plant, Kerr-McGee has excavated and shipped for disposal the contents of the initialiy-identified burial area and has continued decontaminating the building. The licensee has surveyed the soil around the building to detect uranium contamination and submitted a 
request for authorization (pursuant to 10 CFR 20.302) to dispose of $400,000 \mathrm{ft}^{3}$ of uranium-contaminated soil onsite under Option 2 of the 1981 BTP. Staff has estimated that an on-site disposal would reduce decommissioning costs by $\$ 10$ million or more due to the avoidance of costs for disposing of the contaminated soil offsite. The proposed burial also has the advantage of reducing radiation exposure to remediation workers. The licensee's evaluation of the potential for future groundwater contamination beneath the site concluded that it was unlikely for any uranium to reach groundwater in a well located immediately adjacent to the burial area within 1000 years due primarily to the retardation of the uranium by the bedrock at the site.

\section{Current Status}

- NRC termination of the license for the mixed oxide facility is pending

- Termination of the license for the uranium fuel facility is dependent upon proper completion of the following steps:

- Adequate site characterization

- Authorization of onsite disposal in accordance with 10 CFR 20.302

- Decontamination of the building and adjacent solls in accordance with existing criteria

\section{Lessons Learned}

- Limited characterization of the extent and distribution of contaminated material at the site complicated decommissioning

- Prudent measures to reduce the likel ihood of human exposure to the contamination and other prescribed conditions on disposal of contaminated soil may be perceived as being inconsistent with the "unrestricted use" standard for decommissioning 


\section{Northern States Power \\ Pathfinder Atomic Power Supply \\ Sioux Falls, South Dakota}

Decommissioning Issues

- Technical basis for the release of residual contamination on building surfaces containing gamma-emitting radionuclides

- Advantages and disadvantages of phased decommissioning approaches

Facility Description

The Pathfinder Atomic Power Plant was a 66 Megawatt-electric ( 200 Megawattthermal) boiling water reactor operated by Northern States Power (NSP) on a site 5.5 miles northeast of Sioux Falls, South Dakota. The plant ceased operations in September 1967. The fuel was removed from the site and the facility was placed in a Safe Storage (SAFSTOR) condition in 1971. At that time, NSP decontaminated portions of the facility by reducing surface activity and filling the reactor vessel with gravel. About $3,000 \mathrm{ft}^{3}$ ( 400 drums) of radioactive waste were generated in this decontamination effort and shipped offsite for disposal. NSP stored contaminated equipment and piping that was too large to be drummed in the reactor building and spent fuel pool. As a part of the SAFSTOR program, contaminated equipment and material was transferred to a byproduct materials 1 icense in August 1972 and the operating reactor license was terminated. NSP installed non-nuclear boilers in the facility and continued to generate electricity until the present using the plant's turbine generator.

\section{Nature and Extent of Contamination}

Because of Pathfinder's limited operating history (e.g., about 80 days) and lack of any identifiable nuclear fuel leaks during operation, radioactive contamination levels were relatively low and caused only by neutron

activation. The primary radionuclides were ${ }^{60} \mathrm{Co},{ }^{63} \mathrm{Ni}$, and ${ }^{55} \mathrm{Fe} ;{ }^{60} \mathrm{Co}$ dominated in terms of radiological significance. Total activity prior to removal of the reactor pressure vessel was about 563 Curies (Ci), all but $0.044 \mathrm{Ci}$ of which was contained in the pressure vessel and jts internal hardware. Decommissioning generated about $34,450 \mathrm{ft}^{3}$ of waste containing essentially all of the $563 \mathrm{Ci}$. Figure 1 depicts a cross-section of the reactor and fuel handling buildings. Figures 2 and 3 depict the extent of surface contamination within the reactor and fuel handling buildings, respectively.

\section{Decormissioning Criteria}

The criteria used for unrestricted release of the reactor building and fuel handling building were the acceptable surface contamination levels stated in Table 1 of Regulatory Guide 1.86, Termination of Operating Licenses for Nuclear Reactors. The NRC applied an additional criterion that gamma exposure 
rates measured one meter from the building surfaces shall not exce $f 5 \mu R / h r$ above background.

\section{Decommissioning Approach}

NSP initiated final dismantlement and decontamination activity in the late 1980s. In 1990, NSP removed and shipped the reactor vessel intact along with other waste to the low-level radioactive waste disposal facility in Richland, Washington by rail and truck. Dismantlement also included partial demolition of the reactor building (the lower portion of the concrete containment structure will be buried in place) and decontamination of portions of the fuel handling building. The project caused a total estimated exposure to workers of about 4 person-rem and required about one year to complete. Total cost of the decommissioning action was about $\$ 13$ million.

NSP set action levels for contamination below the criteria in Regulatory Guide 1.86 during the radiological survey. Any scan exceeding the criteria triggered additional direct contamination measurements. Those areas exceeding the criteria were decontaminated and resurveyed. Final survey of the site showed that nearly all the areas were remediated to levels less than the "best estimate" of local background radiation.

Some contamination remains in the turbines that are still being used to generate electricity at the plant in conjunction with the non-nuclear boilers. This contaminated equipment will remain at the site under the control of the licensee until it has been properly removed and disposed of or decays below acceptable contamination criteria.

\section{Current Status}

- NRC approved release of the Reactor Building, Fuel Handling Building, and laste Storage Building for unrestricted use in November 1992

\section{Lessons Learned}

- Remediation and measurement technology for surface contamination is readily available and implementable 


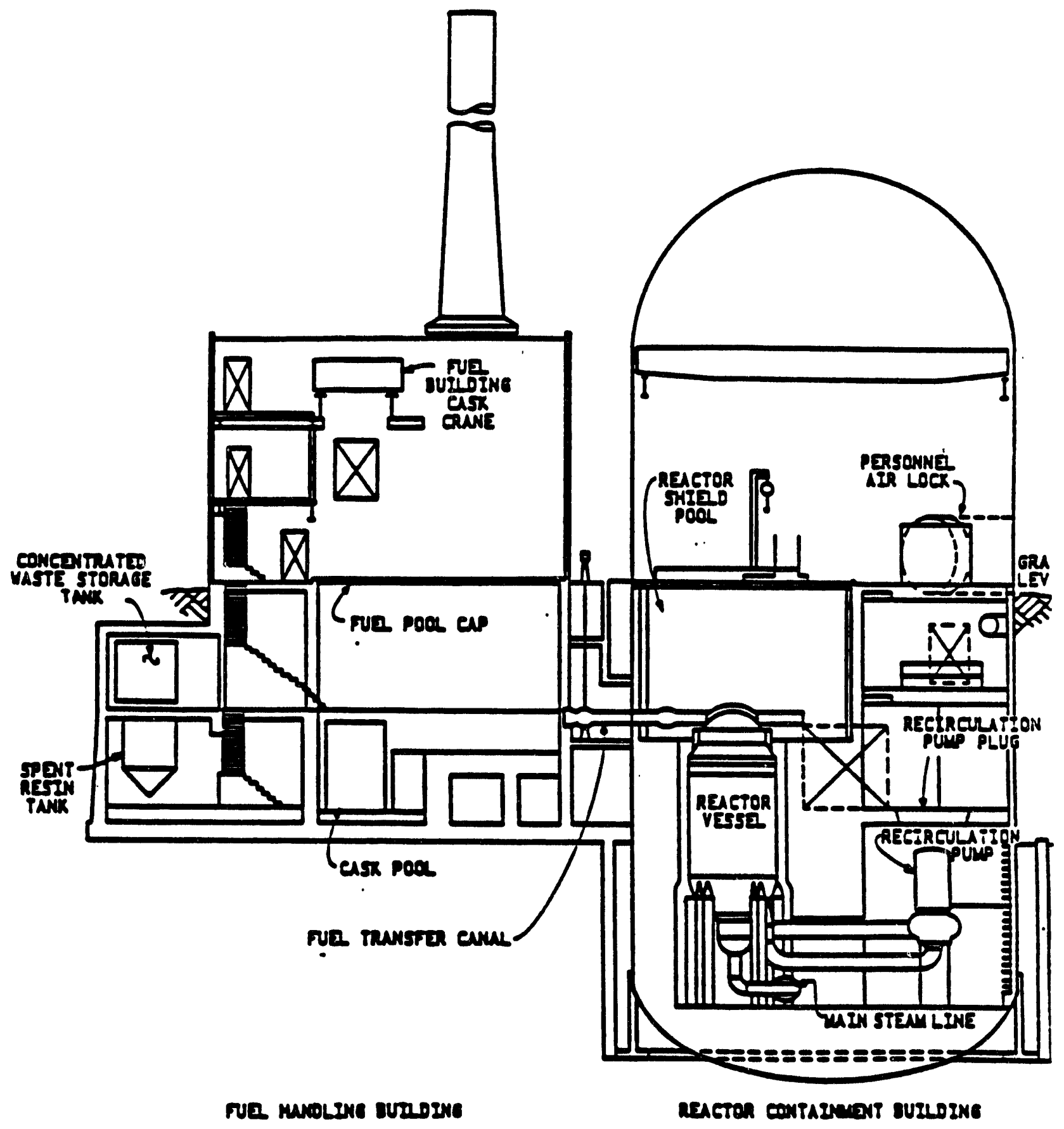

Figure 1. Cross-Section of the Reactor and Fuel Handling Buildings (Ref: Pathfinder Plant Decommissioning Plan, Northern States Power, 1989) 


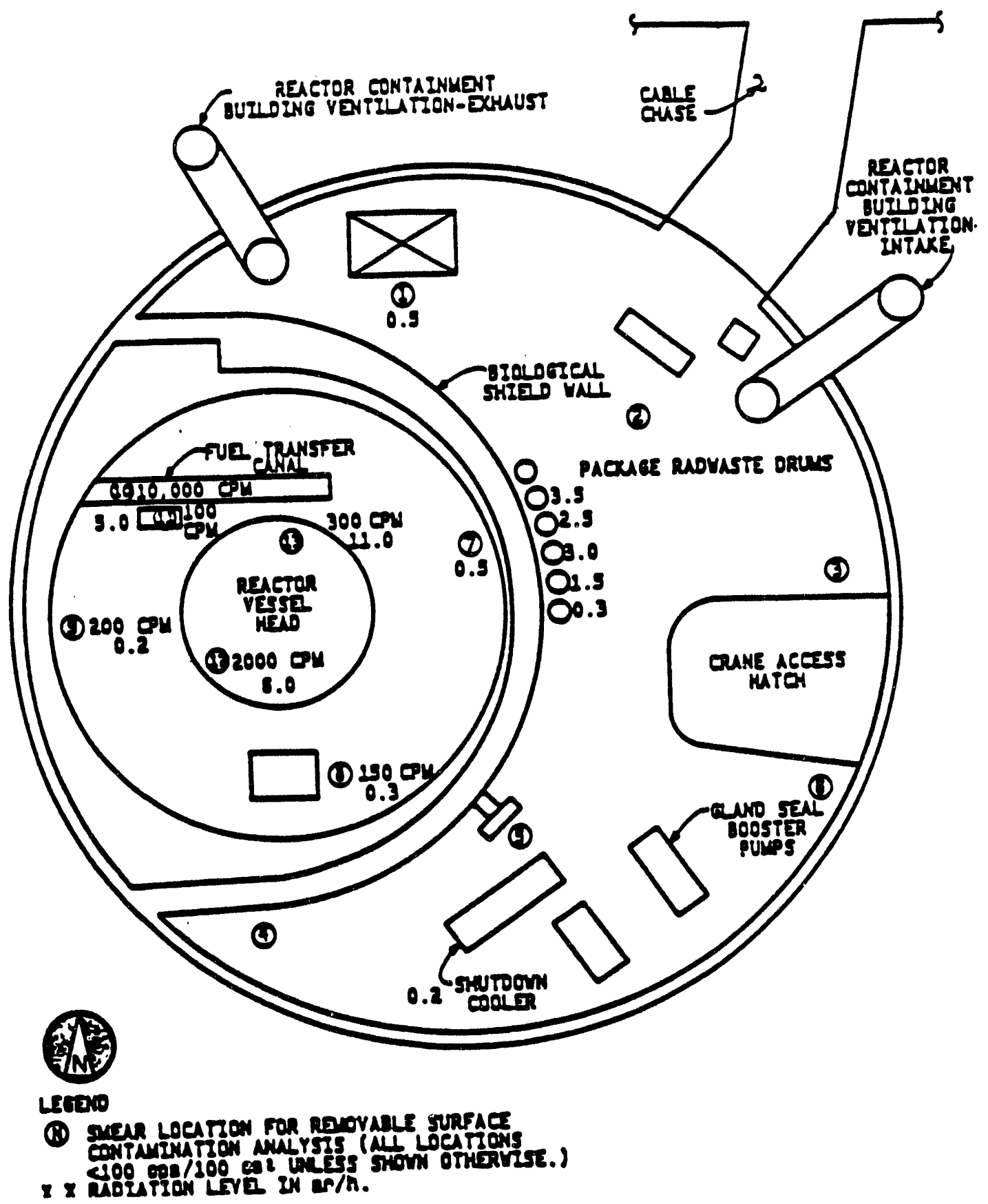

Figure 2. Contamination survey of the Reactor Building at the Equipment Floor Level (Ref: Pathfinder Plant Decommissioning Plan, Northern States Power, 1989) 


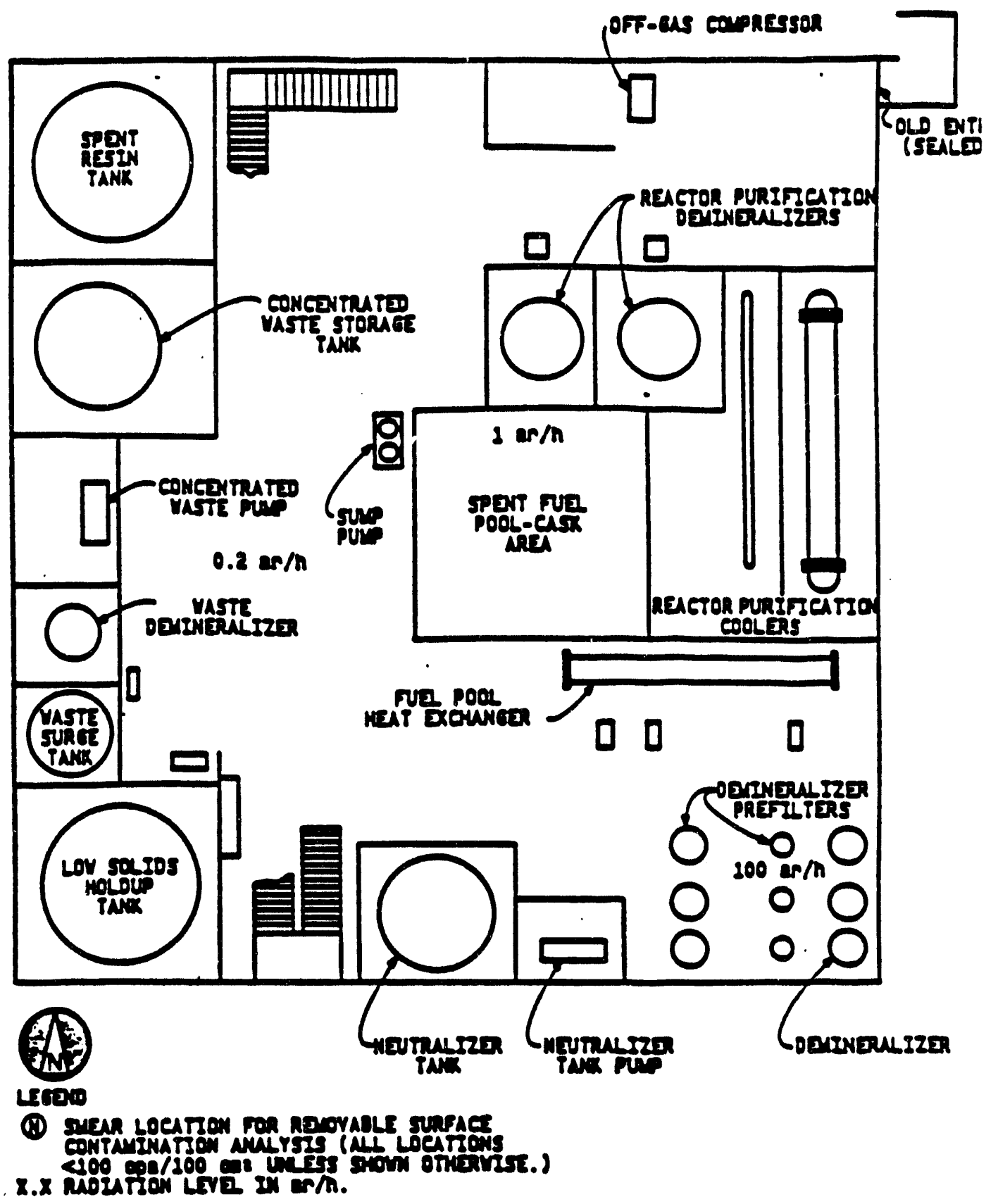

Figure 3. Contamination survey of the Fuel Handling Building at the Basement Level (Ref: Pathfinder Plant Decommissioning Plan, Northern States Power, 1989) 


\section{GTE/Sylvania \\ Manchester, New Hampshire}

Decommissioning Issues

- Long-term reliance on institutional controls for limiting exposure to residual radioactive materials

\section{Eacility Descriotion}

GTE/Sylvania was licensed by the Atomic Energy Commission in 1965 to use thorium dioxide in coating electrodes for high-intensity light bulbs. These operations were conducted at a manufacturing plant in an industrial area in Manchester, New Hampshire. The thorium was suspended in methanol and vacuumdeposited on the electrodes, which were then cleaned and fired at high temperatures to fuse the coating into a ceramic solid. The electrodes were then encapsulated in gas-tight, fused, silica capsules. GTE/Sylvania continued this process until February 1986, when the facility initiated decommissioning of the thorium operation. The site was licensed by the State of New Hampshire from 1966 until the license was terminated at the conclusion of decommissioning in July 1991.

\section{Nature and Extent of Contamination}

Prior to decommissioning, contamination consisted of processed thorium oxide dust ( ${ }^{232} \mathrm{Th},{ }^{223} \mathrm{Th}$, and some decay products) distributed throughout three rooms (light room, chemistry laboratory, and high temperature furnace room (with two high temperature furnaces)). Other contaminated areas included soil beneath a waste storage area, an underground settling tank, and electrical cables and five conduits inside an underground electrical vault. The settling tank was 7.5 feet high with a diameter of about 8 feet and contained about 1 foot of thorium sludge in the bottom. The electrical vault was $5 \times 5 \times 8$ feet and contained about 1.5 feet of thorium sludge on the bottom. Contamination in the settling tank and electrical vault was discovered late in the process of decommissioning; contamination within the electrical vauit was not anticipated because it was not involved in the processing or application of the thorium.

About 600 millicuries of thorium was removed during decommjssioning; the decommissioning project generated a total of about $3800 \mathrm{ft}^{3}$ of low-level radioactive waste, which was sent offsite to a licensed low-level waste disposal facility. Contamination on the surface of the electrical cables three feet underground feeding the electrical vault was about 22,000 disintegrations per minute (dpm) beta-gamma per $100 \mathrm{~cm}^{2}$. After covering with plastic to contain any removable contamination, the surface activity was lowered to about $14,000 \mathrm{dpm} / 100 \mathrm{~cm}^{2}$. The conduit entrances measured up to $9600 \mathrm{dpm}$ direct beta-gamma/100 $\mathrm{cm}^{2}$. Soils beneath the waste storage area are contaminated with thorium up to $500 \mathrm{pCi} / \mathrm{g}$. 
Decommissioning Criteria

The major regulatory criteria applied to cleanup of the GTE/Sylvania included the following:

1. Acceptable surface contamination levels from New Hampshire's "Permissible Levels of Surface Contamination" of $170 \mathrm{dpm} / 100 \mathrm{~cm}^{2}$ (removable), $850 \mathrm{dpm} / 100 \mathrm{~cm}^{2}$ (average fixed) contamination, and $2450 \mathrm{dpm} / 100 \mathrm{~cm}^{2}$ (maximum fixed) surface contamination.

2. Option 4 Concentration Criteria from the 1981 NRC Branch Technical Position (BTP) on Disposal or Onsite Storage of Thorium or Uranium Wastes from Past Operations (46 FR 52061; October 23, 1981) $500 \mathrm{pCi} / \mathrm{g}$ for natural thorium.

Decommissioning Approach

When decommissioning of this site began in June 1986, it was expected to be a routine, short-term project. The original goal of the project was to release the site for unrestricted use (i.e., remove and dispose of all thorium contamination to release the site without restriction because of the presence of radioactive material). Decommissioning was significantly complicated, however, by the discovery of the contaminated settlement tank and electrical vault and by proposed reliance on institutional controls to restrict long-term access to contaminated soll beneath the waste storage area. Most of the excavation and radiological survey work was completed by April 1988. The license for the facility was terminated in July 1991.

Decommissioning activities included the following: a detailed characterization survey; removal and packaging of contaminated equipment; dismantling and packaging of entire section of the plant (two chemistry labs, a hallway, two exterior walls, and roof); removal of High Efficiency Particulate (HEPA) filter; cleanup of the surface of the waste storage area; removal of over 100 feet of contaminated pipe; decontamination of the setting tank and electrical vault; decontamination of two high temperature furnaces; soil sampling; entombment of contaminated soil; shipping all waste to lowlevel radioactive waste disposal facility; final termination survey; and amendment of property deed placing restrictions on long-term use of the contaminated waste storage area.

The licensee stabilized the contaminated soil in place, posted area markers warning of the radioactive contamination, and placed restrictions in the deed rather than to excavate and dispose of the thorium-contaminated soil in the waste storage area and adjacent to the settling tank. A portion of the contaminated 1 and extends beneath the floor of a machine shop. The licensee argued that removal of the contaminated tank and adjacent soils would have been nearly impossible and would have required the demolition of a loadbearing wall and foundation slab. Such demolition and associated waste disposal would have been prohibitively expensive for the licensee. In response to a technical assistance request from the State of New Hampshire, NRC reviewed the proposal to stabilize the soil in situ. Although NRC indicated that it would be more protective and, in the long run, more 
economical to remove the contaminated solls during decommissioning, NRC indicated that in situ disposal of the thorium-contaminated soils would be acceptable under existing NRC guidance. NRC's 1981 Branch Technical Position (BTP) on Disposal or Onsite Storage of Thorium or Uranium Wastes from Past Operations (46 FR 52061; October 23, 1981) allowed disposal of contaminated solis under Option 4 up to $500 \mathrm{pCi} / \mathrm{g}$ for natural thorium with appropriate deed restrictions in areas zoned for industrial use only.

Consistent with Option 4 of the 1981 BTP, the licensee amended the deed to prohibit (1) excavation below 1 foot without prior approval and

(2) construction or occupation of residential or industrial structures or for agricultural purposes. The restricted area has a surface area of

approximately 1.3 milition $\mathrm{ft}^{2}$ and includes (1) contaminated subsurface solls outside the building in the waste storage area, (2) contaminated subsurface solls surrounding the burled settling tank, and (3) contaminated electrical cables and conduits in the burled electrical vault. The licensee estimated a worst case annual dose to an inadvertent intruder of about 770 millirem whole body dose above background in the event the person disregarded the area markers and deed restrictions and occupied the site of the contaminated soil for about 19 hours per day.

\section{Current Status}

- The State of New Hampshire terminated the license for the site on July 30, 1991

\section{Lessons Learned'}

- Non-radiological hazards (high voltage) and excavation impacts sometimes may preclude decontamination efforts

- The decommissioning process was hampered by a lack of specific guidance and regulations for acceptable soil contamination limits

- Smaller Agreement State programs may not have sufficient technical expertise to regulate complicated decommissioning projects

- Use of surrogate radionuclide $\left({ }^{228} \mathrm{Ac}\right.$ for $\left.{ }^{232} \mathrm{Th}\right)$ in situations where secular equilibrium does not exist needs to be validated on a sitespecific basis

'Based on "Decontamination and Decommissioning of Thorium Dioxide Manufacturing Plant," Dennis P. O'Dowd, New Hampshire Department of Public Health Services, Presentation to the Conference of Radiation Control Program Directors Annual Conference, May 1988. 


\section{Radium Chemical Company" \\ Woodside, New York}

Decommissioning Issues

- Radon exposures associated with residual radioactive material

- Disposal of low activity waste from decommissioning in sanitary landfills

\section{Eacility Description}

The Radium Chemical Company site consists of a one-story brick building located in a light industrial section of Woodside, Queens County, New York. The Radium Chemical Company (RCC) produced luminous paint containing ${ }^{226} \mathrm{Ra}$ beginning in 1913 and later manufactured, leased, and sold ${ }^{226} \mathrm{Ra}$ sources to hospitals, medical centers, and research laboratories. The radium sources were stored on-site in lead containers in a poured concrete vault. Following closure of operations in 1983, RCC abandoned the building leaving behind radium sources, contaminated containers and labware, along with building and soil contamination. From 1988 to 1989 , EPA undertook limited emergency removal actions under Superfund to secure the facility and remove radioactive sources.

The site was added to the National Priorities List for remediation under Superfund based on a health advisory issued by the Agency for Toxic Substances and Disease Registry in November 1989. The primary current radiological concern involves radium-contaminated building surfaces and components, hazardous wastes, and soil. Present and future potential exposures are primarily associated with direct gamma exposure and exposure via ingestion/inhalation within the facility.

\section{Nature and Extent of Contamination}

The one-açre site houses a one-story prick building with a floor area of $10,000 \mathrm{ft}^{2}$. RCC leased about $7220 \mathrm{ft}^{2}$ of the building. A detailed survey indicated 19 hotspots with elevated dose rate readings, including 15 hotspots in the source vault. A hotspot is defined in this project as an area that measures more than:

(1) $10 \mathrm{milli} \mathrm{rem} / \mathrm{hr}$ at a distance of $1 \mathrm{~cm}$ from the surface,

(2) 100,000 disintegrations per minute (dpm) per $100 \mathrm{~cm}^{2}$ of removable alpha contamination, or

(3) $250,000 \mathrm{dpm}$ per $100 \mathrm{~cm}^{2}$ removable beta contamination.

The highest hotspot inside the source vault measures $200 \mathrm{millirem} / \mathrm{hr}$ at $1 \mathrm{~cm}$. The maximum surface contamination within the source vault was $847,000 \mathrm{dpm} / 100$ $\mathrm{cm}^{2}$ of removable beta contamination. The higheșt removable beta contamination outside the source vault was $483,000 \mathrm{dpm} / 100 \mathrm{~cm}^{2}$. 


\section{Decommissioning Criteria}

The objective of the remediation is to reduce contamination to a level that will permit release of the site for unrestricted use without generating an excessive amount of radium waste in the process. The criteria to be applied in this remediation include the following:

(1) EPA's $5 \mathrm{pCi}{ }^{226} \mathrm{Ra} / \mathrm{g}$ standard for contaminated soils and materials (based on EPA standards for uranium mill tailings cleanup in 40 CFR Part 192),

(2) EPA's $4 \mathrm{pCi} / 1$ action level for ${ }^{222} \mathrm{Rn}$ in indoor air,

(3) Gamma exposure rate no greater than $20 \mu \mathrm{R} / \mathrm{hr}$ above background (based on 40 (FR Part 192 and EPA guidance), and

(4) Acceptable surface contamination levels from NRC's Regulatory Guide 1.86 for removable, and maximum and average surface activity.

\section{Decommissioning Approach}

EPA considered 4 alternative remedies to cleanup the contamination at the RCC site, including: (1) no action, (2) total decontamination of the facility (e.g., building surfaces, underground piping, sewer lines, and soil) and disposal of radioactive waste offsite, (3) complete dismantling and removal of the contaminated material and its disposal at a radioactive waste disposal facility, and (4) partial decontamination and dismantling of the facility. EPA selected Alternative 4 with the objective of releasing the site for unrestricted use. This alternative provides the best balance of time for completion, volume of contaminated waste, risk to workers, state and public acceptance, and cost.

EPA conducted partial decontamination by first removing hot spots contaminated with ${ }^{226} \mathrm{Ra}$ to reduce worker exposure and the risk of spreading contamination during dismantling. Building masonry with ${ }^{226} \mathrm{Ra}$ concentrations less than $5 \mathrm{pCi} / \mathrm{g}$ was disposed of in a sanitary landfill to reduce the volume and cost of waste disposal in a radioactive waste disposal facility. Although the New York State Department of Labor prohibits disposal of wastes containing more than $0.1 \mathrm{PCi} / \mathrm{g}{ }^{226} \mathrm{Ra}$ in a sanitary landfill or as in situ soil, the agency agreed to waive the requirement due to the technical difficulty in achieving this level because of background levels and the substantial increase in cost associated with disposal of such wastes at licensed disposal facilities.

EPA then dismantled and removed contaminated material, in sequence, from (1) the building interior; (2) roof, windows, and doors; and (3) residual masonry. Contaminated soil above the criteria was excavated and shipped to the Envirocare facility in Tooele County, Utah, or acceptable alternative facility. The projected cost to remediate the site was $\$ 18,699,000$ and required more than two years to complete. 


\section{Currerit Status of Site}

Decontamination and dismantlement of the site is essentially complete. EPA is currently investigating contamination of a sewer 1 ine at the site and assessing the associated extent of contamination and risk. If the risk is excessive and removal can be justified, EPA may excavate the sewer Iine and any associated contamination soil and dispose of it consistent with the criteria used in the rest of the project. EPA may also consider applying supplemental standards in evaluating the contaminated sewer line.

\section{Lessors Learned}

- It was difficult to identify and select appropriate cleanup criteria for the site that satisfied all parties; the delays caused by this difficulty significantly complicated conduct of the remedial action

- Selection of cleanup criteria was complicated by the fact that the lifetime cancer risk from background radiation at the site (in excess of $10^{-3}$ ) exceeded EPA's acceptable risk range in the Superfund Program $\left(10^{-4}\right.$ to $10^{-6}$, with $10^{-6}$ as the point of departure)

- Selection of cleanup criteria was complicated because a suitable methodology did not exist for translating acceptable cleanup criteria for groundwater contamination to soil concentrations

- NRC Regulatory Guide 1.86 has only limited applicability in the remediation because it applies to surface contamination only and its values were not determined on a consistent dose or risk basis 


\section{BOMARC Missile Accident Site McQuire Air Force Base Ocean County, New Jersey}

\section{Decommissioning Issues}

- Dependence of preferred remedial action on the availability of affordable waste disposal capacity

- Relationship between the volume of contamination and the cost of the decommissioning action

- Viability of long-term institutional controls to restrict access to contaminated materials

\section{Eacility Description}

Boeing Michigan Aeronautical Research Center (BOMARC) Missile Site was an active defensive nuclear missile installation from 1958 until 1972. The facility housed missiles equipped with nuclear warheads on a 218 acre site in south-central New Jersey about 18 miles southeast of Trenton (see Figure 1). On June 7, 1960, a fire occurred in one of the onsite shelters housing a missile. The shelter, missile, missile launcher, and warhead were partially consumed by fire. Weapons grade plutonium (WGP) from the nuclear warhead was dispersed to solis and structures in the immediate vicinity of the missile sheiter. The material was dispersed by the fire itself as well as the 30,000 gallons of water applied to control the fire for approximately 15 hours. The Air Force reports that no more than 300 grams of WGP was unaccounted for at the time of the accident. Soon after the accident the Air Force fixed the residual contamination in place by applying fixative paint, concrete, and asphalt over the contaminated areas, including the drainage ditch that conducted contaminated runoff during the accident.

The site is being cleaned up by the Air Force under the Installation Restoration Program Element of the Defense Environmental Restoration Program. The Environmental Protection Agency (EPA) is monitoring cleanup activities at the site in a manner similar to a Superfund site cleanup. The Air Force signed a Record of Decision selecting the preferred remedial action in November 1992.

\section{Nature and Extent of Contamination}

No concentrations of radionuclides attributable to the missile accident were detected in groundwater, surface water, or air at the site. The contaminants of concern ( ${ }^{259} \mathrm{Pu}$ and ${ }^{261^{\circ}} \mathrm{Am}$ ) have been detected in numerous radiological surveys in site soils, sediments, missing missile launcher, and structural materials at the site. ${ }^{240} \mathrm{Pu},{ }^{24} \mathrm{Pu}$, and ${ }^{236} \mathrm{Pu}$ will also be present, but at less significant concentrations. The contamination in the soll appears to be 7 imited to the uppermost foot of soil and is concentrated in discrete "hot spots." The soil contamination does not appear to have migrated vertically 
downward more than a few inches since the accident. Surface activity surveys of the missile shelter and utility bunkers indicated alpha surface activities up to 80,000 counts per minute per $100 \mathrm{~cm}^{2}$. Cores through the concrete floor of the missile shelter indicate plutonium levels within the concrete as high

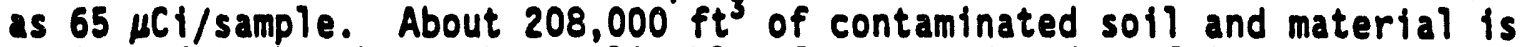
estimated to be above the applicable cleanup criteria, although additional material may be discovered during the course of excavation and remediation (see Figure 2). For example, the missing missile launcher and shelter doors may have been disposed of onsite and would likely be removed during remediation.

\section{Decomissioning Criteria.}

The Air Force developed a site-specific cleanup standard for Pu in soil assuming that people may live on the site at some time in the future. The cleanup standard of $8 \mathrm{pCi} / \mathrm{g}$ of ${ }^{230} \mathrm{Pu}$ was calculated using the computer code RESRAD based upon a lifetime risk objective of $10^{-4}$ cancer risk consistent with current EPA guidance for the Superfund program. The Air Force also proposes to apply the criteria for acceptable surface activity from NRC's Regulatory Guide 1.86 for remediation of the missile shelter, utility bunker, and other structures contaminated on their exterior surfaces. For aipha contamination, these criteria would be $<20 \mathrm{dpm} / 100 \mathrm{~cm}^{2}$ removable activity, $<300 \mathrm{dpm} / 100 \mathrm{~cm}^{2}$ maximum fixed activity, and $<100 \mathrm{dpm} / 100 \mathrm{~cm}^{2}$ average fixed activity.

\section{Decommissioning Approach}

The Air Force considered five alternative remedial actions for the contamination: (1) unrestricted access, (2) institutional control, (3) institutional control with removal of specific materials (e.g., missile launcher), (3) onsite treatment of soils and structures and disposed of contaminated material off site in a radioactive waste disposal facility, and (5) removal of all contaminated material above criteria for offsite disposal at a radioactive waste disposal facility. The Air Force selected Alternative *5 (Offsite disposal) because it was cost-effective, permanent, and environmentally preferred. This alternative includes

- Excavation of contaminated soils containing greater than $8 \mathrm{pCi} / \mathrm{g}$ of Pu

- Excavation and sectioning of contaminated portions of the concrete apron, utility bunkers, and missile shelter

- Excavation and removal (if found) of the missile launcher

- Containerization, transport, and disposal of contaminated materials in an off-site radioactive waste disposal facility operated by the Department of Energy (DOE)

- Restoration of the site by backfilling with clean fill, grading, and revegetation. 
The cost of the preferred remedial action is $\$ 7$ million if disposal is allowed at a DOE disposal facility; commercial disposal would increase the cost to at least $\$ 24$ million.

The Air Force's selection of the preferred alternative is contingent on its cost-effectiveness. If it becomes no longer cost-effective, the Air Force proposes to retain institutional control over the contaminated area, thereby eliminating the only significant route of exposure. This alternative includes monitoring, maintenance, and access control actions currently being conducted at the site.

\section{Current Status of Site}

The Air Force is presently continuing to monitor the site and restrict access to contaminated portious awaiting resolution of the issues associated with waste disposal.

\section{Lessons Learned}

- Limited avallability of disposal capacity for low-level radioactive waste after January 1, 1993 and lack of DOE consent to accept waste for disposal has delayed initiation of the remedial action

- Multiple regulatory reviews by government agencies and the public resulted in late-stage comments that could not reasonably be resolved without delaying the project

- Lack of acceptable cleanup criteria for plutonium delayed progress in remediation until the Air Force developed and negotiated a criterion with State and Federal agencies

- The State disagreed with the Federal agencies (Air Force and EPA) on acceptable risk basis for developing the cleanup criterion for Pu; the State preferred $10^{-6}$, while the Federal agencies preferred a cleanup standard based on $10^{-4}$ lifetime risk. Another group, the Pinelands Commission, asserts that the cleanup criterion should be background, uniess the Air Force can demonstrate no adverse impacts on surface water or groundwater quality 


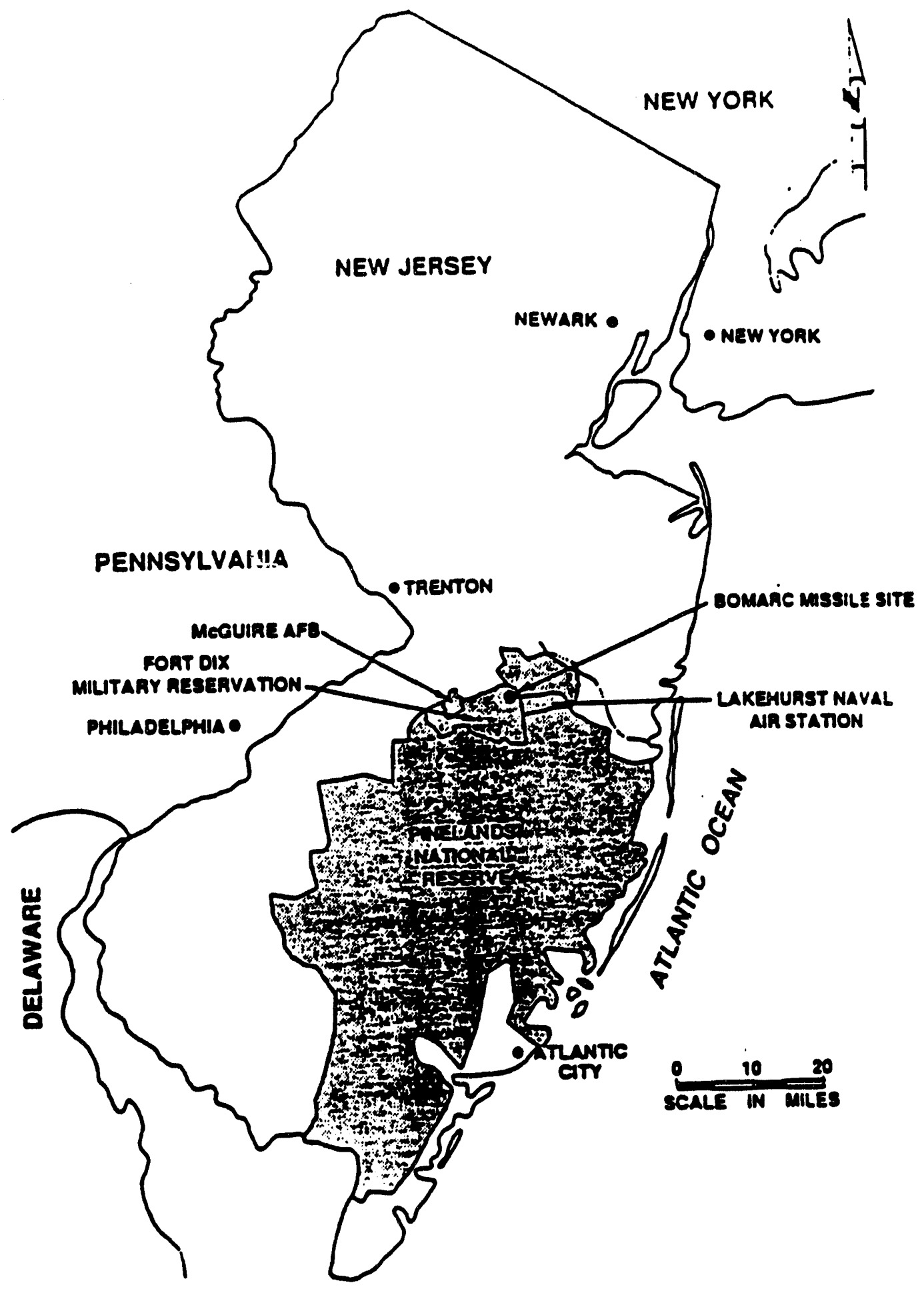

Sourea: Banelk. 1988.

Figure 1. Location of the BOMARC Missile Site (Reference: Record of Decision: BONARC Missile Accident Site, McQuire Air Force Base, New Jersey, U.S. Air Force, November 1992, Pg. 15) 

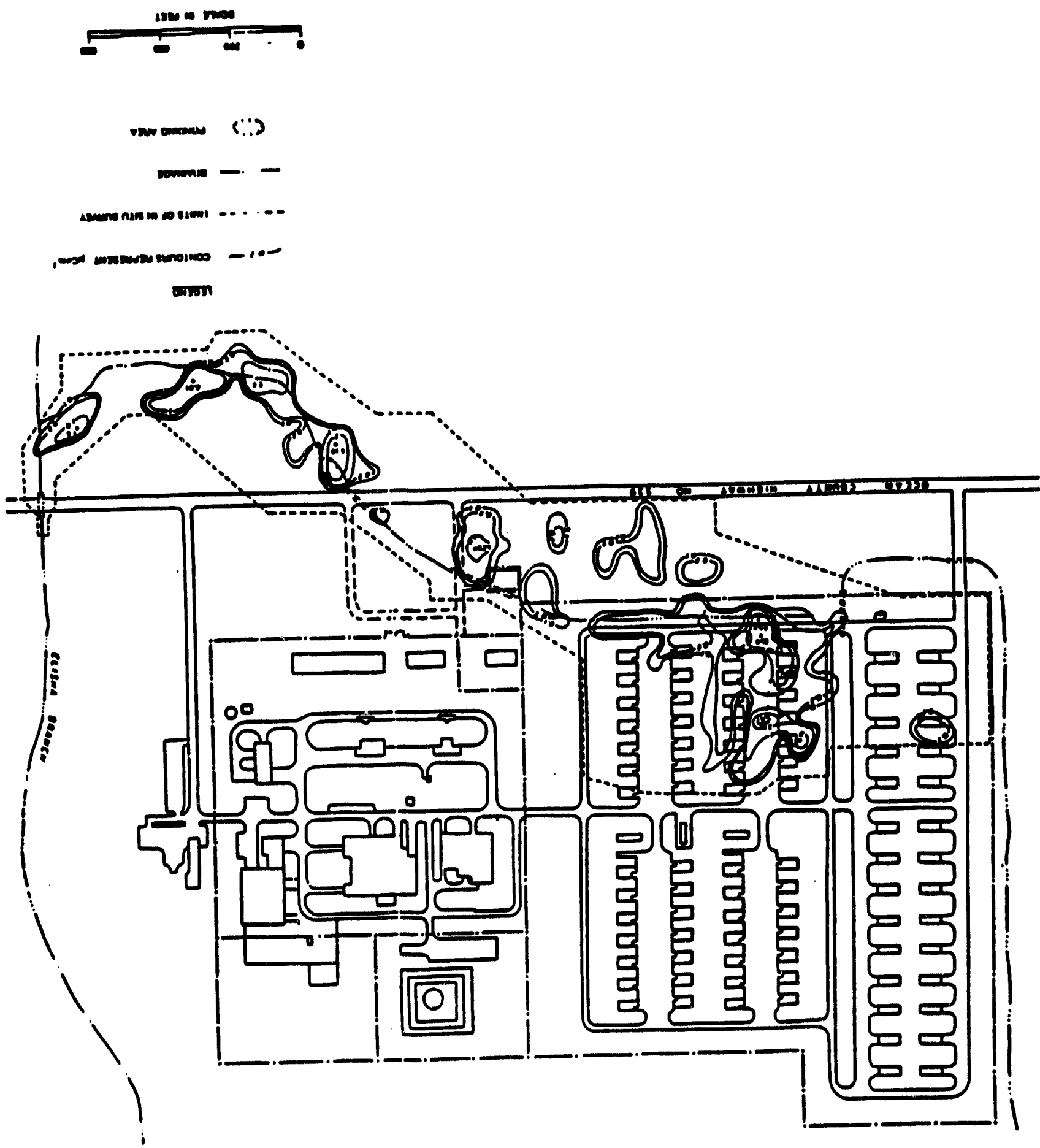


\section{INTERNATIONAL DECOMMISSIONING ACTIVITIES}

Activities related to radiological criteria for decommissioning are occurring both in other countries and in international forums such as the International Atomic Energy Agency (IAEA). In general, the current practice is to derive decommissioning criteria on a case-by-case basis, usually using the guidance of the IAEA Safety Series No. 89, "Principles for the Exemption of Radiation Sources and Practices from Regulatory Control." The IAEA guidance is riskbased and uses exposure to natural background as a reference level. It concludes that the level of trivial individual effective dose equivalent would be on the order of some 10's of $\mu S v$ [a few mrem] per year, however in consideration of multiple sources of exposure the recommendation is $10 \mu S v$ [1 mrem] in a year from each exempt practice. This assumes the practice selected is considered optimal i.e., As Low As is Reasonably Achievable (ALARA). A practice is assumed to be optimal if the estimated collective dose is less than 1 person-sievert/y (100 person-rem/y). The IAEA's examples of practices did not include the unrestricted use of lands and structures after decommissioning but did include consumer products, waste, and recycle--reuse of materials.

During November 1990, the IAEA convened a group of consultants to develop a draft Technical Report entitled, "Criteria for Unrestricted Release of Facilities, sites or Materials from Decommissioning." That work is on hold pending the completion of the technical basis and methodology being developed for the publication of NUREG/CR-5512, "Residual Radioactive Contamination From Decommissioning: Technical Basis for Translating Contamination Levels to Annual Dose." Separate IAEA consultants and advisory group meetings in November 1991 and June 1992, and produced a draft document, "National Policies and Regulations for Decommissioning Nuclear Facilities." This latter document is still early in its development and will require further work before it is suitable for distribution as a draft. Another consultants meeting was held in Vienna, Austria in December 1992 to work on the draft.

In a related area, there has been a recent focus upon waste disposal and recycle at the IAEA. The criterion is typically set at $10 \mu S v$ [1 mrem] per year based on the IAEA Safety Series No. 89 guidance. This work relates to decommissioning criteria to the extent that materials left on site after decommissioning, at some subsequent time, may be freely disposed or recycled or reused without restriction. An IAEA advisory group, in which the NRC is participating, is currently developing a draft document, "Exemption from Regulatory Control Recommended Unconditional Exempt Levels For Solid Radioactive Materials." This document is also in an early stage of development and is not ripe for general distribution as a draft.

Residual contamination limits for decommissioning have been developed in several European countries based on the guidance in IAEA Safety Series No. 89. The most extensive information in the literature is on decommissioning in the Federal Republic of Germany (FRG) where residual contamination limits have 
been incorporated into radiation protection ordinances. However, these ordinances are treated more as guidance to be applied, as appropriate, on a case-by-case basis rather than as regulations. In the FRG approximately $28 \%$ of the electrical power is generated by 20 operating nuclear power plants. Thirteen prototype nuclear power plants have been shut down and are in various stages of decommissioning. In addition several research reactors have been taken out of service. Estimates of total decommissioning wastes from all nuclear installations in FRG before unification range from 90,000 to 120,000 $\mathrm{m}^{3}$. However, by the year 2000 only about $10,000 \mathrm{~m}^{3}$ of decommissioning waste is expected to accumulate.'

Decommissioning in the FRG is being carried out on a case-by-case basis using the following residual contamination guidelines. Surface contamination limits may not exceed $0.37 \mathrm{~Bq} / \mathrm{cm}^{2}\left(10 \mathrm{pCi} / \mathrm{cm}^{2}\right)$ beta-gamma and $0.037 \mathrm{~Bq} / \mathrm{cm}^{2}\left(1 \mathrm{pCi} / \mathrm{cm}^{2}\right)$ alpha, and specific activity limits may not exceed $3.7 \mathrm{~Bq} / \mathrm{g}(100 \mathrm{pCi} / \mathrm{g})$. Recycle of contaminated materials from nuclear installations is encouraged. The preferable option is to recycle this material within the nuclear industry. If this cannot be done for technical or economic reasons, recycle outside the nuclear industry is allowed if, in accordance with the principals in IAEA Safety Series No. 89, individual risks are sufficiently low as not to warrant regulatory concern.

In France most nuclear facilities are owned by the French government through various public companies and organizations. Currently $75 \%$ of the electric power is generated by 50 operating nuclear power plants. There are presently no specific regulatory criteria in place for decommissioning of nuclear facilities. However, in practice France has adopted an early CEC recommendation of $100 \mathrm{~Bq} / \mathrm{g}(2700 \mathrm{pCi} / \mathrm{g})$ as a residual contamination limit in cases where only small total quantities of radioactive material have been involved." [The French are developing recommended residual contaminated limits for CEC under contract] Case-by-case determinations are apparently

'G. Wolany, L. Weill, R. Gortz, "Regulatory aspects of Decommissioning in the Federal Republic of Germany", International Seminar on Decommissioning Policies, Paris, October 2-4, 1991.

2 Meis, H.P., Stang, W., "Decommissioning of Nuclear Power Plant Gundremmingen Unit $A, " 1987$ International Decommissioning Symposium, Pittsburgh, PA, October 1987.

3offman, R., Leidenberger, B., "Optimization of Measurement Techniques for very Low Level Radioactive Waste Material," 1989 International Conference on the Decommissioning of Nuclear Installations, Commission of the European Communities, Brussels, October 1989.

" Hempeimann, W., "Treatment of Waste Metals from Decommissioning," Pittsburgh, PA, October 1987.

s Chapuis, A.M., Guetat, P., Garbay, H.. "Exemption limits for the Recycling of Materials form the Dismantling of Nuclear Installations, " 1987 International Decommissioning Symposium, Pittsburgh, PA, October 1987. 
made in situations where large total quantities of radioactive materials are involved.

In the United Kingdom residual radioactivity criteria for decommissioning is developed on a case-by-case basis using the general principals set out in IAEA Safety Series No. 89.

In Finland there is a federal guide for disposal or recycle of wastes from nuclear facilities. "The guide adopts the dose guidelines from IAEA Safety Series No. 89 and applies the following activity constraints to unrestricted exemption: (a) Total activity concentration of $1 \mathrm{kBq} / \mathrm{kg}$ of beta or gamma activity or $100 \mathrm{~Bq} / \mathrm{kg}$ of alpha activity averaged over a maximum of $1000 \mathrm{~kg}$ of waste, and (b) total non-fixed surface contamination (averaged over $0.1 \mathrm{~m}^{2}$ for accessible surfaces) of $4 \mathrm{kBq} / \mathrm{m}^{2}$ of beta or gamma activity or $400 \mathrm{~Bq} / \mathrm{m}^{2}$ of alpha activity. The guide does not specifically address whether the guidelines apply to lands and structures.

In general, disposal or recycle in European countries of materials (including lands and structures) containing residual radioactivity is carried out in accordance with the principals for limiting radiation dose to members of the public set out in IAEA Safety Series No. 89. However, specific national guidelines derived from these principles (and expressed in terms of residual radioactivity in materials to be released for unrestricted release) have so far been developed principally for recycle of materials from nuclear power plants. Current practice in most European countries is to derive residual radioactivity criteria for 1 ands and structures on a case-by-case basis using the general principals set out in IAEA Safety Series No. 89.

The Commission of European Communities (CEC) has recommended clearance levels for mass and/or surface activity concentration for recycle of materials from dismantling of nuclear installations, based on generic assessment of individual and collective doses from recycle and use of the material.' There are presently no CEC guidelines for unrestricted release of lands and structures. However, the CEC preparing guidelines which are expected to be in place in 1994. Individual member countries would then be expected to adopt these guidelines.

- YVL-Guide 8.2 "Exemption from Regulatory Control of Nuclear Wastes," 2nd Revised Edition, January 5, 1992, Finnish Centre for Radiation and Nuclear Safety, Helsinki, Finland.

'Radiation Protection No. 43 "Radiological Protection Criteria for the Recycling of Materials From Dismantling of Nuclear Installations, " 17 , Commission of the European Communities", Luxembourg, November 1988. 
APPENDIX C

COMMENTER LISTING 


\section{APPENDIX C - COMMENTER LISTING}

The following commenters responded to the Federal Register Notice or made comments at the workshops; note that six letters are duplicates as indicated:

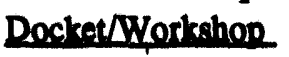

1

2

3

4

5

6

7

8

9

10

11

12

13

14

15

16

17

18

19

20

21

22

23

\section{Commenter}

Science Applications International Corp.

Margaret Gariota

Audubon Council of Texas

Adam H. Levin

Texas Nuclear Responsibility Network

Western States Legal Foundation

Mary Gerry White

Charlotte M. Sholeen, Ph.D.

Dade W. Moeller

Rowena S. Argall, CHP

Consumers Power

Broad Top Township Supervisors

Grace V. Palazzolo

Public Citizen

Duplicate of number 5

Thermal Analytical Inc., TMA

B. Wycliffe Orr

State of South Carolina, DHEC

Coalition on West Valley Nuclear Wastes

Catherine M. Jones, Ph.D.

Margaret J. Miller

Casper W. Hiatt, Ph.D.

ASPI

County Commission, Bedford, PA

Ted Lapis

U.S. Council for Energy Awareness

Duplicate of number 14

SIERRA CLUB, DALLAS GROUP

Fawn Shilling Law

Kennecott (Energy) Uranium Co.

Organization of Agreement States

American Nuclear Society

Assoc. of Solid Waste Mgmt. Officials

U.S. EPA

State of Michigan

Health Physics Society

Carol Cain

Duplicate of number 33

Jared Crawford

Ruth Black

Suzanne H. Williams

Betty S. Lee 


\section{Dectret/Wortuhop}

43

44

45

46

47

48

49

so

51

52

53

54

55

56

57

58

59

60

61

62

63

64

65

66

67

68

69

70

71

72

73

74

75

76

77

78

79

80

81

82

83

84

85

86

87

88

89
Commenter

GB Stockholders Alliance

Bamute Forte

International Fellowship of Reconciliation

Priscilla Tomilinson

Mary P. Sinclair

David R. Brill

Beatrice Shneider

Tom Ferguson

Califonia Integrated Waste Management Board

Nuclear Metals, Inc.

Public Citizen

NC Ground Zero

Georgians Against Nuclear Bnergy

Glenn Carroll

GREENPEACE-Atianta

David Matthews

Joan O. King

Oregon Dept. of Human Resources

Cuyahoga County Dist. Board of Health

OB Nuclear Bnergy

8-Organization Group

New York State BRDA

Sierra Club

CRCPD

Dennis B. Gardiner

Florida Power Corp.

Rick Olen

American Mining Congress

GPU Nuclear

Georgians Against Nuclear Energy

OCRE

Winston \& Strawn

Maggie Kennik

Carl Rupert

Katherine M. Shelly

Nuclear Information and Resource Service

Fuel Cycle Facilities Forum

Northeast Utilities

Yankee Atomic Blectric Company

Public Service of Colorado

State of Wisconsin

Eric N. Johnson

Judith H. Johnsrud, Ph.D.

Boehinger Ingelheim Pharmaceuticals, Inc.

Duplicate of number 73

Helen B. Burgess

NUMARC 


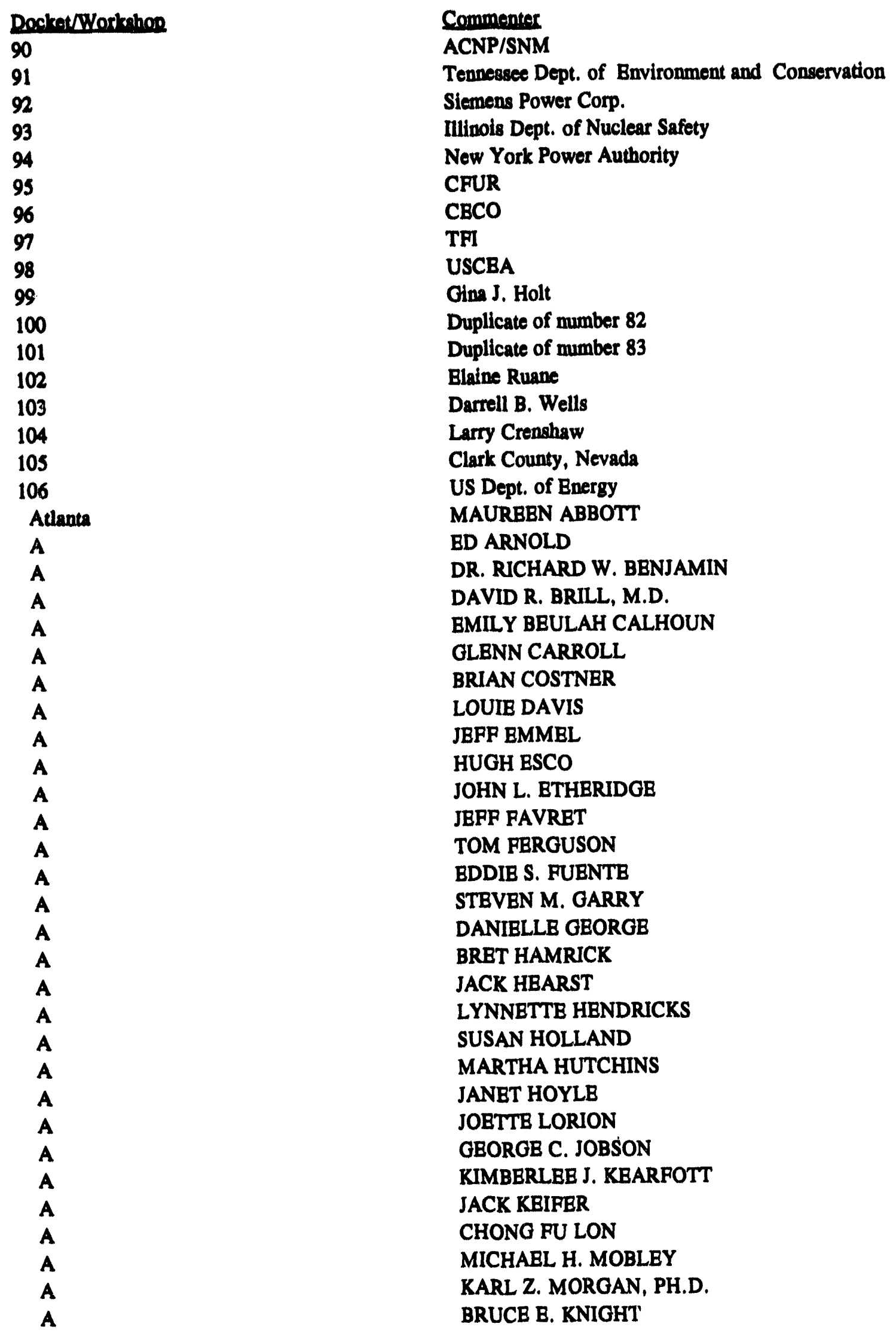




\section{Docket/Workshop}

A

A

A

A

A

A

A

A

A

A

A

A

A

A

Boston

B

B

B

B

B

B

B

B

B

B

B

B

B

B

B

B

B

B

B

B

B

B

Chicago

C

C
Commenter

SCOTT MURRAY

MILDRED McCLAIN, PH.D.

ROD McCOY

ANDY MCDONALD

PAMELA BLOCKLEY O'BRIEN

WILLIAM PASSETTI

PATTY RICHARDSON

CARL RUPERT

MARGARET SHIPLER-FIELDER

GLEN SLAVER

CAROL STANGLER

BILL ULYSNY

KAYE VONTILLIAS

KEES de VENTE

ARTHUR AUDET

ROBERT A. BACKUS

SYDNEY BAIMAN

NANCY BENNINGER

DONNELL BOARDMAN

WILLIAM F. BOYLE

ALLEN BRODSKY

BRAIN BULTER

JOSEPH M. CARDITO

KEITH H. DINGER

DENNIS O. DUMAS

ANN ENO

JANE FLEMING

MICHAEL FORTUN

ALDEN R. GILMAN

CORNELLA ISELIN

JOHN KELLY

DALE MACLEOD

WILLIAM J. MANION

KEVIN T. A. MCCARTHY

RUSS MELLOR

JACK C. MOULTON

MARJORY MYERS

JAMES PERKINS

CHARLES PRATT

DIANE QUIGLEY

ALAN C. RICARDSON

JUDY SCOTNICKI

DAVID SLESINGER

DIANE E. TEFFT

FRANCISO TREJO

MICHAEL TUCKER

ROBERT T. WATKINS

TOM WINTERS, M.D.

JACK ZIMMERMAN

RICHARD ALLEN

ERV BALL

DANIEL BALOCCA 


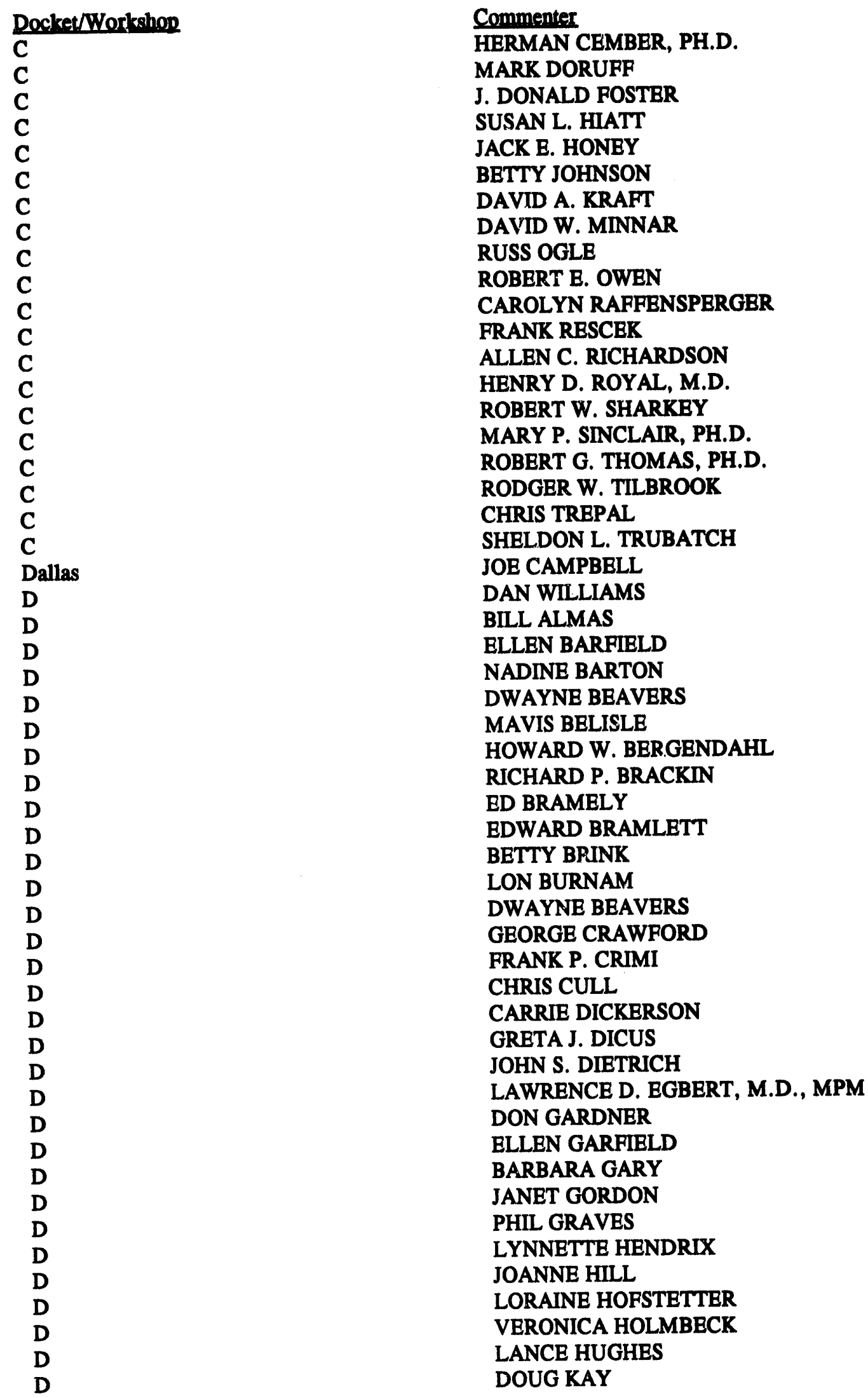




\section{Docket/Workshop}

D

D

D

D

D

D

D

D

D

D

D

D

D

D

D

D

D

D

D

D

D

D

Philadelphia

P

$\mathbf{P}$

P

$\mathbf{P}$

P

$\mathbf{P}$

P

$\mathbf{P}$

$\mathbf{P}$

$\mathbf{P}$

$\mathbf{P}$

P

$\mathbf{P}$

P

P

$P$

P

$\mathbf{P}$

$\mathbf{P}$

$\mathbf{P}$

$\mathbf{P}$

$\mathbf{P}$

$\mathbf{P}$

$\mathbf{P}$

$\mathbf{P}$

$\mathbf{P}$

$\mathbf{P}$

P

$\mathbf{P}$
Commenter

LLOYD A. KIRK

SUSAN LEE

ALVA MORRISON

RUTH E. MCBURNEY

TOM ODEAR

ROY OVERSTREET

GEORGE PALMER

BD PARSONS

DAVID PLATERIO

DONALD A. PODOLOFF, M.D.

ROBERT M. QUILLIN

PAMELA RUSSELL

JAN SANDERS

DAVE SCHRADER

EDWIN T. STILL

MERV TANO

ANTHONY J. THOMPSON, BSQ.

UNKNOWN OBSERVER

BARL VERNUM

LEON WES, PH.D.

DAN WILLIAMS

JIM YOTT

SUSAN BILHORN

HAL BRODIE

ROY W. BROWN

JIM BYRNE

HUGH COOMBS

QURESH DAHODWALA

WILLIAM P. DORNSIFE

RICHARD W. DUBIEL

ROLAND G. FLETCHER

SUE FRACKE

SUSAN GRIFFIN

CASPAR W. HIATT, III, PH.D.

JUDITH JOHNSRUD, PH.D.

JOHN A. KADLECEK, PH.D.

BARRY KOH, PH.D.

TOM LAGUARDIA

A. JOSEPH NARDI

ADAM H. LEVIN

SAMUEL E. PINKARD

SYDNEY W. PORTER, JR.

MAGGIE REILLY

CRAIG RIEMAN

JOBL ROTH

PAMELA RUSSELL

DONALD F. SCHUTZ, PH.D.

DON K. SGARLATA

MICHAEL J. SLOBODIEN

ROBERT STERN

CINDEE VIROSTEK

JUNE WING 


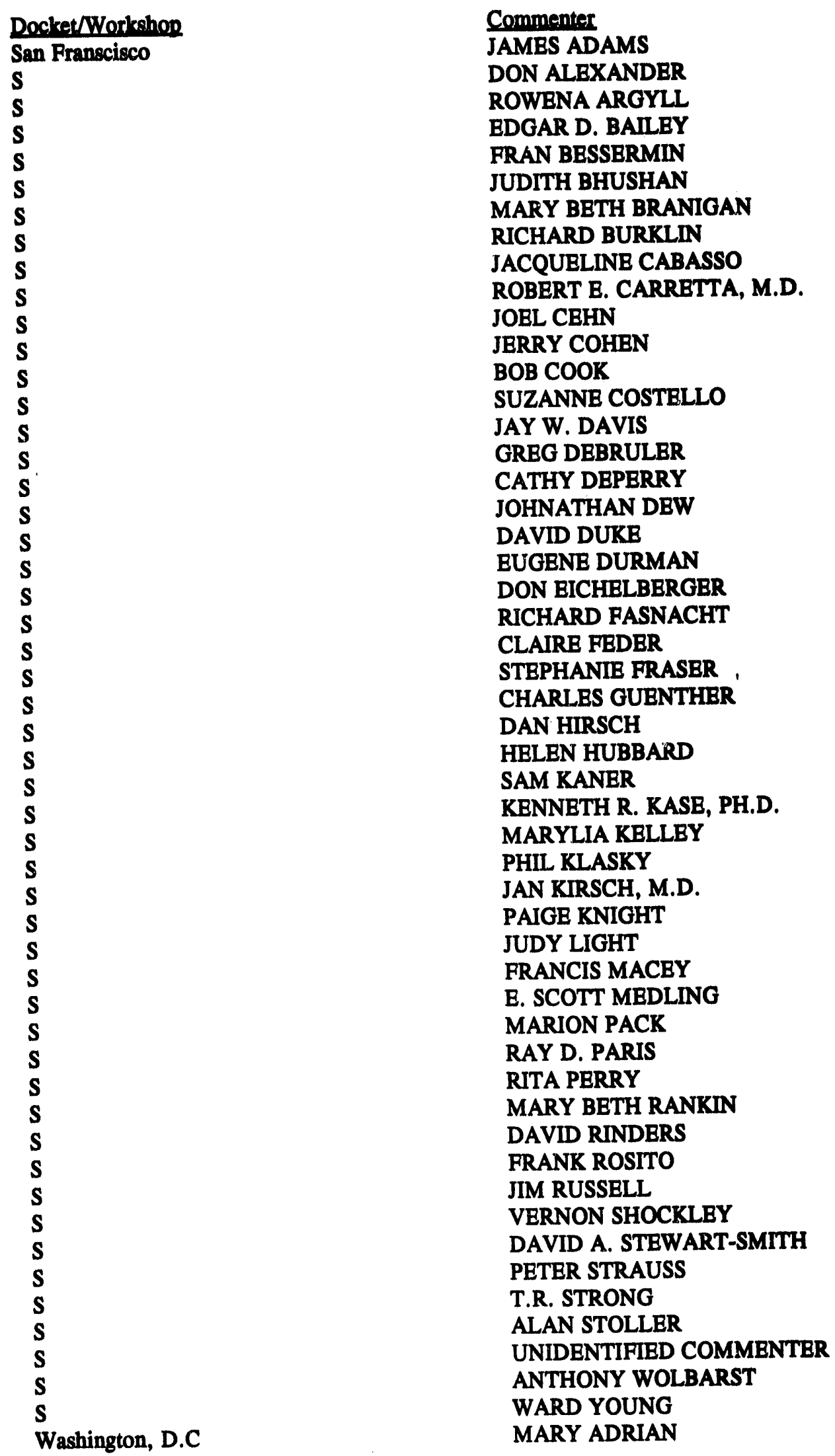




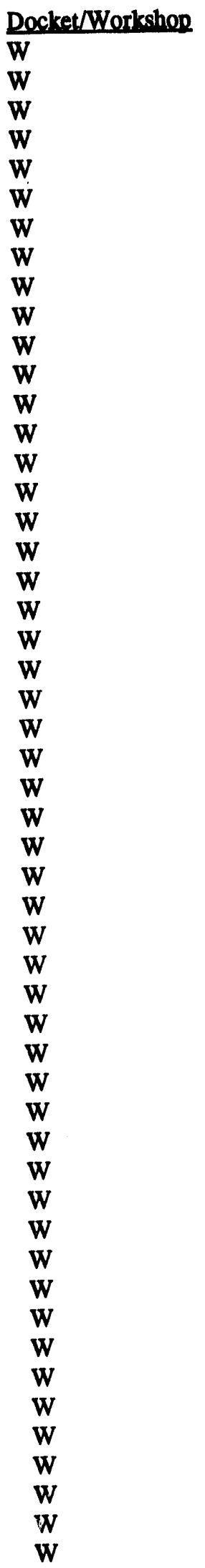

Commenter

MAURICE AXELRAD

CHARLES BARRETT

BRUCE CLEMONS

GREG COMP

A. SCOTT DAM

JAMES DAVENPORT

ALBERT DONNAY

EUGENE DURMAN

DONALD ELLISBURG

KEVIN FRIEL

PAUL E. FULLER

WILLIAM S. GEIGER

MARTIN GILFAND

MORT GOLDMAN

BEVERLY GOOD

PAUL GUNTER

JAMES W. HANSON, M.D.

ROBERT HOLDEN

RICHARD HUMPHREY, M.D.

MELINDA KASSEN

JOHN J. KELLY

G. WAYNE KERR

FELIX KILLAR

JOAN KING

THOMAS J. LAGUARDIA

ROBERT J. LULL, M.D.

BILL, MAGAVERN

ARJUN MAKHIIHANI

CAROL S. MARCUS, PH.D., M.D.

DAVID MILLER

DONALD MORRIS

HENRY W. MORTON

DENNIS NELSON

PHILLIP A. NIEDZIELSKI-EICHNER

MARY OLSON

JACK RANSOHOFF

JESSE J. RILEY

KIM ROBERSON

MIKE SCHAEFFER

KEITH SCHIAGER

JOHN SCHMITT

JUDY SCOTNIKI

STAN SEIKEN

LES SKOSKI

GRAHAM M. SMITH

MERV TANO

ELLIOT TRETTER

MARCUS VOTH, PH.D.

DR. WILLIAM WALKER

ANDY WALLO

HARVEY WASSERMAN

E. IVAN WHITE 
APPENDIX D

COMMENT REFERENCES 


\section{APPENDIX D - COMIMENT REFERENCES}

This section is a reference which relates each comment to its origin. The listed information includes a comment number, the name of the commenter, the workshop at which the comment was made or the docket number of the letter containing the comment, and data for referencing a particular page, line or paragraph . Following is an explanation of the listed information.

The comment number is unique to a single comment made within an issue. If the same comment also applies to another issue code, another number is assigned for use within that other issue code.

The name of the commenter is listed as the last name or if an organization, the full or abbreviated name.

Comments from workshops are identified as C, S, B, D, P, A, and W which correspond to Chicago, San Francisco, Boston, Dallas, Philadelphia, and Washington, D.C.; respectively. If a workshop is identified the next section is a 0 (reserved for docket letters). The next group of numbers identifies the page of the manuscript of the workshop that the comment begins on. This page number is also followed by a 0 (reserved for docket letters). The next set of numbers gives the line number that the comment begins on. An illustrative example follows:

$\{$ Comment \#\}\{Name $\}\{$ Workshop $\}\{$ Reserved $\}\{$ Page \#\}\{Reserved $\}\{$ Line \#\}

$\begin{array}{lllllll}1 & \text { ROYAL } & \text { C } & 0 & 125 & 0 & 7\end{array}$

Identification of comments from docketed letters are similarly identified but begin at comment number 7,000 and the beginning paragraph number is listed instead of a line number. The last number in this series is always a $\mathbf{0}$ (reserved for future use). An illustrative example follows:

\section{$\{$ Comment \#\}\{Name $\}\{$ Docket \#\}\{Page \#\}\{Paragraph \#\}\{Reserved $\}$}

$\begin{array}{llllll}7659 & \text { R. Black } & 40 & 1 & 1 & 0\end{array}$

The following pages contain a column listing of Comment Number, Commenter's Name, Workshop and/or Docket Number, Page Number, Paragraph Number, or Line Number. 
1 ROYAL C 012507 2 RESCEK C 013605 3 WILLIAMS C 014004 4 HONEY C 0146014 5 ROYAL C 0385013 6 TRUBATCH C 0113019

7 BALL C 064017 8 WILLIAMS C 049025 10 RUSSELL C 0167024 11 RUSSELL C 0167024 12 CEMBER C 0536019 13 CEMBER C 0536019 14 WILLIAMS C 0323024 15 SINCLAIR C 012303 16 KRAFT C 0383021 17 WILLIAMS C 0134020 18 MINNAR C 0128035 20 RICHARDSON C 0180015 22 KRAFT C 0184013 24 WILLIAMS C 0161014 26 RESCEK C 0189010 27 RESCEK C 026705 28 DORUPF C 0207025 29 RESCEK C 0160025 30 CEMBER C 0125020 31 RICHARDSON C 0128013 32 RESCEK C 0124012 33 RESCEK C 0124012 35 WILLIAMS C 0185024 37 THOMAS C 05908 38 CEMBER C 0536019 41 WILLIAMS C 0317018 42 CEMBER C 0520012 43 MINNAR C 0518010 45 WILLIAMS C 0519020 47 OWEN C 0261021 48 HIATT C 0194017 49 WILLIAMS C 0191018 S1 RICHARDSON C 0194011 S2 RESCEK C 0195018 S3 KRAFT C 0192011 S4 CEMBER C 0419018 55 RESCEK C 0419024 60 OWEN C 0196023 62 TREPAL C 0170015 63 HIATT C 0196013 64 MINNAR C 025908 65 TREPAL C 0342017 66 OWEN C 033508 67 RESCEK C 0205018 68 HONEY C 020408 69 RESCEK C 0331017 70 KRAFT C 0208015 71 DORUPF C 033103 73 HIATT C 038304 74 HIATT C 0126010 75 SINCLAIR C 013205 76 KRAFT C 068011 77 CEMBER C 013302 78 THOMAS C 0126024 79 ROYAL C 0127012 81 THOMAS C 05908 82 ROYAL C 0127012
83 ROYAL C 0127012 84 TREPAL C 013009 85 ALLEN C 0142019 86 CEMBER C 0330011 87 WILLLAMS C 0166021 88 ROYAL C 031602

89 RICHARDSON C 016608

90 WILLIAMS C 016509 91 SINCLAIR C 0172023 92 CEMBER C 0407025 93 CEMBER C 017507 94 CEMBER C 017701 95 CEMBER C 0409012 96 ROYAL C 062021 97 CEMBER C 048013 98 CEMBER C 0407025 99 CEMBER C 017601 101 RICHARDSON C 0128013 103 RAFFENSPERGER C 0214014 104 WILLIAMS C 0216015 105 WILLIAMS C 021201 106 RESCEK C 0415024 107 WILLIAMS C 0217020 108 HIATT C 0411020 109 DORUFF C 0162014 111 CEMBER C 0164018 112 DORUPF C 06601 113 WILLIAMS C 0413021 114 CEMBER C 021601 115 RICHARDSON C 040003 116 OWEN C 070013 117 OWEN C 070013 119 RAFFENSPERGER C 0171013 120 DORUFF C 039409 121 RAFFENSPERGER C 05205 122 RAFFENSPERGER C 05205 123 TREPAL C 0341012 124 HIATT C 0159016 125 RICHARDSON C 0406014 127 WILLIAMS C 0317018 128 WHITE C 022701 129 HIATT C 067015 130 FOSTER C 055017 131 BALL C 064017 132 CEMBER C 048013 133 SHARKEY C 05504 134 JOHNSON C 04305 135 WILLIAMS C 0134020 136 OWEN C 0147012 137 OWEN C 0147012 138 OWEN C 049003 139 BALOCCA C 053019 140 JOHNSON C 04305 141 TREPAL C 0489015 142 WILLIAMS C 049205 143 OWEN C 070013 144 HIATT C 046005 145 KRAFT C 046105 146 WILLIAMS C 045201 148 OWEN C 0465010 149 SINCLAIR C 047002 150 CEMBER C 0476015 151 MINNAR C 056018 
152 TREPAL C 06106

153 OWEN C 070013

154 MINNAR C 0453021

15S MINNAR C 0453021

156 RESCEK C 0245014

157 THOMAS C 014304

159 RAFPENSPERGER C 0148012

160 BALL C 0139010

163 RESCEK C 036509

164 OWEN C 0352010

165 BALOCCA C 034902

166 MINNAR C 034301

167 ALLEN C 021009

168 WILLIAMS C 0359024

169 SHARKEY C 05504

170 TREPAL C 0357017

171 MINNAR C 0357025

172 WILLIAMS C 0354011

173 MINNAR C 0342021

175 ALLEN C 0271022

176 OGLE C 011309

177 ROYAL C 0513021

179 RAFFENSPERGER C 051503

180 RESCEK C 047803

181 KRAFT C 0471023

182 MINNAR C 0508023

183 BALOCCA C 0512010

184 WILLIAMS C 0512024

185 CEMBER C 0505023

186 BALOCCA C 0512010

188 HONEY C 05807

189 RAFFENSPERGER C 0448021

190 HONEY C 0270014

191 KRAFT C 026908

192 RAFFENSPERGER C 0171013

193 WILLIAMS C 048806

194 MINNAR C 049308

195 RAFPENSPERGER C 042305

197 CEMBER C 0395022

198 RICHARDSON C 040003

199 WILLIAMS C 0396015

200 RESCEK C 039808

201 RICHARDSON C 0217013

202 HIATT C 039507

204 RESCEK C 0218011

209 WILLIAMS C 043107

210 HIATT C 0429014

211 CEMBER C 0392017

212 WILLIAMS C 0265022

213 WILLIAMS C 0265022

214 CEMBER C 020502

215 WILLIAMS C 0265022

216 WILLIAMS C 049025

217 DORUPF C 016406

218 ROYAL C 016002

219 ROYAL C 026306

220 ROYAL C 0177024

221 TREPAL C 06106

222 ROYAL C 062021

223 ROYAL C 062021

224 DORUPF C 06601

226 ROYAL C 015907

227 CEMBER C 048013

228 CEMBER C 013701

\author{
229 WILLIAMS C 0198015 \\ 230 ROYAL C 0177024 \\ 231 RICHARDSON C 0337013 \\ 232 THOMAS C 05908 \\ 234 MNNNAR C 0525014 \\ 235 HONEY C 0525021 \\ 237 RESCEK C 0314014 \\ 238 HIATT C 0312015 \\ 239 RICHARDSON C 0309024 \\ 240 RICHARDSON C 018701 \\ 241 MINNAR C 056018 \\ 242 HONEY C 05807 \\ 244 SHARKEY C 0374012 \\ 245 ALLEN C 0367020 \\ 246 BALL C 064017 \\ 247 THOMAS C 014304 \\ 248 THOMAS C 014304 \\ 249 MINNAR C 056018 \\ 250 HOLDEN C 0349014 \\ 253 RAFFENSPERGER C 0356013 \\ 254 ROYAL C 0225021 \\ 255 RAFPENSPERGER C 026502 \\ 256 WILLIAMS C 022409 \\ 257 RAFPENSPERGER C 022303 \\ 258 SINCLAIR C 0223017 \\ 259 CEMBER C 022207 \\ 260 KRAFT C 022107 \\ 261 SINCLAIR C 0220019 \\ 262 DORUFF C 06601 \\ 263 HONEY C 049404 \\ 264 HIATT C 049501 \\ 265 KRAFT C 0202016 \\ 266 WILLIAMS C 0241024 \\ 267 MINNAR C 0236016 \\ 268 JOHNSON C 0239023 \\ 269 THOMAS C 0255017 \\ 270 OWEN C 0254021 \\ 273 JOHNSỌN C 019902 \\ 274 CEMBER C 033803 \\ 275 TREPAL C 0267025 \\ 276 HONEY C 0367010 \\ 277 JOHNSON C 04305 \\ 279 WHITE C 0114015 \\ 283 JOHNSON C 024903 \\ 285 RESCEK C 036804 \\ 286 RESCEK C 05103 \\ 287 HONEY C 05807 \\ 288 RICHARDSON C 05807 \\ 290 RAPFENSPERGER C 048004 \\ 291 WILLIAMS C 047708 \\ 292 JOHNSON C 048202 \\ 293 TREPAL C 0478015 \\ 294 TREPAL C 0351018 \\ 297 KELLEY S 023010 \\ 298 FASNACHT S 02909 \\ 299 PASNACHT S 029011 \\ 300 RUSSELL S 029020 \\ $301 \mathrm{JIM} \mathrm{S} 03004$ \\ 302 DEBRULER S 030019 \\ 303 KNIGHT S 03203 \\ 304 KNIGHT S 032010 \\ 305 MEDLING S 03305 \\ 306 MEDLING S 033018 \\ 307 DUKE S 034010
}


308 DUKE S 034014 309 KASE S 03504 310 KASE S 03509

311 BAIIEY S 035022

312 BAIIEY S 03601 313 CABASSO S 036019 315 CABASSO S 037016 316 CABASSO S 03704 317 PACK S 03804 318 PACK S 038023 319 STEWARD-SMTTH S 039014 321 DAVIS S 04007 322 BURKLNN S 040018 323 BURKLIN S 040020 324 ADAMS S 04103 326 KELLEY S 042023 327 COHEN S 043017 328 COHEN S 044023 330 COHEN S 043014 331 BESSERMIN S 045015 332 BESSERMN S 045015 333 STRONG S 04606 335 STRONG S 046010 336 CARRETTA S 046023 337 PARIS S 047020 338 PARIS S 047023 339 STRAUSS S 04903 341 STRAUSS S 049013 342 WOLBARST S 049025 343 WOLBARST S 05003 344 WOLBARST S 050017 345 KELLEY S 094025 346 KELLEY S 094025 347 KELLEY S 094025 348 STEWARD-SMITH S 095014 349 KASE S 09605 350 PACK S 09706 351 MEDLNG S 097022 352 MEDLING S 097022 353 MEDLING S $0980 \mathrm{~s}$ 354 CABASSO S 098011 355 CABASSO S 098011 356 CABASSO S 098011 357 JIM S 099015 358 JMM S 010001 359 JIM S 010007 360 WOLBARST S 0100019 361 STRAUSS S 0101021 362 STRAUSS S 010203 363 PARIS S 0102024 364 PARIS S 010307 366 KNIGHT S 0103014 367 KNIGHT S 0103014 368 KNIGHT S 0103014 369 KNIGHT S 0103014 370 KNIGHT S 0103014 371 KNIGHT S 0103014 372 KNIGHT S 0103014 373 KNIGHT S 0103014 374 KNIGHT S 0103014 375 COHEN S 0106011 376 COHEN S 010603 377 MEDLING S 010701 378 ADAMS S 0107014
379 ADAMS S 0107014 380 PACK $\$ 011001$ 382 DEBRULER S 0111025 383 DERRULER S 0.112010 385 FASNACHT S 011302 386 CABASSO S 0114018 387 STRAUSS S 011504 388 STRAUSS S 011602 391 DUKE S 0117012 392 BURKLIN S 0149021 393 BURKLNN S 0149015 394 BURKLIN S 0150018 395 BURKIN S O 150018 396 CABASSO S 0150024 397 CABASSO S 0150024 398 CABASSO S 0150024 400 BURKLIN S 0152022 401 COHEN S 0154024 402 COHEN S 0154024 403 KNIGHT S 015602 404 KNIGHT S 015602 405 STRAUSS S 015909 407 DUKE S 0161019 408 DUKE S 0161013 409 KBILLEY S 0162020 410 KELLEY S 0164015 411 PARIS S 016508 412 MEDLNG S 0269022 413 KASE S 016603 414 MEDLNONG 0270010 415 KASE S 016603 416 KASE S 016603 417 KASE S 016603 418 DAVIS S 0270017 419 KASE S 016701 421 PACK S 0167016 422 DEBRULER S 016907 424 DAVIS S 0270017 425 DEBRULER S 0172016 427 DAVIS S 0271013 428 DEBRULER S 0172025 429 FASNACHT S 027203 430 DEBRULER S 017302 432 FASNACHT S 027207 433 DEBRULER S 0173020 435 DEBRULER S 0174011 438 DEBRULER S 0175025 439 CARRETTA S 0177011 441 CARRETTA S 017807 442 CARRETTA S 0178025 443 CEHN S 0276017 444 CARRETTA S 017906 445 STRAUSS S 0179019 446 COHEN S 0272012 447 KASE S 0180014 448 STRAUSS S 027308 449 FASNACHT S 018108 450 MEDLING S 027407 451 MEDLING S 0181021 452 MEDLING S 0181021 453 MEDLING S 0181021 455 COHEN S 018207 457 COHEN S 018207 458 CABASSO S 027508 
462 MEDLNO 501840 s 463 STEWARD-SMITH $\$ 02770$ \& 464 MBDLNNO $\$ 0184015$ 465 KASE S 0185014 466 KASE S 018609 468 CABASSO S 0187019 470 FASNACHT S 018809 471 FASNACHT S 0188014 474 SHOCKLEY S O 280013 475 BAILEY S 0208020 476 PACK S 028203 477 FASNACHT \$ 020907 478 FASNACHT S 020907 479 CABASSO $\$ 0282010$ 480 DUKE S 021101 482 MEDLNO S 0283023 483 CABASSO S 021303 484 DAVIS S 0284015 485 PACK $\$ 021406$ 486 PACK S 0214015 487 STEWARD-SMITH S 028501 488 PACk S 021406 489 RASNACHT S 0215013 490 FASNACHT S 0215013 491 STEWARD-SMITH S 028501 492 CABASSO S 0216024 493 CABASSO S 0217021 496 KELLEY S 021809 500 KELLEY S 028706 SO1 BURKLIN S 0219013 SO2 BURKIIN S 0219019 S03 BURKLIN S 0219024 508 COHEN S 022308 S10 ADAMS S 0225012 S11 ADAMS S 0225012 S14 KASE S 0227013 S15 KELLEY S 0288020 516 KNIGHT S 029003 519 KNIGHT S 0290016 S20 DURMAN S 0291014 S21 KELLEY S 0294017 522 DURMAN S 0292021 S23 DURMAN S 0292021 S24 KELLEY S 029504 S25 RASE S 029509 S26 RASE S 029609 S27 BESSERMIN S 0299 O S S28 BESSERMIN S 0364020 S29 BESSERMIN S 029905 S31 BESSERMDN S 030002 S32 PARIS S 030102 S33 PARIS S 030102 S34 PARIS S 030102 535 DEBRULER S 0301015 S36 DEBRULER S 030203 S38 DEBRULER S 0303016 540 JMM S 030501 541 JMM S 030501 542 FASNACHT S 030709 543 FASNACHT S 030709 544 CABASSO S 0309015 546 CABASSO S 0310019 547 BAILEY S 0311010 548 BAILEY S 0311010
SSO KELLEY S 0317023

SS1 KERLLYY S 0317016 SS2 KALLEY S 0318010 SS4 XEILLYY S 0319017 S3S STRAUSS 80320019 S56 STRAUSS $\$ 032106$ S58 STRAUSS $\$ 032106$ S59 STEWARD-SMIIH \$ 0321014 S60 STEWARD-SMITE S 0322014 S61 PACK $\$ 032304$ S62 PACK 5032405

S64 MEDLNO $S 0326016$ S65 MEDLNNO S 0326016

567 Unidentified Commenter San Francives 8032501

568 Unidentified Commenter $\$ 0328023$

569 Unidentified Commenter $\$ 033009$

S70 BURKIIN $\$ 0206010$

S71 STRAUSS S 022806

S72 STRAUSS S 022806

573 KNICHT S 0228023

S74 KNIOHT \& 0230019

575 PACK 50233 OS

576 PACK $S 023305$

S77 KNIGHT S 0234023

578 KNIGET S 0234023

S79 JMM S 0235021

$580 \mathrm{JMM} \mathrm{S} 023609$

581 BAILEY S 023704

582 BAILEY S 023704

583 BAILEY S 0237022

S84 BAILEY S 0237022

S8S DEBRULER S 0239 o S

S86 DEBRULER S 023908

587 DEBRULER S 024004

S88 DEBRULER S 0240016

S89 DEBRULER S 0240016

S90 DEBRULER S 0240016

S91 ADAMS S 0241015

592 ADAMS S 024205

S94 ADAMS S 024302

S96 STEWARD-SMITH S 0243020

597 KELLEY S 0245019

598 KELLEY S 024602

599 BURKLIN S 024801

600 DURMAN S 0248023

604 DUKE S 025202

605 BICHELBERGER S 0253012

607 EICHELBERGER S 0253018

609 EICHELBERGER S $0254^{\prime} 09$

611 ARGYLL S 0256015

612 ARGYLL S 0256015

613 COOK S 025802

614 COOK S 0258019

615 COOK S 0259 o 5

616 COOK S 0259020

617 COOK S 025905

618 KELLEY S 026109

620 Unidentified Commenter $\$ 0261020$

622 YOUNG S 0192010

623 FRASER S 019302

625 COOK S $01940 \mathrm{~S}$

627 BRANIGAN S 019602

628 COSTELLOS 0197019

629 COSTELLOS 019809 
632 COHEN S 0198012

633 PERRY S 019902

634 PERRY S 019902

635 ROBERSON S 0199014

636 DEPERRY S 020008

637 DEPERRY S 0200015

639 AROALL S 020102

640 MACEY S 011902

642 MACEY S 011902

643 MACEY S 011902

644 HUBBARD S 0120020

646 HUBBARD S 0120020

647 LIOHT S 0121016

648 LIOHT S 0122018

649 HUOHES S 0122022

651 HUGHES S 0122022

653 KANER S 0124021

654 COHEN S 012601

656 COOK S 0129016

658 COOK S 0129016

659 ALEXANDER S 013101

660 Unidentified Commenter San Francisco S 020011

661 ALEXANDER S 013101

662 ALEXANDER S 013101

664 Unidentified Commenter $\$ 0141019$

665 GEORGE S 013301

666 Unidentified Commenter S 0142012

667 EICHEL BERGER S 0137010

668 EICHELBERGER S 0137012

671 DEW S 0143020

672 Unidentified Commenter S 0144018

673 EICHELBERGER S 013801

674 Unidentified Commenter S 0144018

675 RINDERS S 0140017

O76 BHUSHAN S 0139015

67? Unidentified Commenter S 019103

679 BHUSHAN S 014009

680 FASNACHT S 0444016

681 MEDLING S 0445011

684 KELLEY S 044805

685 CEHN S 0448024

686 CEHN S 0448024

688 CEHN S 0449021

690 ADAMS S 047502

692 CABASSO S 045007

693 KNIGHT S 047608

694 PACK S 045101

695 DEBRULER S 047801

696 MEDLING S 0451016

697 STRAUSS S 0452010

698 ADAMS S 0452019

699 FASNACHT S 045309

700 KASE S 0453020

702 DAVIS S 045608

703 KELLEY S 0458022

705 PESSERMIN S 0480011

706 BESSERMIN S 0480011

708 KELLEY S 0481013

710 CABASSO S 0485021

711 STRAUSS S 0488018

712 DAVIS S 048904

713 PARIS S 0489017

714 MEDLNG S 049005

715 PACK S 049103
716 BESSERMN S 049103

717 DERRULER \& 0491023

718 CABASSO 50492022

720 KBLLEY S 0497 os

722 FRASER $\$ 049802$

724 PARIS $S 0459015$

725 PARIS $S 0459015$

727 BAILEY S 046209

730 MEDLNOS 0463019

732 MEDLNO S 0464024

733 MEDLNN S 0464024

735 BAILEY S 0465010

736 KBLLEY S 0465022

737 PACK S 046703

740 HIATT C 017904

741 KRAFT C 068011

742 HONEY C 05807

743 WIILLAMS C 020907

744 SHOCKLLY S 0351016

746 DAVIS S 035704

749 MEDLING S 0355024

750 KASE S 0346017

751 DAVIS \& 034707

752 DAVIS S 034707

753 CEHN S 0347016

756 STEWARD-SMTTH S 0350010

758 KELLEY S O 358012

759 KELLEY S 0358012

761 COOR S 0336013

762 BRANIGAN S 0335 os

763 ARGALL S 034004

764 ARGALL S 0340021

765 COOK S 0338024

766 STRAUSS S 0354016

$770 \mathrm{JMM} S 0361015$

771 JMM S 0361015

772 BURKLN S 0363014

775 SHOCKLEY S 036506

776 CEHN S 036703

778 CABASSO S 036905

779 CABASSO S 0368013

780 MEDLING S 0369015

781 CABASSO S 037103

783 CABASSO S 0373017

785 DAVIS S 0374011

789 STEWARD-SMITH S 037803

790 KNIGHT S 037903

791 KASE S 0379022

792 KASE S 0379022

793 PACK S 038101

794 DEBRULER S 038305

795 DEBRULER S 0384025

796 DEBRULER S 0384025

797 STRAUSS S 0388013

798 MACEY S 039002

799 MACEY S 039002

800 Unidentified Commenter S 0399017

801 EICHELBERGER S 040302

802 Unidentified Commenter S 0405024

803 Unidentified Commenter S 0407017

804 Unidentified Commenter S 0406020

805 YOUNG S 0407023

807 COOK S 0410012

808 BRANIGAN S 041304 
809 BRANIOAN 80413014 810 CABASSO $\$ 0418011$ 812 MEDLNNG 80419012 815 DAVIS $\$ 0420022$ 821 FASNACAT $\$ 0425020$ 822 Unidentified Commentar $S 042702$ 823 SHOCKLEY S 042801 824 CEIHN $S 0429014$ 82S CBHAN 80429014

O26 PARIS 504310 \& 828 SHOCKI.EY SO 43204 830 SHOCKLBY S 043204 831 BAILEY S 043504 832 BAILEY S 043504 833 CABASSO $\$ 043608$ 834 KELLEY S 0437022 835 MBDLNO 5043806 837 ADAMS 5044109 839 FASNACHT S O 443021

841 ADAMS SO 47502

847 PACK 5048307 849 KNIGHT $\$ 0487010$ 861 FRASER S 0498021 864 DAVIS S 046106 866 DURMAN S 046306 867 STRAUSS S 046401 869 BAILEY S 0465010 874 CABASSO $S 046801$ 877 KELLEY S 0470021 878 KNIGHT S O 472023 880 STRAUSS \& 047403 881 DEBRULER S 0494019

884 Unidentified Commenter San Francicco S 0496019 886 STOLLER S 0411022 887 KLASKY S O 330024 888 FEDER S 040509 889 GUENTHER S 039707 891 ROSITO S 0397014 893 MEDNNO S 0464024 895 MEDNNG S 047408 897 DUMAS B 03803 898 DUMAS B 038010 899 DUMAS B 038010 900 FORTUN B 038016 901 FORTUN B 038021 902 BOYLE B 03909 903 BOYLE B 04008 90S MACLEOD B 041017 906 MACLEOD B 042015 907 MYERS B 043019 909 MYERS B 044011 912 SMITH B 045019 913 SMITH B 045023 914 SMITH B 045023 915 SMITH B 04608 916 SLESINGER B 04702 919 FLEMING B 048022 920 FLEMING B 048022 923 FLEMNN B 049019 925 WATKINS B 051011 927 MCCARTHY B 053012 929 MCCARTHY B 05402 931 MELLOR B O 54019 932 MELLOR B 055014
934 DINGER B 056011 936 DINOER B 057 o s 937 MOULTON B 057022 938 MOULTON B 057022 939 TERFT B 05807 940 TBFFT B 058017 942. TERTT B 058017 943 TEFFT B 058022 944 PERKNNS B 06009 946 PERKNNS B 059015 947 PERKNNS B 059015 948 BACKUS B 060022 949 BACKUS B 06103 951 OLLMAN B 061019 954 GILMAN B 061022 955 GLLMAN B 061019 957 GILMAN B 06202 958 KBLLY B 062017 959 KBLLY B 06304 961 SCOTNICKI B 063018 962 SCOTNICKI B 06401 963 SCOTNICKI B 06501 964 MANION B 06707 965 MANION B 06707 966 MANION B 067013 969 MANION B 067017 970 CARDITO B 06806 971 CARDITO B 068014 972 PERKINS B 09609 973 PERKINS B 096024 978 MANION B 0112020 979 FLEMING B 0114013 980 FLEMING B 0114013 981 DINGER B 0115024 982 DINGER B 011605 983 KELLY B 011701 985 SMITH B 011903 986 PERKINS B 0119023 987 PERKNS B 0119023 988 KELLY B 0155021 989 DINGER B 0156012 991 DINGER B 0160011 994 DINGER B 016208 995 MYERS B 016309 996 MYERS B 016309 997 MANION B 016401 1000 WINTERS B 016506 1002 KELLY B 0170016 1004 FLEMING B 0170024 1005 MACLEOD B 017203 1006 MACLEOD B 0173016 1007 MACLEOD B 0173015 1008 MELLOR B 017401 1009 MELL.OR B 0174022 1010 SMITH B 017508 1011 SLESINGER B 0175023 1012 FLEMING B 0176015 1014 SCOTNICKI B 018007 1015 WATKINS B 0181012 1016 KELLY B 018202 1017 KELLY B 0182014 1019 BOARDMAN B 018306 1020 BOYLE B 0186020 1021 BOYLE B 0186020 
1022 MANION B 018504 1023 sCOTNICA B 0142022 1024 TEFFT B 019001 1025 TBFFT B 0190012 1027 TERFT B 0190021 1028 sCOTNICJ B 0193022 1029 WhITES B 0194017 1030 MYERS B 0195014 1031 MCCARTHY B 0197011 1032 MCCARTEY B 0197021 1033 MCCARTIXY B 0198 o s 1035 BACXUS B 0199010 1036 BACXUS B 01990 is 1037 BACKUS B 0199019 1038 BACXUS B 0199022 1039 BACXUS B 020002 1040 OLMAN B 020107 1041 OLMAN B 020202 1042 MACLBOD B 0207 os 1044 MACLBOD B 0207 Os 1045 WATKINS B 0208016 1046 BOARDMAN B 020909 1047 DWNGER B 0209021 1048 DNOER B 021003 1049 BOARDMAN B 021607 1050 DNAER B 021808 1051 WINTERS B 0219014 1052 PERKINS B 0227023 1054 MOULTON B 022809 1055 KELLY B 0229012 1057 MCCARTHY B 0230017 1058 MACLEOD B 0230024 1059 BOYLE B 0232017 1060 CARDITO B 023601 1063 CARDITO B 0236018 1065 SCOTNICK B $02390 \mathrm{~s}$ 1066 SCOTNICK B 0239020 1067 MANION B 0240024 1068 MANION B 024102 1070 FLEMING B 024305 1071 MANION B 024403 1072 FLEMING B 0244012 1074 BACKUS B 0245015 1075 BACKUS B 0245015 1076 TEFFT B 024707 1077 PERKNNS B 0247024 1079 KELLY B 025002 1080 KELLY B 0250013 1081 KELLY B 0250021 1082 KELLY B 0250021 1083 SCOTNICKI B 0252020 1084 SCOTNICKI B 025303 1085 PERKNNS B 0120024 1086 PERKNNS B 0121 o s 1087 MACLEOD B 0121015 1089 TEFFT B 0123017 1090 TEFFT B 0123017 1091 TEFFT B 0123017 1092 BOARDMAN B 0124021 1093 BOARDMAN B 0126015 1097 MANION B 0131011 1098 MANION B 0131013 1099 CARDITO B 0131023 1100 CARDITO B 0131023
1102 DINGER B 0133012 1103 DNNGER B 0133012 1107 DNOER B 0134014 1108 MACLBOD B 031003 1109 MACLBOD B 031003 1110 DWGER B 0134020 1111 FLBMDNG B 031206 1113 SCOTNICKI B 0136010 1114 SCOTNICXI B 0136010 1115 BOARDMAN B 031302 1117 MYERS B 0137017 1118 MYERS B 013804 1119 SMTTH B 031502 1120 SMITH B 031502 1121 MCCARTHY B 0315022 1122 MCCARTHY B 031607 1123 MCCARTHY B 031706 1124 TEFFT B 0317015 1126 KELLY B 0318015 1128 MYERS B 0319014 1131 PERKINS B 0320016 1132 SCOTNICKI B 0321025 1134 BACKUS B 0323019 1135 FLEMING B 0325017 1136 PERKINS B 025409 1137 MYERS B 032802 1138 KRLLY B 032904 1139 KRILY B 025505 1140 MACLEOD B 033002 1141 BOARDMAN B 0256022 1143 BACKUS B 033708 1144 MELLOR B 0259019 1146 MELLOR B 026003 1148 SLESINGER B 0260025 1150 BACKUS B 0262011 1151 BACKUS B 0262018 1153 DINGER B 033903 1154 FLEMNNG B 0262022 1155 DNGER B 033903 1156 FLEMING B 0262022 1157 SCOTNICKI B 034007 1158 PERKINS B 026505 1159 MYERS B 034109 1160 MYERS B 0341021 1161 WATKINS B 0266017 1163 DINGER B 034909 1165 DNGER B 035005 1166 DINGER B 026708 1169 WINTERS B 0268023 1171 MANION B 0269017 1172 MANION B 0269025 1174 FLEMING B 027405 1176 BOYLE B 0276020 1177 MOULTON B 029304 1178 MYERS B 0293016 1179 MYERS B 029401 1180 SLESINGER B 0294012 1181 PERKINS B 0296023 1182 PËRKINS B 0296023 1183 PERKINS B 029703 1185 FLEMING B 0297014 1186 PLEMING B 0297014 1187 MCCARTHY B 0298013 1188 MCCARTHY B 0299014 
1189 KELLY B 0299021 1190 KELLY B 0299021 1192 MCCARTHY B 0299014 1193 MOULTON B 030204 1194 MOULTON B 030204 1195 MOULTON B 030204 1196 BOARDMAN B 030405 1197 SMITH B 0305012 1198 SMITH B 0305012 1199 MYERS B 0306016 1200 MYERS B 0306012 1201 KELLY B 0366011 1202 KBILLY B 0366011 1203 MACLEOD B 0306021 1204 KELLY B 036801 1205 MACLEOD B 030805 1206 DINGER B 0350013 1207 DINGER B 0351010 1208 DINGER B 0370014 1210 BOYLE B 0371019 1212 MACLEOD B 0353010 1213 PERKINS B 0372018 1214 DNNGER B 0354018 1215 PERKNNS B 038008 1218 DINGER B 0354025 1219 MACLEOD B 0356017 1220 MYERS B 038208 1222 MACLEOD B 0356022 1225 BOARDMAN B 0357011 1226 KELLY B 0385020 1227 KELLY B 0385020 1228 MACLEOD B 0357016 1230 BOARDMAN B 0386021 1231 BOARDMAN B 038709 1232 BOARDMAN B 0387013 1233 BOARDMAN B 0358024 1234 PERKINS B 038804 1235 BOARDMAN B 035904 1236 BOARDMAN B 0359011 1237 MCCARTHY B 038905 1239 MCCARTHY B 0389017 1240 MCCARTHY B 0361020 1242 BACKUS B 0394015 1244 MACLEOD B 0361025 1247 TEFFT B 039601 1248 PERKNS B 0362012 1249 MACLEOD B 0396015 1251 BOARDMAN B 039703 1252 FLEMING B 039804 1253 MYERS B 0399022 1254 FLEMING B 0398015 1255 KELLY B 0400012 1256 BULTER B 0344020 1259 QUIGLEY B 0138018 1260 QUIGLEY B 0310016 1261 QUIGLEY B 0310016 1262 QUIGLEY B 0310016 1263 TREJO B 0141024 1265 TUCKER B 0141019 1266 BRODSKY B 014302 1267 BRODSKY B 0144010 1269 BENNINGER B 0392023 1270 BRODSKY B 0142013 1272 ZIMMERMAN B 014708
1274 BULTER B 0391017 1275 TUCKER B 0141 os 1276 ENO B 0144017 1277 ZMMMERMAN B 0390020 1278 ZMMMERMAN B 0277016 1279 ZMMMERMAN B 0277019 1280 ZMMMERMAN B 0277021 1281 ZMMMERMAN B 0277022 1282 AUDET B 039002 1283 BAMMAN B 0278010 1285 QUIGLEY B 038505 1286 BULTER B 027902 1287 CRAWFORD B 0279021 1288 CRAWFORD B 028003 1289 QUIGLEY B 0381017 1291 CRAWFORD B 0281013 1292 QUIGLEY B 0360011 1294 CRAWFORD B 0281020 1296 CRAWFORD B 0281024 1297 QUIGLEY B 0365018 1298 AUDET B 037502 1299 CRAWFORD B 028202 1300 AUDET B 037502 1301 CRAWPORD B 028207 1302 CRAWFORD B 0280019 1303 CRAWPORD B 0280021 1304 TREJO B 0282025 1305 TREJO B 028302 1306 TREJO B 0283010 1307 RICARDSON B 030105 1308 RICARDSON B 070013 1310 RICARDSON B 070013 1311 BULTER B 040104 1313 ISELIN B 0403025 1314 RICARDSON B 069011 1315 AUDET B 0405021 1316 QUIGLEY B 0127013 1318 QUIGLEY B 0126024 1319 QUIGLEY B 0126024 1320 ZMMMERMAN B 014708 1321 ZIMMERMAN B 014708 1322 ZIMMERMAN B 0147022 1323 QUIGLEY B 065020 1324 QUIGLEY B 06607 1325 QUIGLEY B 06507 1326 TREJO B 014206 1327 QUIGLEY B 066016 1328 BENNINGER B 0346010 1329 PRATT B 021507 1330 PRATT B 0215017 1331 RICARDSON B 02370 ** 1333 BAIMAN B 0212013 1334 BAMMAN B 0214016 1335 QUIGLEY B 020304 1336 QUIGLEY B 020401 1338 BENNDNGER B 0221011 1339 AUDET B 022005 1340 RICARDSON B 033502 1341 QUIGLEY B 0223013 1342 Thompson D 03901 1343 Thompson D 039010 1345 Graves D 03806 1346 Still D 04007 1347 Still D 040011 
1348 Still D 040017 1349 Kirk D 041022 1350 Kirk D 042013 1353 McBumey D 04302 1354 McBurney D 04309 1355 McBurney D 043016 1356 McBurney D 043018 1357 Campbell D 04401 1358 Campbell D 044010 1359 William D 046014 1360 Williams D 04704 1362 Gordon D 048019 1363 Crimi D 050010 1364 Crimi D 050021 1366 Quillin D 051011 1367 Quillin D 051020 1368 Crawford D 05309 1370 Crawford D 054010 1372 Gardner D 05601 1373 Gardner D 05606 1374 Dicus D 057015 1375 Dicus D 05806 1376 Parsons D 05909 1377 Parsons D 059017 1378 Platerio D 06001 1380 Dickerson D 06207 1382 Hofstetter D 06305 1383 Hofstetter D 063023 1385 rison D 06501 1386 Beavers D 06706 i 387 Beavers D 067024 i 389 Hughes D 068023 1'390 Burgendahl D 069020 1393 Bergendahl D 069025 1394 Brink D 07103 1395 Brink D 071014 1397 Podoloff D 07207 1398 Podoloff D 07207 1399 Dietrich D 072015 1400 Dietrich D 07301 1401 Belisle D 073017 1402 Belisle D 07403 1403 Belisle D 074014 1404 West D 07601 1405 West D 076021 1406 Bergendahl D 0112020 1407 Crawford D 0113011 1408 Weat D 011406 1409 Thompson D 0114018 1410 Thompson D 011506 1411 Brink D 011509 1412 Brink D 0115012 1413 McBumey D 011605 1414 McBurney D 0116010 1415 Dicus D 0116019 1416 Dicus D 0116022 1417 Dicis D 011701 1418 Dicus D 0117012 1419 Gordon D 0117021 1420 Gordon D 0117022 1421 Gordon D 011801 1422 Gardner D 0118019 1423 Gardner D 0118019 1424 Parsons D 011903
1425 Williams D 0119020

1426 Crimi D 0121023 1427 Crimi D 0122014

1428 Still D O 122019 1429 Still D 012301 1431 Dickernon D 012307 1432 Dickerson D 012307 1434 Brink D 0123022 1435 BRINK D 012408 1436 Brink D 012408 1437 Crawford D 012502 1438 Crawford D 012503 1439 Beavem D 0125019 1441 Beavers D 012609 1442 Hofstetter D 0126017 1443 Hofitetter D 012701 1444 Hof ftetter D 012701 1445 Quillin D 012801 1446 Quillin D 012801 1447 Belisle D 0128019 1448 Beliule D 0128019 1449 Beliule D 0128019 1450 Podoloff, M.D. D 012905 1451 Podoloff, M.D. D 012907 1452 Bergendahl D 0129014 1453 Thompson D 0129024 1455 Thompson D 013107 1456 Dickerson D 0132017 1457 Parsons D 0132024 1458 Russell D 013505 1459 MORRISON D 015009 1460 PALMER D 037 O 5 1462 UNKNOWN OBSERVER D 0135025 1463 BARFIELD D 0135015 1465 BARTON D 013402 1466 BARTON D 0134014 1467 BARTON D 013309 1468 PALMER D 0121017 1469 PALMER D 0121017 1470 BRINK D 0131023 1471 BRINK D 0132023 1472 OVERSTREET D 0138017 1473 HILL D 0139012 1474 HIIL D 0139020 1475 VERNUM D 014001 1476 VERNUM D 0140010 1477 VERNUM D 0140011 1478 MILLER D 0140014 1479 LEE D 0140022 1480 LEE D 014106 1481 BRAMELY D 014108 1482 UNKNOWN OBSERVER D 0141021 1483 HOLLAND D 0142010 1484 HOLLAND D 0142022 1485 ALLMUS D 0143010 1486 CULL D 014403 1488 GARY D 014407 1489 GARY D 0144012 1490 BURNAM D 0145011 1491 BURNAM D 0145012 1492 BURNAM D 0145018 1493 YOTT D 0146017 1494 UNKNOWN OBSERVER D $01460 \mathrm{~S}$ 1495 Schrader D 013801 
1497 CABASSO S 046801

1498 STILL D 015309

1499 STILL D 015305

1505 THOMPSON D 0157017

1507 READ D 0161016

1508 READ D 0161016

1511 HUGHES D 0165023

1512 HUGHES D 0165023

1513 DIETRICH D 016602

1516 STILL D 0166013

1517 STILL D 0166013

1518 CAMPBELL D 017008

1520 MCBURNEY D 0171015

1522 BERGENDAHL D 0173011 ,

1523 BERGENDAHL D 017402

1524 HUGHES D 017409

1525 HUGHES D 0174021

1527 HUGHES D 0175011

1529 PLATERIO D 017607

1530 PLATERIO D 017607

1531 PLATERIO D 0176024

1532 BERGENDAHL D 018303

1533 BERGENDAHL D 0183016

1534 WEST D 0183022

1535 WEST D 018501

1536 WEST D 018601

1537 WILLIAMS D 0186014

1540 BRINK D 018905

1541 GRAVES D 024102

1542 GRAVES D 024102

1543 DIETRICH D 0189015

1544 DIETRICH D 0189020

1545 DIETRICH D 0190016

1546 HOHSTETTER D 0190019

1547 HOFSTETTER D 0190019

1548 HOFSTETTER D 0243016

1549 HOFSTETTER D 0192015

1551 HOFSTETTER D 0193010

1552 PLATERIO D 0247018

1553 GORDON D 0193017

1554 PLATERIO D 0247022

1556 GORDON $\cap 0194020$

1558 QUILLIN D 0195020

1560 CRAWPORD D 0197018

1561 CRAWFORD D 0232019

1562 CRAWFORD D 0198018

1563 BELISLE D 020203

1566 WILLIAMS D 020308

1568 HUGHES D 020501

1569 HUGHES D 020501

1570 WEST D 0205016

1571 WEST D 0206019

1572 STILL D 0207018

1574 UNKNOWN OBSERVER D 0210015

1577 BARTON D 0213011

1579 UNKNOWN OBSERVER D 021604

1580 UNKNOWN OBSERVER D 021606

1581 BURNAM D 021804

1582 BURNAM D 021804

1583 UNKNOWN OBSERVER D 0221020

1584 UNKNOWN OBSERVER D 0222019

1585 MORRISON D 022907

1586 CRAWFORD D 023208

1587 BERGENDAHL D 0233012
1589 BERGENDAHL D 0233012

1591 BRINK D 023506

1593 BRINK D 0236010

1594 PARSONS D 0236018

1595 PARSONS D 023705

1596 PODOLOFF D 0237019

1598 PODOLOFF D 023803

1599 MCBURNEY D 023809

1601 MCBURNEY D 023809

1602 HUGHES D 0239011

1603 HUGHES D 024003

1604 BELISLE D 024804

1605 THOMPSON D 0252010

1606 THOMPSON D 0252014

1607 DICUS D 0252020

1609 DICUS D 0254015

1610 DICUS D 025305

1611 MORRISON D 0254022

1613 DIETRICH D 0256014

1615 PARSONS D 025807

1616 WES D 0259015

1619 WILLIAMS D 0260024

1620 DICUS D 0263021

1622 GORDON D 026405

1623 GORDON D 026509

1624 GORDON D 026509

1627 QUILLIN D 0267017

1628 CRMI D 0267024

1630 CRMII D 026805

1631. CAMPBELL D 027007

1632 HOFSTETTER D 0272011

1633 UNKNOWN OBSERVER D 0274019 1634 UNKNNOWN OBSERVER D 0274022 1635 UNKNOWN OBSERVER D 0274022 1636 UNKNOWN OBSERVER D 0274019 1637 BARTON D 027502

1639 BARTON D 0277013

1640 UNKNOWN OBSERVER D 0278022

1641 UNKNOW' OBSERVER D 027905

1642 TANO D 029604

1643 TANO D 0296016

1646 RUSSELC D 0301020

1647 WILLLAMS D 0306021

1649 MCBURNEY D 030805

1650 HUGHES D 030903

1651 HUGHES D 0309014

1652 BERGENDAHL D 0312016

1653 BERGENDAHL D 0313020

1654 DICUS D 031407

1655 DICUS D 031408

1658 DICUS D 031405

1659 TANO D 031604

1660 TANO D 0316014

1661 PODOLOFF D 0316024

1662 PODOLOFF D 031707

1663 THOMPSON D 0317021

1665 BARTON D 0382020

1666 BARTON D 038307

1667 BARTON D 0383020

1668 BARTON D 0384012

1669 BARTON D 0384012

1670 UNKNOWN OBSERVER D 038503

1671 UNKNOWN OBSERVER D 038503

1672 UNKNOWN OBSERVER D 0385010 
1673 UNKNOWN OBSERVER D 0384024

1674 CABASSO S 027508

1676 GRAVES D 0388028

1677 GRAVES D 038903

1678 KELLEY S 018302

1681 STRAUSS S 032106

1682 STRAUSS S 032106

1684 BARTON D 038202

1686 UNKNOWN OBSERVER D 0379016

1687 UNKNOWN OBSERVER D 038008

1688 WILLIAMS D 032102

1690 HIATT C 0194017

1691 WILLIAMS D 0321015

1692 GRAVES D 0323017

1693 DINGER B 0115024

1694 GRAVES D 0324024

1695 GRAVBS D 0325015

1696 RANKN S 0128015

1698 QUILLIN D 032609

1699 QUILLIN D 0326012

1700 QUILLIN D 0326023

1701 WEST D 0327020

1702 BOYLE B 0127020

1703 WEST D 032805

1704 WEST D 0328013

1705 WES D 0328021

1706 PACKS 032304

1707 GARDNER D 0333022

1709 BRINK D 033604

1711 RUSSELL D 0336014

1712 BRINK D 0336021

1713 BRINK D 034007

1714 BRINK D 034007

1715 BRINK D 0340017

1717 FLEMNG B 049019

1718 BRACKN D 0343010

1720 BRACKIN D 034407

1721 PODOLOFF D 0350019

1722 MYERS B 0293016

1724 MYERS B 0293016

1728 STILL D 035203

1729 STILL D 035307

1730 BALL C 064017

1733 CAMPBELL D 035909

1734 CAMPBELL D 035806

1736 GORDON D 036207

1737 GORDON D 036207

1738 GORDON D 0363012 '

1739 GORDON D 0363012

1740 GORDON D 0361012

1741 GORDON D 0360010

1742 PODOLOFF D 036402

1744 CRAWFORD D 036607

1745 CRAWFORD D 036607

1746 CRAWPORD D 036607

1747 DIETRICH D 0366020

1748 DIETRICH D 0366020

1749 HOPSTETTER D 0368015

1750 BRACKIN D 037106

1751 BRACKIN D 037106

1752 Unidentified Commenter San Francisco S 0407017

1753 STOLLER S 0411022

1755 KELLY B 0170017

1761 MYERS B 0306012
1762 TREPAL C 06106

1763 PACK S 0225023

1764 DUKE S 021101

1766 UNKNOWN OBSERVER D 0221020

1767 BERGENDAHL D 0341011

1768 BERGENDAHL D 0391011

1769 BEAVERS D 0392011

1770 HUGHES D 0401016

1772 WEST D 0402023

1773 WBST D 040407

1774 MCBURNEY D 0404016

1775 MCBURNEY D 040501

1777 MORRISON D 040608

1779 WILLLAMS D 0407014

1782 GARDNER D 0412014

1783 TANO D 0410012

1784 TANO D 0410012

1785 TANO D 0411012

1786 TANO D 0411025

1787 BELISLE D 0414021

1789 EGBERT D 0417021

1792 BRINK D 0422012

1793 GORDON D 042707

1794 GORDON D 042707

1795 PARSONS D 042801

1798 PARSONS D 0429013

1800 CRAWFORD D 0429024

1801 CRAWFORD D 043004

1802 CRAWFORD D 043004

1804 CRIMI D 043201

1805 STLL D 042506

1807 STILL D 042506

1808 STLL D 043602

1809 CRAWFORD D 0436014

1812 GRAVES D 0437016

1813 GRAVES D 0437016

1814 CRMMI D 0447011

1815 CRMII D 0447011

1816 SCFRADER D 044603

1817 SCHRADER D 044501

1818 SANDERS D 0446010

1819 SANDERS D 0446015

1820 BARTON D 0444018

1821 HENDRICKS D 044404

1822 KAY D 0442020

1823 KAY D 0442025

1824 KAY D 044308

1827 O'DOUL D 0448022

1828 SMITH D 044907

1829 DICUS D 0459022

1831 MCBURNEY D 046008

1832 RICHARDSON D 046304

1834 QUILLIN D 046407

1835 WEST D 0466019

1837 STILL D 0467012

1838 STILL D 046805

1839 BRNNK D 0469020

1841 GORDON D 047205

1844 GORDON D 047304

1846 DICUS D 0473020

1848 PARSONS D 0474019

1849 PARSONS D 0474019

1850 PARSONS D 0474019

1852 STILL D 0475021 
1854 THOMPSON D 047607 1855 THOMPSON D 0476017 1858 BRINK D 047704 1860 BRACKIN D 0477010 1862 CRAWRORD D 047905 1863 HOPSTETTER D 0481016 1864 BRINK D 048209 1865 HUGHES D 048301 1866 HOFSTETTER D 0483024 1867 GORDON D 0484017 1869 PLATERIO D 0485018 1870 EGBERT D 048603 1872 BER GENDAHL D 0489025 1873 MORRISON D 0490016 1875 CAMPBELL D 049201 1876 BRINK D 0492021 1877 WILLIAMS D 0493011 1878 BRACKIN D 0499024 1879 QUILLIN D 0500025 1881 THOMPSON D 0504017 1882 THOMPSON D 0504017 1883 CRAWFORD D 050503 1884 MORRISON D 0505024 1885 CRAWFORD D 0.506022 1886 WILLIAMS D 050707 1887 WILLIAMS D 050707 1888 BRAMLETT D 051209 1891 SANDERS D 0512012 1892 SANDERS D 0512012 1893 HUGHES D 0400023 1894 ODEAR D 0516013 1895 ODEAR D 0516018 1896 ODEAR D 0516025 1897 ODEAR D 051704 1898 ODEAR D 0516013 1901 HOLMBECK D 051801 1903 GARFIELD D 0519012 1904 GARFIELD D 0519017 1905 HOFSTETTER D 052105 1906 PODOLOFF D 0521015 1907 WES D 0521024 1908 GORDON D 052404 1910 GORDON D 0524019 1911 MORRISON D 0526013 1912 MORRISON D 0527018 1913 DICKERSON D 052905 1914 BRINK D 053002 1915 BRINK D 0530015 1916 BRINK D 053001 1917 BELISLE D 053105 1918 EGBERT D 0532010 1919 KIRK D 053501 1920 BRINK D 0535019 1921 EGBERT D 0535022 1922 CAMPBELL D 053602 1923 SANDERS D 037703 1924 SANDERS D 037703 1925 PLATERIO D 032006 1926 PLATERIO D 0320014 1927 BRAMLETT D 0377012 1928 BRAMLETT D 0377022 1929 BRAMLETT D 037907 1930 SMITH D 0211021 1932 SMITH D 021201
1933 SMITH D 021206

1937 BRAMLETT D 0215015 1938 GARFIEL D D 0216021 1939 GARFIELD D 0217018 1940 GARFIELD D 021704 1941 HENDRXX D 0220020 1943 ALMAS D 0220011 1945 SCHRADER D 0278015 1946 KAY D 028003 1947 KAY D 0280012 1948 RUSSELL B 0331022 1951 FLETCHER P 041023 1952 FLETCHER P 041016 1953 BROWN P 04301 1954 BROWN P 043013 1955 JOHNSON P 04404 1956 JOHNSON P 044016 1957 PORTER P 045010 1958 PORTER P 045012 1959 PORTER P 045012 1961 SGARLATA P 04604 1962 SGARLATA P 04606 1964 DUBIEL P 046023 1965 DUBIEL P 04704 1966 DUBIEL P 04708 1967 VIROSTEK P 047012 1968 VIROSTEK P 047021 1969 VIROSTEK P 04802 1971 KADLECEK, PH.D. P 048015

1972 ROTH P 04905

1973 ROTH P 04905 1974 BRODIE P 05006 1975 HIATT III P 05101 1976 HIATT P 05106 1977 SLOBODIEN P O 51022 1980 SLOBODIEN P 052010 1981 SLOBODIEN P 052011 1982 SLOBODIEN P O 52012 1983 KOH P 052021 1984 KOH P 052023 1985 GRIFPIN P 053024 1986 GRIFPIN P 05401 1987 COOMBS P 054014 1988 COOMBS P 054014 1989 COOMBS P 054016 1990 COOMBS P O 54019 1991 FULLER P 05509 1992 FULLER P 055011 1993 FULLER P O 55019 1994 FULLER P 055024 1995 JOHNSRUD P 05701 1996 JOHNSRUD P 057013 1997 JOHNSRUD P 057018 1998 NARDI P 058019 1999 NARDI P 05904 2000 NARDI P 059011 2001 NARDI P 059014 2003 DORNSIFE P 060019 2004 DORNSIFE P 060019 2006 DORNSIFE P 06105 2007 DORNSIFE P 061019 2008 DORNSIFE P 061019 2009 DORNSIFE P 06206 2010 DORNSIFE P 06002 
2012 SCHUTZ P 063024 2013 SCHUTZ P 06308 2014 PINKARD P 06608 2015 STERN P 066023 2016 STERN P 06602 2017 JOHNSRUD P 06909 2018 JOHNSRUD P 069019 2019 JOHNSRUD P 010901 2020 DORNSIFE P 011005 2021 COOMBS P 0113012 2022 COOMBS P 0113012 2023 COOMBS P 0113012 2024 SLOBODIEN P 0113020 2025 SLOBODIEN P 011408 2026 SLOBODIEN P 011409 2027 SLOBODIEN P 0114010 2028 SLOBODIEN P 011408 2029 SLOBODIEN P 011501 2030 SLOBODIEN P 011503 2031 SLOBODIEN P 011506 2032 BRODIE P 0115017 2033 BRODIE P 0115019 2034 BRODIE P 0115022 2035 JOHNSON P 011609 2036 JOHNSON P 0116011 2037 JOHNSON P 0116017 2038 JOHNSON P 0116020 2039 JOHNSON P 0116022 2040 STERN P 0117016 2041 STERN P 011802 2042 STERN P 0118022 2043 KOH P 0120010 2044 FULLER P 012103 2045 FULLER P 012103 2046 FULLER P 012107 2047 FULLER P 0120020 2048 FULLER P 0120020 2049 BROWN P 0121014 2050 DORNSIFE P 0122015 2051 DORNSIFE P 0122017 2052 DORNSIPE P 0122025 2054 JOHNSRUD P 0123017 2055 JOHNSRUD P 0123017 2056 JOHNSRUD P 0123017 2057 JOHNSRUD P 0123022 2058 COOMBS P 0124016 2060 COOMBS P 0124021 2061 COOMBS P 012508 2062 SCHUTZ P 0125012 2063 SCHUTZ P 0125016 2064 SCHUTZ P 0125017 2065 NARDI P 0125023 2067 NARDI P 012609 2068 NARDI P 0126011 2069 NARDI P 0125023 2070 JOHNSON P 0126018 2071 JOHNSON P 0126018 2072 COOMBS P 012709 2073 COOMBS P 0127019 2074 COOMBS P 0127019 2075 SLOBODIEN P 0127023 2076 DUBIEL P 012804 2077 DUBIEL P 012804 2078 DUBIEL P 012804
2079 GRIFFIN P 0128021 2080 GRIFFIN P 0128024 2082 COOMBS P 015509 2083 COOMBS P 01300 is 2084 JOHNSRUD, PH.D. P 013205 2085 JOHNSRUD P 013205 2086 NARDI P 0132025 2087 NARDI P 013303 2088 NARDI P 0133013 2089 NARDI P 0133019 2090 DORNSIFE P 0135022 2091 DORNSIFE P 0135022 2092 COOMBS P 013705 2093 FULLER P 013805 2094 FULLER P 013805 2095 PULLER P 0138020 2096 JOHNSON P 0138025 2098 JOHNSON P 013904 2099 PINKARD P 0139013 2100 PINKARD P 0139013 2102 FRACKE P 0140022 2103 FRACKE P 0140025 2104 FRACKE P 0142023 2105 SZALINSKY P 014303 2106 SZALINSKY P 014303 2107 SCHUTZ P 0147019 2108 SCHUTZ P 0147023 2110 DORNSIFE P 015005 2111 JOHNSRUD P 0151017 2113 JOHNSRUD P 015209 2114 JOHNSRUD P 0152011 2115 JOHNSRUD, PH.D. P 0152014 2121 MINNAR C 0128035 2122 CEMBER C 0520012 2127 DURMAN S 0291014 2129 DINGER B 0156012 2131 DINGER B 0156012 2132 DINGER B 0156012 2134 DINGER B 016201 2136 CARDITO B 0236018 2138 SCOTNICKI B 0136010 2145 DICUS D 031408 2146 DICUS D 031408 2150 GRAVES D 038907 2152 MYERS B 0293016 2157 KAY D 0442025 2158 KAY D 0442025 2162 KELLEY S 021809 2166 DUMAS B 038010 2168 TREPAL C 06106 2170 MINNAR C 025908 2175 DUKE S 0161013 2177 DUKE S 0161013 2178 DUKE S 0161013 2179 PACK S 0167016 2180 PACK S 0167016 2181 DEBRULER S 016907 2183 DAVIS S 0270017 2184 STRAUSS S 027308 2185 CABASSO S 027508 2189 DUKE S 025202 2190 DUKE S 025202 2191 DEPERRY S 0200015 2192 HUBBARD S 0120020 
2193 HUGHES S 0122022

2195 Unidentified Commenter San Francisco S 0 191, 023 2197 WATKINS B 051022

2198 PERKINS B 059015 2200 CARDITO B 068014 2201 MANION B 0113021 2203 SMITH B 011903 2204 SMITH B 045015 2207 MACLEOD B 0173016 2208 BOARDMAN B 018306 2210 BOARDMAN B 018306 2213 GRAVES D 0324024 2216 BRINK D 053001 2217 BRAMLETT D 021501 2220 BRAMLETT D 021501 2222 DEBRULER S 0172016 2223 DAVIS S 034707 2227 GORDON D 0361012 2230 GARFIELD D 021704 2233 DEBRULER S 0240016 2235 MANION B 024102 2237 PERKINS B 0247024 2241 UNKNOWN OBSERVER D 038503 2243 BERGENDAHL D 0391011 2245 HOLMBECK D 0517021 2248 HONEY C 0168016 2250 STRAUSS S 011701 2251 BURKLIN S 0219019 2253 KELLEY S 0318010 2255 STRONG S 046401 2257 TEFFT B 058017 2258 TEFFT B 058017 2260 DINGER B 0209021 2261 BACKUS B 033708 2262 STILL D 015305 2264 THOMPSON D 0157017 2266 BERGENDAHL D 0173011 2267 HUGHES D 017409 2268 WILLIAMS D 0186014 2269 WILLIAMS D 0186014 2271 DIETRICH D 0189015

2273 WEST D 0402023 2274 BRAMLETT D 0215010 2275 BRAMLETT D 0215010 2277 SMITH D 0211021 2280 GORDON D 047304 2285 SLOBODIEN P 011408 2286 COOMBS P 015301 2287 SLOBODIEN P 015402 2289 SLOBODIEN P 015402 2290 PORTER P 0155024 2291 SCHUTZ P 0219017 2292 PORTER, JR. P 0155024 2295 SCHUTZ P 022001 2296 SCHUTZ P 022108 2297 SCHUTZ P 0222015 2298 GRIFFIN P 0223025 2299 PLETCHER P 022508 2300 FLETCHER P 022508 2301 COOMBS P 0226011 2303 COOMBS P 022703 2304 COOMBS P 022708 2305 COOMBS P 022708 2306 FULLER P 0157018
2307 COOMBS P 022708 2308 FULLER P 0158012 2309 FULLER P 0158019 2310 FULLER P 0228015 2311 BRODIE P 022906 2313 BROWN P 015904 2315 BRODIE P 022906 2316 BROWN P 016002 2317 DORNSIFE P 0229020 2318 DORNSIFE P 0229020 2319 DORNSIFE P 0230013 2320 JOHNSON P 0231011 2321 KADLECEK P 016009 2323 JOHNSON P 0231011 2324 KADLECEK P 0160017 2325 JOHNSON P 0231011 2326 JOHNSRUD P 023403 2328 DORNSIFE P 0160021 2329 DORNSIFE P 0161012 2332 PINKARD P 0235020 2333 PINKARD P 0235020 2334 DORNSIFE P 0161012 2335 PINKARD P 0236022 336 KOH P 0237017 2337 KOH P 0161023 2338 SGARLATA P 023806 2340 HIATT III P 0162011 2342 FULLER P 0238021 2343 JOHNSON P 016308 2344 NARDI P 0239023 2346 NARDI P 0239023 2347 NARDI P 0239023 2348 NARDI P 0239023 2349 DORNSIFE P 024109 2350 DORNSIFE P 024204 2351 NARDI P 024407 2352 NARDI P 024407 2353 BROWN P 0244014 $2354 \mathrm{KOH}, \mathrm{P} 024801$ $2355 \mathrm{KOH}$, P 024801 2357 JOHNSRUD P 0249012 2358 NARDI P 0250023 2359 SLOBODIEN P 025302 2360 SLOBODIEN P 025402 2363 SCHUTZ P 0254010 2364 SCHUTZ P 0254010 2365 SCHUTZ P 0254010 2367 JOHNSON P 0256015 2368 JOHNSON P 0256015 2369 KOH, P 0257025 $2370 \mathrm{KOH}$, P 0257025 2371 STERN P 0258015 2372 STERN P 0258015 2374 PINKARD P 0236022 2375 DORNSIFE P 0259018 2376 DORNSIFE P 026002 2377 COOMBS P 0164019 2378 GRIFFIN P 0260011 2379 GRIFFIN P 0260015 2380 GRIFFIN P 0260011 2381 COOMBS P 026101 2382 COOMBS P 026101 2383 JOHNSRUD P 0262011 2385 GRIFFIN P 0165018 
2387 DORNSIFE P 0265010 2388 DORNSIFE P 0265010 2389 PINKARD P 016705 2390 FULLER P 0265022 2391 KOH, P 0266016 2392 FLETCHER P 0167019 2393 BROWN P 0267012 2394 BROWN P 0267012 2395 PORTER, JR. P 0168019 2396 PORTER, JR. P 0168022 2397 SKOSKI P 027406 2398 PORTER P 016902 2399 FRACKE P 0275020 2400 PORTER P 016908 2401 SZALINSKY P 0278020 2402 SZALNNSKY P 027903 2403 BILAORN P 028101 2405 FRACKE P 028205 2407 STERN P 0171022 2408 STERN P 0172012 2409 SCHMIDT P 0284014 2410 STERN P 0172018 2411 SCHMIDT P 028403 2412 SCHMIDT P 024504 2413 WING P 028602 2415 JOHNSRUD P 017309 2417 JOHNSRUD P 017309 2418 JOHNSRUD P 017309 2419 FULLER P 0175011 2420 FULLER P 0175011 2421 FULLER P 0175025 2422 PULLER P 0176010 2424 SCHUTZ P 018106 2425 SCHUTZ P 0181018 2427 NARDI P 018203 2428 DORNSIFE P 0183017 2430 COOMBS P 0184021 2431 KELLY B 06304 2432 JOHNSRUD P 0185018 2433 NARDI P 018803 2434 NARDI P 018803 2435 SCOTNICKI B 063018 2437 DUBIEL P 0192013 2438 DUBIEL P 0193011 2439 WATKINS B 0181012 2440 DUBIEL P 019304 2441 KELLY B 0182014 2442 TEFFT B 019001 2444 PINKARD P 019401 2445 PINKARD P 0194021 2447 GRIFFIN P 0194024 2449 GRIPFIN P 0195021 2451 GRIPFIN P 0195021 2454 JOHNSRUD P 019603 2455 MANION B 0131013 2457 SLOBODIEN P 019801 2458 RUSSELL P 0202010 2459 SCOTNICKI B 034007 2462 KAY D 044308 2463 SHELLY P 0208015 2466 JOHNSRUD P 0211022 2467 JOHNSRUD P 0212014 2468 PINKARN P 021301 2469 COOMBS P 0213012
2470 COOK S 0410012 2471 BROWN P 0217019 2473 COOMBS P 0287018 2476 JOHNSRUD P 0308010 2477 JOHNSRUD P 0308010 2478 JOHNSRUD P 0308010 2479 GRIFFN P 0310013 2480 GRIFFIN P 0310013 2481 GRIPFIN P 0310013 2482 GRIFFIN P 0310015 2483 GRIFFIN P 0310015 2484 GRIFFIN P 0310015 2485 PINKARD P 0311015 2486 PINKARD P 0311015 2487 PINKARD P 0311015 2489 COOMBS P 0312023 2490 COOMBS P 0313011 2491 COOMBS P 0313016 2492 COOMBS P 0314052 2494 BURKLIN S 0152022 2495 SLOBODIEN P 031501 2496 SLOBODIEN P 031502 2497 SLOBODIEN P 031504 2498 SLOBODIEN P 031504 2500 SLOBODIEN P 0315011 2501 SLOBODIEN P 0315019 2502 SLOBODIEN P 0315020 2503 SLOBODIEN P 0315021 2504 SLOBODIEN P 0315021 2505 SLOBODIEN P 0315021 2506 SLOBODIEN P 0316016 2507 VIROSTEK P 0319017 2508 VIROSTEK P 032004 2509 VIROSTEK P O 320022 2510 FLETCHER P 032102 2511 FLETCHER P 0321024 2512 JOHNSON P 0322012

2513 JOHNSON P 0322021 2515 JOHNSON P 0322023 2516 JOHNSON P 0323024 2517 FULLER P 0324024 2518 FULLER P 032602 2519 FULLER P 032602 2520 FULLER P 032602 2521 FULLER P 032607 2522 FULLER P 0326017 2523 FULLER P 032602 2524 BROWN P 0327015 2525 BROWN P 0327015 2526 BROWN P 0327015 2527 BROWN P 0327015 2528 BROWN P 0327021 2529 BROWN P 0329018 2530 BRODIE P 0329025 2531 BRODIE P 033009 2532 BRODIE P 0330012 2533 BRODIE P 033104 2534 BRODIE P 033109 2535 BRODIE P 0331014 2536 BRODIE P 0332015 2537 SCHUTZ P 0334011 2538 SCHUTZ P 0334011 2539 SCHUTZ P 0334011 2540 SCHUTZ P 0334013 
2541 SCHUTZ P 033501 2542 SCHUTZ P 033501 2543 SCHUTZ P 0335011 2544 SCHUTZ P 0335011 2545 NARDI P 0338015 2546 COOMBS P 0337018 2547 COOMBS P 0337018 2548 NARDI P 0343015 2549 DUBIEL P 0345015 2550 DUBIEL P 0345019 2551 DUBIEL P 0345015 2552 PORTER P 034802 2553 PORTER, JR. P 034802 2554 PORTER P 0349013 2555 GRIFFIN P 035105 2556 GRIFFIN P 035106 2557 GRIPFIN P 035109 2558 GRIFFIN $P 035105$ 2559 GRIFFIN P 0352013 2560 GRIFPIN P 0352013 2561 JOHNSRUD P 035409 2562 JOHNSRUD, PH.D. P 035409 2563 JOHNSRUD P 035409 2564 JOHNSRUD, PH.D. P 035502 2565 JOHNSRUD P 035505 2566 JOHNSRUD, PH.D. P 0355014 2567 JOHNSRUD P 0356023 2569 STERN P 0360017 2570 STERN P 0361017 2571 STERN P 0361017 2572 JOHNSON P 036302 2574 KOH, P 036607 2576 SCHUTZ P 0367024 2577 SCHUTZ P 036805 2578 SCHUTZ P 036805 2579 SCHUTZ P 0368 O S 2582 BRODIE P 036902 2584 NARDI P 037704 2585 NARDI P 037704 2586 CRIMI D 043201 2587 NARDI P 0378014 2588 NARDI P 0378014 2589 NARDI P 0378014 2590 DUBIEL P 037905 2591 DUBIEL P 038905 2592 DUBIEL P 038009 2593 PORTER P 038108 2594 PORTER, JR. P 038108 2595 COOMBS P 0381020 2596 COOMBS P 038301 2597 PINKARD P 0385014 2599 NARDI P 0387012 2600 NARDI P 0387012 2601 RICHARDSON P 038904 2602 COOMBS P 039102 2603 COOMBS P 039102 2604 COOMBS P 039102 2605 SCHUTZ P 0391012 2606 SCHUTZ P 0391012 2608 SCHUTZ P 0392024 2609 SCHUTZ P 039308 2610 SCHUTZ P 0392012 2611 KOH P 039408 2613 KOH P 0394017
2615 JOHNSON P 0397017 2616 JOHNSRUD P 0401018 2617 JOHNSRUD P 0401021 2618 PINKARD P 040407 2619 PINKARD P 040407 2620 JOHNSRUD P 0405018 2621 JOHNSRUD P 0405018 2622 JOHNSRUD P 040601 2623 FULLER P 040608 2624 FULLER P 0407017 2625 FULLER P 0407017 2626 FULLER P 0407017 2627 FULLER P 0408012 2629 FULLER P 0409016 2630 FULIER P 0408022 2631 SLOBODIEN P 0411025 2632 SLOBODIEN P 0412010 2634 SLOBODIEN P 041301 2635 SLOBODIEN P 041306 2636 SLOBODIEN P 0413012 2637 SLOBODIEN P 0413014 2638 GRIFFIN P 041406 2639 GRIFFIN P 041406 2640 SCHUTZ P 0414020 2641 SCHUTZ P 0414020 2642 SCHUTZ P 041501 2643 SCHUTZ P 0414020 2644 STERN P 041607 2645 STERN P 041607 2646 PORTER P O 416012 2647 COOMBS P 0419014 2648 SCHUTZ P 0421023 2649 SCHUTZ P 0421023 2650 DUBIEL P 0423015 2651 DUBIEL P 0423016 2652 DUBIEL P 0423015 2653 JOHNSON P 042502 2654 JOHNSON P 042502 2655 JOHNSON P 0425016 2656 JOHNSON P 042502 2657 FRACKE P 0432013 2658 PORTER P 044304 2659 STERN P 044406 2660 STERN P 0444014 2661 PINKARD P 0444023 2663 SCHUTZ P 044701 2665 SCHUTZ P 044701 2666 BROWN P 0448012 2667 BROWN P 0448012 2668 JOHNSRUD P 045008 2670 JOHNSRUD P 045008 2671 FLETCHER P 0450023 2673 FLETCHER P 0450023 2674 JOHNSON.P 045109 2676 SLOBODIEN P 045407 2677 JOHNSON P 0455016 2678 JOHNSON P 0455016 2679 JOHNSON P 0455016 2680 GRIFFWN P 0456012 2681 GRIFFIN P 0456012 2683 SCHÜTZ P 045707 2684 SCHUTZ P 0457019 2685 SCHUTZ P 045707 2686 FULLER P 045907 
2687 STERN P 046201 2688 STERN P 046201 2689 SLOBODIEN P 046401 2690 SLOBODIEN P 046401 2692 COOMBS P 046407 2693 COOMBS P 046407 2696 LaGUARDIA P 037006 2698 REILLY P 037609 2699 LaGUARDIA P 037208 2700 LaGUARDIA P 037202 2701 LaGUARDIA P 03011 2702 RIEMAN P 0426014 2703 RIEMAN P 0426014 2704 HENDRICKS P 0428023 2705 HENDRICKS P 0428023 2706 RIEMAN P 035806 2708 LaGUARDIA P 0371016 2709 BARKER P 0373016 2710 BARKER P 0373016 2711 JOHNSRUD P 0465021 2712 JOHNSRUD P 046608 2713 SCHUTZ P 046709 2714 SCHUTZ P 0468011 2715 SLOBODIEN P 046805 2716 SLOBODIEN P 046805 2717 COOMBS P 046906 2718 RICHARDSON P 0469018 2719 RICHARDSON P 0469018 2720 JOHNSRUD P 047006 2721 BROWN P 047309 2722 GRIFFIN P 047509 2723 GRIFPIN P 047509 2724 PINKARD P 047606 2725 PINKARD P 0476017 2726 GRIFFIN P 0478022 2727 GRIFFIN P 0478022 2729 STERN P 0479016 2731 FULLER P 048104 2732 FULLER P 048104 2733 FULLER P 0482011 2734 COOMBS P 0482017 2735 COOMBS P 048301 2736 FLETCHER P 048401 2737 KOH, P 0485021 2738 JOHNSRUD, PH.D. P 048608 2739 PINKARD P 048903 2740 PINKARD P 048903 2741 VIROSTEK P 0492017 2742 VIROSTEK P 0492017 2743 COOMBS P 049301 2744 JOHNSON P 0493015 2745 FRACKE P 0495014 2746 BYRNE P 0501017 2748 SHELLY P 050205 2749 SHELLY P 050205 2750 LEVIN P 0502012 2751 LEVIN P 0502012 2752 NARDI P 0502018 2753 NARDI P 0503010 2754 DAHODWALA P 0503017 2755 DAHODWALA P 050405 2756 PINKARD P 050508 2757 PINKARD P 0505011 2758 PINKARD P 050602
2759 GRIFFIN P 050704 2760 GRIPFIN P 0507013 2761 KOH P O 507020 2762 JOHNSON P O 509013 2763 FLETCHER P O 511014 2764 FULLER P 051502 2765 COOMBS P 051604 2766 SCHUTZ P 0516018 2767 JOHNSRUD P 0519022 2768 TILBROOK C 0439019 2769 Strong S 04606 2770 BESSERMIN S $02990 \mathrm{~S}$ 2771 CABASSO S 0310019 2773 WATKINS B 026702 2775 MCBURNEY D 0307014 2777 BERGENDAHL D 0351 o 5 2778 BERGENDAHL D 035105 2779 SMITH B 045023 2780 SMITH B 045023 2782 MANION B 06707 2783 MACLEOD B 031003 2784 UNKNOWN OBSERVER D 021606 2786 PASNACHT S 02909 2790 WOLBARST S 050017 2792 MANION B 0130013 2793 PARSONS D 0428023 2794 CRMMI D 043107 2795 STILL D 0434015 2796 CRAWPORD D 0436014 2797 O'DOUL D 0448022 2798 SHOCKLEY S 043405 2799 MACLEOD B 017203 2803 MINNAR C 0236016 2804 RICHARDSON C 0369013 2805 RAFFENSPERGER C 024808 2806 WILLIAMS C 025208 2807 RAPFENSPERGER C 024806 2808 JOHNSON C 024903 2809 RESCEK C 037001 2810 RESCEK C 036804 2811 RESCEK C 036804 2813 BURKLIN S 040018 2814 KNIGHT S 044708 2815 CEHN S 0449011 2817 FASNACHT S 0421019 2818 FASNACHT S 0425020 2819 MELLOR B 055014 2820 PERKINS B 06009 2821 DINGER B 0160011 2823 DINGER B 0132018 2824 BEAVERS D 027502 2825 BEAVERS D 027502 2826 GRAVES D 0388028 2827 BARTON D 038202 2828 TANO D 041001 2829 GARDNER D 0412014 2837 BRINK D 047704 2839 BRACKIN D 0477010 2840 CRAWPORD D 047905 2842 FULLER P 0158022 2844 JOHNSRUD P 023403 2846 BRACKIN D 0180020 2847 BRACKIN D 018106 2848 BRACKIN D 018106 
2849 THOMPSON D 0181013 2850 MOBLEY A 045017 2851 MOBLEY A 045018 2852 MOBLEY A 045019 2853 MOBLEY A 045022 2854 MOBLEY A 04606 2855 CARROLL A 046015 2856 CARROLL A 046015 2857 FUENTE A 04707 2858 FUBNTE A 047011 2859 KEARFOTT A 047022 2860 KEARFOTT A 048010 2861 KNIGHT A 04901 2862 KNIGHT A 04909 2864 de VENTE A 049021 2865 de VENTE A 049021 2866 de VENTE A 049023 2867 GARRY A 05006 2868 GARRY A 050015 2869 COSTNER A 05108 2870 COSTNER A 05108 2871 COSTNER A 051015 2872 COSTNER A 051016 2873 BENJAMIN A 052012 2874 BENJAMIN A 052024 2876 RUPERT A 053016 2877 RUPERT A 053018 2878 RUPERT A 053019 2879 BRILL A 054012 2880 ETHERIDGE A 05504 2881 ETHERIDGE A 05504 2882 ETHERIDGE A 05504 2883 ETHERIDOE A 05508 2885 McCOY A O 55022 2886 JOBSON A 056013 2887 JOBSON A 056021 2888 JOBSON A 056021 2889 SMITH A 057012 2890 SMITH A 057012 2892 MURRAY A 058018 2893 MURRAY A 05903 2894 MURRAY A 059010 2896 McDONALD A 06008 2897 McDONALD A 060015 2898 McCLAIN A 06108 2899 McCLAIN A 061018 2901 PASSETTI A 06203 2903 PASSETTI A 062016 2904 PASSETTI A 062017 2905 MOBLEY A 010301 2908 CEHN S 0272012 2910 MEDLING S 027407 2911 COOK S 025905 2912 RESCEK C 0245014 2913 SHARKEY C 024506 2915 FOSTER C 0148022 2916 WILLIAMS C 0143025 2917 KNIGHT S 0103014 2921 MEDLING S 0445011 2924 PERKINS B 0119023 2925 MYERS B 0137017 2928 STRAUSS S 020704 2929 MORRISON D 040608 2930 GORDON D 052404
2931 TREPAL C $03730 \mathrm{~s}$ 2932 HOLDEN C 043703 2933 DAVIS S 039025 2934 KBLLEY $S 042021$ 2935 STRAUSS S 04909 2936 KBLLEY S 0110021 2937 DEBRULER \& 017501 2938 CABASSO S 0186021 2939 CABASSO S 0217024 2941 KBLLEY S 0286022 2944 BAIIEY S 022006 2945 CABASSO S 0220015 2947 CABASSO S 0220015 2949 PACK S 0226017 2950 KASE S 022702 2951 KNICHT S 029007 2953 PACK S 032502 2954 BAILEY S 0327019 2955 ADAMS S 0242021 2958 EICHELBERGER S 0253023 2959 EICHELAERGER S 0253023

2963 Unidentified Commenter San Francisco S 0141019 2964 Unidentified Commenter San Francisco S 014407 2966 DEBRULER S 0446022 2968 KELLEY S 0495023 2969 KELLEY S 035901 2970 COHEN S 0333022 2971 BAILEY S 0374018 2972 STEWARD-SMITH S 037703 2974 Unidentified Commenter San Francisco S 0495017 2976 SLESINGER B 047022 2977 FLEMING B 04903 2979 BOARDMAN B 018306 2980 BACKUS B 0198023 2981 PLEMING B 031206 2982 PERKINS B 0139019 2983 BACKUS B 0338015 2985 BRINK D 0153018 2986 THOMPSON D 0156018

2987 READ D 0162014 2988 WILLIAMS D 016408 2989 WILLIAMS D 020402 2990 OVERSTREET D 0212021 2992 WILLIAMS D 0260012 2994 BRACKIN D 0420010 2997 CAMPBELL D 0356018 2998 CRAWPORD D 0364020 2999 NARDI P 0377019 3001 GARRY A 010704 3002 CARROLL A 0107024 3003 CARROLL A 010801 3004 CARROLL A 01070 is 3006 RUPERT A 010806 3008 COSTNER A 010908 3009 COSTNER A 0109021 3010 MORGAN A 011107 3011 MORGAN A 0111012 3012 KEARPOTT A 011205 3013 KEARPOTT A 0112021 3014 KEARFOTT A 011301 3015 SMTTH A 011306 3016 SMITH A 0113011 3019 SMITH A 0113021 3020 MURRAY A 0114016 
3021 BRIIL A 011505 3022 BRILL A 0115015 3023 BRILL A 011602 3024 BRILL A 011604 3025 BRILL A 011609 3026 JOBSON A 0116025 3027 JOBSON A 011707 3028 JOBSON A 011707 3029 JOBSON A 011709 3030 JOBSON A 0117010 3031 SMITH A 011901 3032 MOBLEY A 0119013 3033 MOBLEY A 0119023 3035 FUENTE $A$ O 120021 3036 PUENTE A 0120024 3037 MoCLAIN A 012201 3038 MCCLAIN A 012204 3039 MURRAY A 012208 3040 MURRAY A 012208 3041 McCOY A 012302 3042 MaCOY A 012305 3043 McCOY A 012307 3044 MOBLEY A 0123013 3045 MOBLEY A 0123013 3046 JOBSON A 0124012 3047 JOBSON A 0124012 3048 KNIGHT A 0125022 3049 KNIGHT A 0125023 3050 CARROLL A 0126019 3051 SMITH A 0127012 3052 SMITH A 0127017 3053 MORGAN A 012801 3054 MORGAN A 012803 3055 MORGAN A 012809 3056 McDONALD A 0129013 3057 MCDONALD A 0129013 3058 JOBSON A 013106 3059 MURRAY A 013107 3060 MURRAY A 0131013 3061 RUPERT A 013201 3062 MOBLEY A 0132018 3063 MOBLEY A 013309 3064 MPBLEY A 0133011 3065 JOBSON A 013408 3066 JOBSON A 013408 3067 GARRY A 0134019 3068 SMITH A 013601 3069 MORGAN A 0136016 3070 GARRY A 013705 3071 GBORGE A 014104 3072 STANGLER A 014203 3073 STANGLER A 0142015 3074 STANGLER A 0142015 3075 SLAPER A 0143015 3076 FAVRET A 0144011 3077 FAVRET A 0144013 3078 CALHOUN A O 145010 3079 CALHOUN A 0145018 3080 CALHOUN A 0145018 3081 ESCO A 014807 3082 ESCO A 014807 3083 HAMRICK A 014909 3084 EMMEL A 0149022 3085 EMMEEL A 015002
3086 BMMEL A 0150018 3087 BMMEL A 015102 3089 HENDRICKS A 0131022 3091 HENDRICKS A 015208 3092 HENDRICKS A 0152014 3093 KEIFER A 0153025 3094 KEIFER A 0153020 3095 KEIIFER A 015407 3096 RILEY A 0155022 3097 RILEY A 0157025 3098 RILEY A 0158019 3099 RILEY A 0158019 3100 O'BRIRN A 0159023 3101 O'BRIEN A 0159023 3102 O'BRIEN A 0159023 3103 O'BRIEN A 0166013 3105 O'BRIEN A 016707 3106 O'BRIEN A 016707 3107 O'BRIEN A 017102 3108 DAVIS A 0171019 3109 DAVIS A 017304 3110 BRILL A 0178013 3111 BRIL A 017901 3113 MCCARTHY B 0197011 3114 MCCARTHY B 0197011 3116 BOARDMAN B 020909 3122 TEFFT B 058017 3123 MOBLEY A 0179023 3124 RUPERT A 0182022 3125 RUPERT A 018109 3126 RUPERT A 0182022 3127 MoCOY A 0183021 3128 McCOY A 0183021 3129 McCOY A 0184010 3130 McCOY A 0184010 3131 MORGAN A 0186015 3132 MORGAN A 0186015 3133 MORGAN A 018703 3135 MORGAN A 018702 3136 MORGAN A 0187015 3138 MORGAN A 018904 3141 SMITH A 0189025 3142 SMITH A 0189025 3143 KEARFOTT A 019201 3144 KEARFOTT A 0192014 3146 KEARFOTT A 019306 3148 CARROLL A 019702 3149 CARROLL A 019702 3150 CARROLL A 019702 3151 GARRY A 0202014 3152 MORGAN A 0205015 3153 MORGAN A 0205015 3154 MORGAN A 020602 3156 RUPERT A 029205 3157 MOBLEY A 0209024 3158 MOBLEY A 020809 3159 COSTNER A 0209021 3160 MORGAN A 0211021 3161 BRILL A 0215012 3162 McCOY A 0216019 3163 McCOY A 0216019 3164 SMITH A 021803 3165 SMITH A 021803 3166 RUPERT A 022106 
3168 OARRY A 022303 3169 GARRY A 0223013 3170 BENJAMIN A 0223017 3171 RICHARDSON $A 02240$ is 3172 FEROUSON A 022608 3173 FERQUSON A 022608 3174 ABBOTT A 022703 3175 ABBOTT A 022703 3176 SLAPER A 022801 3177 ARNOLD A 022901 3180 KNIGHT A 023204 3181 KNIGHT A 023204 3182 MOCOY A 0233022 3183 MoCOY A 023404 3184 MCCOY A 0234012 3185 COSTNER A 023703 3186 COSTNER A 0235023 3187 ETHERIDGE A 0237017 3188 ETHERIDGE A 0238010 3189 MCCLAIN A 0238023 3190 MOBLEY A 0239011 3191 KNIGHT A 0240021 3193 RICHARDSON A 024202 3194 CARROLL A 0243014 3195 CARROLL A 0243020 3197 MoCOY A 025208 3198 CARROLL A 024509 3199 MCCOY A 025208 3200 MOBLEY A 0253017 3201 BRILL A 025302 3202 RUPERT A 0245013 3203 BRILL A 025302 3204 SMITH A 0242013 3205 SMIITH A 0247019 3206 MOBLEY A 024906 3207 MOBLEY A 024906 3208 MCCLAIN A 0254015 3209 MCDONALD A 0250011 3210 COSTNER A 0255012 3211 COSTNER A 025608 3213 GARRY A 0257011 3214 GARRY A 0257011 3215 SMITH A 026108 3216 MURRAY A 026502 3217 CARROLL A 0267013 3218 CARROLL A 0266019 3219 CARROLL A 0266019 3220 JOBSON A 0269019 3221 JOBSON A 0269019 3222 RUPERT A 029405 3224 MOBLEY A 029806 3226 MOBLEY A 0298012 3227 MOBLEY A 0298012 3228 PASSETTI A 029907 3230 BENJAMIN A 030005 3232 BENJAMIN A 030009 3234 ETHERIDGE A 0300013 3235 ETHERIDGE A 0300016 3236 ETHERIDGE A 0300019 3237 KEARFOTT A 0301013 3238 KEARFOTT A 0301013 3239 RICHARDSON A 030306 3241 MURRAY A 0303013 3242 MURRAY A 0303016
3243 MURRAY A 0303016 3244 MURRAY A 030402 3245 BTHERIDGE $\wedge$ O 304014 3246 ETHERIDOE A 0304014 3247 MOCOY A 0304020 3248 MCCOY A 0304020 3249 MoCOY A 0304020 3250 MaCOY A 0304020 3251 GARRY A 0306015 3252 BRILL A 0312021 3253 BRIIL A 0313023 3254 JOBSON A 0314019 3256 MOROAN A 0315011 3257 MORGAN A 031702 3259 MOBLEY A 0319021 3260 MOBLEY A 0319021 3261 KEARFOTT A 0324014 3262 KRARPOTT A 0324014 3263 KEARFOTT A 0325017 3264 MCDONALD A 0326021 3265 MCDONALD A 0327014 3266 MaDCNALD A 032703 3267 MCDONALD A 0327024 3269 GARRY A 032908 3270 GARRY A 033004 3272 SMITH A 0330012 3273 SMITH A 033101 3275 CARROLL A 033204 3277 CARROLL A 033204 3278 CARROLL A 0333019 3281 MOCOY A 0336010 3282 MCCOY A 0336010 3283 MORGAN A 0337019 3284 MORGAN A 0337019 3286 MURRAY A 0340018 3287 MURRAY A 0340018 3288 MURRAY A 0340018 3289 HCLLAND A 0342014 3290 KEARFOTT A 034309 3291 KEARPOTT A 0343021 3292 KEARFOTT A 0343021 3293 . IOBLEY A 034603 3294 MOBLEY A 034606 3295 MOBLEY A 034906 3296 SMITH A 0347016 3297 GARRY A 0407011 3298 SMITH A 0347016 3299 SMITH A 0347016 3300 SMITH A 0347016 3301 MCCOY A 0350011 3302 CARROLL A 0408013 3303 MaCOY A 0350011 3304 CARROLL A 0408013 3305 CARROLL A 035202 3306 CARROLL A 035202 3307 CARROLL A 040907 3308 LON A 035302 3309 LON A 035302 3310 KNIGHT A 0414017 3312 KEARFOTT A 041809 3314 STANGLER A 035901 3315 HOLLAND A 0419010 3316 DANIELLE A 036009 3317 HOLLAND A 0419010 
3318 DANIELLE A 036009 3319 DANIELLE A 036004 3320 MORGAN A 0421010 3321 DANIELLE A 036102 3322 DANIELLE \& 036102 3323 RILEY A 0362022 3324 KBIFER A 036307 3325 HENDRICKS A 036401 3326 RUPERT A 0421017 3327 HENDRICKS A 036405 3328 HENDRICKS A 0364011 3329 RUPERT A 0421017 3330 HENDRICKS A 0364011 3331 HENDRICKS A 036501 3332 HENDRICKS A 0367015 3333 RUPERT A 0422014 3335 HENDRICKS A 036907 3336 JOBSON A 0427018 3337 HENDRICKS A 036907 3338 McDONALD A 0373021 3340 MORGAN A 0374010 3341 MORGAN A 037502 3342 MORGAN A 0374010 3343 GARRY A $0429025^{\circ}$ 3344 GARRY A 0375020 3345 GARRY A 0429025 3346 GARRY A 037608 3347 GARRY A 037608 3348 MURRAY A 0379021 3349 MURRAY A 0379021 3350 GARRY A 043103 3351 GARRY A 0431019 3352 MURRAY A 038002 3353 GARRY A 0431022 3356 MURRAY A 038002 3357 BRILL A 038102 3358 BRILL A 0381010 3359 HENDRICKS A 043408 3360 BRILL A 0381013 3361 BRILL A 0381015 3362 BRILL A 0381022 3363 BRILL A 0381022 3364 BRILL A 0381017 3365 DAVIS A 0382014 3367 HENDRICKS A 0435010 3368 ETHERIDGE A 038301 3369 ETHERIDGE A 038301 3370 KNIGHT A 0383025 3371 RILEY A 043701 3372 MOBLEY A 038502 3373 RILEY A 043701 3374 MOBLEY A 038508 3375 MOBLEY A 0385014 3376 MOBLEY A 038504 3378 RICHARDSON A 0439013 3379 KEARFOTT A 0386022 3380 RICHARDSON A 0439013 3381 RICHARDSON A 0439013 3382 KEARFOTT A 0387010 3383 KEARFOTT A 038804 3384 KEARFOTT A 038808 3385 GARRY A 0388022 3387 GARRY A 039003 3388 GARRY A 039004
3389 GARRY A 0389014 3391 GARRY A 0391011 3392 RUPERT A 039204 3393 PATTY A 0440011 3394 BENJAMIN A 0393023 3395 BENJAMIN A 039508 3397 BRILL A 039701 3398 GEORGE A 044101 3399 GEORGE A 044108 3400 SMTTH A 039709 3401 GEORGE A 0441018 3402 SMITH A 039709 3403 GEORGE A 0442018 3404 SMITH A 0399015 3405 SMITH A 0399015 3406 GARRY A 044501 3407 ETHERIDGE A 040003 3408 ETHERIDGE A 040005 3410 ETHERIDGE A 0400012 3411 RUPERT A 045401 3412 SMITH A 0400023 3413 RUPERT A 045401 3414 BENJAMIN A 040207 3415 BENJAMN A 040207 3416 MOBLEY A 040305 3417 McDONALD A 0404013 3418 MCDONALD A 0404013 3419 ETHERIDGE A 045408 3421 GARRY A 0405012 3422 ESCO A, 0522010 3423 MOBLEY A 0454022 3424 HENDRICKS A 0523025 3425 HENDRICKS A 0523025 3426 MOBLEY A 045505 3427 MOBLEY A 0455021 3428 HENDRICKS A 052408 3429 PACK A 052502 3430 GARRY A 045707 3432 GARRY A 045707 3433 GARRY A 052603 3434 GARRY A 052603 3435 GARRY A 052603 3436 GARRY A 052603 3437 MOBLEY A 0462020 3438 SMITH A 052701 3439 CARROLL A 0528021 3440 MOBLEY A 0462020 3441 ETHERIDGE A 0531021 3442 MOBLEY A 0462020 3443 MURRAY A 0533013 3444 MURRAY A 0534018 3445 JOBSON A 0536013 3446 JOBSON A 0536013 3447 JOBSON A 0536013 3448 JOBSON A 0536013 3449 MOBLEY A 046408 3450 MOBLEY A 0465022 3451 KEARFOTT A 0466011 3452 RUPERT A 0472022 3453 KEARPOTT A 0466015 3455 KEARPOTT A 0470010 3456 RICHARDSON A 047702 3457 SMITH A 0471022 3458 SMITH A 0471022 
3459 SMITH A 0471022 3463 MOBLEY A 0486012 3464 MOBLEY A 0486012 3465 BRILL A 049206 3466 BRILL A 0493020 3467 RILEY A 0507014 3468 PATTY A 0507021 3469 PATTY A 0507021 3470 PATTY A 0510011 3471 ESCO A 0518020 3472 FAVRET A 0519019 3473 FAVRET A 0519019 3475 FAVORITE A 052004 . 3476 FAVORITE A 052104 3477 PAVORITE A 052104 3478 ULYSNY A 0515021 3479 ULYSNY A 051609 3480 VONTILLIAS A 051309 3481 VONTILLIAS A 051409 3482 VONTILLIAS A 0514015 3484 VONTILLIAS A 051507 3485 HUTCHINS A 0510014 3486 PERKINS A 0443019 3487 HEARST A 043805 3490 PERKINS A 0437012 3491 SHIPLER -FIELDER A 043605 3492 SCHMITT W 02203 3493 SCHMITT W 022019 3495 SCHMITT W 02303 3496 SCIRMITT W 02306 3497 KERR W 02407 3498 KERR W 024013 3499 KERR W 024015 3500 KERR W 024017 3503 WALKER W 025016 3504 WALKER W 025016 3506 WALKER W 02608 3508 LAGUARDIA W 02709 3509 LAGUARDIA W 02709 3510 LAGUARDIA W 027010 3511 LAGUARDIA W 027013 3512 LAGUARDIA W 02801 3513 LAGUARDIA W 02801 3514 LAGUIARDIA W 02808 3515 LAGUARDIA W 028013 3516 LAGUARDIA W 028013 3517 FULLER W 03002 3518 FULLER W 03003 3519 FULLER W 03008 3520 FULLER W 03008 3521 FULLER W 03008 3522 BARRETT W 030018 3523 BARRETT W 030018 3524 BARRETT W 03101 3525 BARRETT W 03101 3526 SCHAEFFER W 031019 3527 SCHAEFFER W 03201 3528 SCHAEFPER W 03201 3530 LULL W 03306 3531 LULL W 033010 3532 WALLO W 034016 3533 WALLO W 034021 3534 WALLO W 034025 3535 WALLO W 03502
3536 WALLO W 03504 3537 WALLO W 03506 3538 WALLO W 03506 3539 MAKRIHANI W 03603 3540 MAKHIHANI W 0360 10' 3541 MAKHIHANI W 03701 3542 MAKRHIIANI W 03702 3543 MAKHIIHANI W 03704 3545 MAKHIEANI W 03709 3546 HOLDEN W 038015 3548 OLSON W 039018 3549 OLSON W 039020 3551 OLSON W 010011 3552 GEIGER W 041017 3553 GEIGER W 04202 3554 GEIGER W 04206 3555 WHITE W 042012 3556 WHITE W 042016 3557 VOTH W 043011 3559 VOTH W 04405 3560 DAM W, 064017 3561 DAM W 064020 3562 MAGAVERN W 044024 3563 MAGAVERN W 045011 3564 DAM W 064023 3565 MAGAVERN W 045011 3566 DAM W 064025 3567 DAM W 06502 3568 DAM W 06502 3569 HUMPHREY W 04609 3570 HUMPEREY W 04609 3572 HUMPHREY W 046016 3573 RILEY W 048020 3575 KASSON W 065016 3576 KASSON W 065016 3577 KASSON W 065016 3578 RILEY W 048024 3579 KASSON W 06606 3580 TANO W 05004 3581 KASSON W 06606 3582 KASSON W 06606 3583 TANO W 050012 3584 KASSON W 06606 3585 TANO W 050012 3586 GILFAND W 051021 3587 GILFAND W 05201 3588 GILFAND W 05204 3589 NIEDZIELSKJ-EICHNER W 053012 3590 NIEDZIELSKI-EICHNER W 053023 3591 NIEDZIELSKI-EICHNER W 053023 3592 KELLY W 066018 3593 NIEDZIELSKI-EICHNER W 054012 3594 NIEDZIEISKI-EICHNER W 054016 3595 KELLY W 066024 3596 NIEDZIELSKI-EICHNER W 054019 3597 KELLY W 06707 3598 WASSERMAN W 068018 3599 SCHIAGER W 05606 3600 SCHIAGER W 05608 3601 SCHIAGER W 056011 3602 WASSERMAN W 068022 3603 SCHIAGER W 05605 3604 ELLISBURG W 070016 3607 ADRIAN W 05809 
3608 ELUISBURG W 07106 3609 SMITH W 07203 3611 HANSON W 059017 3612 HANSON W 06006 3613 DAVENPORT W 06209 3614 SMITH W 07206 3615 MORTON W 07301 3616 MPRTON W 07305 3618 MORTON W 073019 3619 MORTON W 073022 3620 MORTON W 07401 3621 RICHARDSON W 07507 3622 RICHARDSON W 07507 3623 DURMAN W 075019 3624 DURMAN W 07601 3625 DURMAN W 07604 3626 DURMAN W 07604 3627 DORNSIFE W 07804 3628 DORNSIFE W 078011 3631 DORNSIFE W 079017 3632 BARRETT W 0104021 3633 MAKHIHANI W 0105021 3634 MAKHIHANI W 010604 3635 MAKHIHANI W 0106010 3636 MAKHIHANI W 0107019 3637 SCHIAGER W 010801 3639 SCHIAGER W 010801 3640 SCHIAGER W0 10802 3641 SCHIAGER W 0108011 3642 RILEY W 0108024 3643 KILLAR W 010905 3644 KILLAR W 010907 3645 KILLAR W 010907 3646 MORTON W 011003 3647 MORTON W 0110011 3648 MORTON W 011104 3649 WALLO W 0111016 3650 WALLO W 0111017 3651 WALLO W 0111019 3653 GILFAND W 011205 3654 VOTH W 0112019 3655 VOTH W 011302 3656 VOTH W 0112024 3657 VOTH W 0112025 3658 DORNSIFE W 011306 3659 DORNSIFE W 011308 3660 DORNSIFE W 011308 3661 DORNSIFE W 011308 3662 DORNSIFE W 0113010 3663 DORNSIFE W 011404 3664 DORNSIFE W 011404 3665 OLSON W 0114016 3666 OLSON W 0114019 3667 OLSON W 011503 3668 OLSON W 0114025 3669 DAVENPORT W 0115018 3670 FULLER W 0117011 3671 FULLER W 0117023 3672 FULLER W 011802 3673 FULLER W 011806 3674 LAGUARDIA W 0118010 3675 LAGUARDIA W 0118010 3676 LAGUARDIA W 0118018 3677 KASSON W 0119019
3678 KELLY W 012108 3679 KELLY W 0121012 3680 KEILY W 0121014 3681 KaLLY W 0121014 3683 KELLY W 0121019 3684 KELLY W 012209 3685 KERR W 0122024 3686 KERR W 012301 3687 KERR W 012305 3688 TANO W 0123018 3689 TANO W 0123021 3690 TANO W 0123021 3691 WALKER W 012409 3692 WALKER W 0124017 3694 ELLISBURG W 012506 3695 ELULSBURG W 0125025 3696 SCHMITT W 012601 3697 SCHMITT W 012606 3698 SCHMITT W 012609 3699 SCHMTTT W 0126015 3700 WASSERMAN W 0127011 3702 WASSERMAN W 0127016 3704 KILLAR W 0128020 3705 KILLAR W 0128021 3706 KIILLAR W 012903 3707 SMITH W 0130013 3708 SMITH W 0130018 3709 SMITH W 013004 3710 LULL W 0130023 3711 LULL W 013104 3712 DORNSIPE W 013205 3713 GILPAND W 0133010 3714 GILFAND W 0133010 3715 MORTON W 0133014 3716 MORTON W 0133015 3717 MORTON W 0133017 3718 MORTON W 0133023 3719 MAKHIHANI W 013403 3720 MAGAVERN W 0135017 3721 SKOSKI W 0137022 3722 SKOSRI W 0137022 3723 CLEMONS W 0138016 3724 CLEMONS W 0138017 3725 CLEMONS W 013904 3726 CLEMONS W 0138021 3727 RANSOHOFF WO 139010 3728 RANSOHOFF W 0139019 3729 RANSOHOFF W 0139022 3730 DONNAY W 0140010 3731 SCOTNIKI W 0141016 3732 SCOTNIKI W 0141016 3733 RILEY W 0146010 3734 RIIEY W 0146013 3735 SCHIAGER W 014704 3736 SCHIAGER W 014707 3737 SCHIAGER W 0147010 3738 SCHIAGER W 014704 3739 OLSON W 0147017 3741 HANSON W 0149015 3742 HANSON W 0149021 3743 KELLY W 015006 3744 KELLY W 015006 3745 KELLYY W 015006 3746 MAKHIHANI W 0152021 
3747 MAKRIHANI W 0153012 3748 MAKHIIHANI W 015407 3750 KILLAR W 015507 3751 DORNSIFE W 0155024 3752 DORNSIFE W 015603 3753 DORNSIFE W 0156013 3754 DORNSIFE W 0157012 3755 GILPAND W 0158011 3757 GILPAND W 0158013 3758 GILFAND W 0158013 3760 BARRETT W 0159011 3761 BARRETT W 0159011 3762 WALLO W 016307 3763 WALLO W 016307 3765 KASSON W 0165015 3766 KASSON W 016502 3767 KASSON W 016503 3768 KASSON W 016504 3769 VOTH W 016106 3770 VOTH W 016107 3771 BARRETT W 0159013

3772 KILLAR W 015902 3773 KILLAR W 015904 3774 KILLAR W 015904 3775 HANSON W 016403 3777 HANSON $Y 1016403$ 3778 WALLO W 0162020 3779 WALLO W 0162020 3780 SMITH W 0165023 3781 SMITH W 016602 3782 SMITH W 0166014 3783 MORTON W 0166023 3784 MORTON W 016708 3787 TANO W 016803 3788 TANO W 016803 3789 TANO W 0168018 3790 TANO W 016803 3793 OLSON W 016906 3795 OLSON W 0170011 3799 KRLLY W 017109 3800 KELLY W 017206 3803 KELLY W 0173010 3804 KELLY W 0173010 3805 FULLER W 017401 3807 FULLER W 017401 3808 FULLER W 0174025 3809 FULLER W 017509 3811 SCHIAGER W 0175016 3812 SCHIAGER W 0175019 3813 SCHIAGER W 0175014 3815 SCHIAGER W 0175025 3816 SCHIAGER W 017608 3818 SCHIAGER W 0175025 3819 SCHIAGER W 017608 3821 DAVENPORT.W 017702 3822 DAVENPORT W 017702 3823 DURMAN W 0177020 3824 WASSERMAN W 0178016 3826 WALKER W 0180019 3828 MAGAVERN W 0181017 3832 MAGAVERN W 0182019 3833 MAGAVERN W 0183015 3834 MAGAVERN W 0183019 3835 MAGAVERN W 0183019
3837 MAGAVERN W 0183019

3839 LULL W 0185015

3840 LULL W 0185022

3844 LULL W 0186015

3845 LULL W 0186015

3846 LULL W 0186015

3848 LULL. W 0186021

3850 LULL W 0187016

3852 LULL W 0187020

3855 KASSON W 018807

3856 KASSON W 018807

3858 SCEIMITT W 019103

3859 SCFMITT W 019103

3861 RILEY W 0191025

3862 RILEY W 0191025

3863 RILEY W 0191025

3865 RILEY W 0192025

3866 RILEY W 019309

3867 KILLAR W 0193025

3868 KILLAR W 0193025

3869 KILLAR W 0193025

3871 NIEDZIELLSKI-EICHNER W 0195025

3872 NIEDZIELSKI-EICHNER W 019601

3873 NIEDZIEL SKI-EICEINER W 0196023

3874 NIEDZIEISKI-EICHNER W 019705

3877 DAM W 019806

3878 DAM W 019806

3879 DAM W 0198012

3882 HOLDEN W 019909

3883 HOLDEN W 0200020

3887 WHITE W 020104

3888 WHITE W 0201023

3891 WHITE W 0201023

3893 WHITE W 0202015

3895 WHIIE W 0202015

3896 WHITE W 0202015

3898 VOTH W 020402

3899 VOTH W 020404

3900 MACLEOD B 020809

3902 MAKHIHANI W 020509

3903 MAKRHIHANI W 0205012

3905 MAKHIHANI W 020603

3906 MAKHIHANI W 0206017

3908 LULL W 020802

3909 LULL W 020802

3911 DORNSIFE W 0208019

3913 DORNSIFE W 021006

3915 LAGUARDIA W 0210020

3916 LAGUARDIA $W 0210020$

3918 LAGUARDIA W 021205

3919 LAGUARDIA W 021205

3921 SCHMITT W 0212016

3922 SCHMITT W 0212024

3924 SCEMITT W 021307

3925 SCEMITT W 0213010

3926 SCFMITT W 0213015

3927 SCHMITT W 021307

3930 SCHMITT W 0213025

3932 SCHMITT W 021406

3933 SCEMITT W 021406

3934 SCFMMTT W 021503

3935 MORTON W 0216011

3936 CAMPBELL D 035806

3937 MORTON W 0216025 
3938 MORTON W 0216025 3940 ELLISBURG W 0217025 3941 ELLISBURG W 0218014 3943 KELLY W 0219020 3944 KELLY W 022109 3945 KELLY W 0221010 3946 KBLLY W 0222020 3947 HANSON W 022305 3949 HANSON W 022305 3950 HANSON W 0223 O 5 3951 HANSON W 0223019 3953 TANO W 022409 3954 TANO W 0224015 3956 TANO W 022505 3958 OLSON W 0226013 3960 DAVENPORT W 0229018 3961 DORNSIPE W 0231013 3963 DORNSIFE W 023203 3964 XILLAR W 023306 3965 WALKER W 0235020 3966 WALKER W 0235020 3967 KERR W 0236019 3968 KERR W 0236019 3970 OLSON W 0237017 3971 GEIGER W 023805 3972 GEIGER W 023805 3973 GEIGER W 023806 3974 GEIGER W 0238025 3975 RICHARDSON W 0239019 3976 WASSERMAN W 024103 3978 FULLER W 024201 3979 FULLER W 0241023 4001 FLEMING B 0114013 4005 DIETRICH D 0366020 4007 CABASSO S 03701 4009 STRAUSS S 032106 4015 TEPFT B 058022 4016 TEFFT B 058022 4022 DINGER B 0115024 4026 BARTON D 038307 4028 KRAFT C 0471023 4029 KRAFT C 0471023 4030 YOUNG S 0192010 4040 Unidentified Commenter San Francisco S 0328023 4042 KNIGHT S 047608 4043 FORTUN B 038021 4045 MACLBOD B 020705 4055 DICUS D 050103 4056 SCOTNICKI B 06401 4057 BOARDMAN B 018306 4058 MACLEOD B 0121015 4063 BEAVERS D 0392011 4064 SCOTNICKI B 06401 4066 Unidentified Commenter San Francisco S 0255 o 5 4072 KNIGHT S 03203 4073 KNIGHT S 047608 4074 PACK S 048307 4075 MACLBOD B 020705 4076 MORRISON D 0490016 4077 DINGER B 026708 4080 LAGUARDIA W 0242016 4081 ADRIAN W 0244025 4082 ADRIAN W 0244025 4083 DAM W 024606
4084 DAM W 024606 4085 DAM W 0246025 4086 DAM W 0246020 4087 LAGUARDIA W 0248021 4088 LAGUARDIA W 0249019 4089 SMTTH W 025107 4090 MAKHIHANI W 0251025 4091 MORTON W 0254013 4092 MORTON W 025506 4093 MORTON W 025508 4094 RII.EY W 0255013 4095 KELLY W 025709 4096 MORTON W 0258013 4097 KIILAR W 025901 4098 NIEDZIEISKI-EICHNER W 0260015 4099 LAGUARDIA W 0261021 4100 DORNSIFE W 0263024 4101 SCEMIITT W 0267018 4102 SCEMIIT W 0267018 4103 SCEMIIT W 0267019 4104 SCHMITT W 0268016 4105 SCHIAGER W 026906 4106 SCHIAGER W 026909 4107 SCHIAGER W 026909 4108 SCHLAGER W 0269012 4109 SCHIAGER W 0269012 4111 WASSERMAN W 027008 4112 WASSERMAN W 0270020 4113 WASSERMAN W 027101 4115 VOTH W 0271019 4117 WALLO W 023308 4119 OLSON W 0273019 4121 LAGUARDIA W 027402 4122 LAGUARDIA W 027503 4123 MAGAVERN W 027708 4124 GII.FAND W 0278015 4125 GILFAND W 0278015 4127 LULL W 0280010 4128 SMITH W 0281024 4129 SCHMITT W 0282013 4130 SCHMITT W 0282013 4131 KILLAR W 028403 4132 KILLAR W 0284016 4133 KILLAR W 0284016 4134 MORTON W 0285012 4135 MORTON W 0285016 4136 MORTON W 0285021 4137 KELLY W 028608 4140 KRILY W 0286021 4141 DORNSIFE W 0287018 4142 DORNSIFE W 028803 4143 MARCUS W 0288022 4144 MARCUS W 0290017 4145 KING W 0291012 4148 DONET W 029201 4149 CLEMONS W 0292018 4150 CLEMONS W 029309 4151 RANSOHOFF W 029406 4154 RANSOHOFF W 0294014 4155 SCOTNIKI W 0295018 4156 MORRIS W 0296018 4157 SEIKEN W 029706 4158 SEIKEN W 029707 4159 SEIKRN W 0297012 
4160 SEIKEN W 0297019

4161 AXELRAD W 0307014

4162 AXELRAD W 0307014

4163 NIEDZIELSKI-EICHNER W 0308015

4165 MAGAVERN W 0309021

4166 KELLY W 0311013

4167 KELLY W 0311017

4168 KELLY W 0312012

4169 KELLY W 031305

4170 KELLY W 031305

4171 OLSON W 0314015

4172 OLSON W 0314015

4173 OLSON W 0314023

4174 OLSON W 0314018

4175 OLSON W 0315020

4176 KERR W 0316024

4177 KERR W 0317013

4178 KERR W 0317016

4179 SCOTNIKI W 0318023

4180 SCOTNIKI W 0318023

4182 SCOTNIKI W 0319011

4183 SCOTNIKI W 0319011

4184 KILLAR W 0319021

4185 KILLAR W 032006

4186 KILLAR W 0319021

4188 KILLAR W 0321021

4189 KASSEN W 032206

4190 KASSEN W 032206

4191 KASSEN W 0324010

4192 GILFAND W 032603

4193 GILFAND W 032603

4194 SCHMITT W 0326012

4195 SCHMITT W 0326016

4196 SCHMITT W 0326016

4197 SCHMITT W 0326017

4198 SCHMITT W 0326021

4199 SCHMITT W 0326023

4200 SCHMITT W 032704

4201 SCHMITT W 032705

4202 SCHMITT W 032709

4203 SCHMITT W 0327014

4204 SCHMITT W 0327015

4205 DORNSIFE W 032801

4206 DORNSIFE W 032805

4207 DORNSIFE W 032805

4208 DORNSIPE W 032901

4209 DORNSIFE W 032805

4210 DORNSIFE W 032901

4211 DORNSIFE W 032905

4212 DORNSIFE W 032901

4213 WALLO W 0329024

4214 WALLO W 0329025

4215 WALLO W 0329023

4216 WALLO W 033001

4217 VOTH W 0330025

4218 VOTH W 0330025

4219 DAVENPORT W 0334011

4220 DAVENPORT W 0334018

4221 DAVENPORT W 0334020

4222 DAVENPORT W 0334025

4223 TANO W 0335019

4225 FULLER W 0336019

4226 FULLER W 033709

4230 ADRIAN W 03380.1
4231 MAKHIHANI W 0338014 4232 MAKHIHANI W 0338025 4233 MAKHIHANI W 0338025 4234 MAKHIHANI W 0339012 4235 MAKHIHANI W 034001 4236 MAKHIHANI W 034001 4237 MAKHIHANI W 034001 4238 LAGUARDIA W 034103 4239 LAGUARDIA W 034109 4240 LAGUARDIA W 034109 4241 LAGUARDIA W 034306 4242 LAGUARDIA W 034306 4243 LAGUARDIA W 034306 4245 RILEY W 034409 4246 SMITH W 0345023 4247 SMITH W 0345023 4248 SMITH W 0345023 4249 SMITH W 0345023 4250 HOLDEN W 0346023 4251 DAM W 0348019 4252 DAM W 0348019 4253 DAM W 0348020 4254 DAM W 0348023 4256 DAM W 0348025 4257 DAM W 0348025 4260 DAM W 0349015 4261 DAM W 0349023 4262 WASSERMAN W 0351014 4264 WASSERMAN W 0351014 4265 WASSERMAN W 0352013 4266 WASSERMAN W 0352013 4267 KILLAR W 035302 4269 KILLAR W 035302 4270 KILLAR W 0353014 4271 MAGAVERN W 035404 4272 AXELRAD W 035601 4273 WALKER W.0 357019 4274 OLSON W 0358017 4275 OLSON W 0359011 4276 SCHMITT W 0360014 4277 SCHMITT W 0360019 4278 SCHMITT W 0360025 4279 SCHMITT W 036103 4280 SCHMITT W O 360019 4282 MARCUS W 036201 4283 GILFAND W 036309 4284 GILPAND W 0365010 4285 DORNSIFE W 036608 4286 DORNSIFE W 0366016 4287 HANSON W 0367015 4288 HANSON W 0367015 4289 RILEY W 0368013 4290 KILLAR W 0369012 4291 KILLAR W 0369012 4293 KASSEN W 0370023 4294 KASSEN W 0371014 4295 KASSEN W 0371014 4296 KASSEN W 0371014 4297 KASSEN W 0371021 4298 VOTH W 0372020 4299 VOTH W 0372020 4300 HOLDEN W 0374019 4302 HOLDEN W 037503 4303 SCOTNIKI W 0375023 
4304 DAVENPORT W 0376012 4305 DAVENPORT W 0376012 4307 DAVENPORT W 037909 4308 LAGUARDIA W 0379024 4310 WASSERMAN W 038102 4311 GILPAND W 0384025 4312 HUMPHREY W 0385012 4313 KELLY W 0387011 4314 KELLY W 0387011 4315 KELLY W 0387011 4316 MORTON W 0388017 4317 MORTON W 0388017 4318 KILLAR W 038908 4319 KILLAR W 038908 4320 ELLISBURG W 0392017 4321 ELLISBURG W 0392017 4322 SCOTNIKI W 039409 4323 SCOTNIKI W 039409 4324 KASSEN W 0395012 4325 KASSEN W 0395012 4326 KASSEN W 0395012 4327 ELLISBURG W 0399010 4328 ELLISBURG W 039905 4329 ELLISBURG W 040005 4330 SCHIAGER W 0401017 4331 SCHIAGER W 0401017 4332 DORNSIFE W 0402023 4333 DORNSIFE W 0402023 4337 DORNSIFE W 040307 4338 FULLER W 0405010 4339 FULLER W 0405010 4341 PULLER W 0406022 4342 MAKHIHANI W 040707 4343 VOTH W 0412011 4344 VOTH W 0412011 4345 VOTH W 0412022 4346 VOTH W 0412017 4347 VOTH W 0417017 4348 MARCUS W 0410019 4349 GEIGER W 041008 4350 GEIGER W 041008 4351 MARCUS W 041106 4353 MARCUS W 041106 4354 WASSERMAN W 0414016 4355 WASSERMAN W 0414016 4356 WASSERMAN W 0414016 4357 WASSERMAN W 0414016 4358 SAMNICK W 0415015 4359 KILLAR W 041709 4360 RILEY W 0421010 4361 LAGUARDIA W 042207 4362 LAGUARDIA W 0422015 4363 LAGUARDIA W 0423017 4364 LAGUARDIA W 042305 4365 LAGUARDIA W 0423017 4366 LAGUARDIA W 042403 4367 LAGUARDIA W 042403 4368 NIEDZIELSKI-EICHNER W 042505 4369 NIEDZIELSKI-EICHNER W 042505 4370 DAVENPORT W 0425019 4371 DAVENPORT W 0425019 4372 DAVENPORT W 0425019 4373 HANSON W 0426013 4374 HANSON W 0426013
4375 KBLLY W 0427019 4376 KBLLY W 0427019 4378 KASSEN W 042908 4379 HUMPEREY W 043307 4381 MAGAVERN W 043405 4382 SCFMITT W 0434012 4383 SCEMITT W 0434012 4384 SCHMITT W 0434012 4385 SCHMITT W 0434012 4386 SCHMTTT W 0434023 4387 KILLAR W 0435014 4388 KIILAR W 0435014 4389 KERR W 049806 4390 KIILAR W 0436022 4391 KILLAR W 050001 4392 KILLAR W 0436022 4393 FULLER W 0501020 4394 DORNSIFE W 0502011 4395 DORNSIFE W 0502011 4396 GILFAND W 050302 4397 NIEDZIELSKI-EICHNER W 043802 4398 GILPAND W 050302 4399 GILFAND W 050302 4400 GILPAND W 050302 4401 NIEDZIELSKI-EICHNER W 043802 4402 SCHLAGER W 050405 4404 SCHIAGER W 0505012 4406 DORNSIFE W 0439014 4407 DORNSIFE W 0439022

4408 KELLY W 050604 4409 KELLY W 0506016 4410 KELLY W 0506019 4411 KELLY W 0506019 4412 MORTON W 0507010 4413 SCHMITT W 050801 4413 DORNSIFE W 044001 4414 RILEY W 051008 4415 RILEY W 0510010 4416 ELLISBURG W 0441013 4417 WASSERMAN W 0510021 4418 WASSERMAN W 0510021 4419 WASSERMAN W 0510021 4420 KILLAR W 051307 4422 GILPAND W 044206 4423 GILPAND W 044206 4425 GILPAND W 044206 4426 DORNSIFE W 0514012 4427 RILEY W 044304 4428 OLSON W 0514020 4429 SCOTNIKI W 0515023 4432 HANSON W 0516019 4433 MORTON W 0443023 4434 KASSEN W 0518019 1435 KILLAR W 0519020

'36 OLSON W 052304 4437 MAKHIIHANI W 0524014 4438 OLSON W 0526 O 5 4440 MORTON W 0444010 4441 MORTON W 0444010 4442 MORTON W 0444010 4443 COMP W 0530018 4444 COMP W 0530018 4445 COMP W 053101 4446 RANSOHOFF W 05330,7 
4447 RANSOHOFF W 053307 4448 LULL W 0536017 4449 LULL W 0536022 4450 MILLER W 0538019 4451 GILFAND W 053904 4452 SCHMITT W 0540015 4453 MARCUS W 054104 4454 MARCUS W 054105 . 4455 OLSON W 0541014 4456 HUMPHREY W 054307 4457 TANO W 054408 4458 GILPAND W 0544024 4459 SCOTNIKI W 0545024 4460 SCOTNIII W 054609 4461 DAM W 054706 4462 KELLY W 054803 4463 WASSERMAN W 054904 4464 MORTON W 0550017 4465 KILLAR W 0551013 4466 DORNSIFE W 0552018 4467 MAKHIHANI W 0553016 4468 MORTON W 044505 4469 MORTON W 0445019 4470 SCO'INIKI W 0447012 4471 SCOTNIKI W 0447012 4472 SCOTNIKI W 0447012 4473 HUMPHREY W 044806 4474 ROBERSON W 0448021 4475 ROBERSON W 044903 4477 GOLDMAN W 0449017 4478 GOLDMAN W 0450010 4479 NELSON W 0450024 4480 GOOD W 0451021 4482 RANSOHOFF W 0453022 4483 RANSOHOFF W 0453012 4484 RANSOHOFP W 0452014 4485 DONNAY W 0454013 4486 DONNAY W 0454013 4487 RESCEK W 045707 4488 RESCEK W 045708 4489 RESCEK W 045709 , 4490 RESCEK W 0457012 4491 RESCEK W 0457017 4492 GUNTER W 0458010 4493 THOMPSON W 0459023 4494 TRETTER W 0460018 4495 FRIEL W 0461013 4496 DORNSIPE W 0468019 4498 DAM W 0470025 4499 MORTON W 047308 4500 SMITH W 047806 4501 SCHIAGER W 0473013 4502 DORNSIFE W 0474012 4503 SCHMITT W 0478022 4504 SCHMITT W 047901 4505 KILLAR W 047501 4506 WALLO W 047605 4507 KASSEN W 0479024 4508 KASSEN W 048001 4509 MAKHIHANI W 0476021 4510 KASSEN W 0480013 4511 S/CHIAGER W 0477014 4512 KELLY W 0480020 4513 DORNSIFE W 0477023
4514 KELLLY W 048103

4515 MAKHIIHANI W 0486019 4516 MAKHIHANI W 0486019 4517 MARHIHANI W 0486019 4518 GEIGER W 0481012

4520 TANO W 048708

4521 TANO W 048708

4523 DORNSIFE W 0481017

4524 KASSEN W 0490013

4525 DORNSIFE W 0481017

4526 WALLO W $04820 \mathrm{~s}$

4527 WALLO W 048205

4528 WALLO W 0482 O S

4529 WALLO W 048205

4530 KASSEN W 048302

4531 KASSEN W 048302 .

4532 KASSEN W 048302

4533 KASSEN W 048302

4534 MAKHIHANI W 0494017

4535 MAKHIHANI W 049501

4536 DAM W 0484017

4537 DAM W 0484017

4538 OLSON W 0495011

4539 KIILAR W 048503

4541 KILLAR W 0485010

4542 KIILAR W 0485010

4543 KILLAR W 0496018

4544 DAM W 049208

4545 SCHMITT W 0492022

4547 SMITH W 0493025

4650 DANIELLE A 036102

4651 MAKHIHANI W 0106010

4652 NIEDZIEISKI-BICHNER W 0196014

4654 FASNACHT S 0468015

4655 MYERS B 034109

4657 RESCEK C 0314014

4659 RICHARDSON C 0309024

4660 RICHARDSON C 018701

4681 DORNSIFE P 0258015

4773 HOFSTETTER D 064012

4785 SLOBODIEN P 019801

4797 JOHNSRUD P 0151017

4798 JOHNSRUD P 05701

4799 PORTER P 0349013

4803. UNIDENTIFIED COMMENTER S 0191023

4808 COHEN S 043014

4809 DINGER B 0370014

4811 KASE S 029609

4812 CARRETTA S 046023

4813 SCHUTZ P 0391012

4814 DINGER B 034909

4815 QUIGLEY B 065020

4816 FRACKE P 020306

4818 MCBURNEY D 0404016

4820 GRIPFIN P 053024

4821 PINKARD P 0139013

4822 GRAVES D 0324024

4824 JOBSON A 0536013

4825 WHITE W 0202015

A826 DO'RNSIFE W 0439022

4827 GEIGER W 041017

4828 MCBURNEY D 04302

4829 DICUS D 0116022

4830 DORNSIFE W 078011 
4831 BACKUS B 0394015 4832 BACKUS B 0394015 4839 CARRETTA S 017807 4840 CRAWFORD D 053024 4841 RUPERT A 032309

4842 NARDI P O 503010

4843 KASE S 0453020

4844 QUILLIN D 0195020

4845 SMITH A 0347016

4846 MOBLEY A 046408

4847 HOFSTETTER D 0368015

4848 SMITH W 0345023

4849 DAM W 054706

4850 BRANIGAN S 019602

4851 FRASER S 019302

4852 MINNAR C 0518010

4853 MACLEOD B 0173015

4854 WES D 0328013

4855 UNKNOWN OBSERVER D 027905

4856 THOMPSON D 0129024

4857 BRINK D 018905

4858 WILLIAMS D 0186014

4859 SLOBODIEN P 031504

4860 RICHARDSON C 0309021

4861 BAILEY S 0311010

4862 PARSONS D 042801

4863 BELISLE D 0128019

4864 KNIGHT A 04909

4865 MEDLING S 0463019

4866 ROYAL C 062021

4867 CRIMI D 043201

4868 FASNACHT S 018809

4869 CRAWFORD D 036607

4870 PORTER P 045010

4871 VOTH W 0412011

4872 BRODIE P 033009

4873 SCHMITT W 050801

4874 CEHN S 036703

4875 GARRY A 0375020

4876 ELLISBURG W 039905 ।

4877 BRAINIGAN S 041304

4878 HUBBARD S 0120020

4879 NARDI P 0239023

4880 GRAVES D 0323017

4881 DORNSIFE P 06105

4882 RANSOHOFP W 0139010

4883 BERGENDAHL D 0341011

4884 CEMBER C 0476015

4885 MELLOR B 026005

4886 EMMEL A 015102

4887 OLSON W 0495011

4888 GEIGER W 023805

4889 PINKARD P 0476017

7000 Science Applications Internatibnal Corp. 1130

7001 Science Applications International Corp. 1130

7002 Science Applications International Corp. 1130

7003 Science Applications International Corp. 1110

7004 Science Applications International Corp. 1140 7005 Science Applications International Corp. 1140 7006 Gariota 2110

7007 Audubon Council of Texas 3110

7008 Audubon Council of Texas 3120

7009 Audubon Council of Texas 3120

7010 Audubon Council of Texas 3130
7011 Audubon Council of Texas 3130 7012 Audubon Council of Texas 3140 7013 Audubon Council of Texas 3150 7014 Audubon Council of Texas 3150 7015 Audubon Council of Texas 3150 7016 Levin 4120 7017 Levin 4130 7019 Levin 4140 7020 Levin 4150 7021 Levin 4150 7022 Levin 4150 7023 Levin 4160 7024 Levin 4160 7025 Levin 4160 7027 Levin 4170 7029 Levin 4180 7030 Levin 4180 7031 Levin 4180 7032 Levin 4210 7033 Levin 4210 7034 Levin 4210 7035 Levin 4220 7036 Levin 4220 7037 Levin 4270 7038 Levin 4270 7039 Levin 4280 7040 Levin 4280 7041 Levin 4280 7042 Levin 4280 7043 Levin 4280 7044 Levin 4280 7045 Levin 4280 7046 Levin 4280 7048 Levin 42110 7049 Levin 42110

7050 Levin 4320

7051 Levin 4330

7053'Levin 4330

7054 Levin 4340

7056 Levin 4350

7057 Levin 4380

7058 Levin 4380

7059 Levin 4380

7060 Texas Nuclear Responsibility Network 5110 7061 Texas Nuclear Responsibility Network 5110 7062 Texan Nuclear Responsibility Netv: ork 5110 7063 Texas Nuclear Responability Network 5120 7065 Texas Nuclear Reuponsibility Network 5120 7066 Texas Nuclear Responsibility Network 5120 7068 Texas Nuclear Responsibility Network 5130 7069 Texas Nuclear Responsibility Network 5210 7071 Texas Nuclear Responsibility Network 5210 7072 Texas Nuclear Responaibility Network 5210 7073 Texas Nuclear Responsibility Network 5220 7074 Texas Nuclear Responsibility Network 5220 7075 Texas Nuclear Reuponsibility Network 5240 7076 Texas Nuclear Responibility Network 5240 7077 Texas Nuclear Responsibility Network 5250 7078 Texas Nuclear Responsibility Network 5310 7081 Texas Nuclear Responsibility Network 5380 7082 Texas Nuclear Responsibility Network 5340 7083 MOELLER 9470

7084 Texas Nuclear Responsibility Network 5430 7085 Texas Nuclear Responsibility Network 5430 
7086 Texas Nuclear Reaponsibility Network 5430 7087 Texas Nuclear Responaibility Network 5430 7088 Texas Nuclear Responsibility Network s 520 7089 MOELLER 9570

7090 MOELLER 9570

7091 MOELLER 9570

7092 Western States Legal Foundation 6110 7n95 MOELLER 9840

0.6 MOELLER 9920

3), Westem States Legal Foundation 6230

798 Western States Legal Foundation 6230

7099 Western States Legal Foundation 6230

7100 Western States Legal Foundation 6230

7101 Weatem States Legal Foundation 6230

7102 Western Stated Legal Foundation 6230

7103 Weatern States Legal Foundation 6310

7104 Western States Legal Foundation 6630

7106 White 7210

7107 White 7410

7108 White 7410

7109 White 7610

7110 White 7610

7111 White 7610

7112 White 7610

7114 White 7610

7115 White 7610

7116 White 7610

7117 White 7610

7118 White 7710

7119 White 7720

7120 White 7720

7121 White 7720

7122 White 7840

7123 White 7910

7124 White 7910

7125 White 7920

7126 White 7930

7127 White 7930

7128 White 7950

7129 White 7960

7130 White 7960

7131 White 71030

7132 White 71020

7133 White 71040

7134 White 71040

7135 White 71050

7137 White 71120

7138 White 71120

7139 White 71120

7141 White 71140

7142 White 71110

7144 White 71210

7145 White 71210

7146 White 71210

7147 White 71310

7148 Sholeen 8110

7150 Sholeen 8110

7151 Sholeen 8110

7152 Sholeen 8120

7153 Sholeen 8130

7155 Sholeen 8140

7156 Sholeen 8140

7157 Sholeen 8140

7159 Science Applications International Corp. $11: 30$
7160 Science Applications Intermational Corp. 1130

7161 Science Applications International Corp. 1110

7164 Gariota 2110

7171 Audubon Council of Texas 3150

7184 Levin $\$ 160$

7238 Texas Nuclear Responsibility Network 5330

7248 MOELLER 9570

7255 MOELLER 9930

7256 MOELLER 9930

7257 MOELLER 9940

7258 MOELLER 9940

7259 MOELLER 9940

7260 MOELLER 9950

7262 MOELLER 91030

7264 MOELLER 91040

7265 MOELLER 91110

7266 MOELLER 91140

7267 MOELLER 91150

7268 ARGALL 10120

7269 ARGALL 10120

7271 ARGALL 10140

7272 ARGALL 10210

7273 ARGALL 10210

7275 ARGALL 10210

7276 ARGALL 10210

7277 ARGALL 10240

7278 ARGALL 10240

7279 ARGALL 10250

7280 ARGALL 10250

7281. ARGALL 10250

7282 ARGALL 10260

7283 ARGALL 10260

7284 ARGALL 10270

7285 ARGALL 10310

7287 ARGALL 10340

7288 ARGALL 10360

7289 ARGALL 10410

7290 ARGALL 10410

7291 ARGALL 10420

7292 ARGALL 10420

7293 ARGALL 10430

7294 ARGALL 10430

7295 ARGALL 10460

7296 ARGALL 10460

7297 AR'GALL 10460

7298 ARGALL 10550

7300 ARGALL 10540

7301 ARGALl 10560

7302 ARGALL 10510

7303 ARGALL 10510

7304 ARGALL 10510

7305 ARGALL 10510

7306 ARGALL 10570

7307 ARGALL 10510

7308 ARGALL 10610

7309 ARGALL 10630

7310 ARGALL 10630

7311 ARGALL 10660

7312 ARGALL 10640

7313 ARGALL 10650

7314 ARGALL 10730

7315 ARGALL 10730

7316 ARGALL 10730

7318 ARGALL 10720 
7319 ARGALL 10710

7320 ARGALL 10710

7321 Consumers Power 11110

7323 Consumers Power 11240

7324 Broad Top Township Supervisors 12250

7325 Broad Top Township Supervisors 12250

7326 WEST VALLEY NUCLEAR WASTE 19110

7327 Broad Top Township Supervisors 12260

7328 G.V. PALAZZOLO 13110

7329 G.V. PALAZZOLO 13110

7330 PUBLIC CITIZEN 14110

7331 Coalition on Weat Valley Nucleat Waates 19110

7332 PUBLIC CITIZEN 14,320

7333 PUBLIC CITIZEN 14410

7334 PUBLIC CITIZEN 14570

7335 Coalition on West Valley Nuclear Wastes 19140.

7336 PUBLIC CITIZEN 14560

7337 PUBLIC CITIZEN 14570

7338 PUBLIC CITIZEN 14610

7339 PUBLIC CITIZEN 14630

7341 Coalition on West Valley Nuclear Wastes ' 19110

7342 PUBLIC CITIZEN 14670

7343 PUBLIC CITIZEN 14670

7345 Coalition on West Valley Nuclear Wasres 19110

7347 PUBLIC CITIZEN 1468,0

7348 PUBLIC CITIZEN $1468^{\prime} 0$

7350 PUBLIC CITIZEN 14760

7351 PUBLIC CITIZEN 14770

7352 Coalition on West Valley Nuclear Wastes 19210

7353 PUBLIC CITIZEN 14780

7554 PUBLIC CITIZEN 147100

7355 Coalition on West Valley Nuclear Wastes 19210

7356 PUBLIC CITIZEN 14830

7357 PUBLIC CITIZEN 14870

7358 Thermal Analytical Inc., TMA 16120

7359 Thermal Analytical Inc., TMA 16140

7360 Thermal Analytical Inc., TMA 16140

7362 Therrnal Analytical Inc., TMA 16210

7363 Thermal Analytical Inc., TMA 16220

7364 Orr 17110

7365 South Carolina, DHEC 18110

7366 State of South Carolina, DHEC 18110

7367 Coalition on West Valley Nuclear Waste 19220

7368 Coalition on West Valley Nuclear Waste 19230

7369 Coalition on West Valley Nuclear Waste 19230

7370 Coalition on West Valley Nuclear Waste 19240

7371 Jones 20110

7372 Jones 20130

7373 Miller 21120

7374 Miller 21120

7375 Miller 21130

7380 HIATT 22210

7381 ASPI 23110

7382 ASPI 23110

7383 ASPI 23110

7384 ASPI 23110

7385 ASPI 23120

7386 ASPI 23120

7387 ASPI 23120

7388 American Nuclear Society 32110

7389 ASPI 23110

7390 American Nuclear Society 32110

7391 American Nuclear Society 32210

7392 ASPI 23110
7393 American Nuclear Society 32230 7394 American Nuclear Society 32410 7396 American Nuclear Society 32410 7397 American Nuclear Society 32410 7398 ASPI 23250

7399 American Nuclear Society 32420 7400 American Nuclear Society 32420 7401 American Nuclear Society 32430 7402 American Nuclear Society 32510 7404 American Nuclear Society 32520 7405 American Nuclear Society 32520 7406 American Nuclear Society 32520 7407 American Nuclear Society 32520 7408 American Nuclear Society 32530 7409 American Nuclear Society 32610 7411 American Nuclear Society 32620 7412 American Nuclear Society 32620 7413 American Nuclear Society 32620 7414 American Nuclear Society 32620 7415 American Nuclear Society 32630 7416 American Nuclear Society 32630 7417 American Nuclear Society 32630 7418 American Nuclear Society 32730 7419 American Nuclear Society 32730 7421 American Nuclear Society 32730 7422 American Nuclear Society 32740 7423 American Nuclear Society 32740 7424 American Nuclear Society 32750 7425 American Nuclear Society 32750 7426 Americap Nuclear Society 32820 7427 American Nuclear Society 32820 7428 American Nuclear Society 32840 7429 American Nuclear Society 32840 7430 American Nuclear Society 32840 7431 American Nuclear Society 32930 7432 American Nuclear Society 32940 7433 American Nuclear Society 32940 7434 American Nuclear Society 32940 7435 American Nuclear Society 32950 7436 American Nuclear Society 32950 7438 American Nuclear Society 321010 7439 American Nuclear Society 321010 7440 American Nuclear Society 321010 7441 American Nuclear Society 321010 7442 American Nuclear Society 321010 7443 American Nuclear Society 321020 7445 American Nuclear Society 321130 7446 American Nuclear Society 321210 7447 American Nuclear Society 321220 7448 American Nuclear Society 321220 7449 American Nuclear Society 321230 7451 American Nuclear Society 321330 7452 American Nuclear Society 321320 7454 American Nuclear Society 321410 7455 ASTSWMO 33130

7456 ASTSWMO 33130 7457 ASTSWMO 33220 7458 ASTSWMO 33220 7459 ASTSWMO 331230

7460 ASTSWMO 33360

7461 ASTSWMO 33360

7463 ASTSWMO 33410

7464 ASTSWMO 33410

7465 ASTSWMO 33430 
7466 ASTSWMO 33430 7467 ASTSWMO 33440 7468 ASTSWMO 33440 7469 ASTSWMO 33450 7470 ASTSWMO 33450 . 7471 ASTSWMO 33540 7472 ASTSWMO 33540 7473 ASTSWMO 33540 7474 ASTSWMO 33550 7475 ASTSWMO $33610^{\circ}$ 7476 ASTSWMO 33610 7477 ASTSWMO 33630 7478 ASTSWMO 33620 7479 ASTSWMO 33730 7481 ASTSWMO 33740 7483 ASTSWMO 33750 7484 ASTSWMO 33820 7485 ASTSWMO 33820 7486 State of Michigan $3512 \mathrm{~d}$ 7487 State of Michigan 35130 7488 State of Michigan 35140 7489 State of Michigan 35150 7490 state of Michigan 35150 7491 State of Michigan 35210 7492 State of Michigan 35210 7493 State of Michigan 35220 7494 State of Michigan 35220 7495 State of Michigan 35220 7496 State of Michigan 35230 7497 State of Michigan 35230 7498 State of Michigan 35240 7501 State of Michigan 35270 7502 State of Michigan 35250 7503 State of Michigan 35320 7504 State of Michigan 35320 7505 State of Michigan 35320 7507 State of Michigan 35320 7508 State of Michigan 35330 7512 \$tate of Michigan 35340 7513 State of Michigan 35350 7514 State of Michigan 35350 7515 State of Michigan 35360 7516 State of Michigan 35360 7517 State of Michigan 35420 7519 ASPI 23240 7520 State of Michigan 35430 7522 Health Physics Society 36110 7523 Health Physics Society 36120 7524 Health Physics Society 36120 7525 Health Physics Society 36120 7526 Health Physics Society 36210 7527 ASPI 23240

7528 Health Physics Society 36210 7529 Health Physics Society 36210 7530 Health Physics Society 36220 7531 Health Physics Society 36220 7532 ASPI 23230

7533 Health Physics Society 36230 7534 Health Physics Society 36230 7535 Health Physics Society 36230 - 7536 Health Physics Society 36240 7538 Health Physics Society 36240 7539 Health Physics Society 36250 7540 Health Physics Society 36310
7342 Health Phytica Society 36320

7543 ASPI 23220

7544 Health Physice Society 36340

7545 Health Phyvica Society 36340

7547 Health Phydice Society 36410

7548 Health Phydics Socidy 36430

7549 ASPI 23210

7550 Health Phytica Sociaty 36440

7551 ASPI 23210

7552 Health Phytics Society 36440

7554 County Commiasion, Bodford, PA 24250

7555 County Commission, Beford, PA 24110

7556 County Commision, Bedford, PA 24110

7557 Lapis 25110

7558 Lapls 25110

7559 USCEA 26120

7560 USCEA 26110

7561 USCEA 26110

7562 USCEA 26130

7563 USCEA 26210

7564 USCEA 26210

7565 USCEA 26210

7566 USCEA ,26240

7567 USCEA 26240

7568 USCEA 26240

7569 USCEA 26240

7570 USCEA 26240

7571 USCBA 26240

7572 USCEA 26220

7573 USCEA 26220

7574 USCEA 26350

7575 USCEA 26340

7576 USCEA 26350

7577 USCEA 26350

7578 USCEA 26350

7579 USCEA 26350

7580 USCEA 26370

7581 USCEA 26370

7582 USCEA 26430

7583 USCEA 26430

7584 USCEA 26440

7585 SIERRA CLUB -DALLAS GROUP 28120

7586 SIERRA CLUB -DALLAS GROUP 28130

7587 SLERRA CLUB -DALLAS GROUP 28140

7588 SIERRA CLUB, DALLAS GROUP 28160

7590 SIERRA CLUB, DALLAS GROUP 28160

7591 SIERRA CLUB, DALLAS GROUP 28160 7592 SIERRA CLUB, DALLAS GROUP 28170 7593 SIERRA CLUB, DALLAS GROUP 28170 7594 SIERRA CLUB, DALLAS GROUP 28210 7595 SIERRA CLUB, DALLAS GROUP 28220 7596 SIERRA CLUB, DALLAS GROUP 28230 7597 SIERRA CLUB, DALLAS GROUP 28230 7598 SIERRA CLUB, DALLAS GROUP 28240 7599 SIERRA CLUB, DALLAS GROUP 28240 7600 SIERRA CLUB, DALLAS GROUP 28240 7601 SIERRA CLUB, DALLAS GROUP 28250 7603 SIERRA CLUB, DALLAS GROUP 28260 7604 SIPRRA CLUB, DALLAS GROUP 28260 7605 SIERRA CLUB, DALLAS GROUP 28270 7606 SIERRA CLUB, DALLAS GROUP 28310 7607 SIERRA CLUB, DALLAS GROUP 28310 7608 SIERRA CLUB , DALLAS GROUP 28410 7609 F.S. Law 29110 
7610 F.S. Law 29110

7611 P.S. Law 29310

7612 F.S. Law 29410

7613 F.S. Law 29420

7614 P.S. Law 29410

7615 Kennecott Uranium Co. 30120

7616 Kennecou Uranium Co. 30120

7617 Kennecott Uranium Co. 30120

7618 Kennecott Uranium Co. 30130

7619 Kennecott Uranium Co. 30230

7621 Kennecott Uranium Co. 30260

7622 Kennecott Uranium Co. 39260

7623 Kennecott Uranium Co. 30310

7624 Kennecott Uranium Co. 30310

7625 Organization of Agreement States 31120

7628 Organization of Agreement States 31130

7629 Organization of Agreement States 31130

7630 Organization of Agreement States 31130

7631 Organization of Agreement States 31110

7632 Organization of Agreement States 31110

7633 Organization of Agreement States 31240

7634 Organization of Agreement States 31230

7635 U.S. EPA 34110

7636 U.S. EPA 34110

7637 U.S. EPA 34110

7639 U.S. EPA 34110

7640 Health Physics Society 36460

7641 Health Physics Society 36460

7642 Health Physics Society 36520

7643 Health Physics Society 36520

7644 Health Physics Society 36520

7645 Health Physics Society 36530

7646 Health Physics Society 36530

7647 Health Physics Society 36550

7649 Health Physics Society 36560

7650 Hea th Physics Society 36560

7651 He: Ith Physics Society 36620

7652 Cain 37110

7653 Cain 37110

7654 Cain 37150

7655 Crawford 39110

7656 Crawford 39110

7657 Crawford 39110

7658 Crawford 39110

7659 Black 40110

7661 Williams 41110

7663 GE STOCKHOLDERS ALLIANCE 43110

7664 GE STOCKHOLDERS ALLIANCE 43110

7665 GE STOCKHOLDERS ALLIANCE 43140

7666 GE STOCKHOLDERS ALLIANCE 43140

7667 GE STOCKHOLDERS ALLIANCE 43160

7668 GE STOCKHOLDERS ALLIANCE 43160

7669 GE STOCKHOLDERS ALLIANCE 43160

7670 GE STOCKHOLDERS ALLIANCE 43220

7671 GE STOCKHOLDERS ALLIANCE 43220

7672 GE STOCKHOLDERS ALLIANCE 43240

7673 GE STOCKHOLDERS ALLIANCE 43260

7674 B. Forte 44110

7675 International Fellowship of Reconciliation (IPOR) 4511

7676 International Fellowship of Reconciliation (IFOR) 4531

0

7677 Tomlinson 46110

7678 Tomlinson 46210
7679 Sinclair 47210

7680 Sinclair 47210

7682 Sinclair 47210

7683 Sinclair 47210

7685 Sinclair 47110

7687 Sinclair 47310

7689 Sinclair 47410

7690 Brill 48110

7691 Brill 48110

7692 Brill 48110

7694 Brill 48110

7695 Brill 48150

7696 Brill 48150

7697 Brill 48150

7698 Brill 48160

7699 Brill 48160

7700 Brill 48210

7702 Brill 48220

7703 Shneider 49110

7704 Shneider 49110

7705 Ferguson 50110

7706 Ferguson 50110

7707 Ferguson 50110

7708 Ferguson 50110

7709 Ferguson 50140

7711 Ferguson 50220

7712 Perguson 50230

7713 Ferguson 50230

7714 Ferguson 50240

7715 Perguson 50240

7716 Califomia Integrated Waste Management Board' 51110

7718 Nuciear Metals, Inc. 52110

7719 Nuclear Metals, Inc. 52110

7720 Nuclear Metals, Inc. 52110

7722 Nuclear Metals, Inc. 52130 ,

7723 NC GROUND ZERO 54130

7724 NC GROUND ZERO 54140

7725 NC GROUND ZERO 54140

7726 NC GROUND ZERO 54220

7727 NC GROUND ZERO 54220

7728 NC GROUND ZERO 54230

7729 GEORGIANS AGAINST NUCLEAR ENERGY 55110

7730 Carroll 56110

7731 GREENPEACE-ATLANTA 57120

7732 GREENPEACE-ATLANTA 57130

7734 GREENPEACE-ATLANTA 57160

7735 GREENPEACE-ATLANTA 57170

7736 GREENPEACE-ATLANTA 57210

7737 GREENPEACE-ATLANTA 57220

7739 GREENPEACE-ATLANTA 57230

7740 GREENPEACE-ATLANTA 57230

7741 GREENPEACE-ATLANTA 57240

7742 Matthews 58110

7743 Matthews 58110

7744 King 59140

7745 King 59110

7746 King 59110

7747 Oregon Dept. of Human Resources 60110

7748 Cuyahoga County Dist. Board of Health 61130

7750 Cuyahoga County Dist. Board of Health 61240

7751 Cuyahoga County Dist. Board of Health 61240

7752 Cuyahoga County Dist. Board of Health 61250

7753 Cuyahoga County Dist. Board of Health 61310

7755 Cuyahoga County Dist. Board of Health 61310 
7756 Cuyahoga County Dist. Board of Health 61350 7757 Cuyahoga County Dist. Board of Health 61370 7758 Cuyahoga County Dist. Board of Health 61370 7759 Cuyahoga County Diat. Board of Health 61380 7761 Cuyahoga County Diat. Board of Health 61470 7762 Cuyahoga County Dist. Board of Health 61510 7763 Cuyahogu County Dist. Board of Health 61510 7764 Cuyahoga County Dist. Board of Health 61510 7765 GE Nuclear Energy 62120 7766 GE Nuclear Energy 62120 7767 GE Nuclear Energy 62120 7769 GE Nuclear Energy 62140 7770 GE Nuclear Energy 62210 7771 GE Nuclear Energy 62210 7772 GE Nuclear Energy 62210 7773 GE Nuclear Energy 62230 7774 GE Nuclear Energy 62230 7775 GE Nuclear Energy 62.230 7776 GE Nuclear Energy 62230 7777 GE Nuclear Energy 62250 7778 GE Nuclear Energy 62250 7779 GE Nuclear Energy 62250 7780 GE Nuclear Energy 62250 7781 GE Nuclear Energy 62250 7782 8-Organization Group 63120 7784 8-Organization Group 63130 7785 8-Organization Group 63140 7786 8-Organization Group 63140 7787 8-Organization Group 63140 7788 8-Organization Group 63210 7790 8-Organization Group 63220 7791 8-Organization Group 63220 7792 8-Organization Group 63220 7793 8-Organization Group 63240 7794 8-Organization Group 63240 7795 8-Organization Group 63330 7796 New York State ERDA 64130 7797 New York State ERDA 64330 7798 New York State ERDA 64310 7799 New York State ERDA 64320 7800 Sierra Club 65120

7801 Sierra Club 65120

7802 Sierra Club 65130

7803 Sierra Club 65210

7804 Sierra Club 65140

7805 Sierra Club 65150

7806 Sierra Club 65150

7807 Sierra Club 65160

7808 Sierra Club 65210

7809 Sierra Club 65220

7810 Sierra Club 65310

7811 Sierra Club 65330

7812 Sierra Club 65340

7813 Sierra Club 65350

7816 Sierra Club 65430

7817 Sierra Club 65440

7819 Sierra Club 65440

7820 Sierra Club 65450

7821 Sierra Club 65520

7823 Gardiner 67110

7824 Florida Power Cuip. 68120

7825 Florida Power Corp. 68120

7826 Florida Power Corp. 68120

7827 Florida Power Corp. 68230
7828 Florida Power Corp. 68230 7829 Florida Power Corp. 68230 7830 Florida Power Corp. 68260 7831 Florida Power Corp. 68310 7832 Florida Power Corp. 68310 7833 Florida Power Corp. 68320 7835 Florida Power Corp. 68320 7836 Florida Power Corp. 68330 7837 Florida Power Corp. 68330 7838 Florida Power Corp. 68330 7839 Florida Power Corp. 68330 7841 Florida Power Corp. 68360 7842 Florida Power Corp. 68360 7843 Florida Power Corp. 68410 7844 Florida Power Corp. 68420 7846 American Mining Congress 70230 7848 American Mining Congress 70320 7849 American Mining Congress 70320 7850 American Mining Congress 70620 7851 American Mining Congress 70620 7852 American Mining Congress 70620 7853 American Mining Congress 70620 7854 American Mining Congress 70730 7855 American Mining Congress 70730 7856 American Mining Congress 70740 7857 American Mining Congress 70810 7858 American Mining Congress 70810 7859 American Mining Congress 70820 7860 American Mining Congress 70820 7862 American Mining Congress 701120 7863 American Mining Congress 701120 7864 American Mining Congress 701120 7865 American Mining Congress 701120 7866 American Mining Congress 701320 7867 American Mining Congress 701320 7868 American Mining Congress 701330 7869 American Mining Congress 701420 7870 American Mining Congress 701440 7871 American Mining Congress 701440 7872 GPU Nuclear 71110 7873 GPU Nuclear 71110 7874 GPU Nuclear 71120 7875 GPU Nuclear 71120 7876 GPU Nuclear 71120 7877 GPU Nuclear 71120 7878 GPU Nuclear 71120 7879 GPU Nuclear 71210 7880 GPU Nuclear 71210 7881 GPU Nuclear 71230 7882 GPU Nuclear 71230 7883 GPU Nuclear 71240 7885 GPU Nuclear 71250 7886 GPU Nuclear 71250 7887 GPU Nuclear 71260 7890 GPU Nuclear 71260 7891 GPU Nuclear 71270 7892 Georgians Against Nuclear Energy 72110 7893 Georgians Against Nuclear Energy 72220 7894 OCRE 73110 7895 OCRE 73110 7896 OCRE 73120 7897 OCRE 73120 7898 OCRE $7311^{\prime} 30$ 7899 OCRE 73130 
7900 OCRE 73140 7901 OCRE 73140 7902 OCRE 73220 7903 OCRE 73220 7904 OCRE 73220 7905 OCRB 73220 7906 OCRB 71220 7907 OCRE 71220 7908 OCRE 73230 7909 OCRE 73230 7910 OCRE 73230 7911 OCRE 73230 7912 OCRE 73320 7913 OCRE 73310 7914 OCRE 73320 7915 OCRE 73330 7916 OCRE 73350 7917 PCRE 73370 7918 bCRE 73370 7919 OCRE 73410 7920 OCRE 73460 7921 OCRE 73470 7922 OCRE 73540 7923 OCRE 73550 7924 Winston \& Strawn 74220 7925 Winaton \& Strawn 74220 7926 Winton \& Strawn 74410 7927 Winston \& Strawn 74410 7928 Winton \& Strawn 74530 7929 Winuton \& Strawn 74520 7930 Winaton \& Strawn 74610 7931 Winston \& Strawn 74710 7933 Kennik 75110 7934 Rupert 76110 7935 Rupert 76210 7936 Rupert 76210 7937 Rupert 76220 7938 Rupert 76220 7939 Rupert 76340 7940 Rupert 76330 7941 Rupert 76310 7942 Rupert 76310 7943 Rupert 76510 7944 Rupert 76510 7945 Rupert 76610 7946 Rupert 76610 7947 Rupert 76710 7948 Rupert 76810 7949 Rupert 76910 7950 Rupert 76910 7951 Rupert 76910 7953 Rupert 76930 7954 Rupert 76930 7955 Rupert 761010 7956 Rupert 761010 7957 Rupert 761010 7958 Rupert 761020 7959 Rupert 761110 7960 Rupert 761120 7962 Rupert 761120 7963 Rupert 761130 7964 Rupert 761210 7965 Rupert 761210 7966 Rupert 761220
7967 Shelly 77140

7969 Shelly 77150

7970 Shally 77150

7971 Shelly 77160

7972 Shally 77160

7973 Nuclear Information and Rewource Service 78140 7974 Nuclear Information and Resource Service 78210 7975 Nuclear Information and Resource Service 78310 7976 Nuclear Information and Rewource Service 78410 7977 Nuclear Information and Resource Service 78410 7978 Nuclear Information and Resource Service 78410 7979 Nuclear Information and Reeource Service 78510 7980 Nuclear Information and Resource Service 78610 7981 Nuclear Information and Resource Service 78710 7982 Nuclear Information and Resource Service 78710 7983 Nuclear Information and Resounce Service 78810 7984 Nuclear Information and Resource Service 78810 7986 Nuclear Information and Resource Service 78810 7987 Nuclear. Information and Recource Service 781010 7988 Nuclear Information and Recource Service 781110 7989 Nuclear Information and Resource Service 781110 7990 Nuclear Information and Resource Service 781110 7991 Nuclear Information and Resource Service 781110 7992 Nuclear Intormation and Resource Service 781110 7993 Nuclear Information and Resource Service 781210 7994 Nuclear Information and Resource Service 781210 7993 Nuclear Information and Resource Service 781210 7996 Nuclear Information and Resource Service 781310 7997 Nuclear Information and Resources Service 781310 7998 Nuclear Information and Resource Service 781420 7999 Nuclear Information and Resource Service 781410 8000 Nuclear Information and Resource Service 781410 8001 Nuclear Information and Resource Service 781440 8002 Nuclear Information and Resource Service 781440 8003 Nuclear Information and Resource Service 781470 8004 Nuclear Information and Resource Service 781470 8005 Nuclear Information and Resource Service 781530 8006 Nuclear Information and Resource, Service 781540 8008 Nuclear Information and Resource Service 781650 8009 Nuclear Information and Resource Service 781650 8010 Nuclear Information and Resource Service 781650 8011 Puel Cycle Facilities Forum 79130 8012 Puel Cycle Pacilities Porum 79130 8013 Puel Cycle Pacilities Forum 79210 8014 Puel Cycle Pacilities Forum 79210 8015 Puel Cycle Facilities Forum 79220 8016 Puel Cycle Facilities Forum 79220 8017 Puel Cycle Facilities Forum 79220 8018 Puel Cycle Pacilities Porum 79230 8019 Puel Cycle Facilities Forum 79210 8020 Fuel Cycle Facilities Forum 79210 8021 Puel Cycle Facilities Forum 79210 8022 Fuel Cycle Facilities Forum 79220 8023 Fuel Cycle Facilities Forum 79220 8024 Fuel Cycle Pacilities Forum 79240 8026 Puel Cycle Facilities Forum 79310 8027 Fuel Cycle Pacilities Forum 79330 8028 Puel Cycle Facilities Forum 79330 8029 Puel Cycle Pacilities Porum 79410 8030 Fuel Cycle Pacilities Forum 79440 8031 Puel Cycle Pacilitieu Forum 79440 8032 Fuel Cycle Facilities Forum 79460 8036 Fuel Cycle Pacilities Forum 79530 8037 Puel Cycle Facilities Porum 79550 
8038 Fuel Cycle Pacilities Forum 79 s 50 8039 Fuel Cycle Pacilities Porum 79550 8041 Puel Cycle Pacilities Forum 79610 8042 Fuel Cycle Facilities Forum t9 620 8043 Fuel Cycle Pacilities Forum 79620 8044 Fuel Cycle Pacilities Forum 79620 8045 Puel Cycle Pacilities Forum 79630 8046 Fuel Cycle Pacilities Forum 79630 8047 Fuel Cycle Facilities Forum 79640 8048 Fuel Cycle Facilities Forum 79640 8049 Fuel Cycle Facilities Forum 79720 8051 Fuel Cycle Facilities Forum 79730 8052 Fuel Cycle Pacilities Forum 79730 8053 Fuel Cycle Pacilities Forum 79730 8054 Fuel Cycle Pacilities Forum 79740 8056 Puel Cycle Pacilities Forum 79830 8057 Fuel Cycle Facilities Forum 79830 8058 Fuel Cycle Pacilities Forum 79830 8059 Fuel Cycle Facilities Forum 79840 8060 Fuel Cycle Facilities Forum 79840 8061 Fuel Cycle Facilities Forum 79840 8062 Fuel Cycle Pacilities Forum 79920 8063 Fuel Cycle Facilities Forum 79920 8064 Puel Cycle Facilities Porum 79960 8066 Fuel Cycle Facilities Forum 79970 8067 Fuel Cycle Facilities Forum 79970 8068 Fuel Cycle Facilities Forum 791020 8069 Puel Cycle Facilities Forum 791030 8070 Puel Cycle Pacilities Forum 791030 8072 Fuel Cycle Facilities Forum 791050 8073 Fuel Cycle Facilities Forum 791050 8074 Fuel Cycle Facilities Forum 791050 8075 Puel Cycle Facilities Forum 791050 8076 Fuel Cycle Facilities Forum 791110 8077 Fuel Cycle Facilities Forum 791110 8078 Fuel Cycle Facilities Forum 791140 8079 Fuel Cycle Facilities Forum 791140 8080 Fuel Cycle Facilities Forum 791150 8081 Fuel Cycle Facilities Forum 791240 8082 Fuel Cycle Facilities Fortum 791220 8083 Fuel Cycle Facilities Forum 791310 8084 Fuel Cycle Facilities Forum 791310 8085 Fuel Cycle Facilities Forum 791320 8086 Puel Cycle Facilities Forum 791320 8087 Fuel Cycle Facilities Forum 791320 8088 Fuel Cycle Facilities Forum 791360 8089 Puel Cycle Facilities Forum 791360 8090 Fuel Cycle Pacilities Forum 791410 8091 Fuel Cycle Facilities Forum 791410 8092 Fuel Cycle Facilities Forum 791420 8093 Fuel Cycle Facilities Forum 791430 8094 Fuel Cycle Facilities Forum 791430 8095 Fuel Cycle Facilities Forum 791520 8096 Fuel Cycle Facilities Forum 791520 8097 Fuel Cycle Facilities Forum 791530 8098 Fuel Cycle Facilities Forum 791550 8100 Fuel Cycle Facilities Forum 791550 8101 Fuel Cycle Facilities Forum 791560 8102 Fuel Cycle Facilities Forum 791620 8103 Fuel Cycle Facilities Forum 791630 8104 Fuel Cycle Facilities Forum 791630 8105 Fuel Cycle Facilities Forum 791630 8106 Puel Cycle Pacilities Forum 791640 8108 Fuel Cycle Facilities Forum 791640
8109 Fuel Cycle Facilities Forum 791640 8110 Puel Cycle Facilities Forum 791710 8111 Fuel Cycle Facilities Forum 791720 8112 Fuel Cycle Pacilities Forum 791720 8113 Fuel Cycle Facilities Forum 791730 8114 Fuel Cycle Pacilities Forum 791740 8115 Fuel Cycle Pacilities Forum 791730 8116 Northweat Utilities 80110 8117 Northwest Utilities 80130 8118 Northwest Utilities 80210 8119 Northweat Utilities 80210 8120 Northeant Utilities 80210 8121 Northeast Utilities 80210 8122 Northeast Utilities 80230 8123 Northeqst Utilities 80230 8124 Yankee Atomic Electric Company 81110 8125 Yankee Atomic Electric Company 81110 8126 Yankee Atomic Electric Company 81110 8127 Yankee Atomic Electric Company 81150 8128 Yankee Atomic Electric Company 81150 8131 Yankee Atomic Electric Company 81240 8133 Yankee Atomic Electric Company 81250 8136 Yankee Atomic Electric Company 81280 8137 Yankee Atomic Electric Company 81310 8138 Yankee Atomic Electric Company 81310 8139 Yankee Atomic Electric Company 81330 8140 Yankee Atomic Electric Company 81340 8142 Yankee Atomic Electric Company 81350 8143 Yankee Atomic Electric Company 81350 8144 Yankee Atomic Electric Company 81360 8145 Yankee Atomic Electric Company 81360 8146 Yankee Atomic Electric Company 81420 8147 Yankee Atomic Electric Company 81430 8148 Public Service of Colorado 82110 8149 Public Service of Colorado 82120 8150 Public Service of Colorado 82120 8151 Public Service of Colorado 82130 8153 Public Service of Colorado 82140 8154 Public Service of Colorado 82210 8155 Public Service of Colorado 82210 8156 Public Service of Colorado 82210 8157 Public Service of Colorado 82220 8158 Public Service of Colorado 82240 8159 Public Service of Colorado 82240 8160 Public Service of Colorado 82250 8161 Public Service of Colorado 82260 8163 Public Service of Colorado 82310 8164 Public Service of Colorado 82320 8165 Public Service of Colorado 82320 8166 Public Service of Colorado 82330 8167 Public Service of Colorado 82330 8168 Public Service of Colorado 82350 8169 Public Service of Colorado 82350 8171 Public Service of Colorado 82410 8173 State of Wisconsin 83120 8174 State of Wisconsin 83120 8175 State of Wisconsin 83140 8176 State of Wisconsin 83130 8177 State of Wisconsin 83330 8178 State of Wisconsin 83330 8179 State of Wisconsin 83340 8180 State of Wisconsin 83340 8181 State of Wisconsin 83350 8182 State of Wisconsin 83350 
8183 State of Wisconsin 83350 $818 i$ State of Wisconsin 83410 8185 State of Wisconsin 83410 8186 Johnson 84110 8187 Johnson 84120 8188 Johnson 84120 8189 Johnson 84210 8190 Johnson 84220 8191 Johnson 84220 8192 Johnson 84220 8193 Johnson 84220 8194 Johnson 84230 8195 Johnson 84240 8196 Johnson 84250 8197 Johnson 84250 8198 Johnson 84320 8199 Johnson 84320 8200 Johnson 84320 8201 Johnson 84330 8202 Johnson 84340 8203 Johnson 84340 '8204 Johnson 84310 8205 Johnson 84360 8206 Johnson 84360 8207 Johnson 84370 8208 Johnsrud 85110 8209 Johnsrud 85110 8210 Johnsrud 85110 8211 Johnsrud 85110 8212 Johnsrud 85210 8213 Johnsrud 85210 8214 johnsrud 85210 8215 Johnsrud 85210 8216 Johnsrud 85210 8217 Johnsrud 85310 8218 Johnsrud 85410 8219 Johnsrud 85410 8220 Johnsrud 85430 8221 Johnsrud 85430 8222 Johnsrud 85420 8223 Johnsrud 85520 8224 Johnsrud 85530 8225 Johnsrud 85530 8226 Johnsrud 85540 8227 Johnsrud 85630 8228 Johnsrud 85630 8229 Johnsrud 85660 8230 Johnsrud 85660 8231 Johnsnud 85660 8232 johnsrud 85660 8233 Johnsrud 85710 8234 Johnsrud 85710 8235 Johnsrud 85710 8236 Johnsrud 85720 8237 Johnsrud 85710 8238 Johnsrud 85740 8239 Johnsrud 85750 8240 Johnsrud 85760 8241 Johnsrud 85760 8242 Johnsrud $85 \& 10$ 8243 Johnsrud 85810 8244 Johusrud 85830 8245 Johnsrud 85840 8246 Johnsrud 85910
8247 Johnarud 85920

8249 Johnarud 85930

8250 Johnarud ' 851030

8251 Johnarud 851040

8252 Johnarud 851040

8253 Johnurud 851110 8254 Johnarud 851130

8255 BIPI 86120

8256 BIPI 86110

8257 BIPI 86210

8258 BIPI 86220

8259 Burgess 88110

8260 Burgess 88110

8261 NUMARC 89110

8264 NUMARC 89210

8265 NUMARC 89210

8266 NUMARC 89220

8267 NUMARC 89220

8268 NUMARC 89230

8269 NUMARC 89240

8270 NUMARC 89240

8271 NUMARC 89310

8272 NUMARC 89310

8273 NUMARC 89320

8274 NUMARC 89320

8275 NUMARC 89320

8276 NUMARC 89330

8277 NUMARC 89330

8278 NUMARC 89330

8279 NUMARC 89410

8280 NUMARC 89410

8281 NUMARC

8283 NUMARC

8284 NUMARC

8285 NUMARC .

8286 NUMARC 89510 8287 NUMARC 89520 8288 NUMARC 89520 8289 NUMARC 89610 8290 NUMARC 89620 8292 NUMARC 89620 8293 NUMARC 89630 8294 NUMARC 89630 8295 NUMARC 89640 8297 NUMARC 89640 8299 NUMARC 89710 8300 NUMARC 89720 8301 NUMARC 89720 8302 NUMARC 89720 $8303^{\circ}$ UMARC 89720 8304 NUMARC 89720 8305 NUMARC 89810 8306 NUMARC 89810 8307 NUMARC 89820 3308 NUMARC 89810 8309 NUMARC 89910 8310 NUMARC 89910 8311 NUMARC 89910 8312 NUMARC 89920 8313 NUMARC 89930 8314 NUMARC 89930 8315 NUMARC 89930 8316 NUMARC 89930 8317 NUMARC 89930 
8318 NUMARC 891010 8319 NUMARC 891010 8320 NUMARC 891010 8321 NUMARC 101010 8322 NUMARC 891010 8323 NUMARC 891010 8324 NUMARC 891020 8325 NUMARC 891020 8326 NUMARC 891020 8327 NUMARC 891020 8329 NUMARC 891020 8330 NUMARC 891120 8331 NUMARC 891120 8332 NUMARC 891130 8333 NUMARC 891130 8334 NUMARC 891210 8335 NUMARC 891210 8336 NUMARC 891210 8337 NUMARC 891210 8338 NUMARC 891220 8339 NUMARC 891310 8340 NUMARC 891310 8341 NUMARC 891310 8342 NUMARC 891310 8343 NUMARC 891310 8344 NUMARC 891320 8345 NUMARC 891320 8346 NUMARC 891320 8347 NUMARC 891420 8348 NUMARC 891420 8349 NUMARC 891420 8350 NUMARC 891420 8351 NUMARC 891420 8352 NUMARC 891430 8353 NUMARC 891430 8354 NUMARC 891430 8355 NUMARC 891430 8356 NUMARC 891510 8357 NUMARC 891520 8358 NUMARC 891520 8359 NUMARC 891520 8360 NUMARC 891530 8362 NUMARC 891530 8363 NUMARC 891610 8364 NUMARC 891620 8365 NUMARC 891620 8366 NUMARC 891620 8367 NUMARC 891620 8368 NUMARC 891620 8369 NUMARC 891630 8370 NUMARC 891630 8371 NUMARC 891710 8372 NUMARC 891710 8373 NUMARC 891710 8374 NUMARC 891730 8375 NUMARC 891730 8377 NUMARC 891810 8378 NUMARC 891810 8379 NUMARC 891810 8380 NUMARC 891810 8381 NUMARC 891830 8382 NUMARC 891830 8383 NUMARC 891830 8384 NUMARC 891830
8385 NUMARC 892010 8387 NUMARC 892010 8388 NUMARC 892010 8389 NUMARC 892020 8390 NUMARC 892020 8391 NUMARC 892020 8392 NUMARC 892040 8393 NUMARC 892110 8394 NUMARC 892110 8395 NUMARC 892130 8396 NUMARC 892220 8397 NUN ARC 892220 8398 NUMARC 892220 8399 NUMARC 892220 8400 NUMARC 892220 8401 NUMARC 892220 8402 NUMARC 892230 8403 NUMARC 892230 840 'UMARC 892230 8405 IVUMARC 892320 8406 NUMARC 892330 8407 NUMARC 892330 8408 NUMARC 892330 8409 NUMARC 892430 8410 NUMARC 892430 8411 NUMARC 892430 8412 NUMARC 892520 8414 NUMARC 892520 8415 ACNP/SNM 90130 8416 ACNP/SNM 90140 8418 ACNP/SNM 90140 8420 ACNP/SNM 90210 8421 ACNP/SNM 90210 8422 ACNP/SNM 90220 8423 ACNP/SNM 90220 8425 TDEC 91110 8426 TDEC 91110 8427 TDEC 91210 8428 TDEC 91210 8429 TDEC 91210 8430 TDEC 91110 8431 TDEC 91110 8432 TDEC 91210 8433 Siemans Power Corp. 92120 8434 Siemans Power Corp. 92120 8435 Siemans Power Corp. 92120 8436 Siemens Power Corp. 92120 8437 Siemens Power Corp. 92130 8438 Siemens Power Corp. 92130 8439 Siemens Power Corp. 92130 8441 Siemens Power Corp. 92150 8442 Siemens Power Corp. 92150 8443 Siemens Power Corp. 92210 8444 Siemens Power Corp. 92220 8445 Siemens Power Corp. 92220 8446 Siemens Power Corp. 92220 8448 Siemens Power Corp. 92230 8449 Siemens Poiver Corp. 92230 8450 Siemens Power Corp. 92230 8451 Siemens Power Corp. 92240 8452 Siemens Power Corp. 92240 8454 Illinois Dept. of Nuclear Safety 93120 8455 Illinois Dept. of Nuclear Safety 93120 8456 Illinois Dept. of Nuclear Safety 93130 
8457 Illinois Dept. of Nuclear Safety 93130 8458 Illinois Dept. of Nuclear Safety 93130 8459 Ilinois Dept. of Nuclear Safety 93130 8460 Ilinois Dept. of Nuclear Safety 93140 8461 Ilinois Dept. of Nuclear Safety 93240 8463 Illinois Dept. of Nuclear Safety 93220 8465 Ilinois Dept. of Nuclear Safety 93220 8466 Iltinois Dept. of Nuclear Safety 93230 8467 Ilinois Dept. of Nuclear Safety 93230 8468 Ilinois Dept. of Nuclear Saffty 93240 8469 Illinois Dept. of Nuclear Safety 93240 8470 Ilinois Dept. of Nuclear Safety 93240 8471 Ilinois Dept. of Nuclear Safety 93240 8472 Illinois Dept. of Nuclear Safety 93240 8473 Illinois Dept. of Nuclear Safety 93240 8474 Ilinois Dept. of Nuclear Safety 93250 8475 Iltinois Dept. of Nuclear Safety 93250 8476 Ilinois Dept. of Nuclear Safety 93250 8478 Hlinois Dept. of Nuclear Safety 93310 8479 Ilinois Dept. of Nuclear Safety 93310 8480 Iltinois Dept. of Nuciear Safety 93310 8481 Illinois Dept. of Nuclear Safety 93310 8483 Illinois Dept. of Nuclear Safety 93320 8484 Ilinois Dept. of Nuclear Safety 93320 8485 Ilinois Dept. of Nuclear Safety 93320 8487 Illinois Dept. of Nuclear Safety 93330 8488 Ilinois Dept. of Nuclear Safety 93340 8489 Illinois Dept. of Nuclear Safety 93340 8490 Illinois Dept. of Nuclear Safety 93350 8491 Illinois Dept. of Nuclear Safety 93350 8492 NEW YORK POWER AUTHORTTY 94110 8493 NEW YORK POWER AUTHORITY 94210 8494 NEW YORK POWER AUTHORITY 94210 8495 NEW YORK POWER AUTHORITY 94210 8496 NEW YORK POWER AUTHORTTY 94220 8497 NEW YORK POWER AUTHORITY 94220 8498 NEW YORK POWER AUTHORITY 94230 8499 NEW YORK POWER AUTHORITY 94230 8500 NEW YORK POWER AUTHORITY 94230 8501 NEW YORK POWER AUTHORTY 94250 8502 NEW YORK POWER AUTHORITY 94250 8503 CFUR 95120 8504 CFUR 95110 8505 CFUR 95110 8507 CFUR 95110 8508 CFUR 95110 8509 CFUR 95110 8510 CPUR 95110 8511 CPUR 95210 8512 CFUR 95210 8513 CFUR 95210 8514 CFUR 95230 8517 CFUR 95230 8518 CPUR 95260 8519 CFUR 95310 8520 CFUR 95350 8521 CFUR 95350 8522 CFUR 95350 8523 CPUR 95410 8524 CECO 96130 8525 CBCO 96110 8526 CBCO 96110 8527 CECO 96110 8528 CECO 96120
8529 CECO 96120 8530 CECO 96120 8531 CECO 96320 8532 CECO 96320 8533 CECO 96320 8534 CECO 96330 8535 CECO 96330 8536 CECO 96330 8537 CECO 96340 8538 CECO 96340 8539 CECO 96410 8540 CECO 96410 8541 CECO 96420 8542 CECO 96420 8543 CECO 96420 8544 CECO 96420 8545 CECO 96440 8546 CECO 96440 8548 CECO 96510 8549 CECO 96520 8550 CECO 96520 8551 CECO 96520 8552 CECO 96520 8553 CECO 96610 8554 CECO 96610 56 CECO 96620 8557 CECO 96630 8558 CECO 96630 8559 CECO 96630 8560 CECO 96640 8562 CECO 96710 8564 CECO 96710 8565 CECO 96720 8566 CECO 96720 8567 CECO 96850 8568 CECO 96850 8569 CECO 96920 8570 CECO 96920 8571 CECO 96920 8572 CECO 961020 8574 CECO 961020 8575 CBCO 961020 8576 CECO 961020 8577 CECO 961020 8578 CECO 961030 8579 CECO 961030 8580 CECO 961030 8581 CECO 961110 8582 CECO 961110 8583 CBCO 961210 8584 CECO 961110 8585 CECO 961110 8586 CECO 961220 8587 CECO 961230 8589 CECO 961230 8590 CECO 961230 8591 CECO 961230 8592 CECO 961240 8593 CECO 961320 8594 CECO 961320 8595 CECO 961340 \$597 CECO 961360 8598 CECO 961360 8599 CECO 961360 
8600 TFI 97130 8601 TPI 97210 8602 TFI 97130 8603 TFI 97220 8604 TFI 97220 8606 TFI 97220 8607 TFI 97230 8608 TFI 97230 8609 TFI 97230 8610 TFI 97230 8611 TFI 97240 8612 TFI 97240 8613 TFI 97250 8614 TFI 97250 8615 TFI 97310 8616 TPI 97310 8617 TFI 97320 8618 TFI 97330 8619 TFI 97330 8620 TFI 97330 8621 TFI 97330 8622 TFI 97330 8623 TFI 97340 8624 TFI 97350 8625 TFI 97350 8626 TFI 97350 8628 USCEA 98130 8629 USCEA 98140 8630 USCEA 98140 8631 USCEA 98210 8632 USCEA 98210 8633 USCEA 98210 8634 USCEA 98210 8635 USCEA 98210 8636 USCEA 98310 8637 USCEA 98310 8638 USCEA 98320 8639 USCEA 98320 8640 USCEA 98320 8641 USCEA 98320 8642 USCEA 98320 8643 USCEA 98320 8644 USCEA 98330 8646 USCEA 98340 8647 USCEA 98340 8648 USCEA 98340 8649 USCEA 98410 8651 USCEA 98410 8653 USCEA 98420 8654 USCEA 98420 8655 USCEA 98430 8657 USCFA 98430 8658 USCE'A 98440 8659 USCEA 98510 8660 USCEA 98520 8661 USCEA 98520 8662 USCEA 98520 8663 USCEA 98530 8664 USCEA 98530 8665 USCEA 98530 8666 USCEA 98540 8668 USCEA 98540 8669 USCEA 98550 8670 USCEA 98610
8672 USCEA 98620 8673 USCEA 98620 8674 USCEA 98630 8675 USCEA 98640 8676 USCEA 98650 8677 USCEA 98650 8678 USCEA 98650 8679 USCEA 98710 8680 USCEA 98710 8681 USCEA 98730 8682 USCEA 98730 8683 USCEA 98740 8685 USCEA 98750 8686 USCEA 98810 8688 USCEA 98820 8689 USCEA 98830 8690 USCEA 98890 8691 USCEA 98890 8692 USCEA 98890 8694 HOLT 99110 8695 RUANE 102110 8696 WELLS 103130 8698 WELLS 103140 8699 CRENSHAW 104110 8700 CRENSHAW 104110 8701 CLARK COUNTY, NEVADA 105140 8702 CLARK COUNTY, NEVADA 105110 8703 CLARK COUNTY, NEVADA 105140 8704 CLARK COUNTY, NEVADA 105150 8705 CLARK COUNTY, NEVADA 105140 8706 CLARK COUNTY, NEVADA 105140 8707 CLARK COUNTY, NEVADA 105160 8708 CLARK COUNTY, NEVADA 105160 8709 CLARK COUNTY, NEVADA 105210 8710 CLARK COUNTY, NEVADA 105210 8711 CLARK COUNTY, NEVADA 105220 8712 CLARK COUNTY, NEVADA 105220 8713 CLARK COUNTY, NEVADA 105250 8714 CLARK COUNTY, NEVADA 105260 8717 CLARK COUNTY, NEVADA 105310 8718 CLARK COUNTY, NEVADA 105310 8719 CLARK COUNTY, NEVADA 105310 8720 CLARK COUNTY, NEVADA 105330 8721 CLARK COUNTY, NEVADA 105330 8722 CLARK COUNTY, NEVADA 105310 8723 CLARK COUNTY, NEVADA 105350 8724 CLARK COUNTY, NEVADA 105350 8725 CLARK COUNTY, NEVADA 105360 8727 CLARK COUNTY, NEVADA $10531 \mathrm{~J}$ 8728 CLARK COUNTY, NEVADA 105410 8729 CLARK COUNTY, NEVADA 105420 8730 CLARK COUNTY, NEVADA 105420 8732 CLARK COUNTY, NEVADA 105440 8733 CLARK COUNTY, NEVADA 105450 8735 CLARK COUNTY, NEVADA 105450 8736 CLARK COUNTY, NEVADA 105450 8737 CLARK COUNTY, NEVADA 105510 8738 CLARK COUNTY, NEVADA 105510 8739 CLARK COUNTY, NEVADA 105520 8740 CLARK COUNTY, NEVADA 105530 8742 CLARK COUNTY, NEVADA 105540 8743 CLARK COUNTY, NEVADA 105560 8744 CLARK COUNTY, NEVADA 105560 8745 CLARK COUNTY, NEVADA 105610 
8746 CLARK COUNTY, NEVADA 105610 8747 CLARK COUNTY, NEVADA 105620 8748 CLARK COUNTY, NEVADA 105610 8749 CLARK COUNTY, NEVADA 105620 8750 CLARK COUNTY, NEVADA 105620 8751 CLARK COUNTY, NEVADA 105620 8752 CLARK COUNTY, NEVADA 105640 8753 CLARK COUNTY, NEVADA 105650 8754 CLARK COUNTY, NEVADA 105650 8755 CLARK COUNTY, NEVADA 105710 8756 CLARK COUNTY, NEVADA 105710 8757 CLARK COUNTY, NEVADA 105740 8758 CLARK COUNTY, NEVADA 105740 8759 CLARK COUNTY, NEVADA 105760 8761 CLARK COUNTY, NEVADA 105760 8763 OCRE 73320

8764 CFUR 95260

8765 SIERRA CLUB 28140

8766 ASPI 23240

8767 USCFA 26110

8769 SIERRA CLUB 28230

8770 SIERRA CLUB 28170

8771 SIERRA CLUB 28310

8772 NUCLEAR METALS, INC. 52110

8773 NUCLEAR METALS, INC. 52110

8774 Cuyahoga County District Board of Health 61510

8775 Cuyahoga County District Board of Health 61510

8776 AMERICAN MINING CONGRESS 701330

8777 FUEL CYCLE FACILITIES FORUM 79210

8778 FUEL CYCLE FACILITIES FORUM 79970

8779 PUBLIC CITIZEN 14830

8780 NUMARC 891010

8781 ILL. DEPARTMENT OF NUCLEAR SAFETY 93120

8782 CFUR 95230

8783 USCEA 98730

8784 NEW YORK STATE ENERGY RESEARCH AND

DEVELOPMENT AUTHORTY 64310

8785 FUEL CYCLE FACILITIES FORUM 791730

8786 PUBLIC SERVICE 82240

8787 SIEMENS 92130

8788 SIEMENS 92130

8789 SCIENCE APPLICATIONS INTERNATIONAL

CORPORATION 1110

8790 Texas Nuclear Responsibility Network 5430

8791 MOELLER 9570

8792 MOELLER 9840

8793 8-ORGANIZATION GROUP 63220

8794 8-ORGANIZATION GROUP 63220

8795 8-ORGANIZATION GROUP 63220

8797 MOELLER 9840

8799 Levin 4170

8801 PUBLIC CITIZEN 14630

8802 American Nuclear Society 32410

8803 CLARK COUNTY, NEVADA 105110

8804 CLARK COUNTY, NEVADA 105530

8805 CLARK COUNTY, NEVADA 105560

8806 CLARK COUNTY, NEVADA 105560

8807 CLARK COUNTY, NEVADA 105610

8808 CLARK COUNTY, NEVADA 105620

8809 CLARK COUNTY, NEVADA 105620

8810 CLARK COUNTY, NEVADA 105650

8811 State of Michigan 35150

8813 State of Michigan 35270

8814 Health Physics Society $36230^{\prime}$
8815 Health Physics Society 36520

8816 GE Nuclear Energy 62210

8817 Florida Power Corp. 68120

8818 GPU Nuclear 71120

8819 Yankee Atomic Electric Company 81110

8820 Yankee Atomic Electric Company 81110

8821 NUMARC 891310

8822 CECO 96520

8823 CECO 96610

8824 CLARK COUNTY, NEVADA 105610

8825 TFI 97310

8830 FUEL CYCLE FACILITIES FORUM 79220

8831 CECO 961240

8832 Winston \& Strawn 74220

8833 NUMARC 89330

8834 Crawford 39110

8835 ASTSWMO 33820

8836 Johnsrud 85660

8837 SIERRA CLUB, DALLAS GROUP 28230

8838 Nuclear Metals, Inc. 52110

8839 GPU Nuclear 7210

8840 Texas Nuclear Responsibility Network 5110

8841 American Mining Congress 701320

8842 SIERRA CLUB-DALLAS GROUP 28140

8843 SIERRA CLUB-DALLAS GROUP 28140

8844 Levin 4140

8845 Levin 4220

8846 Siemans Power Corp. 92130

8847 Public Service of Colorado 82240

8848 Nuclear Metals, Inc. 52110

8849 American Nuclear Society 321220

8850 King 59110

8851 8-Organization Group 63220

8852 State of Michigan 35220

8853 Illinois Dept. of Public Safety 93310

8854 Public Service of Colorado 82210

8855 NUMARC 891810

8856 DEPARTMENT OF ENERGY 106110 8857 DEPARTMENT OP ENERGY 106110 8858 DEPARTMENT OF ENERGY 106110 8859 DEPARTMENT OF ENERGY 106110 8860 DEPARTMENT OF ENERGY 106110 8861 DEPARTMENT OF ENERGY 106110 8862 DEPARTMENT OP ENERGY 106110 8863 DEPARTMENT OP ENERGY 106210 8864 DEPARTMENT OP ENERGY 106210 8865 DEPARTMENT OF ENERGY 106, 210 8866 DEPARTMENT OF ENERGY 105210 8867 DEPARTMENT OF ENERGY 106210 8868 DEPARTMENT OF ENERGY 106210 8869 DEPARTMENT OF ENERGY 106210 8870 DEPARTMENT OF ENERGY 106210 8871 DEPARTMENT OF ENERGY 106210 8872 DEPARTMENT OF ENERGY 106210 8873 DEPARTMENT OF ENERGY 106210 8874 DEPARTMENT OF ENERGY 106210 8875 DEPARTMENT OF ENERGY 106310 8876 DEPARTMENT OF ENERGY 106310 8877 DEPARTMENT OF ENERGY 106310 8878 DEPARTMENT OF ENERGY 106310 8879 DEPARTMENT OF ENERGY 106310 8880 DEPARTMENT OF ENERGY 106310 8881 DEPARTMENT OF ENERGY 106310 8882 DEPARTMENT OF ENERGY 106310 
8883 DEPARTMENT OF ENERGY 106310 8884 DEPARTMENT OF ENERGY 106310 8885 DEPARTMENT OF ENERGY 106310 8886 DEPARTMENT OF ENERGY 106310 8887 DEPAR'TMENT OF ENERGY 106310 8888 DEPARTMENT OF ENERGY 106310 8889 DEPARTMENT OF ENERGY 106310 8890 DEPARTMENT OF ENERGY 106310 8891 DEPARTMENT OF ENERGY 106410 8892 DEPAR'TMENT OF ENERGY 106410 8893 DEPARTMENT OF ENERGY 106410 8894 DEPARTMENT OF ENERGY 106410 8895 DEPARTMENT OF ENERGY 106410 8896 DEPARTMENT OF ENERGY 106410 8897 DEPARTMENT OF ENERGY 106410 8898 DEPARTMENT OF ENERGY 106410 8899 DEPARTMENT OF ENERGY 106410 8900 DEPARTMENT OF ENERGY 106410 8901 DEPARTMENT OF ENERGY 106410 8902 DEPARTMENT OF ENERGY 106510 8903 DEPARTMENT OF ENERGY 106510 8904 DEPARTMENT OF ENERGY 106510 8905 DEPARTMENT OF ENERGY 106510 8906 DEPARTMENT OF ENERGY 106510 8907 DEPARTMENT OF ENERGY 106510 8908 DEPARTMENT OF ENERGY 106510 8909 DEPARTMENT OF ENERGY 106510 8910 DEPARTMENT OF ENERGY 106510 8911 DEPARTMENT OF ENERGY 106510 8912 DEPARTMENT OF ENERGY 106510 8913 DEPARTMENT OF ENERGY 106510 8914 DEPARTMENT OF ENERGY 106610 8915 DEPARTMENT OF ENERGY 106610 8916 DEPARTMENT OF ENERGY 106610 8917 DEPARTMENT OF ENERGY 106610 8918 DEPARTMENT OF ENERGY 106610 8919 DEPARTMENT OF ENERGY 106710 8920 DEPARTMENT OF ENERGY 106710 8921 DEPARTMENT OF ENERGY 106710 8922 DEPARTMENT OF ENERGY 106710 8923 DEPARTMENT OF ENERGY 106710 8924 DEPARTMENT OF ENERGY 106710 8925 DEPARTMENT OF ENERGY 106810 8926 DEPARTMENT OF ENERGY 106810 8927 DEPARTMENT OF ENERGY 106810 8928 DEPARTMENT OF ENERGY 106810 8929 DEPARTMENT OF ENERGY 106810 8930 DEPARTMENT OF ENERGY 106810 8931 DEPARTMENT OF ENERGY 106810 8932 DEPARTMENT OF ENERGY 106910 8933 DEPARTMENT OF ENERGY 106910 8934 DEPARTMENT OF ENERGY 106910 8935 DEPARTMENT OF ENERGY 106910 8936 DEPARTMENT OF ENERGY 106910 8937 DEPARTMENT OF ENERGY 106910 8938 DEPARTMENT OF ENERGY 106910 8939 DEPARTMENT OF ENERGY 106910 8940 DEPARTMENT OF ENERGY 106910 8941 DEPARTMENT OF ENERGY 106910 8942 DEPARTMENT OF ENERGY 106910 8943 DEPARTMENT OF ENERGY 1061010 8944 DEPARTMENT OF ENERGY 1061010 8945 DEPARTMENT OF ENERGY 1061010 8946 DEPARTMENT OF ENERGY 1061010
8947 DEPARTMENT OF ENERGY 1061010 8948 DEPARTMENT OF BNERGY 1061010 8949 DEPARTMENT OF ENERGY 1061010 8950 DEPARTMENT OF ENERGY 1061010 8951 DEPAR'MMENT OF ENERGY 1061010 8952 DEPARTMENT OF ENERGY 1061010 


\section{APPENDIX E}




\section{APPENDIX E \\ Summary of Comments Received from Generic Environmental Impact Statement (GEIS) Scoping Meetings on Radiological Criteria for Decommissioning}

As part of the effort to codify radiological criteria for decommissioning to determine the extent to which radioactive contamination must be removed or reduced in lands and structures before a nuclear facility can be released and its license terminated, the NRC held public meetings on the scope of the GEIS during July 1993 in Washington, D.C., San Francisco, CA, Oklahoma City, OK, and Cleveland, OH. Interested parties were invited to provide early and comprehensive input before the NRC staff develops the GEIS. A notice in the Federal Register, June 18, 1993, also invited comments.

This Appendix summarizes 642 comments from records of the meetings and an additional 954 comments from 63 letters $^{1}$ received by the NRC from individuals and organizations. The summaries were organized to the following issues and sub-issues. A unique comment number was assigned to each comment and therefore the source of each comment can be identified as to origin, commenter. baginning page number, and line number (for meetings only). Comments received during the meetings are numbered under 700 while docketed letter comments are numbered greater than 700 . A listing of commenters follows the summaries.

ISSUES

PAGE

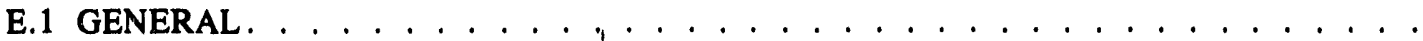

E.1.1 Need for Criteria . . . . . . . . . . . . . . . . .

E.1.2 General Form of Rule . . . . . . . . . . . . . . . . . . . . .

E.1.3 Procedural aspects

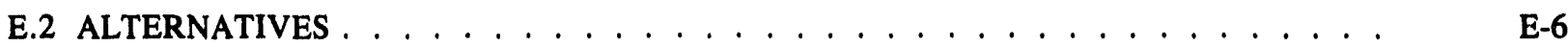

E.2.1 Abandonment of Facilities . . . . . . . . . . . . . . . . . E E-6

E.2.2 No Regulatory Change . . . . . . . . . . . . . . . . . . . . E-6

E.2.3 Risk Limit/ Risk Goal . . . . . . . . . . . . . . . . . . . . . . . . . . . . E-7

E.2.3.1 General . . . . . . . . . . . . . . . . . . . E-7

E.2.3.2 Agrees/Disagrees with Risk limit/goal approach . . . . . . . . . . . E E-7

E.2.4 Return to Background . . . . . . . . . . . . . . . . . . . . E E-10

E.2.4.1 General . . . . . . . . . . . . . . . . . . . . . E-10

E.2.4.2 Agrees/Disagrees with Return to Background Alternative . . . . . . . . . E-11

E.2.5 Best Technology . . . . . . . . . . . . . . . . . . . . . E E-12

${ }^{1}$ This also includes a letter from the US Department of Energy which was received but it was not docketed at manuscript completion. 
E.2.6 Restricted Use . . . . . . . . . . . . . . . . . . . . E E-12

E.2.6.1 Agrees/Disagrees With Restricted Use Alternative . . . . . . . . . . . E E-12

E.2.6.2 Concerns/Questions About This Alternative . . . . . . . . . . . . E-13

E.2.6.3 Procedural Aspects of Restricted Use . . . . . . . . . . . . E-14

E.2.7 Other Comments . . . . . . . . . . . . . . . E E-14

E.3 METHOD OF APPROACH . . . . . . . . . . . . . . . . . . . . . E-14

E.3.1 Facilities Covered . . . . . . . . . . . . . . . . . E E-15

E.3.2 Affected Environment . . . . . . . . . . . . . . . . E E-15

E.3.3 Technical Approach . . . . . . . . . . . . . . . . E E-16

E.4 IMPACTS/COSTS/WASTES . . . . . . . . . . . . . . . . . . . . E E-17

E.4.1 Radiological Impacts . . . . . . . . . . . . . . . . . . . E-17

E.4.1.1 Health Impacts . . . . . . . . . . . . . . . . . . . . . E E-17

E.4.1.2 General Impacts . . . . . . . . . . . . . . . . . . E-17

E.4.1.3 Radiological Impacts to Workers/Public . . . . . . . . . . . . . E-18

E.4.2 Non-radiological impacts . . . . . . . . . . . . . . . . . . . . E E-19

E.4.2.1 Human Health Impacts; Synergism With Chemical Wastes; Construction and

Transportation Accidents . . . . . . . . . . . . . . . . . E E-19

E.4.2.2 Biota . . . . . . . . . . . . . . . . . . . . E-19

E.4.2.3 Economic/Land Use . . . . . . . . . . . . . . . . . . . E E-20

E.4.2.4 Societal . . . . . . . . . . . . . . . . . . . E E-20

E.4.3 Transfer of Risk . . . . . . . . . . . . . . . . . . . E-20

E.4.4 Costs; Measurements Capability . . . . . . . . . . . . . . . . E-20

E.4.5 Wastes . . . . . . . . . . . . . . . . . . . . . . E E-21

E.4.6 Comparison of Impacts and Costs . . . . . . . . . . . . . . . E-22

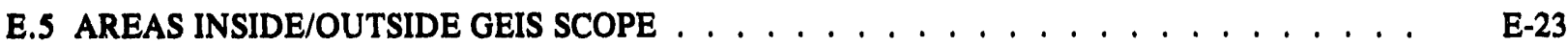

E.5.1 Funding/Plancing of Decommissioning . . . . . . . . . . . . . . E-23

E.5.2 Timing/Ti:neliness Considerations . . . . . . . . . . . . . . . . . E E-24

E.5.3 Continued Liability for Facilities . . . . . . . . . . . . . . . . . . . E-24

E.5.4 Recycle . . . . . . . . . . . . . . . . . . . . . . . . . . E E-25

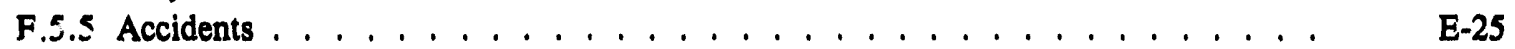

E.5.6 Monitoring . . . . . . . . . . . . . . . . . . . . . . E-25

E.5.7 Hazardous Wastes, Mixed Wastes, Other Agency Regs., Radium . . . . . . . . . . . E-25

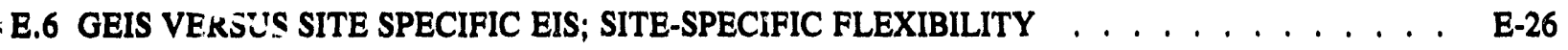

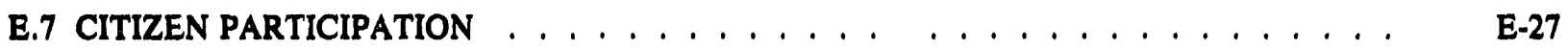

E.8 WASTE MINIMIZATION $\ldots \ldots \ldots \ldots \ldots$ E-28 


\section{E.1 GENERAL}

\section{E.1.1 Need For Criteria}

Most commenters supported the NRC's efforts to establish codification of radiological criteria for decommissioning and expressed a need for uniformity, definition, and clarity $(1,53,57,152,231,327,973$, 982, 1223, 1601, 1617). Two commenters expressed a need for criteria that would ensure full decontamination $(711,827)$. One commenter urged that previously decommissioned sites not be exempted from further consideration (1137) while another commenter requested exemption for uranium mill and ISL facilities (1056). One commenter thought it was impossible or inappropriate to attempt remediation with current technology or any foreseen technology (880). One State related experience with workable approaches to site cleanup (1601).

\section{E.1.2 General Form Of Rule}

Two commenters expressed that the proposed action should be defined as "codification of radiological criteria for decommissioning and decontamination of lands and structures" versus just decommissioning $(716,770)$. Another commenter suggested the use of "Existing Radiological Guidance..." in lieu of "Existing Radiological Criteria ..." as codified decommissioning criteria does not now exist (1614). Two commenters wanted definite criteria that will not be open to interpretation by an industry which might be confused by complex rules or overall policy $(153,241)$. One commenter did not believe that protection of human beings and the environment can be ensured (245); another commenter desired the nuclear power industry to be banned (1597).

One commenter expressed a concern that non-standard reporting of radionuclide concentrations by industry and federal agencies would increase the likelihood of "misleading independent oversight and the general public"(700).

Two commenters expressed concern regarding the impact of easy standards:

An easy standard ensures that it will be easy for the nuclear industry to expand in the future (89).

"Lesser standards shift risks to cio:se least in a position to accept them." These groups include Native Americans, downwinders, and workers in nuclear field center, etc. (414).

Two commenters identified specific problems and presented specific requests:

One commenter wanted the regulatory concern to be how to contain and isolate with zero release the radioactivity that has been generated, no matter where it is physically located. The commenter stated that a generic rule should contain the requirement for a site-specific decommissioning plan that is approved not only by the regulator, but the affected communities. The plan should be based upon a site-specific environmental impact statement that is also generically required (1267).

We recommend "independent" epidemiological studies of people living near facilities and ecosystems monitoring with full public disclosure of shipping manifests, reports, accidents, and releases (604). 
One commenter made detail ad statements regarding the approaches to the GEIS:

The final standards need to be flexibie enough to address concerns noted in all four approaches discussed in the issue paper as well as reduce problems caused by the individual approaches (8868).

The procedural requirements and the basic structure of the standard must be codified. This includes the "risk limit" the process for multi-attribute analyses to deterr ine how far below the risk limit is achievable, and the requirements for dealing with situations that cannot achieve the "risk limit" requirements $(1596,8895)$.

At a minimum, the "risk goals" concept and how it fits within the overall standard must be codified. The actual concentration screening goals, if developed, need not be codified. However, they should be issued for public comment and undergo detailed peer review. The regulation need not be overly prescriptive but at the least, recommended measurement techniques and compliance requirements (e.g., acceptable models, guidance on parameter determination, and guidance on procedures for multi-attribute analyses or other alternative approaches) should be included in a regulatory guide and provided in draft for public comment. The final guidance documents should be placed or their availability announced in the Federal Register to ensure that there is a complete understanding of how compliance should be demonstrated (8899).

One commenter preferred expressing the criteria in terms of dose rather than in terms of extrapolated cancer risks because the latter emphasizes acceptable risk which is loosely based on very soft numbers and introduces issues which are not resolvable (1604).

\section{E.1.3 Procedural Aspects}

Many commenters expressed the need for the GEIS as a tool to focus and evaluate the approaches to establish practical criteria for decommissionin: $(1107,1155,1234,1236)$. Others felt that renediation at this time is inappropriate and insufficient with present knowledge $(653,882)$, and two expressed concerns for the future $(893,909)$. Short term economic benefit enjoyed as a result of compromising the public's health will create a future burden and should not be adopted (1017).

Decommissioning of non-disposable toxicants must be forever open to new information, new technology, and new evaluation with the bottom line always the most advanced scientific facts from all credible sources (935). In light of technology, more scoping meetings were also recommended to discuss what can be done with land which can not be remediated (1413). Another commenter stated that restricted use should be evaluated as an option for any limit or criteria established and be analyzed in GEIS (990).

Two commenters expressed concern that the GEIS would not cover issues which were covered by prior environmental review $(1171,1615)$; others wanted comments from the decommissioning workshops considered as part of the scoping process $(931,952,1140)$; and another considered that a complete GEIS is required by law (1181). There was also concern about generic analyses versus a need for site specific analyses (1246). Some commenters questioned how the NRC could identify environmental review or consultation prior to receiving public comments and whether the scoping meetings were a meaningless exercise $(438,513,1180)$. Another commenter proposed a Manhattan II Project to solve the entire process (937). 
One commenter was pleased that the NRC will continue inspection and enforcement (191); while another proclaimed the real problem was weak NRC staff oversight (797). Others desired to seize the assets of nuclear power utilities and to halt production of nuclear waste $(390,728)$, and viewed the scoping process as a way to deregulate radioactive waste, extend the BRC policy $(151,467)$, and contaminate the environment $(940)$.

One commenter expressed a relationship between the decommissioning criteria and the siting of waste disposal facilities: as the volumes of waste increase, the potential location for sites decrease. The commenter indicated hope that the NRC's rules would preclude his state from selection as a disposal site (465).

Several commenters requested an extension of the comment period for various reasons such as misunderstanding, too short a comment period, and not enough or no notice $(38,92,107,260,303,701,764$, 873).

Many commenters expressed the need for the NRC to develop public trust through reasonable and responsible efforts $(145,148,151,234,246,438,467,513,885,917,923,928,929,931,1180)$. One commenter felt that no government agency "...is truly sincere in wanting to protect the general public from causes of injury..." (279). The following comments are provided for examples of other areas of concern:

GEIS and rule proceeding concurrently (438).

Attempting to hurry the rulemaking process to expedite licensees' avoidance of the liability problem (885)

Desired full hearing with sworn testimony (928).

One commenter considered the scoping meetings as subsidizing the nuclear power industry (225); however, most wanted more meetings or suggested ways to improve attendance through various advertising $(147,265$, $276,204,1593)$. One commenter suggested an easier to read document - not written as if by a lawyer - as an aid to the public (263).

Several commenters stated the implications (costs, potential overlapping, or uncertainties) of the NRC rulemaking and interaction with other federal and state agencies and hoped for consistency and agreement (187, $321,408,446,1048,1052,1099,1287,8893$ ). The GEIS should consider the different kinds of facilities to be decommissioned and the likelihood that the NRC's rule might be adopted by other agencies (429).

Some specific comments regarding interaction between the NRC and local or state governments were made:

NRC must listen to the communities which are most affected and the communities which, because of economic and discriminatory factors, are the most unable to deal with problems (188).

The commenter would not want to see state requirements that were less restrictive than federal requirements (189)

Provide citizens' groups with a simplified written explanation that shows how to register a complaint or concern to the NRC (192). 
If the NRC's determination that a site should be decommissioned is based on the finding that there is no risk to the safety of persons and the environment from radioactive materials at the site, then there would clearly be no basis to continue to assert federal jurisdiction over the site, and the state would be free to impose such other restrictions as it desired. The NRC should not suppose that it could both terminate its jurisdictional interest and maintain federal preemption of state law (748).

The NRC should have a consistent approach to radiological and chemical risks, building consistency for future compliance with state laws for post-decommissioning owners of the property (347).

The NRC may want to work towards consistent approaches for risks from radionuclides and chemicals so that anyone taking over the decommissioned property will already comply with state laws. Property that has been maintained in compliance with such laws would be much more attractive to prospective buyers (950).

In the opinion of several commenters, peer review and formal consensus by scientists is required for the rule making and the GEIS $(227,259,8899)$. One commenter recommends consulting physicians as part of the GEIS (226). One commenter expressed concern about the general public's knowledge of nuclear plants and noted how long it took the public to be informed that smoking causes cancer (288).

One commenter was "frightened" at the manner in which governmental regulatory bodies pander to radical environmental organizations and believes they should instead be listening to scientific fact and make judgments based on actual risk assessments rather than on far-fetched scenarios from the "uninformed hysteria of a radical few" (297).

One commenter recommended that the final guidance documents should be placed, or their availability announced, in the Federal Register to ensure that there is a complete understanding of how compliance should be demonstrated ( 8899 )

\section{E.2 ALTERNATIVES}

\section{E.2.1 Abandonment Of Facilities}

Some commenters said that a decommissioning alternative of the abandonment of facilities should be considered in the GEIS $(252,492,718)$. One commenter said that abandonment with no remediation should be considered (252); another said that whether to remediate rather than abandon should be considered (492); and one would reject an abandonment alternative, but believes it should be considered in the GEIS (718).

\section{E.2.2 No Regulatory Change}

Several commenters opposed an alternative of no regulatory change $(210,1147,1281,1426)$ as allowing "industry" undue influence (210), as insufficiently protective of biota (1081), or as perpetuating an unacceptable status quo (1426). One commenter favored a no-regulatory-change alternative "because the present system has worked well to date" (807). 


\section{E.2.3 Risk Limit/Risk Goal}

\section{E.2.3.1 General}

Some commenters advocated a lifetime or 100 -year risk limit $(1335,1463)$. One said that the limit should be based on a collective 100-year dose less than that which would result in one cancer fatality (1335). Another suggested radiological limiting criteria similar to those for exposure to chemicals and linked to lifetime (rather than annual) cancer risks to the public of $10^{-5}$ to $10^{-6}$, and suggested that these risks be discussed in section 5 of the GEIS (1463). One commenter noted that a "dose constraint" of about 30 millirem/year is consistent with the EPA's individual $10^{-4}$ risk constraint (8880).

Some commenters said that a risk goals "concept" or procedures for risk limit, ALARA analysis, and situations where risk limits cannot be achieved must be "codified" $(1299,8896)$. Actual concentration screening goals need not be codified (1299), and ALARA analysis might not be required if goals are used, but there should be a "general assessment" to' ensure that the application of goals will not be detrimental, and the added analytic burden is justified for "large" complex actions (8905).

There were various comments on the application of the ALARA principle $(1335,8896,8899,8902,8905)$. A commenter said that the ALARA principle should be applied, using not more than $\$ 10,000$ per person-rem, only in cases where the 100-year dose exceeds that which would cause one cancer fatality (1335). Another said that procedures for ALARA should be "codified" (8896), while another said that such procedures should be provided in a regulatory guide (8899). Others said that ALARA analysis allows consideration of practicality and a balancing of all pertinent risks and benefits (8902) or should be made on a site-specific basis when risk limits are used (8905).

A commenter distinguished between risks accepted voluntarily, and with informed consent, and those imposed involuntarily (424).

One commenter expressed no confidence in the NRC's application of ALARA because of the way it was thought to have been misapplied in a particular case (1220).

One commenter asked about the basis for the announced limits of 0.03 to 60 millirem/year to be considered in the GEIS (65). [The 0.03 value is equivalent to the EPA criterion of $10^{-6}$ lifetime risk, and the $60 \mathrm{millirem} / \mathrm{year}$ value was chosen as applicable to any one source rather than the 10 CFR Part 20 value of 100 millirem/year which applies to all sources.]

\section{E.2.3.2 Agrees/Disagrees with Risk Limit/Goal Approach}

Many commenters agreed with a risk limit or risk goal appronch $(3,24,26,30,114,118,119,127,132,134$, $238,239,325,330,344,500,789,790,810,830,973,987,988,1027,1033,1224,1229,1248,1337,1359$, $1362,1365,1595,8861,8863,8870,8875,8882,8886)$. Other commenters did not support such an approach

$(178,256,312,413,475,537,813,889,964,1148,1182,1187,1297,1329,1605)$. 


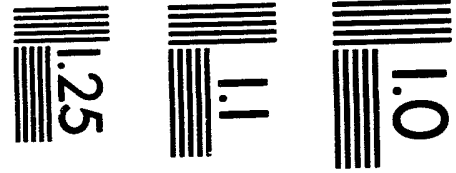

$$
\begin{aligned}
& \text { 咅正 }
\end{aligned}
$$

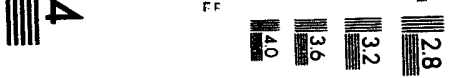

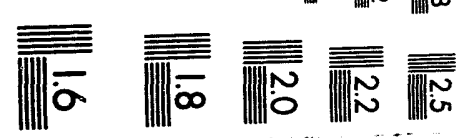



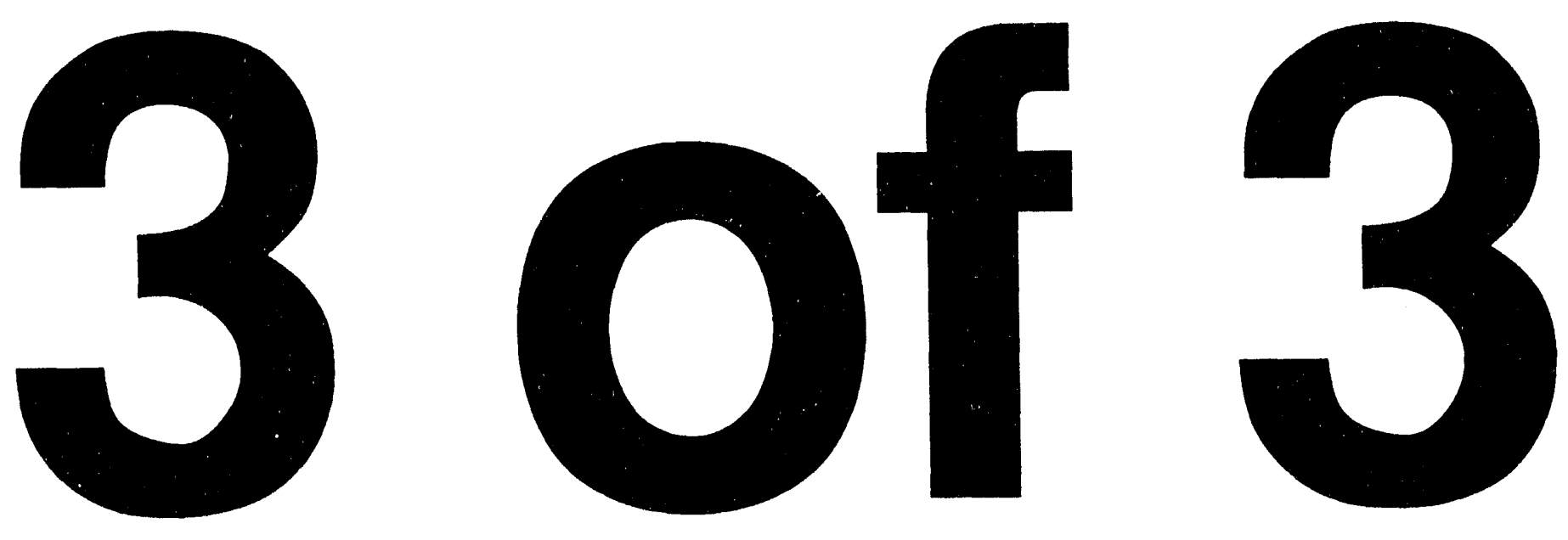
Reasons, conditions or considerations for agreement with risk limits or risk goals included:

Following international, national, or scientific- professional recommendations on radiation exposures, such as 100 millirem per year to individuals, the general public, or critical groups $(3,24,26,68,114$, $118,119,127,330,377,830,1033,1229,1358,1608,8857)$.

The ALARA principle should be applied along with risk limits or risk goals to reduce radiation doses $(3,68,132,330,789,790,810,973,988,1027,1365,8861,8863,8882,8886)$.

The dose range considered by the NRC should be from the lowest reasonably measurable to a limit of 100 millirem/year $(24,26,1248)$; we question the stated range to be considered of 0.03 to 100 millirem/year $(24,1602)$; it is unreasonable to include 0.03 millirem/year as there is no way to measure compliance (1248).

The NRC should not consider dose values for standards below which accurate and reliable data are available at reasonable cost (30); remediation to background levels might be set as a goal but not as a limit for a standard that might require remediation, disproportionate to risk, with no incremental benefit and the likelihood of increasing other risks. Health risks are the appropriate starting points for such standards (8870).

Setting too low a dose limit would require slight soil contamination, generated in compliance with regulations, to be included as radioactive waste (31).

The commenter notes that 100 millirem/year is about the range of natural background radiation in the United States (68).

Some comments suggested screening radiation levels of 25 millirem/year (114) or a dose constraint of 30 millirem/year ( 25 rounded to one significant figure) $(1359,8875)$. One commenter recommended the use of $10 \mathrm{mrem} / \mathrm{y}$ for site-specific contamination to satisfy ALARA considerations for both cleanup workers and members of the general public (1607).

Contrary to some erroneous inferences national, international, and governmental standards for protection against radiation have not changed significantly through reassessments over the past 30 years and remain at 500 millirem/year for members of the general public, as modified by the ICRP/NCRP to 100 millirem per year for continuous averaged exposures with infrequent 5 -year total exposures of 500 millirem (119).

Site-specific appropriate ALARA considerations should be secondary to dose limits and not drive them (132).

Protection criteria should be based on real rather than hypothetical risks. Too stringent limits would be unsound policy (134). Guidance is needed for making ALARA determinations $(973,8882)$; without guidance ALARA is an enigma (132).

Set risk levels erring on the low side because accidents will occur and there might be "unassessed" 
long-term effects (207).

The language of the regulation should be clear and concrete about risk limits and not leave interpretation to licensees $(239,500)$.

On risk limits or dose limits we take the stance of zero tolerance, no exposure to residual radiation at decommissioned sites (325).

Consider basing radiological criteria on risk determinations similar to hose for chemical exposures, e.g., $10^{-5}$ or $10^{-6}$ lifetime cancer risk (344).

The collective 100-year dose that could result in one cancer fatality should be the limit below which no further remediation is required. For greater doses apply ALARA at no more than $\$ 10,000$ per person-rem (789).

Use 10,000 person-rem as a threshold below which, at low doses and dose rates, there is no cancer risk, and apply ALARA at no more than $\$ 10,000$ per person-rem only for greater collective doses $(790,1362,1365)$.

A risk limit approach with ALARA applied allows flexibility and maintains doses low; this system is used now and works effectively (810). There should be enough site-specific flexibility in applying ALARA (1027); there is no evidence of a need for change from established regulatory practice (1033).

The ANS supports "tiered" regulatory limits for decommissioning to both restricted and unrestricted use, with specific criteria to limit the choice of restricted use (987).

Procedures for "risk limit, " ALARA, and situations where a limit cannot be met must be "codified" (988). Set an overall limit of 100 millirem/year total effective dose equivalent above background to any member of the public, regardless of exposure pathway, from all man-made sources (1033).

Ensure that all risks are realistically characterized in ALARA assessments (8861). Allow the use of either risk-based approach or specific standards (1595):

For "small" decontamination actions costly ALARA analysis might not be warranted, and it might be appropriate to establish activity per unit mass or area screening levels to establish practicable compliance below risk limits (8886).

Reasons, conditions, or considerations in disagreeing with risk limits or risk goals included:

Risk based criteria assumes everyone has a similar response to radiation doses, "and we should assume otherwise" (178).

One commenter said that risk limits or goals are "a defective methodology" because they cause controversy over measurements and demonstrating compliance (312). 
Some commenters do not favor an ALARA approach and believe it emphasizes short-term costs over long-term health impacts or that costs should not be a controlling factor in radiation protection regulation $(377,964,1187,1297)$.

Some commenters favored other approaches such as return-to background over risk limits or goals $(413,537,1182)$.

Avoid setting risk goals or limits because "reductions put forward in annual limits"... "cause grief to persons in industry" (475).

Commenter does not support risk goals because unreasonable goals might be set to attempt to achieve zero risk and require remediation to unattainable levels (613).

The commenter believes risk goals and limits imply a "hedonic calculus, " raise questions of acceptability of risk, and "might put God out of business" (889).

A dose limit of 100 millirem/year would be the same as if the facility were never closed (1329).

One commenter preferred expressing the criteria in terms of dose rather than in terms of extrapolated cancer risks because the latter emphasizes acceptable rick which is loosely based on very soft numbers and introduces issues' which are not resolvable (1605).

\section{E.2.4 Return To Background}

\section{E.2.4.1 General}

A number of commenters dealt with determining, measuring, defining, or otherwise assessing natural background radiation $(34,368,431,761,1087,1192)$. Some advocated that the NRC carry out studies, surveys, or monitoring tb gather and publish "comprehensive" information on background radiation and the practicality of its measurement locally and nationally on which to base regulatory decisions $(34.368,761,1087$, 1192). One commenter advocated additional studies by local "independent scientists" (431). Some recommended "codifying" specific levels [sic] of single radionuclides and location-specific radiation levels $(368,761)$.

Some comments said that "background" means "pre-existing naturally-occurring background" $(58,1192)$.

Some comments noted that a return-to-background criterion is impractical owing to the variability of background radiation $(1233,1481)$, would result in "different standards nationwide" and significantly increased quantities of waste, raises unresolved technical questions of definition and measurement, and should never be defined as a single number (1481).

One commenter noted that the "public and affected community" would have to be involved in determining background at a particular facility (421). 


\section{E.2.4.2 Agrees/Disagrees with Return-To-Background Alternative}

Several commenters supported a return-to-background approach $(47,60,94,155,183,203,213,236,242,248$, $282,366,399,411,417,432,457,466,502,552,719,721,762,777,780,828,835,875,892,941,953$, $960,1011,1024,1059,1068,1131,1138,1219,1227,1272,1336,1480,1487,1598)$ with most asserting a preference for return to "pre-existing," "naturally-occurring, " natural," "pristine," "original, "pre-licensure," or "zero exposure above naturally-occurring" conditions, without particular explanation for the preference.

Some commenters emphasized completeness of cleanup $(248,399,466,725,752,762,828,835,875,953$, 960).

Several commenters would require return to background as a condition for release to unrestricted use $(155,366$, $457,725,752,875,892,1011,1024,1131)$.

Some commenters said that not requiring a return-to-background approach would be a "subsidy" or "welfare" to industry $(411,1272)$; others felt that licensees should continue to be held responsible for costs and controls at sites not returned to background $(502,1131)$.

One commenter said that NRC dose limits are fairly responsible, but would "call for exposure to the public indistinguishable from background" (236).

Some commenters advocated return to background on the basis of personally propounded hypotheses about radiation effects (183) or personal interpretation of technical data (457); two commenters advocated a return-to-background approach until "no hazard to human health" is demonstrated $(242,892)$.

One commenter proposed that local councils of "citizens" should make technical and procedural determinations about background radiation (282).

Several commenters disagreed with a return-to-background approach $(9,34,73,88,136,314,334,476,533$, $612,816,904,979,1051,1393,1547,1572,8869$ ) mostly for reasons such as technical impracticality, infeasibility, lack of scientific justification, or the variability of background and the difficulty of its definition and measurement.

Some commenters noted that a return-to-background approach would result in differing and inequitable standards nationwide $(9,334,612,979)$.

Commenters noted that "there is no special merit in distinguishing between man-made and natural sources" (73), that background is a quantity, not zero, and is time and site specific (816).

Some commenters said that a return-to-background requirement would result in extreme expenses without commensurate benefit to health or to society, might even increase risks or impacts to people or the environment $(816,1393,8869)$, and could be "unwise," "unsound," and "foolish" policy $(136,904)$.

Some commenters said that a return-to-background standard would increase waste disposal problems by generating more waste $(9,334,979)$.

One commenter stated that the concept has little applicability since it can only be defined for species not found in nature. Adoption of a dose limit from residual contamination makes this alternative extraneous and it should not be considered as the preferred alternative (1613). 


\section{E.2.5 Best Technology}

Most of those commenting on the best available technology approach opposed it as, e.g., "insufficient," "not appropriate," a "defective" methodology $(313,376,412,781,814,866,1149,1464,8874)$.

One commenter said that the term "best available technology" requires better definition before it can be considered as an alternative (173), while another said that best effort is too subject to interpretation and regulatory language should be clear and not allow for interpretation (240).

Two commenters said that they favored the alternative approach of return-to-background over a best effort approach $(412,781)$.

Two commenters said that a best effort approach would be a "subsidy to industry" (412), or would potentially allow licensees to leave sites with high levels of residual radioactivity (814).

Three commenters said that a best technology approach would put economic considerations ahead of concern for public health and safety $(376,866,1464)$.

Two commenters noted that, as "best effort" will change with advances in technology, facility closures would, potentially, never be final|(814), or periodic re-evaluation would be required, and technology-based standards should be used only when risk-based standards cannot be applied in a timely manner (8874).

Three commenters said that the GEIS should consider a best available technology approach $(478,1105,1478)$ and should specify the time period in which best available technology will be "determined" (405) or how best effort will be evaluated to determine whether it protects public health and promotes the development of new technology (1478).

\section{E.2.6 Restricted Use}

\section{E.2.6.1 Agrees/Disagrees With Restricted-Use Alternative}

[NOTE: Different commenters apparently used the notion of restriction on use in different ways. Some meant that there should be no decommissioning unless no further restriction on use is required; others meant that facilities could be decommissioned with some restrictions imposed on subsequent use. The former are noted here as disagreeing with a restricted-use alternative; the latter are noted as agreeing with a restricted-use alternative.]

Many commenters agreed that a decommissioning-to-restricted-use alternative should be considered $(8,20,83$, $96,137,154,158,164,185,193,199,208,215,243,257,284,292,304,308,310,317,319,323,324$, $333,375,400,437,461,501,612,615,618,712,720,732,734,891,989,1139,1091,1152,1189,1273$, $1288,1290,1482,1562,1565,1609,8891)$; several others opposed such an alternative $(358,367,386,753$, $585,805,847,1201,1277,1424,1561)$.

One commenter stated that agencies requiring only unrestricted use limits did not impose any significant benefit; rather it resulted in wasted resources and contributed to filling limited disposal volumes with slightly contaminated material without significantly enhancing possible uses of contaminated sites (1611).

Some commenters said that restricted use should be an option adjunctive to other alternatives rather than a separate alternative $(20,333,1189,1562,1565,1612,1619)$. 
Some commenters suggested imposing restrictions through limitations on land use through deeds, covenants, or restrictive easements $(8,333,732,1189,1565,1609)$, or by a "trusteeship alternative" devolving continued responsibility upon each successive owner of the property $(319,734)$. Three commenters felt that restrictions such as land-use limitations could not be assured after decommissioning or into a distant future $(386,605$, 1561).

Several commenters linked a restricted-use alternative to some aspect of radioactive-waste management or to continued on-site waste storage or entombment $(83,154,164,199,243,304,310,324,375,387,437,646$, $759,1288)$.

A number of commenters, both of those who opposed and of those who favored a restricted-use alternative, noted a need to maintain clear responsibility for costs and controls for required radiation safety measures (193, $215,308,501,529,720,734,799,1152,1162,1189,1273,1290,1424,1482)$.

Some commenters alluded to or specifically suggested a "seventh alternative" of indefinite extension of "licenses and liabilities" $(367,783,799)$.

Some commenters said that they do not ibelieve that nuclear power plant sites can be decommissioned to unrestricted use $(284,292,317)$.

One commenter suggested successive decommissionings to a series of different restricted uses (308)

\section{E.2.6.2 Concerns/Questions About This Alternative}

Two commenters expressed concern about the ability to assure institutional controls, security measures, or financial responsibilities over potentially long time periods $(109,479,966)$; one said that past and present institutional controls should be reviewed (966).

Two commenters were concerned about how to enforce, or demonstrate compliance with, restrictions on use $(1406,1566)$; one said that guidance documents must be available on how to demonstrate compliance with restrictions on use (1566).

Two commenters said that restrictions on use should be evaluated as an option under other alternatives ( 990 , 996); another said that the incremental costs between cleanup to restricted use and other alternatives should be analyzed and include the "full costs and benefits of restricted use" (405).

One commenter said that land-use options should be considered as an independent alternative and cleanup impacts should be evaluated for various land-use "scenarios" (996); another said that the GEIS should consider the various kinds of restricted use and the various associated levels of cleanup required (401).

A commenter questioned the technical ability to remediate sites for public use because problems of radioactive waste disposal remain unresolved (883).

Concerns that licensees might "preferentially choose" a restricted-use alternative can be addressed by providing specific criteria for limiting its application (989). Another commenter believed this alternative was a cheap out and would not protect the public (1600).

One commenter said that regulatory control and "licensee liability" must be maintained until the site is returned to "natural, preexisting background levels and zero release of radioactivity that has been 'cleaned up' "[sic] (1569). 
One commenter said that a restricted-use alternative "sentences sites" to continued hazardous uses and creates "sacrifice zones" (1570).

\section{E.2.6.3 Procedural Aspects of Restricted Use}

A commenter said that "scoping hearings and rulemakings" should be held on what to do with lands that can not be remediated for release to public use (883).

A commenter said that the standard should include a process to establish restricted use as a control measure for the achievement of risk limits (982); another said that restrictions on use should be realistic as to actual public risk and that the criteria should consider, reusability of sites for other industries or for expansion of existing industries (906).

Some commenters said that land-use restrictions should be considered in implementing restricted use $(610,990$, 1610 ) or that the existence of a mechanism for land-use restrictions should be acknowledged but not considered in detail in the GEIS (1202). One commenter favored a "regulatory easement" that would allow the NRC to "come in at any later date and assert its regulatory interest" (318).

Some commenters advocated that restricted use be considered as adjunctive to other alternatives rather than as a separate alternative $(611,614,990,1285)$.

Several commenters noted procedural aspects covered in Sections E.2.6.1 or E.2.6.2 above, q.v. (320, 966, $987,1152,1406)$.

\section{E.2.7 Other Comments}

Three commenters linked restricted use to some aspect of waste handling or disposal $(425,934,1567)$. Two emphasized a need for long-term control of "radioactivity" or "radioactive waste/ contamination" $(425,934)$. One said that "clean-up" should not be limited to current knowledge or techniques (934). One said that the GEIS should address improbable "scenarios" such as the NRC's allowing decommissioning with the licensee turning responsibility for on-site spent fuel over to the Department of Energy (1576).

One commenter said to add an alternative of combining a generic, health-based federal standard with site-specific standards and to discuss in the GEIS the relative merits of having federal, state, or local site-specific standards (1103). Another commenter said that the GEIS should use specific facilities as examples in discussing the environmental implications of decommissioning (1291).

A commenter said to expand the scope of the GEIS to include lessons learned from past experience and a "broader list of alternatives" (1291).

One commenter noted that the current definition of decommissioning doesn't technically incorporate the alternative of restricted use (499).

\section{E.3 METHOD OF APPROACH}

NRC should use realistic cost estimates for waste disposal based on projects of the compacts developing waste disposal sites. If the evaluation of some alternatives indicates waste volumes that are factors of 2-3 times larger than what was generally anticipated for LLW disposal sites, NRC should factor in the impacts associated with the potential need to site additional disposal facilities. In addition, the need to comply with waste form 
requirements of various disposal sites should be included in the impact analysis for the evaluation of alternatives (1019).

\section{E.3.1 Facilities Covered}

Six commenters advocated that the GEIS consider a more comprehensive range of facilities, materials, impacts, or regulations to be applied $(41,1053,1142,1169,1296,1383)$. Some said that both radiological and nonradiological impacts should be covered $(41,1053)$. Some said that the GEIS should consider all nuclear-related facilities whether or not regulated by the NRC $(41,1142,1169,1296,1383)$. One commenter said that the GEIS should "cover the worst possible case" (262); another was concerned that the GEIS might not "cover a site that was extremely contaminated" (269).

Several commenters objected to, questioned, or said there should be some rationale presented for not considering in the GEIS those facilities previously decommissioned or currently proceeding with decommissioning $(122,251,773,959,1435)$. One commenter said the GEIS should consider alternatives for applying different decommissioning standards to existing (licensed) facilities and to proposed (not yet licensed)facilities (1069). One commenter said that, for SDMP sites, the GEIS should evaluate the differences between the risks incurred due to the final rule and the current criteria for SDMP sites (1093).

Some commenters recommended that the GEIS discuss specific sites as exemplars $(190,1117,1128,1174$, 1292). One commenter said to select a few sites "from one extreme of contamination to the other" and go through a complete process from GEIS to decommissioning (190). One commenter emphasized full-scale characterization of representative sites using the same methodologies to be implemented $(1117,1128,1174)$.

Several commenters recommended that the GEIS or the standard to be developed consider various types of facilities or deal differently with different facilities $(298,430,448,809,945,1075,1078,1215)$. Some commenters said that decommissioning criteria for fuel-cycle facilities should be different from those for nonfuel-cycle facilities $(298,448,945,1215)$. One said that there should be different GEIS analyses for groups of facilities, and suggested specific groupings (1078). Two commenters urged that uranium mills and tailings, or ISL facilities, be excluded from the scope of the GEIS or from the decommissioning criteria because they are already separately regulated $(809,1056)$. One commenter recommended that the NRC include uranium enrichment plants in the scope of the GEIS and consider gaseous diffusion, and gas centrifuge and atomic vapor laser isotope separation technologies generically (575).

The extent of variation to be expected in the decommissioning impact and costs per unit of capacity within each group of facilities should also be explicitly considered. For example, the cost of decommissioning nuclear power plants may not depend linearly on size, and the nature of this dependence should be analyzed (1080).

\section{E.3.2 Affected Environment}

One commenter said that the GEIS "inappropriately excluded the issue of groundwater and surface water contamination" and that the GEIS should include clean-up of water bodies (1072). Another commenter said that the proposed scope of the GEIS is "deficient" in omitting clean-up of water bodies (1579).

A commenter said that the NRC should not limit the EIS or GEIS to a specific site but should inclide the "totality of impact" on "all affected areas and environments" from all licensed and unlicensed activities that "comprise the nuclear industry" (1143).

One commenter said that the GEIS should be an efficient evaluation limited to reasonable, generally-applicable alternatives appropriately analyzed in general categories (1443). Two commenters suggested four sub-categories 
to consider for land use of: residential, agricultural, recreational, and commercial/industrial $(1443,1488)$.

One commenter cited three areas of deficiency in the scope of the GEIS as: not evaluating risks from both radioactive and non-radioactive materials, not addressing risks from waste disposal, and omitting clean-up of water bodies (1579).

One commenter cited a need to recognize that efforts to remediate risks from radioactive materials can cause non-health-related secondary ecological or social impacts, and said that the criteria selected must be balanced to protect all "these resources" (8859).

\section{E.3.3 Technical Approach}

Some commenters emphasized the need to assess "all" impacts of various kinds $(15,17,22,40,72,340,702$, $583,973,1005,1109,1195,1382,8861,8866)$. Of these, some said to consider individual or collective impacts on workers or the public, or impacts on the environment $(15,22,583,973,1005,8866)$. Others said to consider both radiological and non-radiological impacts or synergistic impacts $(40,72,340,502,583,1037)$, or to consider both long-term and short-term impacts from both NRC-regulated and non-NRC-regulated facilities $(40,1382)$.

Some commenters said that assessments should be based on realistic, or accurate and reliable, data and assumptions, and on comparable methodologies $(17,29,33,793,821,836,899,1187,1242,1243,1247$, $1471,1505,1537,8861)$.

Some commenters said to avoid overestimating benefits of remediation, biasing data, wasting resources to remediate trivial risks, or doing more harm than $\operatorname{good}(22,72,296,793,997,1005,1125,1195,1243,1490$, $8860,8886,8906)$.

A number of commenters said that costs or incremental costs should be considered in analyses $(15,29,33,222$, $340,404,583,946,1002,1158,1195,1490,8863,8902)$, and one commenter found any consideration of costs to licensees "offensive" (851), while another said that analysis of costs and benefits "should not be part of the NRC's primary area of responsibility" (255).

Commenters offered a variety of suggestions for the bases of analytic methodologies to use in assessing individual or collective doses or risks $(351,791,803,915,956,1000,1158,1176,1245,1250,1328,1332$, $1333,1339,1360,1367,1374,8876$ ). [See also Section E.2.6 for summaries of specific numerical recommendations.]

One commenter suspected that current technology is not capable of remediation of sites for safe release to public use (1324).

One commenter recommended that the NRC consider recycle/reuse standards, criteria, or protocols in the decommissioning standards process (8950). 


\section{E.4 IMPACTS/COSTS/WASTES}

\section{E.4.1 Radiological Impacts}

\section{E.4.1.1'Health Impacts}

Some commenters questioned the accuracy of dose or health risk estimates or of the reliability of their source $(75,79,184,220,233,267,415,1433)$.

Current radiological protection recommendations or standards have not changed significantly over many years and are sufficient to protect public health or the environment $(120,549,831,1340,8877)$. One commenter said that the NRC rule should be consistent with established standards (8893).

Some commenters said that estimated risk factors have increased $(124,1338,1370,1492)$.

The GEIS should address uncertainties in radiological health estimates $(126,180,887,1006,1009,1095)$.

Some commenters said that health criteria should be scientifically based and related to real, not hypothetical, risks $(138,608,915,1123,1258)$.

Some commenters said that no exposure to radiation is safe and exposures should be minimized $(159,182,427$, $472,926,1013,1599)$; but another said that the concept that any amount of radiation is harmful "ignores reality" (1013), while another said that unreliable speculation of incremental impacts at lower doses based on existing higher-dose data must be avoided (1123).

One commenter said that health effects on special groups such as elderly people or children should be considered (202).

Some commenters said to conduct epidemiologic studies in conjunction with decommi.sioning $(271,378,383)$, or to gather information for establishing criteria (374).

One commenter said that health effects are "deleterious," "horrifying," and "long-term" (450).

Some commenters offered personal interpretations of health effects of radiation exposure $(458,468)$.

One commenter said to consider synergistic effects (703).

One commenter said to consider 10,000 person-rem collective dose in 100-year increments to be a level below which no cancer is produced $(786,787)$.

One commenter said that the health risks from radiation should be treated differently from those from chemical carcinogens (1054).

\section{E.4.1.2 General Impacts}

One commenter recommended to consider the total cancer risks, radiological and chemical, associated with decommissioning, and to consider some community "right-to-know" actions if decommissioned facilities pose a lifetime cancer risk greater than 10 to the minus five -- similar to the manner in which California state laws hàve risk-based "triggers" that require public notice (527). 


\section{E.4.1.3 Radiological Impacts to Workers/Public}

A number of commenters said to apply ICRP/NCRP or federally-adopted criteria for limiting doses to the public or to apply ALARA for additicnal dose reduction $(6,71,117,128,541,545,550,557,599,988,991,994$, $1248,1249,1254,1357,1437,1459,1467,1475,1476)$.

Several commenters emphasized not wasting resources nor introducing error 'jy considering hypothetical costs and impacts of complying with values below those that can be reasonably measured or evaluated and practically used; use realistic bases for assessment of real risks to those who are affected $(28,35,77,541,560,1014$, $1082,1188,1241,1249,1254,1256,1305,1386,1472,8890$ ).

Some commenters said that the dose range to be evaluated should begin at zero above background $(60,1153)$. Others said to use 10 millirem per year as a de facto threshold below which no cancer is produced regardless of collective dose (594) and to use collective dose over time rather than annual dose rates to measure risk (595), or to establish a dose-based criterion with the lowest dose rates reasonably determined by pathway analysis after decommissioning to "coincide" with an average yearly individual total effective dose equivalent of 25 millirem (1082).

One commenter noted that changing from a contamination-limit system to a dose-limit system will require "adjustments" to account for "differences in radionuclides" (33).

Several commenters said to consider the total, cumulative, radiation exposures from all sources or total impacts from both radiological and non-radiological risks $(87,566,575,579,948,1055,1096,1151,1463,1525$, 1550).

One commenter said that internal radiation dose is "more biologically damaging" than external radiation dose (162).

One commenter said to consider "non-fatal as well as fatal cancers" (300).

Some commenters expressed "concerns" about, or urged consideration of, particular groups such as workers, elderly people, children, and gardeners $(201,216,361,403)$.

Some commenters said to consider EPA standards in performing pathway analyses for biological exposures or to specify the considerations for performing pathway analyses $(370,717,776,1082)$.

One commenter said that radiation risk models overestimate doses and risks by factors of 10 to a thousand (562).

Some commenters expressed concern about the 1 aalth impacts of radioactive waste handling or disposal (634, $639,1583)$.

One commenter said to update the information for, rather than eliminate from consideration, those items previously considered as announced in the Federal Register notice (971).

Some commenters said to consider in assessments four sub-alternatives of land use as: residential, agricultural, recreational, and commercial/industrial $(1134,1188,1241)$.

One commenter stated that use of $10 \mathrm{mrem} / \mathrm{y}$ for site-specific contamination would satisfy ALARA considerations for both cleanup workers and members of the general public (1606).

NUREG/CR-6156 
Comments not otherwise summarized here, or repeating information summarized elsewhere in subsections of E.2, E.3, or E.4 of this document , q.v. $(1373,1378,1491,1493,1494,1506,1550,1576,8866,8876,8878$, 8880).

\section{E.4.2 Non-radiological impacts}

\section{E.4.2.1 Human Health Impacts; Synergism With Chemical Wastes; Construction and Transportation Accidents}

It is importarit to consider non-radiological impants to the public, workers, or the environment, inter alia, to avoid overestimating benefits of radiological risks averted or to avoid doing more harm than good $(22,567$, $580,1003,1004,1046,1098,1196,1212,1513,1519,1524,1528,1531,1589$ ).

Some commenters said to consider various aspects of potential hazards, radiological and non-radiological, from transportation accidents in the GEIS $(194,197,633,638,1060,1239,1532,1589)$, and one said to include risks of low-probability-high-impact events (581).

One commenter said to consider the "measurable perception of risk in various communities" (316); another said to discuss untested assumptions that are used in risk calculations (551).

Several commenters want to include various aspects of waste disposal or waste management as a GEIS issue $(581,638,852,1060,1115)$, and one said to include requirements that wastes be handled within RCRA Subtitle C (657).

Two commenters said to consider issues of workers' health $(582,587)$.

One commenter distinguished informed risks with consent as different from other risks (597).

Some commenters said that the GEIS should address synergistic effects $(506,774,1115)$.

Comments repeating information summarized elsewhere in subsections of E.2, E.3, or E.4 of this document, q.v. $(345,704,755,1578)$.

\section{E.4.2.2 Biota}

Some commenters said to consider migration pathways or bio-concentration of radionuclides $(84,384,393)$; others said to consider the EPA's health standard for groundwater and air in analyzing pathways for human and biota exposures $(558,1315)$ !

Some commenters said to consider the impact of waste storage or disposal on ecosystems $(393,1420)$.

Some commenters said to conduct epidemiological studies and monitor ecosystems near facilities $(603,869)$.

Several commenters said to consider non-radiological impacts, e.g., to avoid erroneous evaluation of overall impacts $(576,657,1533,8858)$.

Comments not otherwise summarized here or summarized in other subsections of E.2, E.3, or E.4 of this document, q.v. $(660,661)$. 


\section{E.4.2.3 Economic/Land Use}

One commenter said to consider non-health impacts (419).

A commenter said that cleaning to an ALARA standard will alter future site use (420).

One commenter said that decommissioned facilities should be put to new commercial uses to avoid adverse economic or social impacts (907).

Some commenters said to account for land use as part of dose assessment methodology $(1001,1193,1244$, 1603).

Some commenters said to base criteria on probable risks to those affected economically in the nearby community $(1421,1422,1508)$.

\section{E.4.2.4 Societal}

Several commenters said that assessments should be balanced to be protective of cultural resources, Native American sites of special significance, or other potentially affected groups $(200,272,596,656,8858)$; while one said to consider the effects of exported nuclear technology on countries with little environmental protection regulation (443).

One commenter said to compare how different approaches might affect problems of undue influence of "industry" or licensees over the public (1073); another said to consider voluntary vs. involuntary risk (1088).

One commenter said to evaluate variables such as "community concerns" (1509).

Comments not otherwise summarized here or summarized in other subsections of E.2, E.3, or E.4 of this document, q.v. (571, 659).

\section{E.4.3 Transfer of Risk}

A number of commenters noted that aspects of the transfer of risk involved the moving radioactive waste off site $(83,285,293,612,625,631,635,640,641,648,1402,1522,1563,1580,1586)$.

One commenter raised a question of to whom the term "acceptable risk" applies (385).

One commenter said that economic costs should not be transferred to the public (1190).

\section{E.4.4 Costs; Measurements Capability}

Many commenters gave expectations of the scope of the GEIS to include generic waste disposal costs with categorization for each alternative $(404,559,592,1217,1510,1546,1581)$, associated timing $(14,1000)$, and consideration of different waste management technologies $(37,372)$. Similarly, impacts from on-site disposal of wastes were recommended to be explicitly included $(339,1581)$. Specific cost analyses which were recommended were: health care and relocation expenses $(381,871)$; independent monitoring $(381,554,637$, $1311)$; regulatory costs to state and local governments $(509,1100)$; costs of contamination of land and groundwater at the facilities (1100) or disposal sites (758); costs of not implementing alternatives (888); all nonmonied costs (897) and industrial risks $(1261,1520)$; potential need of more disposal sites $(1022,1210)$; the variation of decommissioning costs per size of facility (1499); and transportation, and radiological and 
non-radiological risks to the public and workers during all phases of waste disposal $(341,343,1581)$.

Several commenters stated that the full cost of "complete decontamination" must be borne by the generator along with all liability for personal and property damage to locations where the licensee sends radioactive materials or wastes for treatment, storage, or disposal $(63,435,723,1384)$. [See also section E.5.1, Funding/Planning of Decommissioning.]

One commenter recommended that theoretical measurement of radiological criteria risk-based determinations parallel those used for chemical exposures such as lifetime cancer risk of $10^{-5}$ or $10^{-6}(343)$. Others believed the licensee must also have a reasonable opportunity to demonstrate compliance with the release criteria developed $(1502,1618)$ but that it will not be feasible or practical to assess contamination levels or to demonstrate compliance to cleanup values below several mrems per year $(1007,1016,1023,1231,1502,1541)$. Continuing, the NRC should not waste resources or introduce error by considering hypothetical costs and impacts of complying with values that cannot, in practice, be used (590). Carefully documenting practical limits of measurability and compliance demonstration in the GEIS will be important for gaining public acceptance of realistic protective site cleanup standards (1473). The NRC should establish a dose-based site cleanup criterion, where compliance is demonstrated based upon pathways dose assessment methodologies such as those found in NUREG/CR-5512 (1501).

\section{E.4.5 Wastes}

One commenter stated that the GEIS should not cover issues that have been previously covered or are not significant (616), but the EIS should consider when and where to dispose of wastes and the costs and risks of disposal $(616,1414,1419,1577)$. One commenter stated that the GEIS should include the combined total and short and long-lived, long-term effects and health and safety impacts of decommissioning and decontamination activities for all nuclear facilities; as well as, both radiological and non-radiological impacts from all other nuclear facilities that are not regulated by the NRC (620). Another commenter stated that the dire seriousness of the issue should preclude limiting clean-up to present day technologies (981). Another commenter stated that a generic rule to regulate the siting of nuclear waste would be both highly inappropriate and insufficient with the present knowledge (454).

Other commenters expressed a need for full evaluation of waste generation associated with each alternative (112, $149,598,613,628,726,968,1000,1582)$. This should include hazards of transportation $(149,174,632$, $637,1238)$, and radiological and non-radiological risks at intermediate sites for storage, handling, and packaging and at final disposal sites (1582). Similarly, impacts from on-site disposal or burial of wastes should be explicitly included $(839,1582)$. Dispersal by means of industrial furnace was not acceptable $(161,647)$. One commenter recommended research to neutralize radioactivity (278). Two commenters stated that nobody wants the wastes in their backyard, and that creates problems that should have further consideration $(289,637)$. Two commenters were alarmed about the possible extension of the BRC policy, and not requiring monitoring of all nuclear waste $(627,1263)$.

One commenter suggested that in the disposal of very long-lived radioactive materials, we might not be able to take account of the changed conditions tens of thousands of years hence (86) while others desired that containment be held to zero release levels forever $(100,110,1400)$. Another stated that decommissioning of a contaminated site does not eliminate the radioactive and chemical wastes, but rather repackages and reconfigures them on-site, or moves them to another location (1582). One stated that it was foolish to contaminate new sites $(637)$ and another desired on-site storage $(629,632)$ or entombment $(1585)$. Other commenters remarked that decommissioning of a power plant may produce enormous volumes of radioactive wastes $(150,1203,1527,1534)$, yet we do not know how to deal with the waste $(250,884)$. Other commenters were concerned with the required number, size, and safety of storage sites $(449,469,617,618$, 
$642,652,654,1191,1197,1262,1620)$.

Several commenters suggested that reclassification and segregation of radioactive waste on the basis of half-life (long or short), toxicity (based on half-life level $>100$ years), or source would provide more disposition options $(364,380,397,439,746,550,586,865,1588)$. Others stated that the problem of where or when to store spent fuel is a decommissioning issue and should be regarded as such $(307,739,1135)$.

\section{E.4.6 Comparison of Impacts and Costs}

Many commenters discussed the use of the "as low as reasonably achievable" (ALARA) process as an appropriate method for considering the total detriment and benefit associated with remedial alternatives in the decommissioning process. They noted that for such a process to result in good risk management decisions, all attributes (detriments or benefits) need to be compared from an equal base $(570,573,973,994,997,1000$, $1002,1543,8861,8863)$. One also noted that comparison of very conservative public health impacts to realistic or best-estimate worker or ecological impacts will bias decisions (8861). It should include both radiological and non-radiological impacts from licensed facilities $(574,585)$ and all other nuclear facilities that are not regulated by the NRC (483). The costs must be considered for all analyses as well as "total and real" impacts to the public and to workers $(559,1002,1423,1518,1521)$. Certain specific recommendations and comments included:

One commenter stated that the NRC should not waste resources considering hypothetical costs or impacts of complying with criteria that cannot be met in a practical sense (1012). One commenter recommended the lowest reasonable measurable dose be determined (1436) and that the NRC should not consider establishing cose values for site cleanup standards below values where accurate and reliable data is available or obtainable at reasonable costs (1515).

One commenter recommended the development of both population risk and individual risk in analyses (8867).

One commenter recommended that a term such as "years of life lost" be developed and used to express the potential health impact of a given action or decision (565). Another recommended measurement tool was "one excess cancer per million exposed people" (848). Other commenters described the use of "significant threat to public health and safety" and "significant" as inadequate $(920,1390)$. One commenter used a value for lifetime cancer risk as greater than $10^{-5}(585)$.

One commenter desired an evaluation and analysis of the incremental costs as between cleanup to restricted use and the other alternatives for setting the radiological criteria for decommissioning, including the full costs and benefits of restricted use (572).

One commenter stated that it would be appropriate to use general categories for the analyses. For example, land uses should be limited to four types: commercial/ industrial, agricultural, residential, and recreational (1553). Cost and benefits should only be calculated generically for each alternative in order to compare the totals which could be expected to result from applying the generic criteria to all affected sites. Site specific details are not appropriate for such a generic analysis and should be considered in separate, site specific environmental analyses and not in this GEIS (1554).

One commenter recommended the evaluation of past and present uses of institutional controls, as well as discuss how the financial and other responsibilities of licensees will be maintained (964). 
One commenter requested that the GEIS relate risk, uncertainty, and radioactivity in real world terms (141).

Regarding cost specifically, one commenter stated that the most expensive solution is not the safest or the best, but frequently misguided (593) while another stated the only consideration is to ensure maximum protection of human health and the environment, without regard to cost (1067). Several commenters objected to trying to balance cost against cleanup and dangers to human life $(456,1157,1385,1465)$ while another commenter objected to changing from a process that was safe and predictable to a process that considers cost-benefit ratios (591). One commenter stated that a cost analysis and benefits should not be part of the NRC's primary area of "responsibility" (255). One stated that decontamination can not be bottom-lined, least cost (1161); another urged the NRC to reject a "reasonable cost" concept (1214).

Conversely, one commenter cautioned that the financial impacts of changing decommissioning standards should be carefully considered. The creation of more restrictive decommissioning standards will dramatically increase operating costs for NRC licensees without commensurate benefits to the public health. Licensees should not be forced to shoulder these costs. Changes in decommissioning standards that increase decommissioning costs, such as a return to background standard, may force licensees to cancel new projects because the eventual cost of decommissioning will be prohibitive (819).

One commenter offered the following ALARA determination techniques:

If the collective dose is above 10,000 person-rem, the ALARA principle should be used to determine whether or not to decontaminate further. A value of not more than $\$ 10,000$ per person-rem for collective doses above 10,000 person-rem in today's dollars should be used in that ALARA calculation (1366).

If the collective 100-year dose is Inss than that which will result in one cancer fatality (based on the best current cancer risk/dose model), that should be the limit below which no further decontamination is required. The ALARA principle (using not more than $\$ 10,000$ per person-rem) should be used in cases where the 100-year dose is greater than that which will result in one cancer fatality (1368).

The Commission should set the value at 10,000 person-rem below which, for purposes of regulation, no cancer would be produced (1375).

One commenter recomm aded that the NRC consider disposal of material removed -quantities, disposition, and time frame - as part of the GEIS. This, issue is of concern to the industry and to the public for cost, environmental, and public health risk reasons. The availability (or unavailability) of effective treatment and land disposal will significantly impact the required cost analyses for all the GEIS alternatives (1573).

\section{E.5 AREAS INSIDE/OUTSIDE GEIS SCOPE}

\section{E.5.1 Funding/Planning of Decommissioning}

Many commenters agreed that the NRC should not cover issues that have been previously covered or are not significant $(13,19,338,997,1166,1226,1284)$. Many other commenters did not agree with the indicated omissions $(406,1198,1200,1439,1455)$ and one desired an update from the previously used 1988 data (1427).

One commenter stated that the GEIS should evaluate costs and impacts of various regulatory approaches from the lowest reasonably measurable dose up to 100 mrems per year, i.e., the dose limit recommended for members of the public by national and international radiation protection experts, NCRP and ICRP (1165). 
Commenters called for thorough planning for decommissioning and requested public involvement. Topics for planning included: economic analysis, management and disposition of nonhazardous solid waste (mostly construction and demolition wastes), and any mixed hazardous wastes. The recommended planning included both off-site and on-site waste management considerations $(853,859,870)$.

One commenter wanted wastes to be stored on-site at the point of generation in above-ground, monitored, retrievable storage facilities until a permanent solution is found (896).

Many commenters were concerned if the licensees (including the utilities) had adequate funds to perform decommissioning and wanted this topic to be in the GEIS $(291,389,396,407,434,503,1020,1026,1303$, 1410). Other comments regarding funds and their use included:

Two commenters called for seizing the assets of utilities to pay for decommissioning $(507,1584)$ and converting the resources of national laboratories to the cleanup effort (507).

Two other commenters stated that citizens committees and state and local environmental agencies should be given funds and invited to participate in all monitoring of the facility to be decommissioned $(637,1303)$.

One commenter felt that the availability of funding for restricted use should be reviewed (407).

Another commenter wanted provisions for health care costs and relocation expenses for those affected by radioactive contamination, and provisions for funds for independent monitoring of decommissioning (498).

\section{E.5.2 Timing/Timeliness Considerations}

Several commenters supported the NRC"s elimination of the subject of timeliness of decommissioning from study under the GEIS because they have been previously considered and would merely dilute the effort at hand to evaluate the comparative impacts of alternatives for setting radiological criteria $(481,482,490,1284,1438$, $1440,1442)$. However, other commenters opposed the elimination $(491,493,1084,1177,1428)$ for reasons which included a potential for substantial environmental and cost penalties incurred by delays.

Two commenters stated that there is no need to rush decommissioning $(322,741)$.

One commenter recommended that the NRC reconsider its preferred choice of.decommissioning options, e.g.,

DECON, SAFSTOR, and ENTOMB which have different timing impacts and costs (730).

\section{E.5.3 Continued Liability for Facilities}

Commenters urged the NRC to consider liability in the GEIS and stated that liability should remain with generators of wastes for as long as they need to be managed, i.e., over the lifetime of the waste regardless of where the material is located $(99,287,301,359,398,495,594,595,936,1066,1355,1404,1405,1452$, $1453,1486,1535)$. Clarifying comments included:

Consider non-fatal as well as fatal cancers among the risks to be considered, and consider who will be liable for costs of "future damages or illness or whatever"(301).

The generic standard needs to allow for site-specific considerations, including financial compensation by the industry to the community (488). 
The GEIS should consider ways to hold the licensee responsible for the costs of the waste and contamination as a part of the licensing process (495).

Liability should extend to locations where the licensee sends radioactive waste material for treatment, storage, or disposal (594).

\begin{abstract}
Alternatives should include the indefinite extension of licenses and liabilities. Sites would be decommissioned, but licensees would continue to hold a possession-only type license and continue to be held financially liable for damages. This alternative would be close to the present regulatory approach for toxic chemicals. All parties responsible for toxic waste disposal, that is, present and past landowners, operators and waste generators, continue to be responsible for clean-up, as if all these parties were licensed (1355).
\end{abstract}

\title{
E.5.4 Recycle
}

Several commenters want the GEIS to cover the recycle of wastes and contaminated material, i.e., criteria for release of contaminated equipment, components, piping, and other similar materials $(167,494,860,862$, $1064,1295,1441)$. A recommendation was made to include a regulatory requirement for the licensee to state clearly how it proposed to safely dispose of all contaminated waste streams (1062). Another commenter recommended a review of impacts of deliberate intrusion into waste storage facilities for raw material (355). One commenter implied that short-lived wastes could be held on site and handled separately (1411).

\section{E.5.5 Accidents}

One commenter urged the NRC to set an overall limit of $100 \mathrm{mrem} / \mathrm{yr}$ total effective dose equivalent (TEDE) to any member of the public regardless of the pathway of exposure for above background levels from all man-made sources (1034). Another commenter addressed the need for training of medical and other personnel for adequate response to radiological accidents ( 025$)$.

\section{E.5.6 Monitoring}

One commenter stated that it is imperative that before any monitoring begins, citizens groups and the NRC analyze all possible pathways for radiation to have escaped over the life of the facility (638). Another recommended that the NRC ensure adequate monitoring before, during, and after decommissioning (843). One commenter recommended occasional spot monitoring even after clean up to make sure that nothing has been missed or brought back onto the property. There should be a period of years between the end of clean up and any new use of the property in order that post-clean-up monitoring can occur (1594).

One commenter recommended independent epidemiological studies of people living near facilities and ecosystems (605). Another commenter wanted monitoring for radon in wells before starting decommissioning (273).

\section{E.5.7 Hazardous Wastes, Mixed Wastes, Other Agency Regs., Radium}

One commenter stated that the GEIS as presently scoped erroneously omits consideration of non-radioactive hazardous pollutants, and is thus not capable of providing an accurate or meaningful evaluation of the costs and benefits of decommissioning (1529). The presence of nonradioactive chemical contaminants at NRC-licensed facilities may exacerbate the risks posed by radioactive contaminants. Non-radioactive chemical contaminants aiso sometimes involve non-cancer risks, which need to be taken into account (1044). One commenter stated that it is very important for the NRC and the EPA to coordinate their regulatory requirements for mixed wastes; 
it is critical for this proposal (1616). Another commenter wanted planning for decommissioning to include the management and disposition of the very substantial amounts of nonhazardous solid waste (mostly construction and demolition wastes), and any mixed hazardous wastes resulting from the dismantling of NRC-licensed facilities. This planning should cover both off-site and on-site waste management and disposal considerations, to include technical capability and capacity (1412). Other related comments were:

Because of the clear application of state and local law after a site is released from NRC regulatory control, each of the alternatives discussed in the GEIS should be evaluated to prevent the creation of impediments to the application and enforcement of state and local regulation (1318).

Once nonhazardous solid waste materials pass out of the Commission's nuclear regulatory management, they will be managed under the Resource Conservation and Recovery Act (RCRA) and applicable State solid waste laws and regulations, to include any special management requirements considered appropriate due to their former or current radiological content (854).

The combined hazardous and nuclear mixed wastes which will result from decommissioning must be handled within the national hazardous waste management system (i.e., RCRA Subtitle C), and this rulemaking should make that restriction absolutely clear (856).

One commenter encouraged including in the GEIS discussion of the establishment of separate radiological criteria for radon and radium as important to the soil contamination issue for fuel-cycle facilities (133). Another commenter recommended that the GEIS distinguish between man-made radionuclides and naturally occurring radionuclides (1045).

\section{E.6 GEIS VERSUS SITE SPECIFIC EIS; SITE-SPECIFIC FLEXIBILITY}

Most commenters indicated a need for a generic EIS $(2,462,513,515,607)$ but they wanted a process to determine site specific criteria $(7,90,130,139,166,169,211,217,254,441,462,874,900,1032,1041$, $1092,1118,1444,1469,8905)$; or they wanted requirements for licensees to perform a site specific EIS (43, $45,48,50,172,306,348,705,707,771,903,1116,1124,1126,1129,1222,1275,1278,1293,1444,1549$. 1555).

One commenter stated that just the larger facilities should require a separate EIS for each major decommissioning project (306).

Two commenters stated that the site-specific EIS should allow for the application of clean-up requirements which may be more restrictive than those that might be in the GEIS $(45,1118)$.

Two commenters disagreed with the NRC's intent to use the GEIS in order to eliminate from consideration in the site-specific decommissioning EIS those issues that have been addressed in the GEIS $(48,54)$. Another commenter disagreed with them but added that the purpose of the GEIS is to assess the overall total impacts of decommissioning all nuclear facilities; while the purpose of the site-specific EIS is to address impacts associated with a single site and those at other affected locations and times (709). Another commenter stated that none of the issues proposed to be eliminated due to prior analysis should be omitted from the GEIS, nor from subsequent licensee-specific EIS (1167).

Two commenters stated that the concept of a GEIS was unacceptable, unscientific, defeating the function of an EIS, or threatening to the public health and safety $(972,1062)$. One commenter felt it inappropriate to exclude issues in site-specific proceedings because they were deemed "resolved" by a GEIS (1264). Another 
stated that because each plant decommissioning is unique in its nuclear process, geographical location, and the degree of contamination, it seems apparent that all decommissioning regulations must be set up on a case by case basis (903).

One commenter stated that mechanisms for ensuring compliance with land use restrictions need not be considered in detail in the GEIS because many of them would not be applicable to specific sites (1206).

One commenter recommended that the GEIS should discuss how the National Environmental Policy Act will be applied to individual decommissioning actions if the proposed rule is adorted (1429).

\section{E.7 CITIZEN PARTICIPATION}

Several commenters noted that interactive public participation is important to the process of NRC rule making and that the GEIS should consider involving local citizens in approving licensing and decommissioning plans $(101,177,218,326,363,365,409,477,521,531,749,829,846,901,1029,1265,8856)$.

Commenters further noted that risks are different at each site (524), and that the GEIS should have a mechanism for local public involvement in risk assessments $(958,1449)$. Two commenters stated that local communities should have the power and authority to decide how a site and facility are dealt with $(779,1445,1447)$, while another desired that only local citizens who live near the site be afforded this participation and exclude outsiders (911). The various comments made regarding local concerns also included:

The rule should require that all communities along transportation routes for radioactive materials be informed of the potential hazards and emergency procedures $(196,224)$.

Consider total cancer risks, radiological and chemical, associated with decommissioning, and consider some community "right-to-know" actions if decommissioned facilities pose a lifetime cancer risk greater than 10 to the minus five -- similar to the manner in which California state laws have risk-based "triggers" that require public notice $(346,949)$.

Workers and families of workers involved in decommissioning of a facility should be informed of the long-term health effects of radiation (198).

There were several comments made encouraging the involvement of local public groups participating in establishing site specific background criteria $(171,280,352,423,433)$, although two commenters wanted to pursue the use of scientific experts in this matter $(350,433)$. Another commenter stated that the GEIS should include consulting with physicians (530).

Other commenters also stated that too much attention is given to people with little or no scientific background $(280,295)$. Another desired that scientists review the GEIS for lay people who may not understand all of the considerations $(512,529)$. One questioned if it is reasonable to ask citizens to discuss highly technical things (617). A different view point was made in suggesting that provisions for continual public reviews of scientific literature should be part of the new rules (551).

Several commenters stated that the GEIS should provide a mechanism for funding of local citizen groups for evaluating plans and monitoring of decommissioning $(101,845,1029,1076,1304)$. Another commenter supported the need for funding in that local groups must hire their own technical experts (637).

One commenter requested provisions for citizen groups to register a complaint or concern to the NRC (522). 
Several commenters stated that citizen participation would be facilitated through better education of the public $(179,228,395)$.

Two commenters requested that the NRC provide for full opportunity for public comment and hearings (1225, $1327,1448)$. Others advocated that more efforts should be made to get more involved and questioned if there were enough meetings $(186,471,930)$. More advertising through television was recommended (523). Three commenters requested the comment period be extended $(511,525,1323)$.

Comments were made which implied that public trust and less misunderstanding must be developed by the NRC:

One commenter considered the meetings a sham and inappropriate (518).

Other commenters implied that potential attendees are concerned about the value of the meetings and if their attendance' would be productive $(218,206,249)$.

Another wanted the meetings in the vicinity of each facility (520).

One commenter desired a clearer presentation of issues (more readable by the general public (526).

Another commenter was suspicious that the previously held workshops are not part of the scoping process and stated that the enhanced participatory rulemaking is another manipulation of public trust (932). One commenter asked and received confirmation that both the scoping materials and the results of the workshops will be part of the NRC's decision record for the rulemaking. Commenter then requested that her oral comments at the Philadelphia workshop and her subsequent written comments be incorporated into the scoping process (44).

One commenter stated that carefully documenting practical limits of measurability and compliance demonstration in the GEIS will be important for gaining public acceptance of realistic protective site cleanup standards (1175).

A question was raised as to how the GEIS should discuss the National Environmental Policy Act and how it will be applied to individual decommissioning actions if the proposed rule is adopted (975). Other commenters questioned how the GEIS will interact with EPA requirements (444) and if requirements for local groups would parallel EPA models $(270,277,302)$.

\section{E.8 WASTE MINIMIZATION}

Many commenters recommended that the NRC should discourage or stop those nuclear operations which generate nuclear wastes $(98,205,223,247,275,286,294,394,470,529,766,785,872,938,978,1058$, $1170,1216,1283,1454)$.

One commenter hoped that the $\mathrm{N} \mathrm{C}$ would require complete decontamination and minimization of wastes that are generated in the clean-up (1205). Another cautioned that decommissioning of a power plant will produce four times more radioactive wastes than the entire operating years, yet we don't know how to deal with the waste (626).

Two commenters expressed concern regarding the lack of permanent sites for storing radioactive wastes (294, 833). Commenters suggested: nobody wants the wastes in their backyard (636) and that it is foolish to contaminate new sites with waste (294). 
The GEIS must include restrictions on licensing new facilities or extending licenses on existing facilities that cannot comply with the decommissioning criteria to be established (1216). A commenter stated that utilities that built nuclear power plants should have already had the means of taking care of the waste before $t$ ' $y$ were allowed to build the plant (636).

One commenter recommended that the NRC should ensure adequate monitoring before, during, and after decommissioning and ensure that wastes removed from the site are taken to approved facilities, and that during clean up the guidelines of "zero release of radiation" is followed (844). Another cautioned that transportation will lead to accidents and highway contamination (294).

Specific recommendations were made by one commenter. Reclassify low-level radioactive waste on the strict basis of half-life, and deal separately with long-lived and short-lived radionuclides in minimizing and disposing of waste. Alternative waste minimization solutions such as on-site storage for decay, should be used by medical institutions and others using short-lived materials (645).

One commenter questioned the NRC's policy of not requiring the licensee to conduct additional cleanup in response to NRC criteria or standards, established after NRC approved of the (new) plan, and to remove hazards to human health unless the NRC decides they are "significant" (1371). 


\section{COMMENT REFERENCES}

This section is a reference which relates each comment to its origin. The listed information includes a comment number, the name of the commenter, the meeting at which the comment was made or the docket number of the letter containing the comment, and data for referencing a particular page, line or paragraph. Following is an explanation of the listed information.

The comment number is unique to a single comment made within an issue. If the same comment also applies to another issue code, another number is assigned for use within that other issue code.

The name of the commenter is' listed as the last name or if an organization, the full or abbreviated name.

Comments from meetings are identified as $\mathrm{DC} 1$ or $2, \mathrm{CA} 1$ or $2, \mathrm{OK} 1$ or 2 , and $\mathrm{OH} 1$ or 2 which correspond to Washington, D.C., San Francisco, CA, Oklahoma City, OK, and Cleveland, OH.; respectively. The number 1 or 2 refer to a day time or evening mecting. The next group of numbers identifies the page of the manuscript of the workshop that the comment begins on. The next set of numbers gives the line number that the comment begins on. An illustrative example follows:

$$
\text { \{Comment \#\} \{Name\} \{Meeting }\} \quad \text { Page \#\} \{ Line\#\} }
$$

1 ROYAL $\quad$ OK2 $\quad 125 \quad 7$

Identification of comments from docketed letters ${ }^{2}$ are similarly identified but begin at comment number 700 and the beginning paragraph number is listed instead of a line number. An illustrative example follows:

\section{$\{$ Comment \#\}\{Name $\}\{$ Docket \#\}\{Page \#\}\{Paragraph \#\}}

$\begin{array}{lllll}7659 & \text { BLACK } & 40 & 1 & 1\end{array}$

The following pages contain a column listing of Comment Number, Commenter's Name, Workshop and/or Docket Number, Page Number, Paragraph Number, or Line Number.

\footnotetext{
2The letter received from the US Department of Energy was assigned number 99 as it was not formally docketed at manuscript completion.
} 
1 DAM

2 DAM

3 DAM

4 DAM

5 DAM

6 DAM

7 DAM

8 DAM

9 DAM

10 DAM

11 DAM

12 DAM

13 DAM

14 DAM

15 DAM

17 HENDRICKS

18 HENDRICKS

19 HENDRICKS

20 HENDRICKS

21 HENDRICKS

22 HENDRICKS

23 HENDRICKS

24 HENDRICKS

25 HENDRICKS

26 HENDRICKS

28 HENDRICKS

29 HENDRICKS

30 HENDRICKS

31 HENDRICKS

32 HENDRICKS

33 HENDRICKS

34 HENDRICKS

35 HENDRICKS

36 HENDRICKS

37 HENDRICKS

38 JOHNSRUD

39 JOHNSRUD

40 JOHNSRLD

41 JOHNSRUD

42 JOHNSRUD

43 JOHNSRUD

44 JOHNSRUD

45 JOHNSRUD

46 JOHNSRUD

47 JOHNSRUD

48 JOHNSRUD

49 JOHNSRUD

50 JOHNSRUD

51 JOHNSRUD

52 JOHNSRUD

53 JOHNSRUD

54 JOHNSRUD

55 JOHNSRUD

56 JOHNSRUD

57 JOHNSRUD

58 JOHNSRUD

59 JOHNSRUD

60 JOHNSRUD

61 JOHNSRUD

62 JOHNSRUD

\begin{tabular}{|c|c|c|}
\hline 61 & 31 & 3 \\
\hline DC1 & 31 & 4 \\
\hline DC1 & 31 & 6 \\
\hline DC1 & 31 & 6 \\
\hline $\mathrm{DCl}$ & 31 & 7 \\
\hline $\mathrm{DCl}$ & 31 & $10^{\prime}$ \\
\hline DCl & 31 & 13 \\
\hline $\mathrm{DCl}$ & 31 & 17 \\
\hline $\mathrm{DCl}$ & 32 & 2 \\
\hline $\mathrm{DCl}$ & 32 & 3 \\
\hline $\mathrm{DCl}$ & 32 & 4 \\
\hline DC1 & 32 & 7 \\
\hline $\mathrm{DC1}$ & 32 & 17 \\
\hline $\mathrm{DC} 1$ & 32 & 19 \\
\hline DC1 3 & 33 & 3 \\
\hline $\mathrm{DCl}$ & 3 & 4 \\
\hline DCl & 3 & 14 \\
\hline DCI & & 17 \\
\hline DC1 & & 15 \\
\hline DC1 & & 15 \\
\hline $\mathrm{DCl}$ & & 15 \\
\hline DC1 & & 35 \\
\hline $\mathrm{DC} 1$ & & 36 \\
\hline $\mathrm{DC} 1$ & & 36 \\
\hline DC1 & & 37 \\
\hline $\mathrm{DCl}$ & & 36 \\
\hline $\mathrm{DCl}$ & & 37 \\
\hline DCl & & 37 \\
\hline DC1 & & 37 \\
\hline $\mathrm{DCl}$ & & 37 \\
\hline $\mathrm{DCl}$ & & 38 \\
\hline $\mathrm{DCl}$ & & 39 \\
\hline DCl & & 39 \\
\hline DCl & & 39 \\
\hline DC1 & & 39 \\
\hline $\mathrm{DCl}$ & 40 & 23 \\
\hline DC1 & 4 & 1 \\
\hline DC1 & 4 & 2 \\
\hline DCI & 4 & 11 \\
\hline DC1 & 4 & 23 \\
\hline $\mathrm{DCl}$ & 4 & 3 \\
\hline $\mathrm{DC} 1$ & 4 & 4 \\
\hline $\mathrm{DCl}$ & 4 & 14 \\
\hline $\mathrm{DCl}$ & 4 & 4 \\
\hline DC1 & 4 & 4 \\
\hline $\mathrm{DCl}$ & & 5 \\
\hline DC1 & 4 & 5 \\
\hline $\mathrm{DCl}$ & & 6 \\
\hline DC1 & & 6 \\
\hline DCl & & 6 \\
\hline DCl & & 17 \\
\hline$D C 1$ & & 7 \\
\hline $\mathrm{DCl}$ & & 17 \\
\hline DC1 & & 18 \\
\hline DC1 & & 18 \\
\hline DC1 & & 19 \\
\hline DC1 & & 19 \\
\hline DC1 & & 9 \\
\hline DC1 & 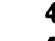 & 9 \\
\hline DC1 & & 30 \\
\hline
\end{tabular}

\begin{tabular}{|c|c|c|c|c|}
\hline 63 & JOHNSRUD & DC1 & 50 & 14 \\
\hline 64 & HENDRICKS & DC1 & 51 & 10 \\
\hline 65 & LTTLEFIELD & DC1 & 54 & 7 \\
\hline 66 & LTTLEFIELD & DC1 & 54 & 7 \\
\hline 67 & JOHNSRUD & DC1 & 55 & 2 \\
\hline 68 & JOHNSON & DC2 & 25 & 10 \\
\hline 69 & JOHNSON & DC2 & 25 & 14 \\
\hline 70 & JOHNSON & DC2 & 25 & 18 \\
\hline 71 & JOHNSON & DC2 & 26 & 1 \\
\hline 72 & JOHNSON & DC2 & 26 & 6 \\
\hline 73 & JOHNSON & DC2 & 26 & 11 \\
\hline 74 & JOHNSON & DC2 & 26 & 11 \\
\hline 75 & JOHNSON & $\mathrm{DC} 2$ & 27 & 19 \\
\hline 76 & JOHNSON & $\mathrm{DC} 2$ & 27 & 19 \\
\hline 77 & JOHNSON & $\mathrm{DC} 2$ & 28 & 3 \\
\hline 78 & JOHNSON & DC2 & 28 & 3 \\
\hline 79 & NELSON & DC2 & 28 & 19 \\
\hline 80 & NELSON & DC2 & 29 & 1 \\
\hline 81 & NELSON & DC2 & 29 & 7 \\
\hline 82 & NELSON & DC2 & 29 & 10 \\
\hline 83 & NELSON & DC2 & 29 & 18 \\
\hline 84 & NELSON & DC2 & 30 & 5 \\
\hline 85 & NELSON & DC2 & 30 & 5 \\
\hline 86 & NELSON & DC2 & 30 & 20 \\
\hline 87 & NELSON & DC2 & 31 & 6 \\
\hline 88 & NELSON & DC2 & 31 & 13 \\
\hline 89 & LATSON & DC2 & 34 & 9 \\
\hline 90 & D'ARRIGO & DC2 & 34 & 23 \\
\hline 91 & D'ARRIGO & DC2 & 34 & 23 \\
\hline 92 & D'ARRIGO & DC2 & 35 & 4 \\
\hline 93 & D'ARRIGO & DC2 & 35 & 7 \\
\hline 94 & D'ARRIGO & DC2 & 35 & 14 \\
\hline 95 & D'ARRIGO & DC2 & 35 & 14 \\
\hline 96 & D'ARRIGO & DC2 & 35 & 24 \\
\hline 98 & D'ARRIGO & DC2 & 37 & 2 \\
\hline 99 & D'ARRIGO & DC2 & 37 & 18 \\
\hline 100 & D'ARRIGO & DC2 & 38 & 6 \\
\hline 101 & D'ARRIGO & DC2 & 38 & 13 \\
\hline 102 & D'ARRIGO & DC2 & 38 & 20 \\
\hline 103 & D'ARRIGO & DC2 & 38 & 13 \\
\hline 104 & D'ARRIGO & $\mathrm{DC} 2$ & 38 & 18 \\
\hline 105 & NELSON & DC2 & 40 & 18 \\
\hline 106 & NELSON & DC2 & 41 & 20 \\
\hline 107 & OLSON & DC2 & 42 & 6 \\
\hline 109 & OLSON & $\mathrm{DC2}$ & 42 & 22 \\
\hline 110 & OLSON & DC2 & 43 & 21 \\
\hline 111 & OLSON & DC2 & 44 & 3 \\
\hline 112 & OLSON & DC2 & 44 & 3 \\
\hline 114 & MCLAIN & OK1 & 23 & 6 \\
\hline 115 & MCLAIN & OK1 & 23 & 7 \\
\hline 116 & MCLAIN & OK1 & 23 & 7 \\
\hline 117 & STILL. & OK1 & 25 & 15 \\
\hline 118 & STILL & OK1 & 25 & 15 \\
\hline 119 & STILL & OKI & 24 & 20 \\
\hline 120 & STILL & OK1 & 25 & 2 \\
\hline 122 & STILL & OK1 & 27 & 7 \\
\hline 123 & STILL & OK1 & 27 & 7 \\
\hline 124 & STILL & OK1 & 28 & 1 \\
\hline 125 & STILL & OKI & 28 & 10 \\
\hline 126 & STILL & OKI & 29 & 2 \\
\hline
\end{tabular}




\begin{tabular}{|c|c|c|c|c|}
\hline 127 & STILL & OK1 & 12 & \\
\hline 128 & STILL & OK1 & 13 & \\
\hline 129 & STILL & OK1 & 15 & \\
\hline 130 & STILL & OK1 & 17 & \\
\hline 132 & STILL & OK1 & 18 & \\
\hline 133 & STILL & OK1 & 25 & \\
\hline 134 & STIILL & OK1 & 4 & \\
\hline 136 & STILL & OK1 & 10 & \\
\hline 137 & STILL & OK1 & 11 & \\
\hline 138 & STILL & OK1 & 7 & \\
\hline 139 & CUDDY & OK1 & 2 & 2 \\
\hline 141 & CUDDY & OK1 & 3 & 6 \\
\hline 142 & CUDDY & OK1 & 3 & 6 \\
\hline 145 & CUDDY & OK1 & 34 & 3 \\
\hline 147 & GARDNER & OK1 & 35 & 9 \\
\hline 148 & MEDLEY & OK2 & 25 & 23 \\
\hline 149 & MEDLEY & OK2 & 32 & 16 \\
\hline 150 & GARDNER & OK1 & 38 & 21 \\
\hline 151 & MEDLEY & OK2 & 42 & 3 \\
\hline 152 & SINCLAIR & OK2 & 43 & 23 \\
\hline 153 & SINCLAIR & OK2 & 43 & 23 \\
\hline 154 & SINCLAIR & OK2 & 43 & 20 \\
\hline 155 & GARDNER & OK1 & 40 & 4 \\
\hline 156 & SINCLAIR & OK2 & 43 & 21 \\
\hline 157 & SINCLAIR & OK2 & 43 & 22 \\
\hline 158 & GARDNER & OK1 & 40 & 7 \\
\hline 159 & GARDNER & OK1 & 40 & 11 \\
\hline 161 & SINCLAIR & OK2 & 46 & 5 \\
\hline 162 & GARDNER & OK1 & 40 & 19 \\
\hline 164 & BARFIELD & OK2 & 47 & 18 \\
\hline 165 & BARFIELD & OK2 & 47 & 18 \\
\hline 166 & GARDNER & OK1 & 41 & 18 \\
\hline 167 & SINCLAIR & OK2 & 46 & 12 \\
\hline 168 & SINCLAIR & OK2 & 46 & 12 \\
\hline 169 & GARDNER & OK1 & 41 & 21 \\
\hline 170 & GARDNER & OK1 & 41 & 21 \\
\hline 171 & CUDDY & $\mathrm{OK} 2$ & 49 & 16 \\
\hline 172 & CUDDY & OK2 & 49 & 16 \\
\hline 173 & CUDDY & OK2 & 50 & 3 \\
\hline 174 & CUDDY & OK2 & 50 & 16 \\
\hline 175 & BELISLE & OK1 & 42 & 17 \\
\hline 176 & CUDDY & OK2 & 50 & 25 \\
\hline 177 & CUDDY & OK2 & 52 & 10 \\
\hline 178 & BELISLE & OK1 & 43 & 3 \\
\hline 179 & CUDDY & OK2 & 52 & 20 \\
\hline 180 & CUDDY & OK2 & 54 & 10 \\
\hline 181 & CUDDY & OK2 & 54 & 10 \\
\hline 182 & BELISLE & OK1 & 43 & 3 \\
\hline 183 & BELISLE & OK1 & 43 & 15 \\
\hline 184 & BELISLE & OK2 & 55 & 18 \\
\hline 185 & BELISLE & OK1 & 43 & 20 \\
\hline 186 & BARFIELD & OK1 & 44 & 14 \\
\hline 187 & BARTON & OK2 & 58 & 22 \\
\hline 188 & BARFIELD & OK1 & 45 & 9 \\
\hline 189 & BARTON & OK2 & 61 & 3 \\
\hline 190 & BARTON & OK2 & 62 & 18 \\
\hline 191 & BARTON & OK2 & 65 & 5 \\
\hline 192 & BARTON & OK2 & 68 & 12 \\
\hline 193 & BARFIEL.D & OK1 & 45 & 14 \\
\hline 194 & BARTON & OK2 & 73 & 24 \\
\hline
\end{tabular}

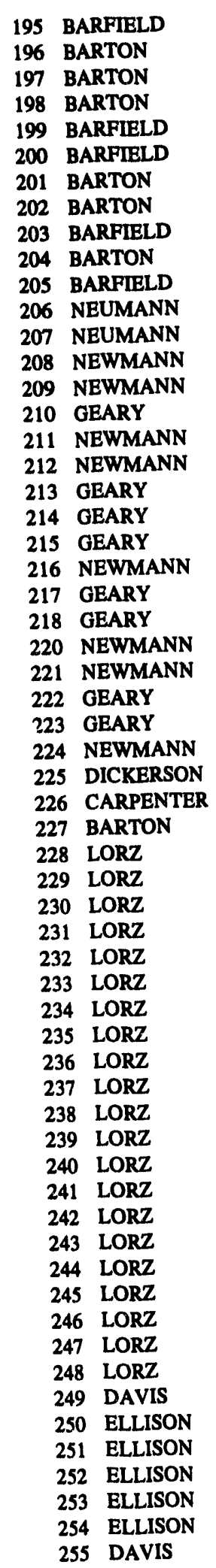

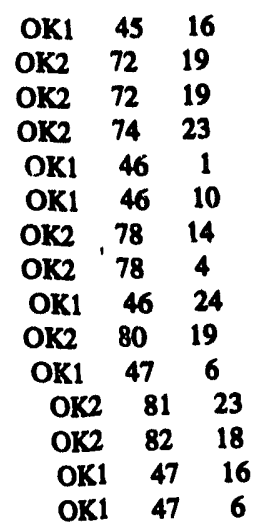

OK2 845

OK1 489

OK1 $48 \quad 19$

$\begin{array}{lll}\text { OK2 } & 84 & 8\end{array}$

$\begin{array}{lll}\text { OK } 2 & 84 & 8\end{array}$

OK2 $84 \quad 16$ OK1 $48 \quad 24$

$\begin{array}{lll}\text { OK2 } & 86 & 7\end{array}$

OK2 $86 \quad 15$ $\begin{array}{lll}\text { OK1 } & 49 & 7 \\ \text { OK1 } & 49 & 9\end{array}$

$\begin{array}{lll}\text { OK2 } & 88 & 23\end{array}$

OK2 905

OK1 $49 \quad 12$

$\begin{array}{lll}\text { OK2 } & 91 \quad 12\end{array}$

OK2 $103 \quad 22$

OK1 $50 \quad 21$

$\begin{array}{lll}\text { OH2 } & 21 & 2\end{array}$

OH2 212

OH2 212

OH2 $21 \quad 24$

OH2 $24 \quad 10$

OH2 $23 \quad 1$

$\begin{array}{lll}\mathrm{OH} 2 & 22 & 14\end{array}$

$\begin{array}{lll}\mathrm{OH} 2 & 23 & 7\end{array}$

OH2 $23 \quad 24$

OH2 $24 \quad 5$

OH2 245

OH2 $24 \quad 14$

$\begin{array}{lll}\mathrm{OH} 2 & 24 & 14\end{array}$

OH2 254

OH2 $25 \quad 8$

OH2 $25 \quad 19$

OH2 $25 \quad 19$

$\mathrm{OH} 2264$

$\begin{array}{lll}\mathrm{OH} 2 & 26 & 10\end{array}$

$\begin{array}{lll}\text { OH } 2 & 27 & 14\end{array}$

$\begin{array}{lll}\mathrm{OH} 2 & 27 & 21\end{array}$

OH2 $28 \quad 8$

$\mathrm{OH} 2 \quad 30 \quad 25$

$\begin{array}{lll}\mathrm{OH} 2 & 31 & 17\end{array}$

OH2 $33 \quad 1$

$\mathrm{OH} 233 \quad 1$

OH2 338 
Appendix E

GEIS Comments

\begin{tabular}{|c|c|c|c|c|}
\hline 256 & DAVIS & $\mathrm{OH} 2$ & 10 & \\
\hline 257 & DAVIS & $\mathrm{OH} 2$ & 13 & \\
\hline 258 & DAVIS & $\mathrm{OH} 2$ & 13 & \\
\hline 259 & DAVIS & $\mathrm{OH} 2$ & 21 & \\
\hline 260 & AVENI & $\mathrm{OH} 2$ & 15 & \\
\hline 262 & HANNAH & $\mathrm{OH} 2$ & 40 & 8 \\
\hline 263 & HANNAH & $\mathrm{OH} 2$ & 40 & 21 \\
\hline 264 & HANNAH & $\mathrm{OH} 2$ & 40 & 21 \\
\hline 265 & LORZ & $\mathrm{OH} 2$ & \multicolumn{2}{|c|}{22} \\
\hline 266 & NELSON & DC2 & \multicolumn{2}{|c|}{1} \\
\hline 267 & NELSON & $\mathrm{DC2}$ & \multicolumn{2}{|c|}{1} \\
\hline 268 & BARTON & OK1 & \multicolumn{2}{|c|}{6} \\
\hline 269 & BARTON & OK1 & \multicolumn{2}{|c|}{6} \\
\hline 270 & BARTON & OK1 & \multicolumn{2}{|c|}{10} \\
\hline 271 & BARTON & OK1 & \multicolumn{2}{|c|}{14} \\
\hline 272 & BARTON & OK1 & \multicolumn{2}{|c|}{14} \\
\hline 273 & BARTON & OK1 & \multicolumn{2}{|c|}{22} \\
\hline 274 & BARTON & OK1 & \multicolumn{2}{|c|}{1} \\
\hline 275 & BARTON & OK1 & \multicolumn{2}{|c|}{20} \\
\hline 276 & BARTON & OK1 & 60 & 7 \\
\hline 277 & BARTON & OK1 & \multicolumn{2}{|c|}{10} \\
\hline 278 & NIPPER & OK1 63 & \multicolumn{2}{|c|}{17} \\
\hline 279 & NIPPER & OK1 & 10 & 10 \\
\hline 280 & GEARY & OK1 & 14 & 14 \\
\hline 281 & GEARY & OK1 & 17 & 17 \\
\hline 282 & GEARY & OKI & 21 & \\
\hline 283 & GEARY & OK1 & 23 & \\
\hline 284 & GEARY & OKI & 66 & 7 \\
\hline 285 & GEARY & OK1 & 18 & 8 \\
\hline 286 & GEARY & OK1 & 21 & 1 \\
\hline 287 & GEARY & OK1 & 67 & 3 \\
\hline 288 & GEARY & OK1 & 68 & 0 \\
\hline 289 & DICKERSON & OK1 & 70 & 1 \\
\hline 291 & DICKERSON & OK1 & 70 & 18 \\
\hline 292 & DICKERSON & OK1 & 71 & 2 \\
\hline 293 & DICKERSON & OK1 & 71 & 20 \\
\hline 294 & DICKERSON & OK1 & 72 & 12 \\
\hline 295 & ELLIS & OK1 74 & 25 & \\
\hline 296 & ELLIS & OK1 & 2 & \\
\hline 297 & ELLIS & OK1 & 19 & \\
\hline 298 & GOLTEIN & CA1 & 20 & 11 \\
\hline 299 & GOLTEIN & CAl & 20 & 17 \\
\hline 300 & GOLTEIN & CAI & 21 & 9 \\
\hline 301 & GOLTEIN & CA1 & 21 & 14 \\
\hline 302 & GOLTEIN & CAl & 21 & 18 \\
\hline 303 & GOLTEIN & CA1 & 22 & 18 \\
\hline 304 & GOLTEIN & CAI & 23 & 4 \\
\hline 305 & GOLTEIN & CA'1 & 23 & 4 \\
\hline 306 & GOLTEIN & CA1 & 231 & 10 \\
\hline 307 & DAVENPORT & CA1 & 25 & 13 \\
\hline 308 & DAVENPORT & CA1 & 26 & 5 \\
\hline 310 & DAVENPORT & CA1 & 27 & 14 \\
\hline 311 & DAVENPORT & CA1 & 27 & 15 \\
\hline 312 & DAVENPORT & CAl & 27 & 22 \\
\hline 313 & DAVENPOR'I & CA1 & 27 & 22 \\
\hline 314 & DAVENPORT & CA1 & 27 & 22 \\
\hline 315 & DAVENPORT & CA1 & 28 & 3 \\
\hline 316 & DAVENPORT & CA1 & 28 & 12 \\
\hline 317 & DAVENPORT & CAI & 29 & 14 \\
\hline & & CA1 & 30 & \\
\hline
\end{tabular}

319 DAVENPORT

320 DAVENPORT

321 DAVENPORT

322 DAVENPORT

323 LUCHION

324 LUCHION

325 LUCHION

326 LUCHION

327 FULLER

328 FULLER

329 FULLER

330 FULLER

331 FULLER

332 FULLER

333 FULLER

334 FULLER

335 FULLER

336 FULLER

337 FULLER

338 FULLER

339 FULLER

340 FULLER

341 FULLER

342 FULLER

343 MCLAY

344 MCLAY

345 McLAY

346 McLAY

347 McLAY

348 YOUNG

349 YOUNG

350 YOUNG

351 YOUNG

352 YOUNG

353 YOUNG

354 YOUNG

355 YOUNG

356 YOUNG

357 YOUNG

358 YOUNG

359 YOUNG

360 YOUNG

361 YOUNG

362 YOUNG

363 , HITZ

364 HITZ

365 HITZ

366 HITZ

367 HITZ

368 HITZ

369 HITZ

370 HITZ

371 HITZ

372 HITZ

373 HITZ

374 HITZ

375 KLASKY

376 KLASKY

377 KLASKY

378 KLASKY $\begin{array}{ccc}\text { CA1 } & 32 & 13 \\ \text { CA1 } & 32 & 13 \\ \text { CA1 } & 33 & 24 \\ \text { CA1 } & 35 & 1\end{array}$

$\begin{array}{lll}\text { CA1 } & 37 & 3\end{array}$

$\begin{array}{lll}\text { CA1 } & 37 & 8\end{array}$

$\begin{array}{lll}\text { CA1 } & 37 \quad 10\end{array}$

$\begin{array}{lll}\text { CA1 } & 37 & 22\end{array}$

$\begin{array}{lll}\text { CA1 } & 39 & 18\end{array}$

CAI $39 \quad 20$

CA1 $39 \quad 20$

CA1 $39 \quad 23$

CA1 $40 \quad 1$

CA1 405

CA1 $40 \quad 12$

CA1 $40 \quad 22$

CA1 $40 \quad 24$

CA1 $40 \quad 24$

CA1 $41 \quad 2$

CA1 $41 \quad 9$

CA1 $41 \quad 13$

CA1 $41 \quad 19$

CA1 $41 \quad 20$

CA1 $41 \quad 22$

$\begin{array}{lll}\text { CA1 } & 42 & 17\end{array}$

CA1 $42 \quad 22$

CA1 431

CAI 434

CA1 $43 \quad 19$

CA1 453

CA1 455

CA1 $45 \quad 9$

CA1 $45 \quad 13$

CA1 $45 \quad 20$

CA1 $45 \quad 22$

CA1 $45 \quad 23$

CA1 $45 \quad 24$

CA1 $46 \quad 2$

CA1 $45 \quad 24$

CA1 $46 \quad 6$

$\begin{array}{lll}C A 1 & 46 & 15\end{array}$

CA1 $46 \quad 15$

$\begin{array}{lll}C A 1 & 46 & 21\end{array}$

CA1 4621

CA1 $48 \quad 19$

CA1 $49 \quad 11$

CA1 4921

CA1 $49 \quad 25$

CA1 503

CA1 $50 \quad 8$

CA1 $50 \quad 8$

CAI $50 \quad 13$

CA1 $50 \quad 19$

CA1 $50 \quad \therefore 2$

CA1 $50 \quad 19$

CA1 517

$\begin{array}{lll}\mathrm{CA} 1 & 52 & 8\end{array}$

$\begin{array}{lll}\text { CA1 } & 52 & 24\end{array}$

CA1 $52 \quad 25$

CA1 $53 \quad 4$ 


\begin{tabular}{|c|c|c|c|c|}
\hline 379 & KLASKY & CAl & 53 & 4 \\
\hline 380 & KLASKY & CA1 & 53 & 14 \\
\hline 381 & KLASKY & CA1 & 53 & 18 \\
\hline 382 & KLASKY & CAI & 53 & 20 \\
\hline 383 & KLASKY & CAl & 53 & 23 \\
\hline 384 & KLASKY & CAI & 54 & 9 \\
\hline 385 & KLASKY & CAI & 57 & 1 \\
\hline 386 & KLASKY & CAI & 58 & 2 \\
\hline 387 & KLASKY & CAl & 58 & 21 \\
\hline 388 & KLASKY & CAI & 59 & 4 \\
\hline 389 & KLASKY & CAl & 59 & 5 \\
\hline 390 & KLASKY & CAI & 59 & 8 \\
\hline 391 & KLASKY & CAI & 59 & 10 \\
\hline 393 & KLASKY & CAl & 60 & 1 \\
\hline 394 & KLASKY & CAl & 60 & 3 \\
\hline 395 & KLASKY & CAl & 60 & 9 \\
\hline 396 & KLASKY & CAl & 61 & 22 \\
\hline 397 & DAKE & CA1 & 63 & 11 \\
\hline 398 & DAKE & CAI & 63 & 17 \\
\hline 399 & DAKE & CAI & 63 & 24 \\
\hline 400 & STRAUSS & CA2 & 14 & 17 \\
\hline 401 & STRAUSS & CA2 & 14 & 22 \\
\hline 402 & STRAUSS & CA2 & 14 & 22 \\
\hline 403 & STRAUSS & CA2 & 15 & 7 \\
\hline 404 & STRAUSS & $\mathrm{CA}_{2}$ & 15 & 9 \\
\hline 405 & STRAUSS & CA2 & 15 & 10 \\
\hline 406 & STRAUSS & CA2 & 15 & 23 \\
\hline 407 & STRAUSS & $\mathrm{CA} 2$ & 17 & 6 \\
\hline 408 & CABASSO & $\mathrm{CA2}$ & 18 & 13 \\
\hline 409 & CABASSO & CA2 & 18 & 22 \\
\hline 410 & CABASSO & CA2 & 18 & 22 \\
\hline 411 & CABASSO & $\mathrm{CA2}$ & 20 & 21 \\
\hline 412 & CABASSO & CA2 & 21 & 5 \\
\hline 413 & CABASSO & $\mathrm{CA} 2$ & 21 & 7 \\
\hline 414 & CABASSO & $\mathrm{CA} 2$ & 21 & 9 \\
\hline 415 & CABASSO & $\mathrm{CA}_{2}$ & 21 & 18 \\
\hline 416 & CABASSO & CA2 & 21 & 24 \\
\hline 417 & CABASSO & CA2' & 22 & 20 \\
\hline 418 & CABASSO & CA2 & 22 & 25 \\
\hline 419 & CABASSO & CA2 & 23 & 2 \\
\hline 420 & CABASSO & CA2 & 23 & 2 \\
\hline 421 & CABASSO & CA2 & 23 & 17 \\
\hline 422 & CABASSO & $\mathrm{CA} 2$ & 23 & 18 \\
\hline 423 & CABASSO & $\mathrm{CA} 2$ & 23 & 14 \\
\hline 424 & CABASSO & CA2 & 23 & 21 \\
\hline 425 & CABASSO & CA2 & 25 & 5 \\
\hline 426 & CABASSO & $\mathrm{CA2}$ & 25 & $\ddot{13}$ \\
\hline 427 & CABASSO & $\mathrm{CA} 2$ & 27 & 6 \\
\hline 428 & CABASSO & CA2 & 28 & 11 \\
\hline 429 & KELLEY & CA2 & 30 & 17 \\
\hline 430 & KELLEY & CA2 & 130 & 19 \\
\hline 431 & KELLEY & $\mathrm{CA} 2$ & 30 & 24 \\
\hline 432 & KELLEY & $\mathrm{CA} 2$ & 31 & 1 \\
\hline 433 & KELLEY & $\overline{C A 2}$ & 31 & 3 \\
\hline 434 & KELLEY & $\mathrm{CA}_{2}$ & 31 & 6 \\
\hline 435 & KELLEY & CA2 & 31 & 17 \\
\hline 436 & KELLEY & $\mathrm{CA}_{2}$ & 31 & 25 \\
\hline 437 & KELLEY & $\mathrm{CA2}$ & 32 & 4 \\
\hline 438 & KELLEY & $\mathrm{CA2}$ & 33 & 3 \\
\hline 439 & KELLEY & $\mathrm{CA} 2$ & 34 & 6 \\
\hline
\end{tabular}

\begin{tabular}{|c|c|c|c|c|c|}
\hline 440 & KELLEY & CA2 & 35 & 14 & \\
\hline 441 & KELLEY & CA2 & 35 & 18 & \\
\hline 442 & KELLEY & CA2 & 36 & 13 & \\
\hline 443 & EICHELBERGER & CA & A2 & 38 & 21 \\
\hline 444 & EICHELBERGER & CA & A2 & 39 & 16 \\
\hline 445 & EICHELBERGER & CA & A2 & 39 & 20 \\
\hline 446 & EICHELBERGER & CA & A2 & 39 & 23 \\
\hline 447 & KELLEY & CA2 & 40 & 8 & \\
\hline 448 & WARREN & OH1 & 23 & 24 & \\
\hline 449 & WARREN & OH1 & 24 & 11 & \\
\hline 450 & WARREN & $\mathrm{OH} 1$ & 24 & 18 & \\
\hline 451 & WARREN & OH1 & 24 & 18 & \\
\hline 452 & WARREN & OH1 & 24 & 18 & \\
\hline 453 & WARREN & $\mathrm{OH} 1$ & 25 & 6 & \\
\hline 454 & WARREN & OH1 & 25 & 6 & \\
\hline 455 & WARREN & OH1 & 25 & 6 & \\
\hline 456 & WARREN & OH1 & 25 & 11 & \\
\hline 457 & BLOCK & $\mathrm{OH} 1$ & 28 & 25 & \\
\hline 458 & BLOCK & OH1 & 28 & 5 & \\
\hline 459 & BLOCK & OH1 & 27 & 14 & \\
\hline 460 & BLOCK & OH1 & 28 & 15 & \\
\hline 461 & BLOCK & $\mathrm{OH} 1$ & 27 & 4 & \\
\hline 462 & BLOCK & OH1 & 29 & 8 & \\
\hline 463 & BLOCK & OH1 & 29 & 8 & \\
\hline 464 & \multicolumn{2}{|c|}{ WEATHERINGTON-RICE } & $\mathrm{OHI}$ & 1130 & 14 \\
\hline 465 & \multicolumn{2}{|c|}{ WEATHERINGTON-RICE } & $\mathrm{OHI}$ & 30 & 3 \\
\hline 466 & GANIS & $\mathrm{OH} 1$ & 31 & 19 & \\
\hline 467 & GANIS & OH1 & 32 & 21 & \\
\hline 468 & GANIS & OH1 & 38 & 16 & \\
\hline 469 & PERERA & OH1 & 44 & 10 & \\
\hline 470 & PERERA & OHI & 45 & 2 & \\
\hline 471 & PERERA & OH1 & 45 & 3 & \\
\hline 472 & COOK & OH1 & 45 & 23 & \\
\hline 473 & COOK & $\mathrm{OH} 1$ & 48 & 3 & \\
\hline 474 & COOK & $\mathrm{OH} 1$ & 48 & 5 & \\
\hline 475 & McKENNA & $\mathrm{OH} 1$ & 49 & 9 & \\
\hline 476 & McKENNA & OH1 & 49 & 18 & \\
\hline 477 & McKENNA & OHI & 50 & 2 & \\
\hline 478 & McKENNA & OH1 & 50 & 7 & \\
\hline 479 & McKENNA & OH1 & 50 & 9 & \\
\hline 480 & \multicolumn{2}{|c|}{ ENERGY RESEARCH } & \multirow{2}{*}{\multicolumn{2}{|c|}{$32 \quad 17$}} & 0 \\
\hline 481 & DAM & $\mathrm{DC} 1$ & & & \\
\hline 482 & HENDRICKS & DCl & 34 & 17 & \\
\hline 483 & JOHNSRUD & DC1 & 42 & 3 & \\
\hline 484 & OLSON & DC2 & 42 & 12 & \\
\hline 485 & GRESALFI & DC2 & 44 & 15 & \\
\hline 486 & SINCLAIR & OK2 & 46 & 5 & \\
\hline 487 & BARFIELD & OK2 & 47 & 18 & \\
\hline 488 & GEARY & OK2 & 86 & 7 & \\
\hline 489 & BARTON & OK1 & 51 & 6 & \\
\hline 490 & FULLER & CA1 & 41 & 9 & \\
\hline 491 & STRAUSS & CA2 & 15 & 23 & \\
\hline 492 & STRAUSS & CA2 & 15 & 23 & \\
\hline 493 & CABASSO & CA2 & 25 & 13 & \\
\hline 494 & CABASSO & $\mathrm{CA2}$ & 25 & 13 & \\
\hline 495 & KELLEY & $\mathrm{CA} 2$ & 31 & 25 & \\
\hline 496 & GOLTEIN & CAl & 21 & 14 & \\
\hline 497 & YOUNG & CA1 & 45 & 3 & \\
\hline 498 & KLASKY & CA1 & 53 & 20 & \\
\hline 499 & D'ARRIGO & DC2 & 36 & 18 & \\
\hline
\end{tabular}


Appendix E

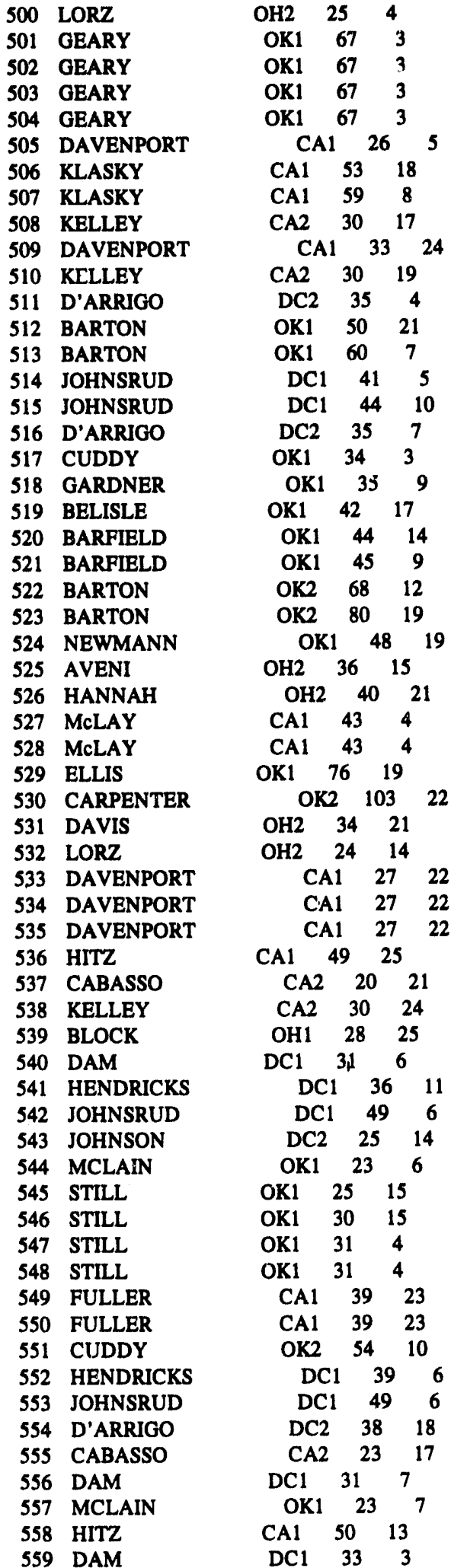

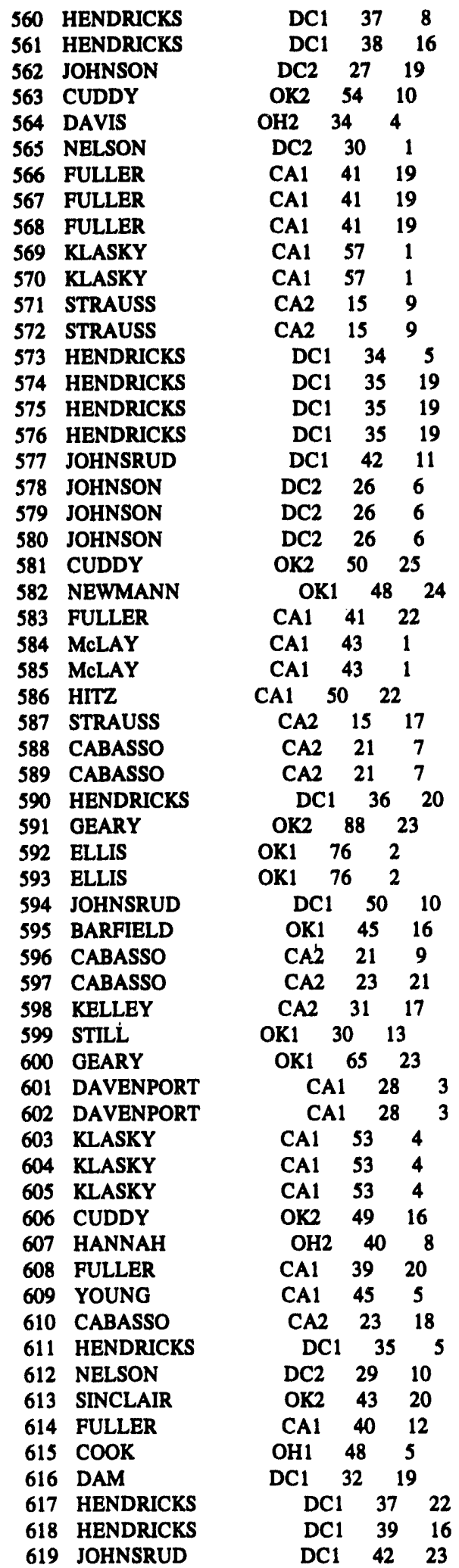




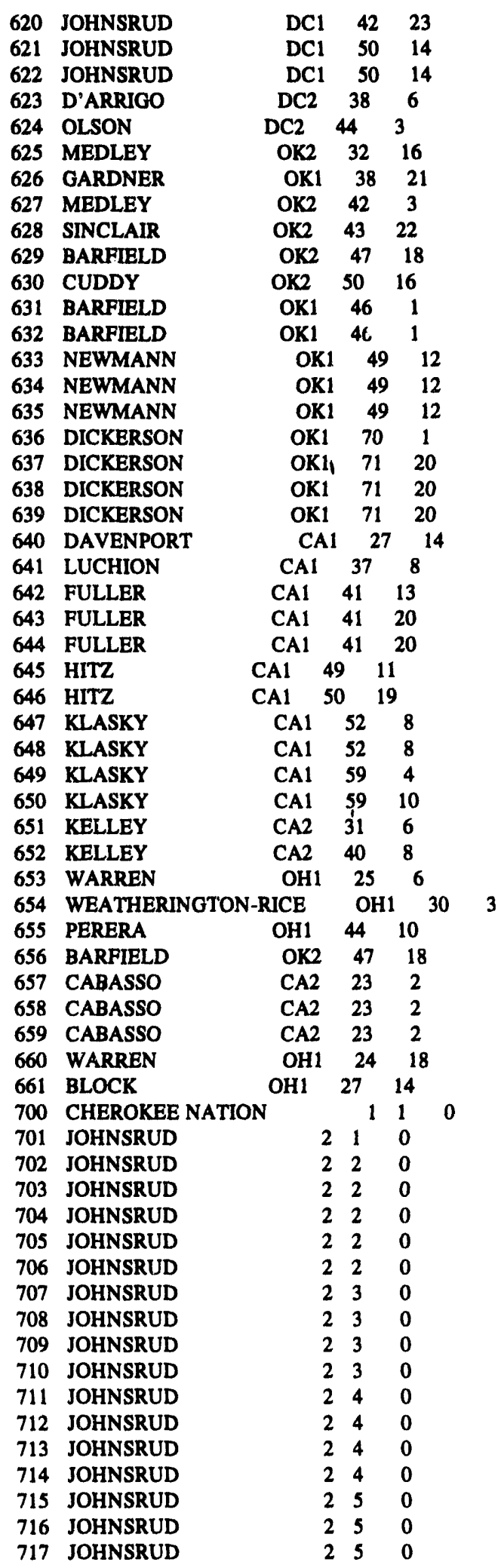

\begin{tabular}{|c|c|c|c|c|}
\hline 718 & JOHNSRUD & 2 & 5 & 0 \\
\hline 719 & JOHNSRUD & 2 & 5 & 0 \\
\hline 720 & JOHNSRUD & 2 & 6 & 0 \\
\hline 721 & JOHNSRUD & 2 & 6 & 0 \\
\hline 722 & JOHNSRUD & 2 & 6 & 0 \\
\hline 723 & JOHNSRUD & 2 & 6 & 0 \\
\hline 724 & JOHNSRUD & 2 & 6 & 0 \\
\hline 725 & JOHNSRUD & 2 & 6 & 0 \\
\hline 726 & JOHNSRUD & 2 & 6 & $\mathbf{0}$ \\
\hline 727 & JOHNSRUD & 2 & 6 & 0 \\
\hline 728 & JOHNSRUD & 2 & 6 & 0 \\
\hline 729 & JOHNSRUD & 2 & 6 & 0 \\
\hline 730 & STATE OF NEVADA & & 3 & 5 \\
\hline 731 & STATE OF NEVADA & & 3 & 5 \\
\hline 732 & STATE OF NEVADA & & 3 & 5 \\
\hline 734 & STATE OF NEVADA & & 3 & 8 \\
\hline 735 & STATE OF NEVADA & & 3 & 8 \\
\hline 736 & STATE OF NEVADA & & 3 & 8 \\
\hline 739 & STATE OF NEVADA & & 3 & 8 \\
\hline 741 & STATE OF NEVADA & & 3 & 7 \\
\hline 743 & STATE OF NEVADA & & 3 & 9 \\
\hline 744 & STATE OF NEVADA & & 3 & 9 \\
\hline 745 & STATE OF NEVADA & & 3 & 10 \\
\hline 746 & STATE OF NEVADA & & 3 & 10 \\
\hline 747 & STATE OF NEVADA & & 3 & 10 \\
\hline 748 & STATE OF NEVADA & & 3 & 10 \\
\hline 749 & HITZ & 1 & 0 & \\
\hline
\end{tabular}

750 HITZ 41

751 HITZ 4110

752 HITZ 4110

753 HITZ 4110

755 HITZ 4110

756 HITZ 4220

$\begin{array}{lllll}757 & \text { HITZ } & 4 & 2 & 0\end{array}$

758 HITZ 4220

$\begin{array}{lllll}759 & \text { HITZ } & 4 & 2 & 0\end{array}$

760 HITZ $42 \quad 0$

$\begin{array}{lllll}761 & \text { HITZ } & 4 & 2 & 0\end{array}$

762 BIZZARRO

763 BIZZARRO

764 KLINE

765 KLINE

766 KLINE

767 KLINE

768 KLINE

769 KLINE

770 KLINE

771 KLINE

772 KLINE

773 KLINE

774 KLINE

775 KLINE

776 KLINE

777 KLINE

778 KLINE

779 KLINE

780 KLINE

781 KLINE

782 KLINE

783 KLINE

$\begin{array}{llll} & 5 & 1 & 0 \\ & 5 & 1 & 0 \\ 6 & 1 & 0 \\ 6 & 1 & 0 \\ 6 & 1 & 0 \\ 6 & 1 & 0 \\ 6 & 1 & 0 \\ 6 & 1 & 0 \\ 6 & 2 & 0 \\ 6 & 2 & 0 \\ 6 & 2 & 0 \\ 6 & 2 & 0 \\ 6 & 2 & 0 \\ 6 & 2 & 0 \\ 6 & 2 & 0 \\ 6 & 2 & 0 \\ 6 & 2 & 0 \\ 6 & 3 & 0 \\ 6 & 2 & 0 \\ 6 & 2 & 0 \\ 6 & 2 & 0 \\ 6 & 2 & 0\end{array}$




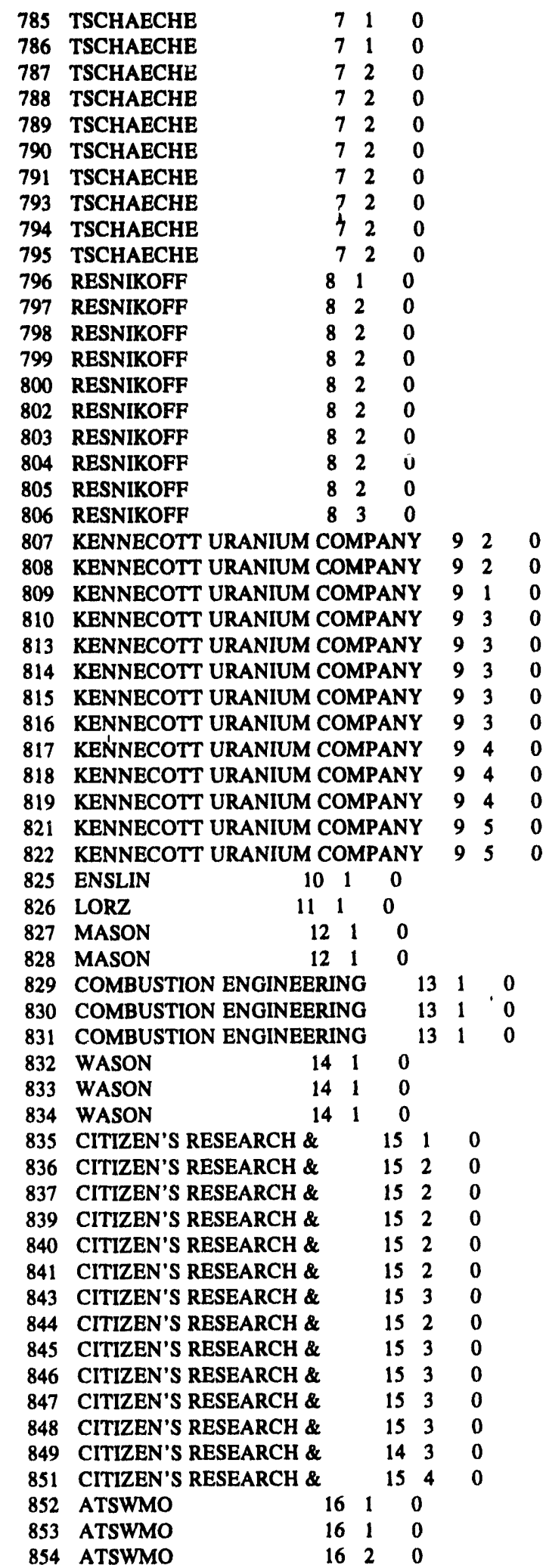

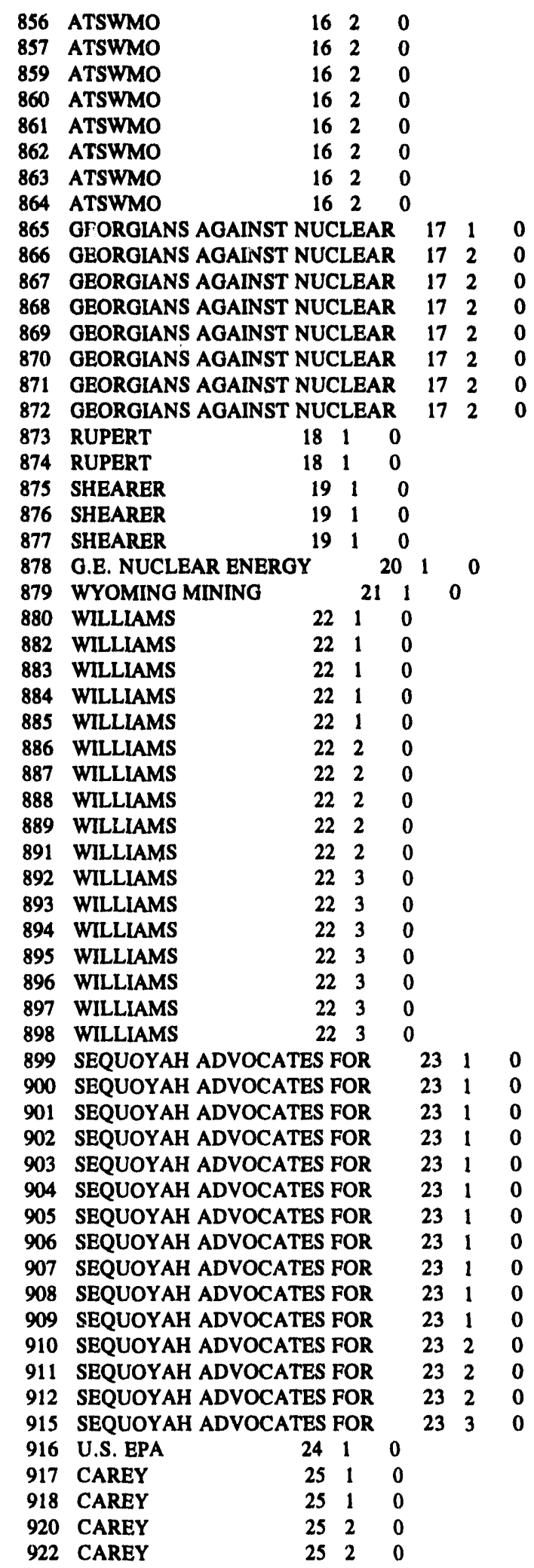




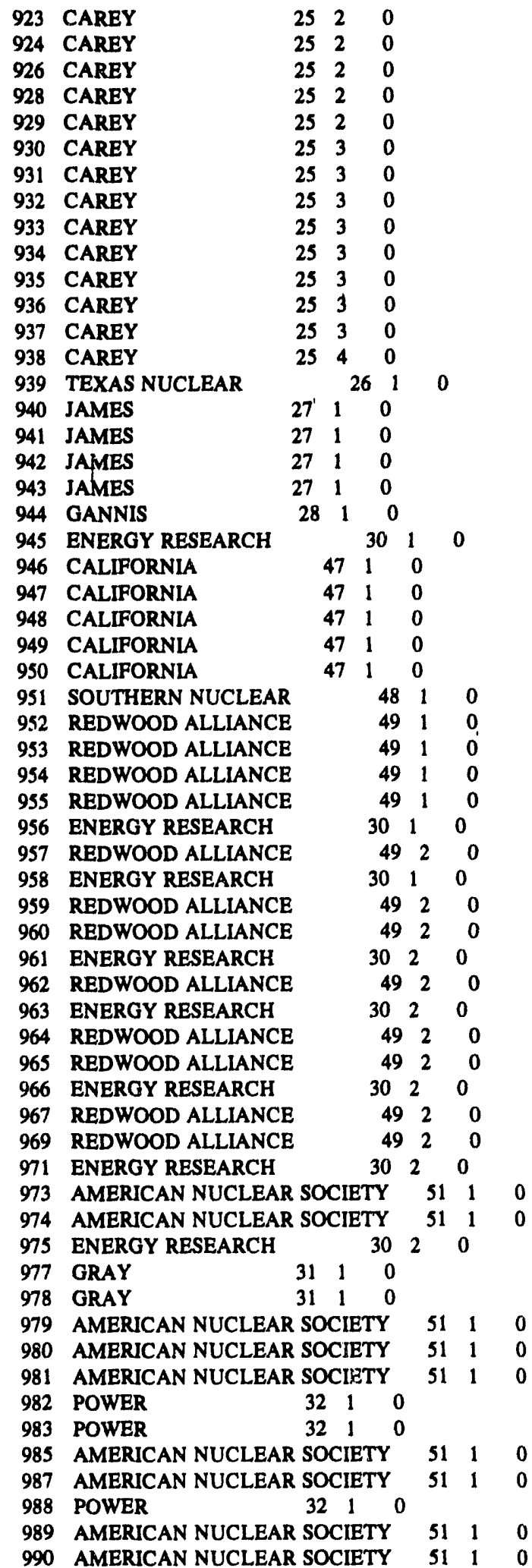

\begin{tabular}{|c|c|c|c|c|}
\hline 91 & 321 & & & \\
\hline 92 & WER & & & \\
\hline 93 & AMERICAN NUCLEAR SOCIETY & 51 & 2 & $\mathbf{0}$ \\
\hline 94 & AMERICAN NUCLEAR SOCIETY & 51 & 2 & \\
\hline 95 & AMERICAN NUCLEAR SOCIETY & 51 & 2 & \\
\hline 96 & POWER & & & \\
\hline 1 & AMERICAN NUCLEAR SOCIETY & 51 & 2 & 0 \\
\hline & POWER & & & \\
\hline 00 & AMERICAN NUCLEAR SOCIETY & 51 & 2 & $\mathbf{0}$ \\
\hline 01 & POWER & & & \\
\hline 02 & AMERICAN NUCLEAR SOCIETY & 51 & 2 & $\mathbf{0}$ \\
\hline 03 & AMERICAN NUCLEAR SOCIETY & 51 & 2 & \\
\hline 04 & POWER & & & \\
\hline 05 & POWER & & & \\
\hline 6 & STERNGLASS & 0 & & \\
\hline 07 & POWER & & & \\
\hline 08 & POWER & & & ' \\
\hline 109 & IRIGONEGARAY \& ASSOCIATES & 53 & 1 & $\mathbf{0}$ \\
\hline 10 & IRIGONEGARAY \& ASSOCIATES & 53 & 1 & 0 \\
\hline 11 & IRIGONEGARAY \& ASSOCIATES & 53 & 1 & 0 \\
\hline & POWER & & & \\
\hline 13 & IRIGONEGARAY \& ASSOCIATES & 53 & 1 & 0 \\
\hline & POWER & & & \\
\hline 15 & IRIGONEGARAY \& ASSOCIATES & 53 & 1 & 0 \\
\hline & POWER & & & \\
\hline 17 & IRIGONEGARAY \& ASSOCIATES & 53 & 1 & 0 \\
\hline 18 & IRIGONEGARAY \& ASSOCIATES & 53 & 1 & 0 \\
\hline 19 & POWER & & & \\
\hline 20 & IRIGONEGARAY \& ASSOCIATES & 53 & 2 & 0 \\
\hline 21 & AY \& ASSOCIATES & 53 & 2 & 0 \\
\hline 22 & POWER & & & \\
\hline 23 & WORLD W & 331 & 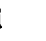 & 0 \\
\hline 24 & NSTITUTE & 331 & 1 & 0 \\
\hline 25 & TCH INSTITUTE & 331 & & 0 \\
\hline 6 & WORLD WATCH INSTITUTE & 331 & & 0 \\
\hline 7 & MINING CONGRESS & 34 & 2 & 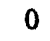 \\
\hline 8 & MINING CONGRESS & 34 & 2 & 0 \\
\hline 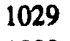 & RAY \& ASSOCIATES & 53 & 2 & 0 \\
\hline 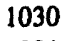 & MINING CONGRESS & 34 & 2 & 0 \\
\hline 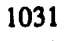 & \& ASSOCLATES & 53 & 2 & 0 \\
\hline & NG CONGRESS & 34 & 2 & 0 \\
\hline 3 & C CONGRESS & 34 & 2 & 0 \\
\hline 5 & AINING CONGRESS & 34 & 3 & 0 \\
\hline 7 & 541 & 0 & & \\
\hline 8 & IEER \& N & 0 & & \\
\hline 39 & NGRESS & 34 & 3 & 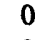 \\
\hline 1040 & NG CONGRESS & 34 & 4 & 0 \\
\hline 41 & NG CONGRESS & 34 & 6 & 0 \\
\hline 42 & MINING CONGRESS & 34 & 6 & 0 \\
\hline 1043 & MINING CONGRESS & 34 & 7 & 0 \\
\hline 1044 & IEER \& NACE & 0 & & \\
\hline 1045 & AMERICAN MINING CONGRESS & 34 & 8 & 0 \\
\hline 1046 & IEER \& NACE & 0 & & \\
\hline 1047 & IEER \& NACE & 0 & & \\
\hline 1048 & IEER \& NACE & 0 & & \\
\hline 349 & AMERICAN MINING CONGRESS & 34 & 8 & 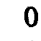 \\
\hline 1050 & MINING CONGRESS & 34 & 8 & \\
\hline 51 & AMERICAN MINING CONGRESS & 34 & 8 & 0 \\
\hline & IEER \& $\mathbf{N}$ & 0 & & \\
\hline & IEER \& NAC & 0 & & \\
\hline
\end{tabular}




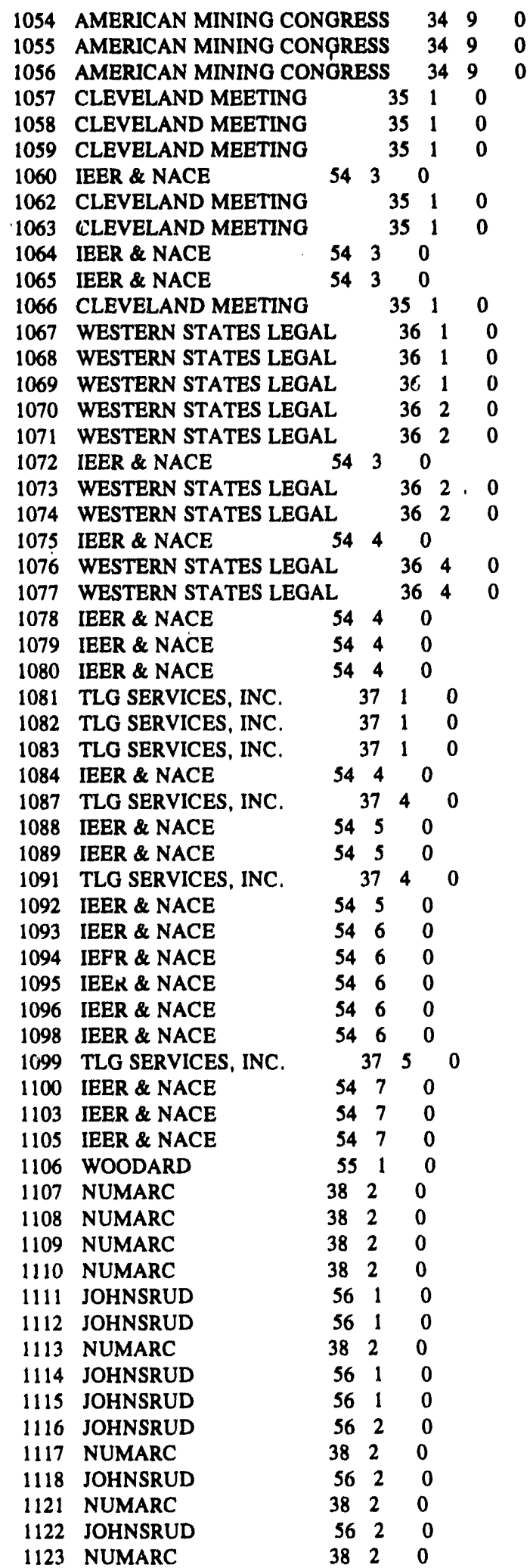

\begin{tabular}{|c|c|c|c|c|}
\hline 1124 & JOHNSRUD & 56 & 2 & 0 \\
\hline 1125 & NUMARC & 38 & 2 & 0 \\
\hline 1126 & JOHNSRUD & 56 & 3 & 0 \\
\hline 1127 & JOHNSRUD & 56 & 3 & 0 \\
\hline 1128 & NUMARC & 38 & 3 & 0 \\
\hline 1129 & JOHNSRUD & 56 & 3 & 0 \\
\hline 1130 & NUMARC & 38 & 3 & 0 \\
\hline 1131 & JOHNSRUD & 56 & 3 & 0 \\
\hline 1132 & JOHNSRUD & 56 & 3 & 0 \\
\hline 1133 & JOHNSRUD & 56 & 4 & 0 \\
\hline 1134 & NUMARC & 38 & 3 & 0 \\
\hline 1135 & JOHNSRUD & 56 & 4 & 0 \\
\hline 1137 & JOHNSRUD & 56 & 4 & 0 \\
\hline 1138 & JOHNSRUD & 56 & 4 & 0 \\
\hline 1139 & JOHNSRUD & 56 & 4 & 0 \\
\hline 1140 & JOHNSRUD & 56 & 4 & 0 \\
\hline 1141 & JOHNSRUD & 56 & 5 & 0 \\
\hline 1142 & JOHNSRUD & 56 & 5 & 0 \\
\hline 1143 & JOHNSRUD & 56 & 5 & 0 \\
\hline 1144 & JOHNSRUD & 56 & 5 & 0 \\
\hline 1145 & JOHNSRUD & 56 & 5 & 0 \\
\hline 1146 & JOHNSRUD & 56 & 5 & 0 \\
\hline 1147 & JOHNSRUD & 56 & 5 & 0 \\
\hline 1148 & JOHNSRUD & 56 & 5 & 0 \\
\hline 1149 & JOHNSRUD & 56 & 5 & 0 \\
\hline 1150 & JOHNSRUD & 56 & 5 & 0 \\
\hline 1151 & NUMARC & 38 & 3 & 0 \\
\hline 1152 & JOHNSRUP & 56 & 5 & 0 \\
\hline 1153 & JOHNSRUD & 56 & 6 & 0 \\
\hline 1154 & JOHNSRUD & 56 & 6 & 0 \\
\hline 1155 & NUMARC & 38 & 3 & 0 \\
\hline 1156 & NUMARC & 38 & 3 & 0 \\
\hline 1157 & JOHNSRUD & 56 & 6 & 0 \\
\hline 1158 & NUMARC & 38 & 5 & 0 \\
\hline 1160 & NUMARC & 38 & 5 & 0 \\
\hline 1161 & JOHNSRUD & 56 & 6 & 0 \\
\hline 1162 & JOHNSRUD & 56 & 6 & 0 \\
\hline 1163 & NUMARC & 38 & 5 & 0 \\
\hline 1164 & NUMARC & 38 & 5 & 0 \\
\hline 1165 & NUMARC & 38 & 5 & 0 \\
\hline 1166 & NUMARC & 38 & 3 & 0 \\
\hline 1167 & JOHNSRUD & 56 & 6 & 0 \\
\hline 1168 & JOHNSRUD & 56 & 6 & 0 \\
\hline 1169 & JOHNSRUD & 56 & 6 & 0 \\
\hline 1170 & JOHNSRUD & 56 & 6 & 0 \\
\hline 1171 & JOHNSRUD & 56 & 7 & 0 \\
\hline 1174 & NUMARC & 38 & 7 & 0 \\
\hline 1176 & NUMARC & 38 & 7 & 0 \\
\hline 1177 & JOHNSRUD & 56 & 7 & 0 \\
\hline 1178 & NUMARC & 38 & 7 & 0 \\
\hline 1179 & NUMARC & 38 & 7 & 0 \\
\hline 1180 & JOHNSRUD & 56 & 7 & 0 \\
\hline 1181 & JOHNSRUD & 56 & 7 & 0 \\
\hline 1182 & JOHNSRUD & 56 & 7 & 0 \\
\hline 1187 & JOHNSRUD & 56 & 7 & 0 \\
\hline 1188 & NUMARC & 38 & 8 & 0 \\
\hline 1189 & JOHNSRUD & 56 & 7 & 0 \\
\hline 1191 & JOHNSRUD & 56 & 8 & 0 \\
\hline 1192 & JOHNSRUD & 56 & 8 & 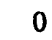 \\
\hline 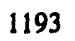 & NUMARC & 38 & 8 & \\
\hline
\end{tabular}




\begin{tabular}{|c|c|c|c|c|}
\hline 1194 & NUMARC & 38 & 8 & 0 \\
\hline 1195 & JOHNSRUD & 56 & 8 & 0 \\
\hline 1196 & JOHNSRUD & 56 & 8 & 0 \\
\hline 1197 & JOHNSRUD & 56 & 8 & 0 \\
\hline 1198 & JOHNSRUD & 56 & 8 & 0 \\
\hline 1199 & JOHNSRUD & 56 & 8 & 0 \\
\hline 1200 & JOHNSRUD & 56 & 8 & 0 \\
\hline 1201 & JOHNSRUD & 56 & 8 & 0 \\
\hline 1202 & NUMARC & 38 & 9 & 0 \\
\hline 1203 & JOHNSRUD & 56 & 8 & 0 \\
\hline 1205 & JOHNSRUD & 56 & 8 & 0 \\
\hline 1206 & NUMARC & 38 & 9 & 0 \\
\hline 1207 & NUMARC & 38 & 9 & 0 \\
\hline 1208 & JOHNSRUD & 56 & 9 & 0 \\
\hline 1209 & JOHNSRUD & 56 & 9 & 0 \\
\hline 1210 & JOHNSRUD & 56 & 9 & 0 \\
\hline 1212 & NUMARC & 38 & 9 & 0 \\
\hline 1213 & NUMARC & 38 & 9 & 0 \\
\hline 1214 & JOHNSRUD & 56 & 9 & 0 \\
\hline 1215 & GOITEIN & 571 & 1 & 0 \\
\hline 1216 & GOITEIN & 571 & 1 & 0 \\
\hline 1217 & GOITEIN & 571 & 1 & 0 \\
\hline 1218 & NUMARC & 38 & 9 & 0 \\
\hline 1219 & GOITEIN & 572 & 2 & 0 \\
\hline 1220 & GOITEIN & 572 & 2 & 0 \\
\hline 1222 & $\mathbf{G}$ & 572 & & \\
\hline
\end{tabular}

1223 BECHTEL ENVIRONMENTAL,

1224 BECHTEL ENVIRONMENTAL,

1225 BECHTEL ENVIRONMENTAL,

1226 NUMARC 3810

1227 GEARY $39 \quad 1 \quad 0$

1228 BECHTEL ENVIRONMENTAL, 58,2

1229 BECHTEL ENVIRONMENTAL, $\quad 58 \quad 2 \quad 0$

1230 MARINO $40 \quad 1 \quad 0$

1231 BECHTEL ENVIRONMENTAL, $\quad 58 \quad 2 \quad 0$

1233 BECHTEL ENVIRONMENTAL, $\quad 58 \quad 2 \quad 0$

1234 COMMONWEALTH EDISON $\quad 41 \quad 1 \quad 0$

1235 COMMONWEALTH EDISON $\quad 41 \quad 1 \quad 0$

$\begin{array}{lllll}1236 & \text { COMMONWEALTH EDISON } & 41 & 2 & 0\end{array}$

1237 COMMONWEALTH EDISON $41 \quad 2 \quad 0$

1238 BECHTEL ENVIRONMENTAL, $58 \quad 2 \quad 0$

1239 BECHTEL ENVIRONMENTAL, $\quad \begin{array}{lll}58 & 2 & 0\end{array}$

1240 BECHTEL ENVIRONMENTAL, $\quad 58 \quad 2 \quad 0$

1241 COMMONWEALTH EDISON 412

1242 COMMONWEALTH EDISON 41120

1243 BECHTEL ENVIRONMENTAL, $58 \quad 2 \quad 0$

1244 BECHTEL ENVIRONMENTAL, $58 \quad 2 \quad 0$

1245 COMMONWEALTH EDISON 41220

1246 COMMONWEALTH EDISON $\quad 41 \quad 2 \quad 0$

1247 COMMONWEALTH EDISON $\quad 41 \quad 3 \quad 0$

1248 COMMONWEALTH EDISON $\quad 4130$

1249 COMMONWEALTH EDISON $41 \quad 3 \quad 0$

1250 COMMONWEALTH EDISON $41 \quad 3 \quad 0$

1251 COMMONWEALTH EDISON 41310

1252 COMMONWEALTH EDISON $\quad 41 \quad 3 \quad 0$

1254 COMMONWEALTH EDISON $41 \quad 3 \quad 0$

1255 COMMONWEALTH EDISON $\quad .41330$

1256 COMMONWEALTH EDISON $\quad 41400$

1257 COMMONWEALTH EDISON $\quad 41440$

1258 COMMONWEALTH EDISON

\begin{tabular}{|c|c|c|c|c|}
\hline 1259 & COMMONWEALTH EDISON & 414 & & 0 \\
\hline 1260 & COMMONWEALTH EDISON & 414 & 4 & $\mathbf{0}$ \\
\hline 1261 & COMMONWEALTH EDISON & 414 & 4 & 0 \\
\hline 1262 & COMMONWEALTH EDISON & 415 & 5 & 0 \\
\hline 1263 & ULAN & 0 & & \\
\hline 1264 & NUCLEAR INFORMATION AND & 43 & 1 & 0 \\
\hline 1265 & NUCLEAR INFORMATION AND & 43 & 1 & 0 \\
\hline 1266 & NUCLEAR INFORMATION AND & 43 & 1 & 0 \\
\hline 1267 & NUCLEAR INFORMATION AND & 43 & 2 & 0 \\
\hline 1271 & NUCLEAR INFORMATION AND & 43 & 2 & 0 \\
\hline 1272 & NUCLEAR INFORMATION AND & 43 & 3 & 0 \\
\hline 1273 & NUCLEAR INFORMATION AND & 43 & 3 & 0 \\
\hline 1274 & NUCLEAR INFORMATION AND & 43 & 3 & 0 \\
\hline 1275 & CONCERNED CITIZENS FOR & 441 & & 0 \\
\hline 1276 & CONCERNED CITIZENS FOR & 441 & & 0 \\
\hline 1277 & NUCLEAR INFORMATION AND & 43 & 3 & 0 \\
\hline 1278 & FULLER & 0 & & \\
\hline 1279 & FULLER & 0 & & \\
\hline 1281 & NUCLEAR INFORMATION AND & 43 & 4 & 0 \\
\hline 1282 & NUCLEAR INFORMATION AND & 43 & 4 & 0 \\
\hline 1283 & NUCLEAR INFORMATION AND & 43 & 4 & 0 \\
\hline 1284 & UTILITY.DECOMMISSIONING & 462 & 2 & 0 \\
\hline 1285 & UTILITY DECOMMISSIONING & 464 & 4 & 0 \\
\hline 1286 & NUCLEAR INFORMATION AND & 43 & 5 & 0 \\
\hline 1287 & UTILITY DECOMMISSIONING & 464 & & 0 \\
\hline 1288 & STATE OF NEVADA & 38 & 0 & \\
\hline 1289 & STATE OF NEVADA & 38 & 0 & \\
\hline 1290 & STATE OF NEVADA & 37 & & \\
\hline 1291 & RESNIKOFF & $\mathbf{0}$ & & \\
\hline 1292 & RESNIKOFF & 0 & & \\
\hline 1293 & WASON & 0 & & \\
\hline 1294 & ATSWMO & 0 & & \\
\hline 1295 & ATSWMO & 0 & & \\
\hline 1296 & WILLIAMS & 0 & & \\
\hline 1297 & CAREY & 0 & & \\
\hline 1298 & POWER & 0 & & \\
\hline 1299 & AMERICAN NUCLEAR SOCIETY & 51 & 1 & 0 \\
\hline 1300 & AMERICAN NUCLEAR SOCIETY & 51 & 1 & 0 \\
\hline 1301 & AMERICAN NUCLEAR SOCIETY & 51 & 1 & 0 \\
\hline 1302 & CITIZEN'S RESEARCH \& & 153 & 0 & \\
\hline 1303 & CITIZEN'S RESEARCH \& & 153 & $\mathbf{0}$ & \\
\hline 1304 & GEORGIANS AGAINST NUCLEA & AR & 2 & 0 \\
\hline 1305 & SEQUOYAH ADVOCATES FOR & 23 & 1 & 0 \\
\hline 1306 & STATE OF NEVADA & 35 & 0 & \\
\hline 1307 & STATE OF NEVADA & 38 & 0 & \\
\hline 1308 & STATE OF NEVADA & 39 & 0 & \\
\hline 1309 & STATE OF NEVADA & 39 & 0 & \\
\hline 1310 & CITIZEN'S RESEARCH \& & 153 & 0 & \\
\hline 1311 & CITIZEN'S RESEARCH \& & 153 & 0 & \\
\hline 1312 & CITIZEN'S RESEARCH \& & 153 & 0 & \\
\hline 1313 & GEORGIANS AGAINST NUCLEA & AR & 2 & 0 \\
\hline 1314 & HITZ & 0 & & \\
\hline 1315 & HITZ & 0 & & \\
\hline 1316 & HITZ & 0 & & \\
\hline 1317 & GEORGLA POWER COMPANY & 50 & 1 & 0 \\
\hline 1318 & STATE OF NEVADA & 310 & 0 & \\
\hline 1319 & ATSWMO & 0 & & \\
\hline 1320 & ATSWMO & 0 & & \\
\hline 1321 & ATSWMO & 0 & & \\
\hline & REDWOOD & 493 & & \\
\hline
\end{tabular}




\begin{tabular}{|c|c|c|c|c|c|c|}
\hline 1323 & JOHNSRUD & 21 & O & & & \\
\hline 1324 & WILLIAMS & 21 & 0 & 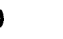 & & \\
\hline 1325 & CAREY & 2 & 0 & & & \\
\hline 1326 & CAREY & 2 & 0 & & & \\
\hline 1327 & CAREY & 2 & 0 & & & \\
\hline 1328 & KLINE & 2 & 0 & & & \\
\hline 1329 & KLINE & 2 & 0 & & & \\
\hline 1330 & KLINE & 2 & 0 & & & \\
\hline 1331 & TSCHAECHE & 7 & 2 & 0 & & \\
\hline 1332 & TSCHAECHE & 7 & 2 & 0 & & \\
\hline 1333 & TSCHAECHE & 7 & 2 & 0 & & \\
\hline 1334 & TSCHAECHE & 7 & 2 & 0 & & \\
\hline 1335 & TSCHAECHE & 7 & 2 & 0 & & \\
\hline 1336 & RESNIKOFF & 82 & 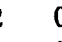 & 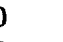 & & \\
\hline 1337 & RESNIKOFF & 82 & 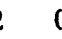 & 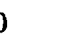 & & \\
\hline 1338 & RESNIKOFF & 82 & 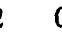 & 0 & & \\
\hline 1339 & CITIZEN'S RESEARCH \& & & 15 & 3 & 0 & \\
\hline 1340 & CITIZEN'S RESEARCH \& & & 15 & 3 & 0 & \\
\hline 1341 & REDWOOD ALLIANCE & & 49 & 1 & 0 & \\
\hline 1342 & REDWOOD ALLIANCE & & 49 & 1 & 0 & \\
\hline 1343 & REDWOOD ALLIANCE & & 49 & 2 & 0 & \\
\hline 1344 & AMERICAN NUCLEAR SO & CIET & TY & 51 & 2 & 0 \\
\hline 1345 & AMERICAN NUCLEAR SO & CIET & TY & 51 & 2 & 0 \\
\hline 1346 & POWER & 3 & 0 & & & \\
\hline 1347 & POWER & 3 & 0 & & & \\
\hline 1348 & HITZ & & 0 & & & \\
\hline 1349 & KLINE & 2 & 0 & & & \\
\hline 1350 & KLINE & 2 & 0 & & & \\
\hline 1351 & KLINE & 2 & 0 & & & \\
\hline 1352 & WILLIAMS & 223 & 3 & 0 & & \\
\hline 1353 & JAMES & 1 & 0 & & & \\
\hline 1354 & ENERGY RESEARCH & & 30 & 2 & 0 & \\
\hline 1355 & RESNIKOFF & 82 & 2 & 0 & & \\
\hline 1356 & SEQUOYAH ADVOCATES & FOR & & 23 & 2 & 0 \\
\hline 1357 & COMBUSTION ENGINEER & ING & & 13 & 1 & 0 \\
\hline 1358 & REDWOOD ALLIANCE & & 49 & 2 & 0 & \\
\hline 1359 & REDWOOD ALLIANCE & & 49 & 2 & 0 & \\
\hline 1360 & REDWOOD ALLIANCE & & 49 & 2 & 0 & \\
\hline 1361 & AMERICAN NUCLEAR SO & CIE & TY & 51 & 2 & 0 \\
\hline 1362 & TSCHAECHE & 7 & 2 & 0 & & \\
\hline 1363 & TSCHAECHE & 7 & 2 & 0 & & \\
\hline 1364 & TSCHAECHE & 7 & 2 & 0 & & \\
\hline 1365 & TSCHAECHE & 7 & 2 & 0 & & \\
\hline 1366 & TSCHAECHE & 7 & 2 & 0 & & \\
\hline 1367 & TSCHAECHE & 7 & 2 & 0 & & \\
\hline 1368 & TSCHAECHE & 7 & 2 & 0 & & \\
\hline 1369 & TSCHAECHE & 7 & 2 & 0 & & \\
\hline 1370 & WILLIAMS & 222 & 2 & 0 & & \\
\hline 1371 & WILLIAMS & 222 & 2 & 0 & & \\
\hline 1372 & CITIZEN'S RESEARCH \& & & 15 & 2 & 0 & \\
\hline 1373 & TSCHAECHE & 7 & 1 & 0 & & \\
\hline 1374 & TSCHAECHE & 7 & 1 & 0 & & \\
\hline 1375 & TSCHAECHE & 7 & 2 & 0 & & \\
\hline 1376 & TSCHAECHE & 7 & 2 & 0 & & \\
\hline 1377 & TSCHAECHE & 7 & 2 & 0 & & \\
\hline 1378 & TSCHAECHE & 7 & 2 & 0 & & \\
\hline 1379 & HITZ & 1 & 0 & & & \\
\hline 1380 & HITZ & 1 & 0 & & & \\
\hline 1381 & TSCHAECHE & 7 & 2 & 0 & & \\
\hline 1382 & JOHNSRU & 2 & 2 & 0 & & \\
\hline
\end{tabular}

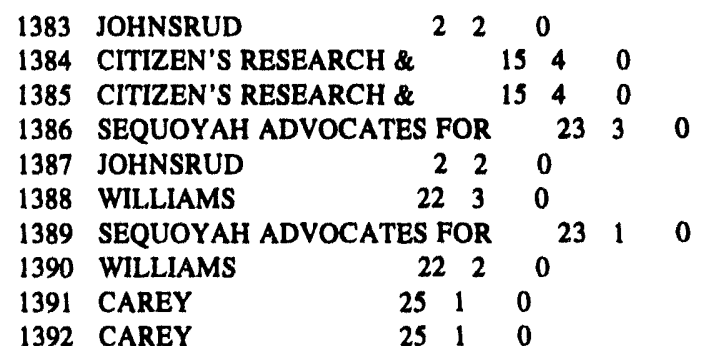




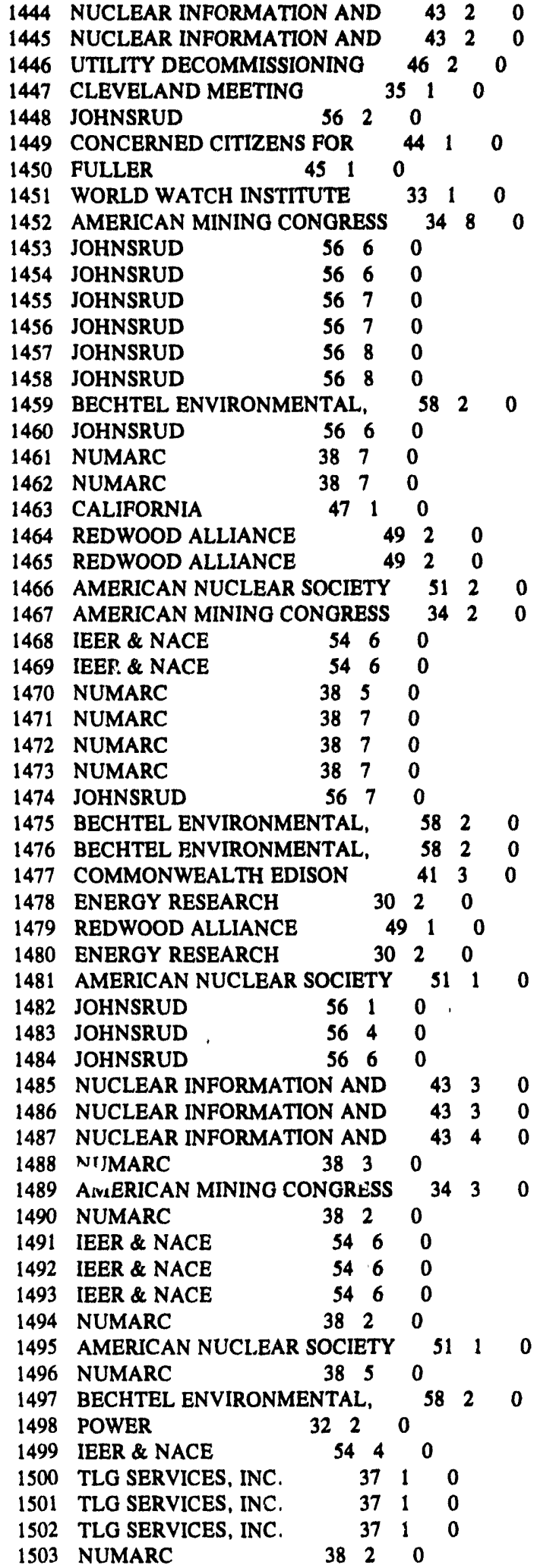

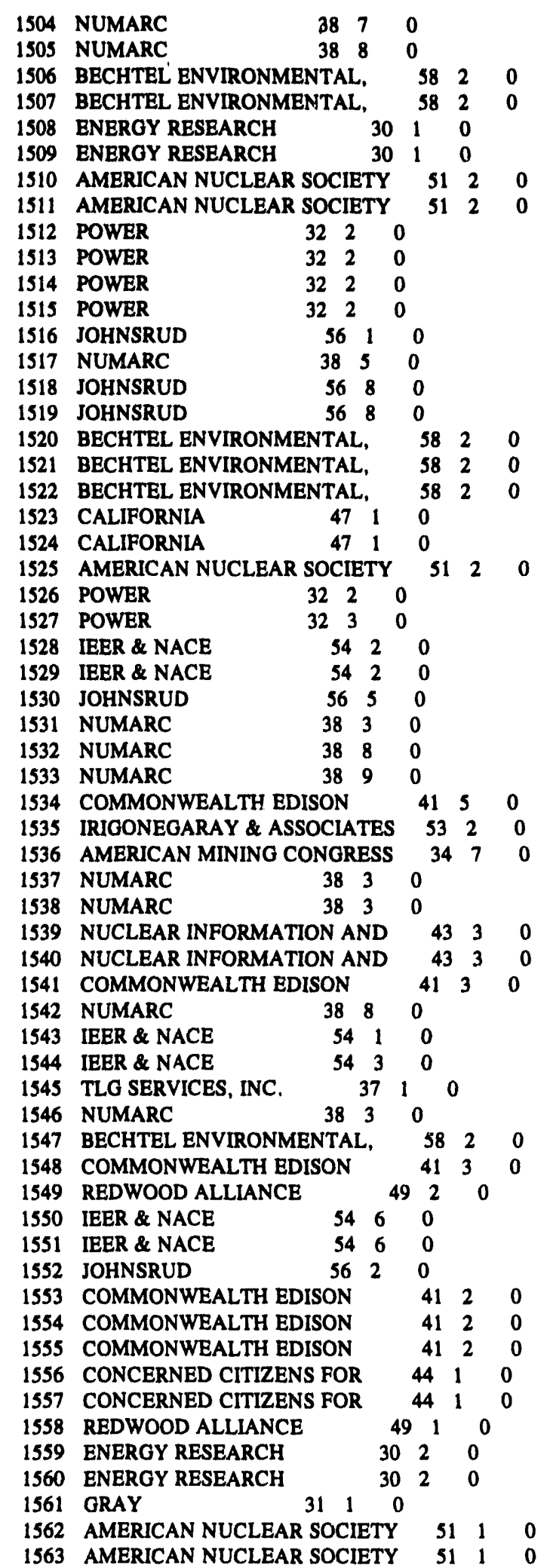




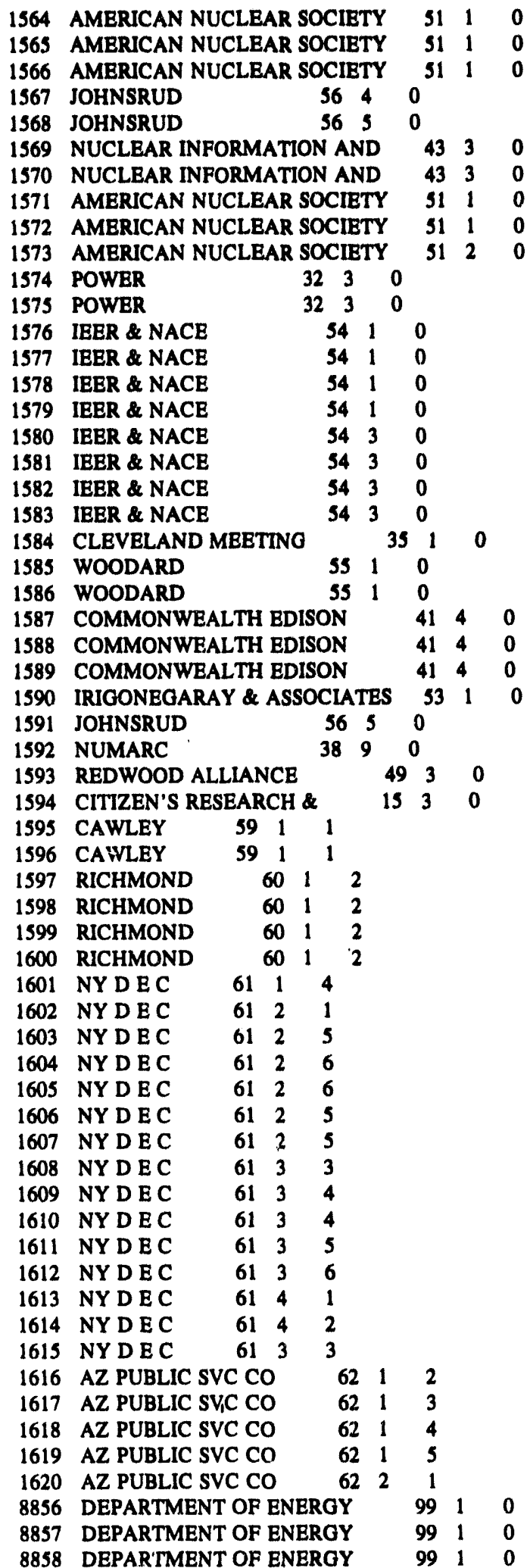

8859 DEPARTMENT OF ENEROY 8860 DEPARTMENT OF ENBRGY 8861 DEPARTMENT OF ENBRGY 8862 DEPARTMENT OF ENERGY 8863 DEPARTMENT OF ENEROY 8864 DEPARTMENT OF ENEROY 8865 DEPARTMENT OF ENEROY 8866 DEPARTMENT OF ENEROY 8867 DEPARTMENT OF ENERGY 8868 DEPARTMENT OF ENERGY 8869 DEPARTMENT OF ENERCY 8870 DEPARTMENT OF ENERGY 8871 DEPARTMENT OF BNERGY 8872 DEPARTMENT OF ENERGY 8873 DEPARTMENT OF ENERGY 8874 DEPARTMENT OP ENEROY 8875 DEPARTMENT OP ENBROY 8876 DEPARTMENT OF ENERGY 8877 DEPARTMENT OF ENERGY 8878 DEPARTMBNT OF ENEROY 8879 DEPARTMENT OF ENERGY 8880 DEPARTMENT OF ENERGY 8881 DEPARTMENT OF ENEROY 8882 DEPARTMENT OF ENERGY 8883 DEPARTMENT OF ENERGY 8884 DEPARTMENT OF BNERGY 8885 DEPARTMENT OF ENERGY 8886 DEPARTMENT OF ENEROY 8887 DEPARTMENT OF ENEROY 8888 DEPARTMENT OF ENEROY 8889 DEPARTMENT OF ENERGY 8890 DEPARTMENT OF ENBROY 8891 DEPARTMENT OF ENBROY 8892 DEPARTMENT OF ENERGY 8893 DEPARTMENT OF ENERGY 8894 DEPARTMENT OF ENERGY 8895 DEPARTMENT OF ENERGY 8896 DEPARTMENT OF ENERGY 8897 DEPARTMENT OF ENERGY 8898 DEPARTMENT OF ENERGY 8899 DEPARTMENT OF ENERGY 8900 DEPARTMENT OF ENERGY 8901 DEPARTMENT OF ENERGY 8902 DEPARTMENT OF ENERGY 8903 DEPARTMENT OF ENERGY 8904 DEPARTMENT OF ENEROY 8905 DEPARTMENT OF ENERGY 8906 DEPARTMENT OF ENERGY 8907 DEPARTMENT OF ENERGY 8908 DEPARTMENT OF ENERGY 8909 DEPARTMENT OF ENERGY 8910 DEPARTMENT OF ENERGY 8911 DEPARTMENT OF ENERGY 8912 DEPARTMENT OF ENERGY 8913 DEPARTMENT OF ENERGY 8914 DEPARTMENT OF ENERGY 8915 DEPARTMENT OF ENERGY 8916 DEPARTMENT OF ENERGY 8917 DEPARTMENT OF ENERGY 8918 DEPARTMENT OF ENEROY

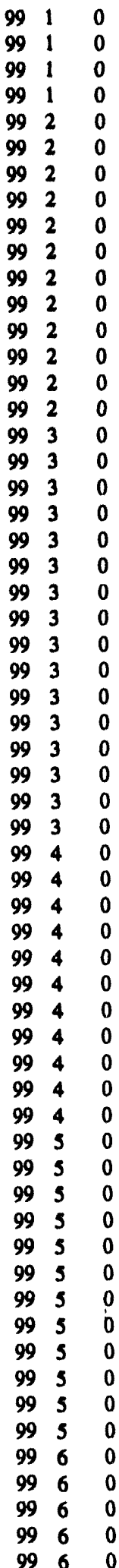


8919 DEPARTMENT OF ENEROY 8920 DEPARTMENT OF ENBRGY 8921 DEPARTMENT OF ENEROY 8922 DEPARTMBNT OF ENEROY 8923 DEPARTMENT OF ENERGY

8924 DEPARTMENT OF ENEROY 8925 DEPARTMENT OP ENEROY

8926 DEPARTMENT OF ENERGY 8927 DEPARTMENT OF ENERGY

8928 DEPARTMENT OF ENEROY

8929 DEPARTMENT OF ENERGY

8930 DEPARTMENT OF ENEROY

8931 DEPARTMENT OF ENBROY

8932 DEPARTMENT OF ENERGY

8933 DEPARTMENT OF ENEROY

8934 DEPARTMENT OF ENERGY

8935 DEPARTMENT OF ENERGY

8936 DEPARTMENT OF ENERGY

8937 DEPARTMENT OF ENERGY

8938 DEPARTMENT OF ENERGY

8939 DEPARTMENT OF ENEROY

8940 DEPARTMENT OF ENERGY

8941 DEPARTMENT OF ENERGY

8942 DEPARTMENT OF ENEROY

8943 DEPARTMENT OF ENERGY

8944 DEPARTMENT OF ENEROY

8945 DEPARTMENT OF ENERGY

8946 DEPARTMENT OF ENERGY

8947 DEPARTMENT OF ENERGY

8948 DEPARTMENT OF ENERGY

8949 DEPARTMENT OF ENERGY

8950 DEPARTMENT OF ENERGY

8951 DEPARTMENT OF ENEROY

8952 DEPARTMENT OF ENERGY

9970

9970

9970

9970

9970

9970

$\begin{array}{lll}99 & 8 & 0\end{array}$

9980

9980

$\begin{array}{lll}99 & 8 & 0\end{array}$

$\begin{array}{lll}99 & 8 & 0\end{array}$

$\begin{array}{lll}99 & 8 & 0\end{array}$

$\begin{array}{lll}99 & 8 & 0\end{array}$

9990

9990

9990

9990

$99 \quad 9 \quad 0$

$99 \quad 9 \quad 0$

9990

9990

9990

9990

9990

$9910 \quad 0$

$9910 \quad 0$

$9910 \quad 0$

$9910 \quad 0$

$9910 \quad 0$

$9910 \quad 0$

$9910 \quad 0$

$99 \quad 10 \quad 0$

$9910 \quad 0$

$\begin{array}{lll}99 & 10 & 0\end{array}$ 

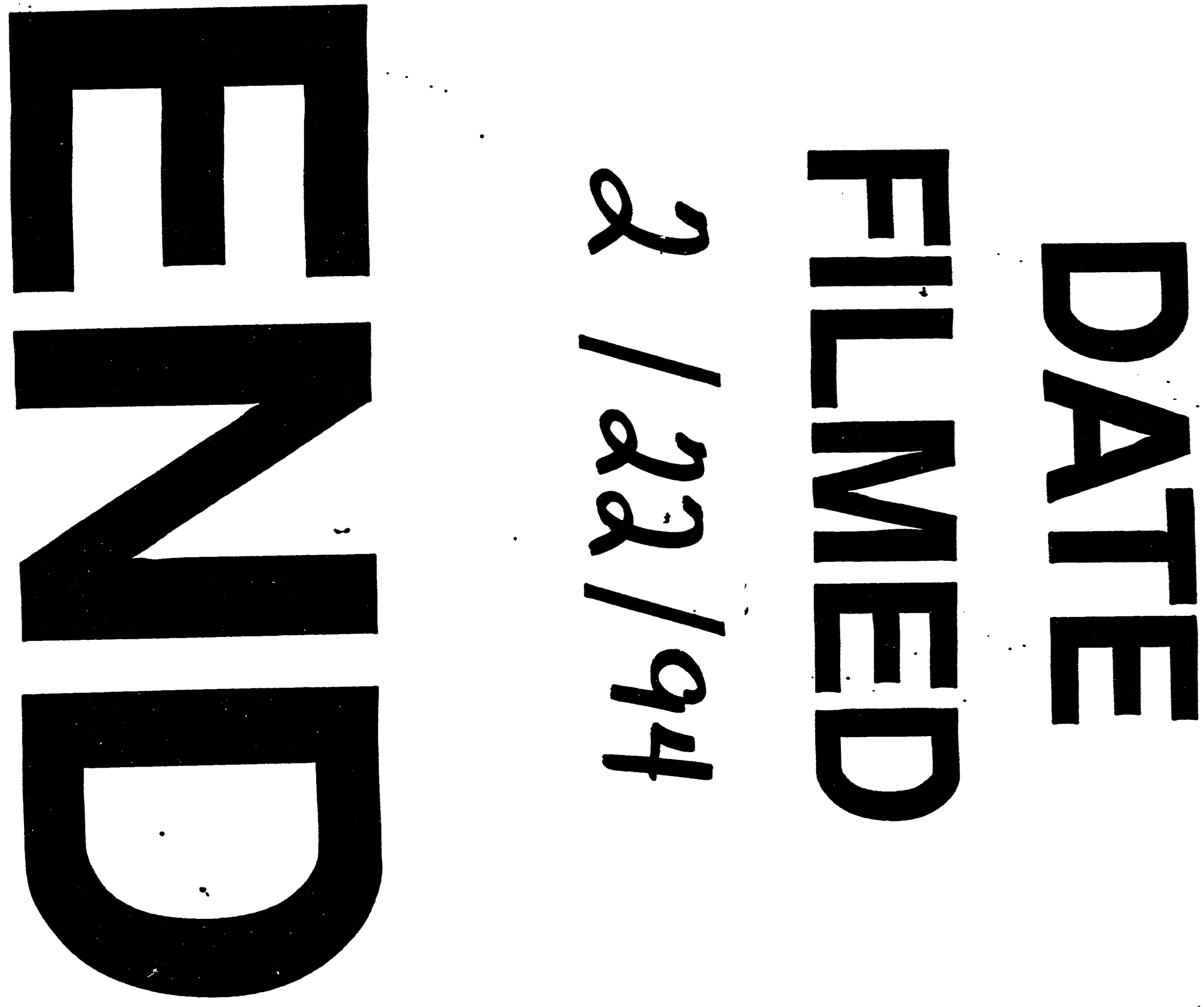
